

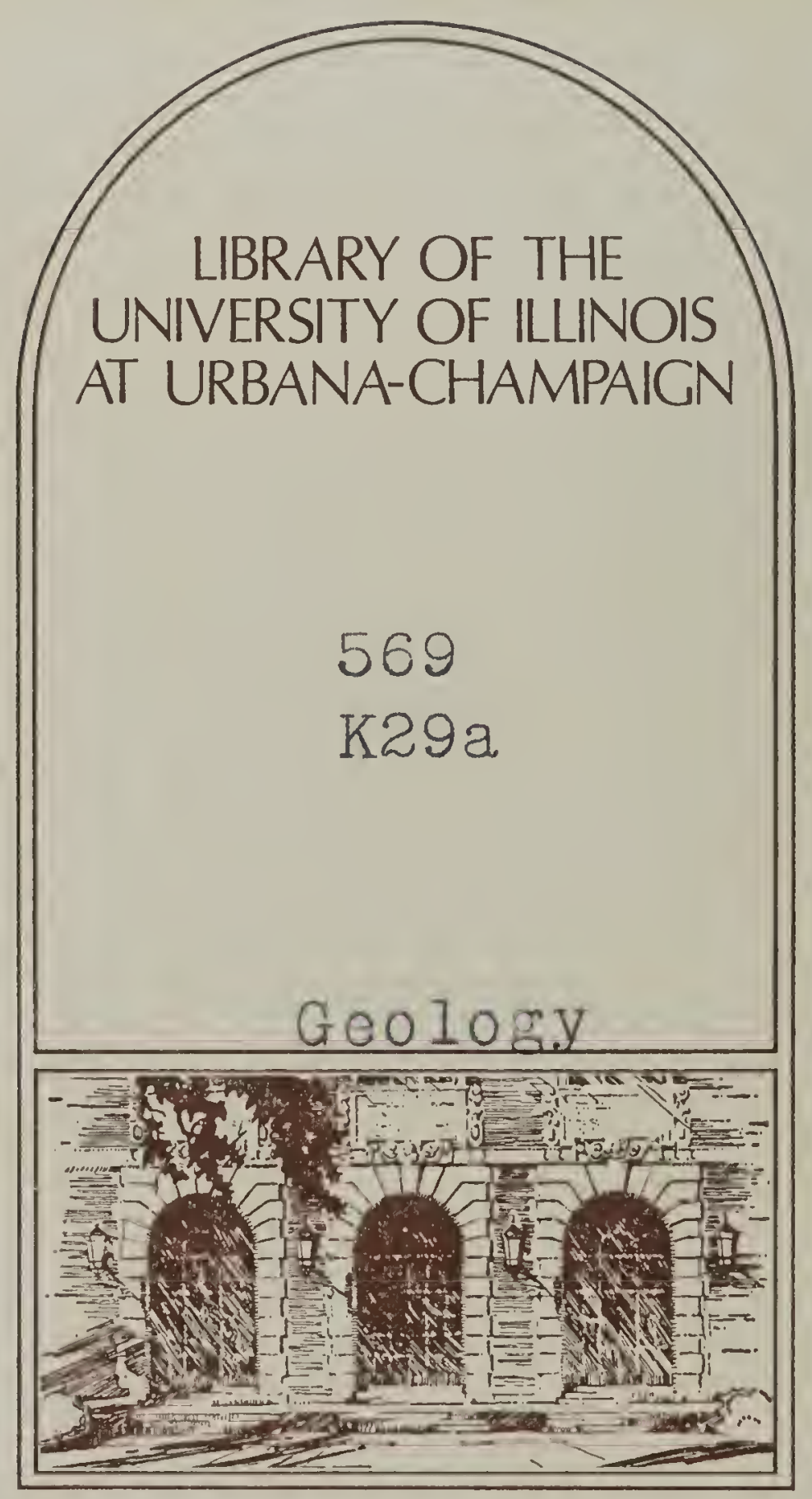


The person charging this material is responsible for its return to the library from which it was withdrawn on or before the Latest Date stamped below.

Theft, mutilation, and underlining of books are reasons for disciplinary action and may result in dismissal from the University.

To renew call Telephone Cenfer, 333-8400

UNIVERSITY OF ILLINOIS LIBRARY AT URBANA-CHAMPAIGN

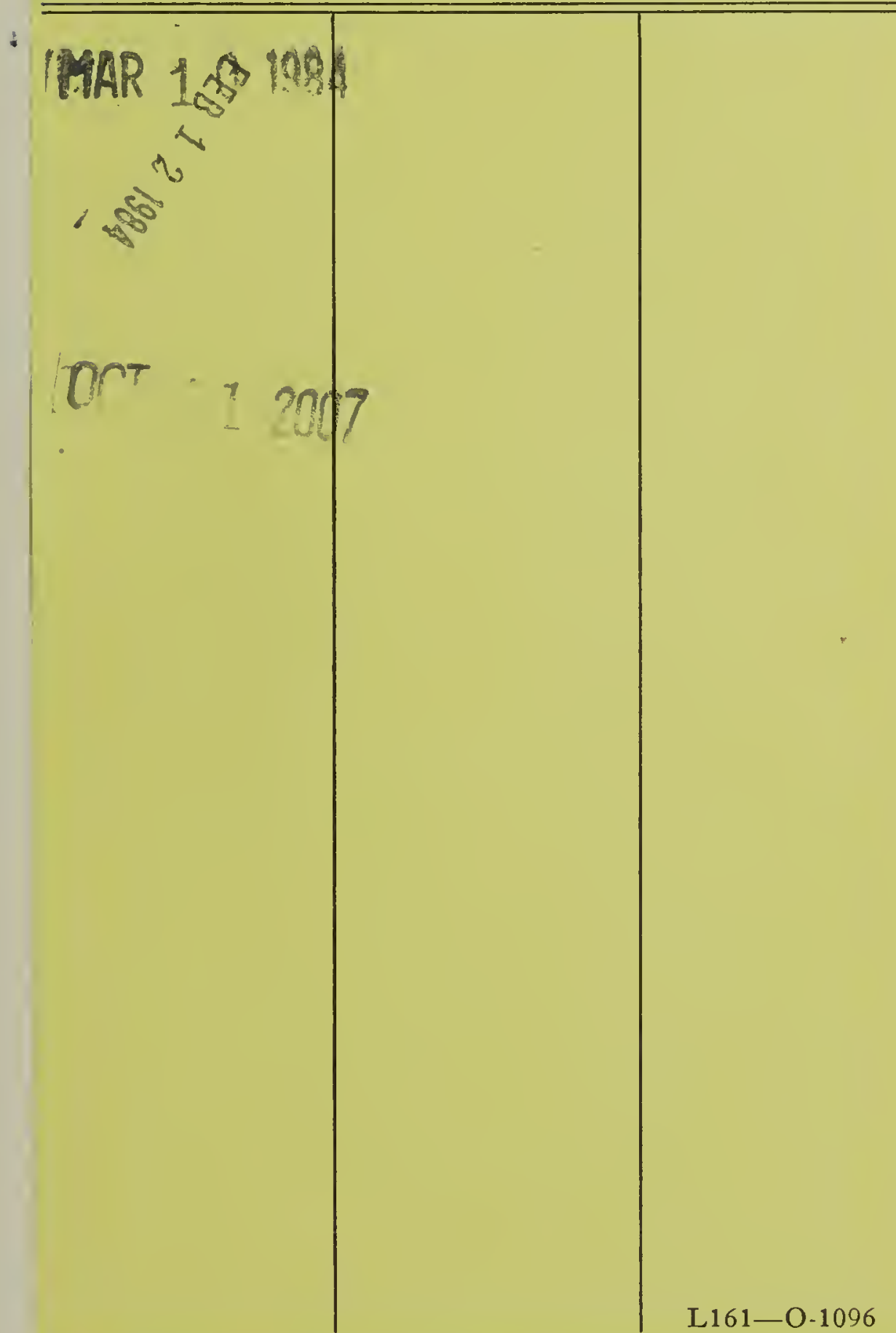





\section{CONTRIBUTIONS TO PALAEONTOLOGY}

FROM THE CARNEGIE INSTITUTION OF WASHINGTON

\section{ADDITIONS TO THE TERTIARY HISTORY OF THE PELAGIC MAMMALS ON THE PACIFIC COAST OF NORTH AMERICA}

BY

REMINGTON KELLOGG

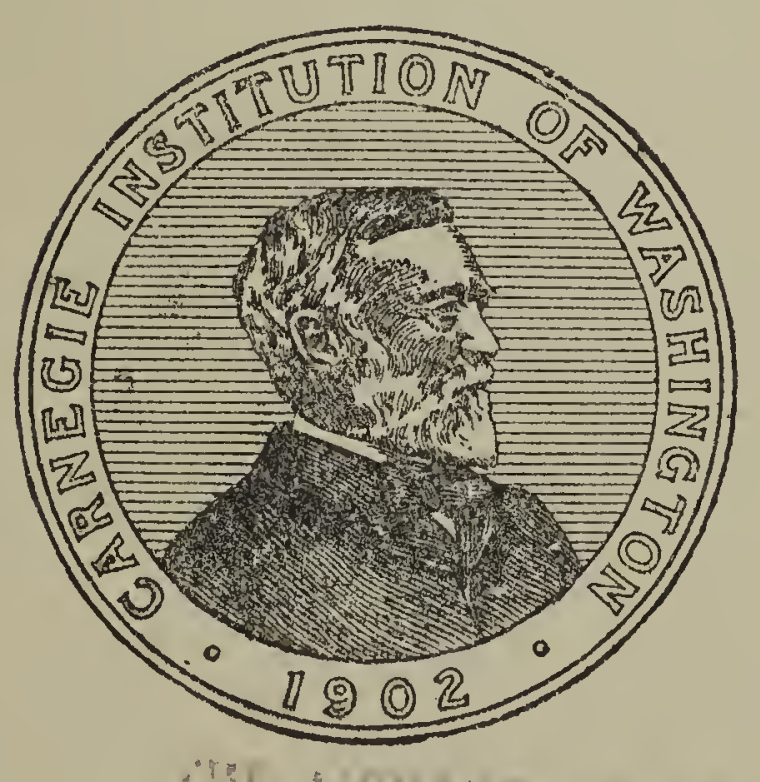

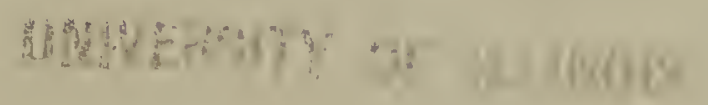

Published by the Carnegie Institution of Washington Washington, April, 1925 


\section{CARNEGIE INSTITUTION OF WASHINGTON}

Publication No. 348

$$
\begin{aligned}
& \text { bopies of flis bo: } \\
& \text { finns:nnow } \\
& \text { APR } 221925
\end{aligned}
$$

WABHINGTON, D.C. 


\section{CONTENTS.}

I. Two Fossil Physeteroid Whales from California. Plates 1 to 8 , Plate 9 (figs. 1 and 2), and 4 text-figs................... $1-34$

II. Fossil Cetotheres from California. 10 text-figs.............. 35-56

III. A New Fossil Sirenian from Santa Barbara County, California. Plates 9 (fig. 3), 10 and $11 \ldots \ldots \ldots \ldots \ldots \ldots \ldots \ldots \ldots \ldots \ldots \ldots$. $57-70$

IV. New Pinnipeds from the Miocene Diatomaceous Earth near Lompoc, California. Plates 12 and 13 , and 10 text-figs............ $71-96$

V. Structure of the Flipper of a Pliocene Pinniped from San Diego County, California. 29 text-figs . . . . . . . . . . . . . . . . . 97-116 



\section{TWO FOSSIL PHYSETEROID WHALES FROM CALIFORNIA.}

Hitherto, the only occurrences in North America of remains of fossil sperm whales have been confined to the Atlantic Coast. In 1920, a skull of an apparently unknown physeteroid was found in San Luis Obispo County, California, and afterwards presented by the discoverer, Mr. Joseph Walker, to the Museum of Palaeontology of the University of California. During the past year, portions of the rostrum and mandibles of a much larger species, which were collected by Mr. Charles O. Roe in 1909 from the sea-cliff near the Santa Barbara lighthouse, were presented to the United States National Museum. The infrequent occurrence of sperm-whale skulls lends especial interest to these specimens and they may prove to be of some importance in the general problem dealing with the lines of evolution in the Cetacea as well as in the problem of geological correlation.

In connection with studies upon fossil toothed whales, notes have been made from time to time upon many of the previously described species, and some of these observations have been incorporated in the present paper. Inasmuch as these descriptions were published in different years and in several different countries, it seems particularly desirable to give a brief résumé of what is actually known concerning those fossil cetaceans which appear to be related to the California specimens. As originally defined, most of the fossil forms would be excluded from the family Physeteridae, for these species have teeth in the upper jaws. Acquisition of new material is continually altering our concepts of the lines of evolution in the families and genera of the Cetacea, as illustrated by the changes in the relations of the various bones which compose their skulls. New structural features, or possible explanations for modifications observed in living genera, are frequently supplied by each discovery.

Since 1846, at least 25 genera have been proposed for remains of fossil cetaceans which at one time or another have been referred to as physeteroids. For convenience they are listed alphabetically with the year of publication: Balaenodon, 1846; Diaphorocetus, 1894; Dinoziphius, 1880; Eucetus, 1867; Eudelphis, 1872; Graphiodon, 1870; Homoeocetus, 1867; Hoplocetus, 1848-52; Hypocetus, 1894; Mesocetus, 1892; Ontocetus, 1869; Orcopsis, 1876; Orycterocetus, 1853; Palacodelphis, 1872; Palaeodelphis, 1872; Paracetus, 1894; Physeterula, 1877; Physetodon, 1879; Physodon, 1872; Platyrhynchus, 1876; Priscophyseter, 1886; Prophyseter, 1905; Scaldicetus, 1867; Scaptodon, 1918; and Thalassocetus, 1905 . Of these 25 genera, 8 were based on the 5 known skulls, 1 on the extremity of a rostrum, 1 on an imperfect mandible, 2 on vertebrae, and the remainder on 1 or more teeth. 
Furthermore, some 42 specific names have been applied to remains of these cetaceans found in various parts of the world. To attempt an orderly classification of this large number of very imperfectly known forms is well-nigh impossible without having access to the original material, and in event of that possibility it is extremely doubtful if anything of importance would be added to our present knowledge. Many of these species are known to the writer only from the original descriptions, and some of these specimens have never been figured. Those species which have been described from teeth will be difficult to allocate until skulls are found. It is very likely that additional material will show that some of them belong to other families, for large tusk-like teeth are present in one or more members of three families of living cetaceans.

Abel ${ }^{1}$ has attempted to reduce the number of generic types by making the following allocations, although it appears to the writer that they are not justified in all cases. The genera Balaenodon, Dinoziphius, Eucetus, Eudelphis, Homoeocetus, Hoplocetus, Palacodelphis, Palaeodelphis, and Physodon were referred to the genus Scaldicetus; Orcopsis and Platyrhynchus were allocated to the genus Physeterula. One skull from Patagonia has had four generic names, Hypocetus, Mesocetus, Paracetus, and Diaphorocetus, applied to it and of these the last mentioned has priority. It is possible that some of the eight generic names which are thus left, Graphiodon, Ontocetus, Orycterocetus, Physetodon, Priscophyseter, Prophyseter, Scaptodon, and Thalassocetus, may become synonyms when more adequate material is obtained.

From a geological standpoint, the history of the Physeteridae or sperm whales is comparatively short, for the oldest types now known were obtained in the Patagonian tuff formation on the coast of Chubut Territory, Argentine Republic. Two skulls, representing different genera, have been obtained from this Lower Miocene formation. In dimensions and general form, the largest of these skulls is very closely allied to a fossil sperm whale from the St. Marys formation of Maryland, and seems distinguishable from the smaller form, Diaphorocetus poucheti, by differences in the conformation of the maxilla along the lateral wall of the supracranial basin, in the number and position of the maxillary foramina, and possibly by the number of teeth in the upper jaw. The characteristic features of the living sperm whales, as for instance the development of the great supracranial basin, were well developed in these early Miocene forms, and the largest form attained a considerable size for the type skull is nearly 6 feet long.

The type skull of Diaphorocetus poucheti is in a fair state of preservation. The supraoccipital is damaged on each side, portions of

${ }^{1} \mathrm{O}$. Abel, Les Odontocètes du Bolderien (Miocene supérieur) d'Anvers, Mem. Mus. roy. d'hist. nat. de Belgique, Bruxelles, vol. 3, pp. 52, 75, 1905. 
the right and left maxillae and premaxillae are missing at the level of the nasal passages; the left lachrymal and jugal are lost, as well as a portion of the left supraorbital process of the frontal. The distal end of the rostrum has been broken off and the ends of the maxillae have spread apart. No teeth are in place, but the alveoli on the distal half of the rostrum are relatively large and well defined. This skull was found at "Bahia Nueva-immediaciones de Puerto Madryn, Territorio del Chubut, Lat. $42^{\circ} 30^{\prime}$ Sud," Patagonia, Argentine Republic, in the Patagonian tuff formation. The type is now preserved in the Museo de La Plata.

The genus Mesocetus, which Moreno ${ }^{1}$ proposed for this species was preoccupied, having been given to a genus of fossil whalebone whales by Van Beneden ${ }^{2}$ in 1883 . It was, therefore, renamed Diaphorocetus by Ameghino $^{3}$ in 1894 , and assigned to the family Pontoplanodidae. Lydekker, ${ }^{4}$ not knowing that Ameghino had renamed the genus, gave this species the name of Hypocetus. He refigures the type skull and assigns the genus to the family Physodontidae. Cope ${ }^{5}$ shows that Lydekker in the text proposes to call the genus Paracetus but, in the heading and on the plate, the latter cites the form as Hypocetus. It appears that Lydekker changed Paracetus to Hypocetus after writing the account of this form, and neglected to make the correction in the text. This interpretation is borne out by the following quotation from an advance notice by that writer: "Another member of the same family (i. e. Physodontidae) is represented in the Museum by a smaller cranium, to which I have assigned the name Hypocetus." Cope refers Moreno's species to the family Physeteridae. Ameghino cites some of the preceding allocations and expresses the opinion that this species should be placed in the Physeteridae, thus agreeing with Cope that Diaphorocetus does not belong to some other family. Little or nothing further was published in regard to this genus until 1905 when Professor $\mathrm{Abel}^{8}$ commented on it as follows:

I would remark that the relationship between the genera Scaldicetus [=Physodon, in part] and Hypocetus [= Diaphorocetus] are uncertain, as the teeth in this latter form, found in the Miocene of Chubut, Patagonia, are unknown. The skull is different from that of Scaldicetus, but belongs without doubt to a physeterid.

1 F. P. Moreno, Noticias sobre algunos cetáceos fósiles y actuales de la Republica Argentina conservados en el Museo de La Plata, Revista del Museo de La Plata, vol. 3, p. 395, pl. 10, 1892.

2 P. J. Van Beneden, Les Mysticètes à courts fanons des sables des environs d'Anvers, Bull. Acad. Roy. Sci. de Belgique, Bruxelles, ser. 2, vol. 50, pp. 22-23, 1880.

${ }^{3}$ F. Ameghino, Enumération synoptique des espèces de mammifères fossiles des formations éocènes de Patagonie, Bol. Acad. Nac. Ciencias de Cordoba, Buenos Aires, vol. 13, p. 437, February, 1894.

${ }^{4}$ R. Lydekker, Contributions to a knowledge of the fossil vertebrates of Argentina: II. Cetacean skulls from Patagonia, Annales del Museo de La Plata, vol. 2, for 1893, p. 8. April, 1894.

${ }^{5}$ E. D. Cope, Fourth contribution to the marine fauna of the Miocene period of the United States, Proc. Amer. Philos. Soc., Philadelphia, vol. 34, pp. 135-136, 1895.

6 R. Lydekker, The La Plata museum, Nat. Sci., vol. 4, No. 24, p. 125, February, 1894.

${ }^{7} \mathrm{~F}$. Ameghino, Notas sobre cuestiones de geologia y paleontologia Argentinas, Bol. Inst. Geografico Argentino, vol. 17, pp. 87-119 (separate, footnote, p. 15), 1896.

${ }^{8}$ O. Abel, Les Odontocètes du Bolderien (Miocene supérieur) d'Anvers, Mem. Mus. roy. d'hist. nat. de Belgique, Bruxelles, vol. 3, p. 70, 1905. 
It will be noted that there seems to be no division of opinion regarding the general relationships of Diaphorocetus. The large supracranial basin, the unsymmetrical nasal passages, the broad depressed basal portion of the rostrum, the expanded post-narial process of the right premaxilla, the narrow and deep antorbital notches all indicate its relation to the Physeteridae. The most salient characters by which it is distinguished from the recent genus Physeter are the presence of well-defined alveoli in the maxillae, of which, when the skull was intact, there were more than 13 on each side, and by the mesial constriction of the rostrum. Some rudimentary teeth are occasionally found in Physeter, but the alveolar septa are lacking, the groove being continuous in young skulls and more or less rudimentary.

Comparison of Diaphorocetus with other extinct physeteroids from later formations is rendered difficult on account of the fragmentary condition of the skulls of the latter thus far described. The European Upper Miocene genus Physeterula ${ }^{1}$ is known only from one or two imperfect crania lacking the rostrum and a mandible with teeth. The mandibular teeth are worn on the superior and posterior surfaces, from which it is inferred that teeth were present in the upper jaw also, but as the rostrum is lacking its form can not be determined. It is probable, however, that the genus is quite closely related to Diaphorocetus though the type species, Physeterula dubusii, is much larger than that form. It appears that the teeth of Physeterula have lost their enamel. With the exception of Miller $^{2}$ who is inclined to refer Physeterula dubusii Van Beneden and Physodon patagonicus Lydekker, as he says "without too great hesitation," to the Delphininae, the consensus of opinion as expressed in the published statements of various writers, including those who actually have had the opportunity to study the specimens, seems to be in favor of associating these forms with the sperm whales.

Any attempt to elucidate the status of the large toothed cetacean from Chubut Territory, Patagonia, described by Lydekker ${ }^{3}$ as Physodon patagonicus will be somewhat involved, for the original description is so brief that many important details are necessarily omitted and the generic name is preoccupied. As originally applied, Physodon leccense was given by Gervais ${ }^{4}$ to teeth from the Miocene sand stone of Lecce in the compartment of Puglia, Italy, which Costa $^{5}$ had referred to the genus Phoca. This limestone has been

1 O. Abel, op. cit., vol. 3, pp. 74-82, 1905.

2 G. S. Miller jr., The telescoping of the cetacean skull, Smithsonian Misc. Coll., vol. 76, No. 5, Publ. 2720, pp. 44-45, 49, August 31, 1923.

${ }^{3}$ R. Lydekker, Contributions to a knowledge of the fossil vertebrates of Argentina: II. Cetacean skulls from Patagonia, Annales del Museo de La Plata, vol, 2 for 1893, pp. 4-7, pl. 2, April 1894.

${ }^{4}$ P. Gervais, Coup d'Oeil sur les Mammifères fossiles de l'Italie, Bull. Soc. Geol. de France, Paris, ser. 3, vol. 29, p. 101, 1872.

s O. G. Costa, Paleontologia del Regno di Napoli, Atti della Accad. Pontaniana, Naples, vol. 5, fasc. 5, pp. 242-244, pl. 1, figs. 1-2, 1853. 
assigned to the Langhian stage of the Lower Miocene. Some of these teeth have been figured ${ }^{1}$ and discussed, but it is not necessary to make any further mention of this Italian form, because Physodon of Haldemann ${ }^{2}$ has many years priority. This necessitates the selection of another generic name for the Patagonian species. A survey of the literature shows that $\mathrm{Abel}^{3}$ has attempted to meet this difficulty by referring Physodon patagonicus to the genus Scaldicetus, but as will be shown later this association may not be entirely justified.

Winge ${ }^{4}$ has revived the genus Hoplocetus of Gervais for those fossil physeteroids which have teeth coated with enamel in the upper jaws. Hoplocetus crassidens, ${ }^{5}$ the type species, ${ }^{6}$ was based upon two teeth, $111 \mathrm{~mm}$. and $121 \mathrm{~mm}$. long respectively, obtained from the "falun" of Romans in the department of Drôme, France. These enamel-crowned teeth are slightly curved and are characterized by the excessive thickness of the cement as well as by the wellmarked constriction of the base of the crown. This constriction undoubtedly is indicative of old age. Deperet ${ }^{7}$ states that the teeth of Physodon differ from those of Hoplocetus in that the enamel of the crown passes into the cement part, or root, without forming an enlargement at the base, as in the latter genus. This also may be a peculiarity associated with growth, but the important fact to be noted is that isolated teeth do not afford at present any means for determining the type of skull to which they may belong. At least five types of fossil physeteroid skulls which possess teeth in the upper jaw are now known from Miocene formations, and there is no assurance that those of the Helvetian Hoplocetus actually pertain to any one of these cetaceans. There appears to be more justification for allocating imperfectly known forms from the same formation, or from formations of similar age, to some better preserved specimen, than there is for lumping one or more forms based on similarly inadequate material and from deposits which are not conceded to be equivalent in time with some one well-known type. In view of the present uncertainty which surrounds the availability of previously

${ }^{1}$ P. J. Van Beneden and P. Gervais, Ostéographie des Cétacés vivants et fossiles, Paris, pp. 334-335, pl. 20, figs. 16-18, 1880.

${ }^{2}$ S. S. Haldemann, A monograph of the Limniades and other freshwater univalve shells of North America, Supplement to Part I, p. 2, October 1840.

${ }^{3}$ O. Abel, Les Odontocètes du Bolderien (Miocene supérieur) d'Anvers, Mem. Mus. roy. d'hist. nat. de Belgique, Bruxelles, vol. 3, p. 52, 1905.

4. Winge, A review of the interrelationships of the Cetacea, Smithsonian Misc. Coll., vol. 72, No. 8, Publ. 2650, pp. 42, 44, 92, 1921.

${ }^{5}$ P. Gervais, Zoologie et Paléontologie Françaises' (Animaux Vertébrés) ou Nouvelles Recherches sur les Animaux Vivants et Fossiles de la France, vol. 1, Cahier 21, p. 161, vol. 2, explan. for pl. 20, figs. 10-11 (page not numbered), 1848-52.

B O. P. Hay, Bibliography and catalogue of the fossil vertebrata of North America, Bull. No. 179, U. S. Geol. Surv., Dept. Interior, p. 596. 1902 (type fixed).

${ }^{7}$ C. Deperet, Recherches sur la succession des faunes de vertébrés Miocènes de la vallée du Rhône, Archiv. Mus. d'hist. nat. de Lyon, vol. 4, p. 276, 1887. 
proposed genera, it seems desirable to designate Physodon patagonicus Lydekker as the type of a new genus, which may be called Idiorophus.

This genus is based on a skull with most of the brain case missing, in which, however, nearly all the teeth are present, both mandibles, and "a certain number of dorsal and caudal vertebrae." When complete the skull was about 6 feet long. The species patagonicus is characterized by the number and position of the maxillary foramina, the long laterally compressed extremity of the rostrum with arched premaxillae, and teeth in both jaws. The teeth are large, long, terete, and but little curved, the crowns being conical and covered with rugose enamel. On each side, 3 of the upper teeth at the end of the rostrum are situated in the premaxilla. While the supracranial basin of the skull, characteristic of the physeteroid whales, is stronglydeveloped in this species, the genus Idiorophus is distinguishable from Physeter by the curvature of the lateral margins of the rostrum, the shape of the supraorbital process of the frontal, and the presence of numerous maxillary teeth. From Diaphorocetus it differs, apparently, by the greater number of maxillary foramina, by the elevation of the premaxillae on the rostrum, and the fact that the premaxillae are in contact along their inner margins and thus completely roof the vomerine gutter. The figures of Diaphorocetus poucheti and those of Physodon patagonicus given by Lydekker are from different points of view, but those for the latter give one the impression that in addition to other features they illustrate a more massive form. It would not, however, be necessary on that account alone to consider it as generically distinct.

The teeth of Idiorophus patagonicus (Lydekker) present the characters of a young Scaldicetus and closely resemble teeth of young individuals of Scaldicetus grandis from the Anversian stage of Antwerp, Belgium, described by Du Bus ${ }^{1}$ under the names of Palaeodelphis coronatus and Palaeodelphis minutus. They are, however, intermediate in size between these two, and apparently do not show the characteristic development of an anterior and a posterior cutting edge as in the latter. The teeth of the Patagonian cetacean have relatively longer crowns.

Considering the evidence as a whole, it seems reasonable to suppose that Physodon patagonicus Lydekker really belongs to some genus other than Scaldicetus, but whether they exhibit any close relationship can scarcely be decided until additional material representing both genera shall have been obtained, or at least until the type skull of the former is re-examined.

\footnotetext{
1 B. A. L. Du Bus, Mammifères nouveaux du Crag d'Anvers, Bull. Acad. Roy. des Sci., des Lettres et des Beaux-Arts de Belgique, Bruxelles, ser. 2, vol. 34, No. 12, pp. 504, 505, 1872.

$\mathrm{O}$. Abel, Les Cdontocètes du Bolderien (Miocène Supérieur) d'Anvers, Mem. Mus. roy. d'hist. nat. de Belgique, Bruxelles, vol. 3, p. 64, fig. 3, and p. 65, fig. 4, 1905.
} 
The only European species of Scaldicetus which can be compared with Idiorophus patagonicus (Lydekker) is Scaldicetus mortezelensis from the Anversian stage of the Antwerp basin, Belgium. A very imperfect skull of this species has been figured by Abel, ${ }^{1}$ from which it would appear that the rostrum is narrower at the base, but the interspace between the premaxillae at the base of the rostrum is wide as in Diaphorocetus poucheti.

Forty-five teeth, measuring from 200 to $240 \mathrm{~mm}$. in length and assumed to belong to one individual, formed the basis for the species caretti, ${ }^{2}$ the type of the genus Scaldicetus. These teeth are slightly curved and the enamel on the crown is striated longitudinally. For this reason, teeth are the sole criterion for the genus Scaldicetus and, on basis of similarity observed between the teeth, Abel $^{3}$ referred Eudelphis mortezelensis Du Bus to this genus. Two teeth are known for this species, and one of these measures $88 \mathrm{~mm}$. in length, of which $11 \mathrm{~mm}$. is occupied by the crown. All comparisons with Scaldicetus, as mentioned in the foregoing paragraph, must be made upon this skull.

Teeth found in the United States and Europe resembling those of Scaldicetus caretti and originally described under different generic and specific names, have been assembled by Professor Abel ${ }^{5}$ under the names of Scaldicetus caretti, grandis, and mortselensis. According to his carefully considered diagnosis of the genus Scaldicetus, the teeth in young animals are elongated, and nearly terete, with rather short crowns, which are coated with longitudinally striated enamel and present an anterior and posterior cutting edge or carina as in Squalodon. The enamel crown does not terminate obliquely where it joins the root, as in Squalodon, but the line of junction is usually transverse. In older individuals, the top of the root becomes worn away anteriorly and posteriorly, producing a constriction between it and the crown, while the apex of the latter suffers a transverse truncation. In still older individuals, the constriction between the crown and root becomes deeper, and the crown finally breaks off, leaving only the root in the jaw. This root becomes gibbous near the middle, owing to the increase in thickness of the cement layer, while the core of dentine is exposed at the top. The surface of the dentine, like the enamel, is marked by longitudinal grooves.

Besides the teeth of Scaldicetus grandis from the Upper Miocene of Antwerp, mentioned above, numerous other teeth described under various generic and specific names have been allocated to that species

1 O. Abel, op. cit., vol. 3, p. 67, fig. 5, 1905.

2 B. A. L. Du Bus, Sur quelques Mammifères du Crag d'Anvers, Bull. Acad. Roy. des Sci., des Lettres, et des Beaux-Arts de Belgique, Bruxelles, ser. 2, vol. 24, No. 12, pp. 567-568, 1867.

${ }^{3}$ O. Abel, op. cit., vol. 3, p. 67, 1905.

B. A. L. Du Bus, Mammifères nouveaux du Crag d'Anvers, Bull. Acad. Roy. des Sci., des Lettres, et des Beaux-Arts de Belgique, Bruxelles, ser. 2, vol. 34, No. 12, p. 500, 1872.

O. Abel, op. cit., vol. 3, pp. 56-68, 1905. 
by Professor Abel. They are from Belgium, Holland, England, Northern Germany, and France. Some belong to the Middle and Upper Miocene of Continental Europe, and others to the Red Crag of Suffolk, England, which is a Pliocene formation.

Another group of species described under different names, but assigned to Scaldicetus caretti Du Bus by Abel are also from the Miocene and Pliocene of Europe, including localities in Denmark, Holland, Belgium, Germany, England, France, Italy, and Malta; and likewise from the United States. One of the North American species assigned to Scaldicetus caretti was originally described by Leidy ${ }^{1}$ in 1877 under the name of Dinoziphius carolinensis. This species was based on a single tooth belonging to an old individual and now in the Academy of Natural Sciences of Philadelphia, which was obtained by the Pacific Guano Company in the course of their operations in the Ashley River phosphate deposits near Charleston, South Carolina. The crown with its enamel is missing; the cement layer of the root is rather thick (9 mm.), giving it a quite gibbous form, and the dentine does not show transverse wavy lines. As preserved, this tooth measures $211 \mathrm{~mm}$. in length, with a maximum transverse diameter of $80 \mathrm{~mm}$., while the greatest diameter of the end of the root is about $23 \mathrm{~mm}$.

The other North American species allocated with Scaldicetus caretti by Abel has been uniformly known in American literature since 1868 under the name originally given it by Leidy, ${ }^{2}$ Hoplocetus obesus. The species obesus was originally founded on 2 teeth from the "post-pliocene formation of Ashley River, in the vicinity of Charleston," South Carolina, obtained by Professor F. S. Holmes. The largest tooth is imperfect, with part of the enamel crown worn away and the end of the root missing. The band of enamel on the crown is striated longitudinally and measures about $6 \mathrm{~mm}$. in depth. The root is fusiform, slightly curved, with an axis of dentine about equal in diameter to the crown, and a thick layer of cement. In a straight line the largest tooth measures $93 \mathrm{~mm}$. and the greatest diameter of the root is approximately $40 \mathrm{~mm}$. The teeth of young individuals of Scaldicetus caretti when complete have the crowns covered with rugose enamel, but with increasing age and wear the roots become thickly coated with cement and the crowns assume many different forms and are finally worn away altogether, leaving only the thick fusiform root. A lack of understanding of these changes has caused the establishment of a large number of nominal genera and species.

\footnotetext{
$1 \mathrm{~J}$. Leidy, Description of vertebrate remains, chiefly from the phosphate beds of South Carolina, Journ. Acad. Nat. Sci. Philadephia, ser. 2, vol. 8, p. 216, pl. 34, fig. 6, 1877.

2 J. Leidy, Notice of some extinct cetaceans, Proc. Acad. Nat. Sci. Philadelphia, vol. 20, pp. 196-197, August 1868.
} 
The type tooth of Dinoziphius carolinensis is too large and those of Hoplocetus obesus are too small to bear any close relation to the large physeteroid from the Upper Miocene St. Marys formation of Maryland described by Cope $^{1}$ as Paracetus mediatlanticus. The type specimen consists in an incomplete skull (plates 4,5 ); the right supraorbital process of the frontal is present though much worn and incomplete, but the braincase and the extremity of the rostrum are missing. The rostrum of the type specimen was formerly included in the exhibit of the Maryland Geological Survey in the Statehouse at Annapolis. A large fragment consisting of the lateral crest of the maxilla and the supraorbital process of the frontal remained in the collection of Johns Hopkins University. Both of these specimens have been placed on deposit in the United States National Museum where they have been fitted together. The skull was found at Drum Point on the western shore of Chesapeake Bay, Calvert County, Maryland.

This species has arched premaxillae and a broad, sloping, basal area as in the South American Lower Miocene Idiorophus patagonicus. The maxillae and premaxillae were also probably prolonged anteriorly, forming a beak as in that species. The skull appears to differ from that of $I$. patagonicus in the wide interval between the opposite margins of the premaxillae, thus exposing the mesorostral gutter, the greater depth of the lateral crest of the maxilla at the level of the orbit, as well as in the position of the maxillary foramina. Eight alveoli are present in each maxilla, but they are not deep, not more than $50 \mathrm{~mm}$. at the most; the greatest transverse diameter of the last alveolus at the surface is about $21 \mathrm{~mm}$., that for the fourth is $27 \mathrm{~mm}$., while that for the anterior is $23.5 \mathrm{~mm}$.

As will become apparent from an examination of Moreno's figures and a careful study of the descriptions given by that writer and by Lydekker, Paracetus mediatlanticus of Cope does not bear any generic relationship to Diaphorocetus poucheti. If they represented different species of the same genus, for Paracetus is a synonym of Diaphorocetus, one would expect to find certain minor differences, but rarely if ever do such differences involve the position and number of important foramina for nerves and blood-vessels. In Diaphorocetus poucheti the largest maxillary foramen connecting with the infraorbital system is situated posterior to the antorbital notch, while in mediatlanticus it is situated at the level of it. The great depth and unusual thickening of the maxilla on the lateral wall of the supracranial basin at the level of the orbit as well as other peculiarities defined in the key which follows this discussion distinguish the species mediatlanticus from Diaphorocetus poucheti. Such a grouping

1 E. D. Cope, Fourth contribution to the marine fauna of the Miocene period of the United States, Proc. Amer. Philos. Soc., Philadelphia, vol. 34, No. 147, pp. 135-137, 189 h 
of skulls exhibiting different types of supracranial modifications would be wholly at variance with accepted methods of classification. In view of these differences, it is necessary to apply some generic name other than Diaphorocetus to the large physeteroid from the St. Marys formation.

Fortunately, an Upper Miocene genus does appear to be available for this species. This genus ${ }^{1}$ was originally based on two rather large teeth of peculiar form and appearance, "fragments of both sides of the lower jaw, and a portion of a rib." These specimens should be in the Academy of Natural Sciences of Philadelphia, but so far as I am aware they have not been seen by anyone since 1869 when Leidy again mentioned and described them. At that time, Leidy mentioned and described a fragment of an upper jaw "accompanying the teeth," but said nothing of fragments of the lower jaw nor of a rib. The original description was probably faulty in this respect. These specimens are from an Upper Miocene formation in Virginia and were obtained by Leidy from Professor Francis B. Holmes of Charleston, South Carolina. Leidy's clear description and excellent figures of the type teeth of Orycterocetus quadratidens, ${ }^{2}$ published in 1869 , leave no doubt as to their character, but the question of their relationship to the other species mentioned above, particularly to Cope's Paracetus mediatlanticus, is of special interest.

The description of the portion of the rostrum which accompanied the type teeth, and which Leidy in 1869 called a portion of the upper jaw, is as follows:

A fragment of the upper jaw accompanying the teeth, about eight inches long, accommodated as many teeth. The alveoli were separated by thin partitions, and their bottom was separated from the dental canal by a thick layer of porous bone. Two alveoli, perfect at their outer parapet, are an inch and three-fourths deep by an inch in diameter. The outer part of the jaw at the side of these alveoli is three and a quarter inches deep.

If we consider that this fragment really belonged with the type teeth and that the latter originally had their place in it, we can picture Orycterocetus quadratidens as a species of approximately the same size as Paracetus mediatlanticus, with a row of slender upper teeth extending about 3 inches beyond the maxilla and a similar row in the mandible. A peculiarity of the teeth of Orycterocetus quadratidens is the cross banding of the dentine which Leidy refers to as "annular lines of growth." Structures similar to these are present in some of the fossil species of Physeter and allied genera figured by Van Beneden

1 J. Leidy (Observations on extinct Cetacea), Proc. Acad. Nat. Sci. Philadelphia, vol. 6, p. 378, August 1853.

2 J. Leidy, The extinct mammalian fauna of Dakota and Nebraska, including an account of some allied forms from other localities, together with a synopsis of the rammalian remains of North America, Journ. Acad. Nat. Sci. Philadelphia, ser. 2, vol. 7, pp. 436-437, pl. 30, figs. 16, 17, 1869. 
and Gervais. ${ }^{1}$ The peculiar appearance of these teeth, as figured by Leidy, is due to the loss of the cement which encircles the longitudinal axis of dentine. According to Leidy's measurements for the fragment of the maxilla and alveoli of Orycterocetus quadratidens, there is little difference in size between it and the corresponding portion of the maxilla in the skull of the type of mediatlanticus. The vertical depth of the maxilla of the St. Marys physeteroid, as measured from the premaxillary suture to the alveolar row, gradually increases anteriorly and at the level of the first alveolus measures $75 \mathrm{~mm}$. The alveoli average about an inch in diameter at the surface and the sockets are not more than 2 inches deep. The fragment of the maxilla described by Leidy was about 8 inches long and contained the same number of alveoli. In all probability it represented a section of the rostrum, corresponding in part to that which is missing from Cope's type. Both specimens were obtained from nearby Upper Miocene formations. Although the exact locality in Virginia from which the original material representing Orycterocetus quadratidens was obtained may never be ascertained, it seems probable that this species at least did bear some resemblance to the St. Marys physeteroid, and for this reason the latter may tentatively be known as Orycterocetus mediatlanticus (Cope).

Originally, Leidy referred Orycterocetus quadratidens to the Delphinidae, but in 1869 he was inclined to regard it as related to the sperm whale. In 1890, Cope actually referred the species to Physeter, while Professor Abel in 1905 regarded the teeth of this species as closely resembling, except in size, two found in the Upper Miocene formation of the Antwerp basin which he thought might belong to the physeteroid genus Thalassocetus established by him on a portion of a skull from the same formation.

There is another North American Upper Miocene pelagic mammal which should be considered in the present discussion, and that is Ontocetus emmonsi of Leidy. ${ }^{2}$ This fossil mammal has been referred to the Physeteridae, but all that is known concerning it consists of a single, large, somewhat mutilated tooth from the Miocene of North Carolina. The type locality, formation, and present whereabouts of this specimen are unknown. According to Leidy, this tooth is curved, laterally compressed, and fluted. When perfect it measured 10 or more inches in length, about 4 inches in an anteroposterior direction, and approximately 2.5 inches transversely. The dimensions of the tooth, as will be observed, are similar to those of large teeth of Physeter catodon, but the curvature is more pronounced. It also exhibits certain transverse markings which resemble those on

${ }^{1}$ P. J. Van Beneden and P. Gervais, Ostéographie des Cétacés vivants et fossiles, Paris, pl. 20,1880 .

J. Leidy (Remarks on Dromatherium sylvestre and Ontocetus emmonsi), Proc. Acad. Nat. Sci. Philadelphia, vol. 11, p. 162, 1859. 
fossil teeth assigned to Physeter and allied genera. None of these teeth, however, whether recent or fossil, have the cement fluted to any appreciable extent, so far as known. This fluting may have influenced Leidy when he advanced the opinion that Ontocetus might be allied to the walrus. This is not impossible, but the tusks of Odobenus are comparatively straight, while this tooth may have been curved.

An entirely different view was advanced by Cope ${ }^{1}$ who, in 1869, remarks that the tooth of Ontocetus belongs to a large sirenian allied to Halicore. It is not probable that this view is correct, for the reason that sirenian canines are either coated with enamel on all sides, or on the front and sides. There is no evidence that the tooth of Ontocetus was thus covered, though it may have been when perfect. The annular lines mentioned by Leidy are observable on teeth of Physeter and Orycterocetus. It should be noted, however, that the longitudinal fluting of the surface of the tooth of Ontocetus already alluded to, suggests a similar conformation in Halicore and other sirenians. This, perhaps, is the characteristic which is most suggestive of sirenian relationship, unless the central accumulation of osteodentine be so regarded. The tooth possessed a comparatively thin coat of cementum, in which respect it differs from teeth of fossil and of adult living sperm whales, though agreeing with them in that the interior was built up with a large amount of osteodentine.

On referring to Emmons's figure ${ }^{2}$ of this tooth, it seems probable that Ontocetus emmonsi represents some cetacean allied to the sperm whale, but until additional specimens have been obtained its relationships are likely to remain in doubt. Taking into consideration Leidy's statement that the cement on this tooth is comparatively thin and the general appearance of the tooth as figured by Emmons, it appears that the longitudinal fluting which has caused so much discussion is due in part to erosion and in part to the entire absence of cement in places. Similar fluting has been observed by the writer on the dentinal axes of other large physeteroid teeth. The external coat of cement which encircles the dentinal axis is usually thick and conceals this fluting when present. Teeth similar in size and general appearance to Ontocetus emmonsi are present in both jaws of a fossil physeteroid from the Miocene of Santa Barbara County, California.

A review of the known fossil and living physeteroids reveals the fact that they may be divided into two more or less clearly marked groups, those with long rostra, no sagittal crest, rise of anterior

\footnotetext{
${ }^{1}$ E. D. Cope, Synopsis of the extinct Mammalia of the cave formations in the United States, with observations on some Myriopoda found in and near the same, and on some extinct mammals of the caves of Anguilla, W. I., and of other localities, Proc. Amer. Philos. Soc., Philadelphia, vol. 11, p. $190,1869$.

2 E. Emmons, Manual of geology, 2d ed., tert-fig. 187 (lower figure) on p. 219 [figure of type tooth, 0.5 nat. size].
} 
border of lateral wall of supracranial basin within antorbital notch, small lachrymals, elongate jugals with long styliform processes, small pterygoids, expanded palatines, and large infraorbital foramina, and those with short rostra, well-developed sagittal crest, rise of anterior border of lateral wall of supracranial basin outside of antorbital notch, large thickened lachrymals, jugals with very short styliform processes, expanded pterygoids, small palatines, and small infraorbital foramina. To the first family, the Physeteridae, the following genera are referred: Diaphorocetus, Idiophyseter, Idiorophus, Ontocetus, Orycterocetus, Physeter, Physeterula, Scaldicetus, Thalassocetus; the second family, the Kogiidae, is represented by the living genus Kogia.

\section{Key to Skulls.}

$A^{1}$. Rostrum strongly constricted from side to side mesially.

$\mathrm{B}^{1}$. Lateral margin of maxilla excessively thickened at level of supraorbital process of frontal; rise of anterior border of supracranial basin is within antorbital notch and not without as in Kogia, and gradually attains a considerable elevation immediately in front of temporal fossa and a little within vertical plane of supraorbital border; external border of maxilla rolls over the underlying frontal above the temporal fossa and the longitudinal thickening of the former marks the lateral boundary of the supracranial basin; size large.

$\mathrm{b}^{1}$. A large foramen (the orifice looking upward and connecting with the infraorbital system) pierces the maxilla some $113 \mathrm{~mm}$. above the large maxillary incisure on the anterior margin of "the rising lateral wall of the supracranial basin; a large maxillary foramen between antorbital notch and nasal passage on rising edge of supracranial basin, but situated below level of incisure; a smaller one at the same level, just posterior and internal to it; a longitudinal groove leading from the inferior maxillary foramen and directed almost obliquely forward is pierced in its fundus by another foramen; in front of this groove is a wide depressed orifice of still another foramen which pierces the maxilla close to its premaxillary border; a large foramen pierces the maxilla on the lateral wall of supracranial basin at level of nasal passages; right premaxilla pierced near anterior part of ethmoid crest by a large circular foramen; rostrum vaulted; rostral portion of premaxilla elevated; margins of premaxillae not in contact at level of anterior margin of ethmoid crest; antorbital notches relatively small and narrow; more than 8 alveoli in each maxilla; maxillae not closely approximated from a ventral view, exposing a considerable portion of anterior extension of vomer; palatines large, horizontally expanded, and not overridden to any marked degree by pterygoids; a single ventral infraorbital orifice bounded internally by palatine and externally by maxilla; length of rostrum $800+\mathrm{mm}$.; elevation of lateral crest of supracranial basin above orbit, apex broken off, $310 \mathrm{~mm}$; ; length of rostral fragment on middle line $800 \mathrm{~mm}$.; breadth of rostrum at antorbital notches, estimated $710 \mathrm{~mm}$; breadth of extremity of rostrum at point where broken off 172 mm. (See pls. 4, 5.)............. Orycterocetus mediatlanticus (Cope). 
$\mathrm{B}^{2}$. Lateral margin of maxilla not excessively thickened at level of supraorbital process of frontal.

$\mathrm{C}^{1}$. As many as 24 teeth in each mandible.

$\mathrm{b}^{2}$. A large foramen (the orifice looking upward and connecting with the infraorbital system) pierces the maxilla on the summit of the lateral crest of the supracranial basin above the orbit; a large maxillary incisure between antorbital notch and nasal passage on anterior rising edge of supracranial basin; a much smaller one internal and slightly below it (the two foramina almost confluent); a small foramen below and anterior to large maxillary foramen, but without longitudinal groove as in Orycterocetus; a minute foramen situated mesially and anterior to all of the above-mentioned foramina; and still another small depressed foramen which pierces the maxilla on its premaxillary border; portion of premaxilla which is pierced by a foramen apparently missing; rostrum vaulted; inner margins of premaxillae in contact anteriorly, completely roofing mesorostral gutter; premaxilla arched or elevated anteriorly; antorbital notches relatively small and rounded; a small antorbital process of the maxilla; premaxilla projecting anteriorly beyond maxilla; external margin of maxilla relatively thin in front of antorbital notch, but further forward this thin margin disappears in conquence of its downward curvature and the lateral compression of the extremity of the rostrum; 22 teeth in upper jaw, 3 of which are inserted in premaxilla; 24 teeth in mandible; teeth large, long (slightly more than $100 \mathrm{~mm}$.), terete, slightly curved, and cylindrical in section; enamel on crowns finely striated longitudinally; crowns of teeth conical, about $32 \mathrm{~mm}$. long; length of rostrum about $1,240 \mathrm{~mm}$.; elevation of lateral crest of supracranial basin above orbit about $175 \mathrm{~mm}$.; total length, as preserved, about $1,600 \mathrm{~mm}$.; breadth of rostrum at antorbital notches about $650 \mathrm{~mm}$.......... Idiorophus patagonicus (Lydekker).

$\mathrm{C}^{2}$. Not more than 20 teeth (so far as known) in each mandible.

$b^{3}$. Occiput abruptly truncated; size large, total length of skull more than $1,000 \mathrm{~mm}$.; a large foramen (the orifice looking upward and connecting with the infraorbital system) pierces the maxilla on the rising lateral wall of the supracranial basin at the level of the orbit; the large maxillary incisure is probably situated between antorbital notch and nasal passage as there is a notch at that point on broken border of right maxilla; external border of maxilla does not roll over underlying frontal above temporal fossa, but instead marks the lateral boundary of the supracranial basin; rostrum not sufficiently well known for diagnosis; premaxillae flattened anterior to nasal passages; inner margins of premaxillae not in contact at level of anterior margin of ethmoid crest; antorbital notches small; a distinct antorbital process of the maxilla; zygomatic processes narrowing anteriorly, pointed; 20 alveoli in each mandible; teeth measure from 50 to $130 \mathrm{~mm}$. in length; maximum thickness of largest teeth about $30 \mathrm{~mm}$.; enamel not present on crowns of teeth; mandibular teeth worn on superior and posterior surfaces, from which it is inferred that teeth were present in upper jaw; occipital face of skull slightly rounded; length of rostrum, as estimated, 1,000 $\pm \mathrm{mm}$.; elevation of lateral crest not known; total length of skull, estimated, 
$1,350 \pm \mathrm{mm}$.; breadth of skull across supraorbital processes, estimated, $705 \mathrm{~mm} . . . . . . . . .$. . Physeterula dubusii Van Beneden.

$b^{4}$. Occiput obliquely truncated; size medium, total length of skull less than $700 \mathrm{~mm}$.; a small foramen (the orifice looking upward and connecting with the infraorbital system) pierces the maxilla on the summit of the lateral crest of the supracranial basin behind the orbit; maxillary foramina opening into a slit-like incisure in maxilla between antorbital notch and nasal passage, and situated posterior to antorbital notch; external border of maxilla rolls over the underlying frontal above the temporal fossa, and the longitudinal thickening of the former marks the lateral boundary of the supracranial basin; rostrum compressed dorso-ventrally; premaxillae flattened or depressed anteriorly; inner margins of premaxillae in contact at level of anterior margin of ethmoid crest; antorbital notches deep and narrow; a distinct antorbital process of the maxilla; supraorbital process shallow; postnarial process of premaxilla broad, forming medial surface of posterior wall of supracranial basin; a large premaxillary foramen in right premaxilla situated anterior to antorbital notches; mesorostral gutter broad; occipital face of skull somewhat flattened, not produced beyond level of posterior borders of exoccipitals and zygomatic processes, although portions of the condyles do project; zygoma narrow, attenuated, and pointed anteriorly; lachrymal not extending inward beyond ventral infraorbital orifice; more than 13 alveoli in maxilla; teeth not described; 18 or 19 alveoli in each mandible; length of rostrum, estimated $380+\mathrm{mm}$; total length of skull as preserved $582 \mathrm{~mm}$; breadth of rostrum at antorbital notches $244+\mathrm{mm}$....... Diaphorocetus poucheti (Moreno).

$\mathrm{A}^{2}$. Rostrum not strongly constricted from side to side mesially (so far as known).

$B^{3}$. Size medium or small (skulls, so far as known, not exceeding 3 feet in length).

$\mathrm{C}^{3}$. Distance between outer margins of condyles more than one-third of breadth of skull across supraorbital processes of frontals; occipital face of skull rounded; inner margins of premaxillae in contact at level of anterior margin of ethmoid crest; mesorostral gutter broad; supraorbital process moderately thick; superior face of supraorbital process sloping obliquely downward, posterior and external borders concave; maxilla thin above orbit, with characteristic antorbital notch and longitudinal thickening posterior to maxillary incisure and along lateral wall of supra-cranial basin; maxillary canal opening into a slit-like incisure as in Physeter; a large foramen in right premaxilla situated anterior to maxillary incisure; rostral portion of premaxilla flattened or depressed; supracranial basin large, walls descend abruptly; cranium asymmetrical; postnarial process of premaxilla broadly expanded, forming about two-thirds of posterior wall of basin; occiput abruptly truncated; rostrum not constricted from side to side mesially; more than four alveoli in each maxilla; lachrymal not extending inward beyond infraorbital orifices; palatines small, narrow, and overridden posteriorly by pterygoids; a pair of ventral infraorbital orifices on each side; palatal surface of 
maxillae depressed laterally, forming a median ridge in front of palatines; most of vomer concealed from a ventral view by close approximation of maxillae, the axial ridge alone being visible; more than 4 alveoli in each maxilla; alisphenoids large; total length of skull as preserved $615 \mathrm{~mm}$; ; breadth of rostrum at antorbital notches, estimated $368 \mathrm{~mm}$...... Idiophyseter merriami gen. and sp. new.

$\mathrm{C}^{4}$. Distance between outer margins of condyles certainly less than one-third of breadth of skull across supraorbital processes of frontals.

$c^{1}$. Estimated breadth of skull across supraorbital processes $550 \pm \mathrm{mm}$.; inner margins of premaxillae almost in contact at level of anterior margin of ethmoid crest, a wide interspace opposite premaxillary foramen, and from this point anteriorly the inner margins of the premaxillae gradually converge; rostrum long, dorso-ventrally compressed, tapering anteriorly, but not noticeably constricted; supraorbital region not known; posterior borders of maxillary incisures apparently on a line with anterior borders of nasal passages; occipital face of skull flattened, not produced beyond level of posterior margins of exoccipitals and zygomatic processes, although the condyles do project posteriorly; a large foramen in left premaxilla anterior to antorbital notches; a rather large foramen in right maxilla close to premaxillary border and immediately in front of anterior margin of ethmoid crest; only two teeth in place but, judging from width of intervals between alveoli, the number of teeth in each maxilla may equal 19 and in premaxilla 3 or 4 ; teeth of young individuals elongated, nearly terete, with rather short crowns which are coated with longitudinally striated enamel; teeth of old individuals with well-marked constriction between base of crown and root, with the latter gibbous near middle, and with enamel on crown striated longitudinally; length of tooth $88 \mathrm{~mm}$., of which the crown measures $11 \mathrm{~mm} .^{1}$; total length of skull as preserved $812 \pm$ mm............ Scaldicetus mortezelensis (Du Bus).

$c^{2}$. Estimated breadth of skull across supraorbital processes $320 \mathrm{~mm}$.; supraorbital processes of frontals not completely overridden by maxillae (breadth of border not covered by maxilla $20 \mathrm{~mm}$.); superior face of supraorbital process oblique, characterized by the steep slope; posterior and ventral borders of this process are concave; postorbital projection rather long, pointed; maxilla relatively thin above orbit, with characteristic antorbital notch, and with longitudinal thickening posterior to maxillary incisure along lateral wall of supracranial basin; an antorbital process of maxilla; infraorbital canal apparently opening into a slit-like incisure in maxilla as in a young Physeter; supracranial basin large, with a steep slope to walls; cranium asymmetrical, strongly warped toward left side; bones on right side of basin constitute approximately two-thirds of breadth of braincase; postnarial process of premaxilla resembling that of Idiophyseter; occiput abruptly truncated; parietals visible on vertex as a narrow plate inserted between supraoccipital and frontals; zygomatic process very small; articular surface (glenoid fossa) triangular, not strongly excavated.... Thalassocetus antwerpiensis Abel.

\footnotetext{
1 The teeth of Scaldicetus grandis measure from 85 to $140 \mathrm{~mm}$. in length and those of Scaldicetus caretti from 140 to $260 \mathrm{~mm}$.
} 
$\mathrm{B}^{4}$. Size large (skulls of adult males attaining a length of 16 feet or more); breadth of rostrum at middle about three-fourths of that at base; distance between outer margins of condyles about onetenth of breadth of skull across supraorbital processes.

$\mathrm{b}^{1}$. A large passage (connecting with the infraorbital system) opening into a slit-like incisure in maxilla between antorbital notch and nasal passage; foramen in right premaxilla situated posterior to maxillary incisure in skulls of adults and in front of the same in young; rostrum very broad for its length, and depressed or excavated from above; rostral portion of premaxilla flattened; mesorostral gutter exposed for most of its length; extremities of premaxillae projecting beyond maxillae; cranium asymmetrical; a large supracranial basin with abruptly descending walls; lateral border of maxilla somewhat elevated at the level of the supraorbital process; antorbital notches deep and narrow; postnarial process broader than rest of right premaxilla; occiput abruptly truncated; occipital condyles relatively small; alveolar groove continuous, no septa, and no permanent teeth in upper jaw; 27 teeth in each mandible; zygoma complete; lachrymal extending inward to or beyond infraorbital orifice; palatines large, expanded horizontally, and overridden posteriorly and mesially by the pterygoids; inner margins of maxillae not in contact from a ventral view, thus exposing axial ridge of the vomer anterior to palatines........... Physeter catodon Linnaeus.

The influence which the developing fat or spermaceti cushion has exerted in modifying the appearance of the skull is more evident in the living genus Physeter than in the Lower Miocene genera Idiorophus and Diaphorocetus. Even in these Lower Miocene genera, this cushion had profoundly altered the appearance of the dorsal surface of the braincase, as is shown by the presence of a large supracranial basin. The roof of the braincase seems to have been depressed below its original level by this additional weight. The culmination of this tendency toward the abnormal development of a spermaceti cushion may be observed in the living genus Physeter, the size of whose skull is disproportionate, both in respect to the brain and to the body. In this genus, the spermaceti cushion has attained a great size and, in correlation with this increase, the bones comprising the rostrum have expanded horizontally. With the development of the supracranial basin, the frontals were depressed along the median line, one nasal bone was lost, and the left nasal passage greatly enlarged. Along with these asymmetrical modifications, there has been a corresponding development of a massive skull with ponderous bones to support the great weight of the spermaceti cushion and to counteract the resistance of the water. The posterior margin of the facial depression is more abruptly elevated than in any other family of cetaceans, and the basin extends farther backward. ' In the upper jaw, the teeth have become atrophied in the genus Physeter and are hidden in the gum. 
From the foregoing, it will become apparent that there are a number of as yet unknown fossil types to explain the course of some of these modifications; hence the description of these California physeteroids may afford additional data for the evolutionary history of this family.

Through the courtesy of Professor B. L. Clark and Mr. E. L. Furlong, the writer was given permission to describe the cetacean material in the Palaeontological Museum of the University of California. The writer also takes this opportunity to thank Dr. John C. Merriam and the Carnegie Institution of Washington for the support which has made this study possible. For the privilege of studying the fossil and living cetaceans in the United States National Museum I am indebted to Mr. C. W. Gilmore and Mr. Gerrit S. Miller jr., curators of their respective departments. The drawings of the specimens herewith given were carefully executed by Mrs. Freida Abernathy and nearly every character described or figured has been corroborated by comparison with skulls of living and fossil cetaceans, as well as with the published figures and descriptions of European specimens.

Idiophyseter merriami, new genus and species.

Type specimen.-Cat. No. 24287, Museum of Palaeontology, University of Califfornia. The type consists of an imperfect skull; the jugals, periotics, tympanics, extremity of the rostrum, and the zygomatic processes are missing. The maxillae, premaxillae, and pterygoids are imperfectly preserved.

Type locality.-The occurrence is as follows: Near latitude $35^{\circ} 33^{\prime} 40^{\prime \prime}$ North and longitude $120^{\circ} 48^{\prime} 32^{\prime \prime}$ West, near the town of Templeton, San Luis Obispo County, California. Section 29, Range 11 East, Township 27 South, Adelaida Quadrangle, U. S. Geological Survey.

Horizon.-The specimen was discovered and excavated by Mr. Joseph Walker in the fall of 1920. It was found embedded in a stratum of clay which was exposed at the bottom of a deep ravine. Some of the matrix was submitted to Dr. G. P. Merrill, head curator, Department of Geology, United States National Museum, and he reports that it is an aluminous clay and, judging from the character of the decomposition products, derived from volcanic detritus of an andesitic nature. The deposits in this region appear to be equivalent in time to the Temblor formation of the Middle Miocene.

One distinguishing feature of this fossil skull, as compared with skulls of adults of Physeter, is its relatively small size. A skull of a foetus in the United States National Museum measures $851 \mathrm{~mm}$. in length and this is slightly larger than this fossil specimen. Skulls of adult males of Physeter are known which measure at least 16 feet in length. Because of many corresponding features, it will be advisable to compare this fossil skull chiefly with Physeter, adults of which are the largest known physeteroids. Comparison will also be made with the Pigmy Sperm whale, Kogia.

\section{SKULL.}

\section{DORSAL VIEW.}

The anterior extremity of the rostrum was not found and, although the restoration (pl. 1, fig. 1) is in accordance with the curvature of that portion of the outer surface of the right maxilla which is preserved, it is possible that the rostrum originally may have been somewhat longer. The slope of the outer face of the right maxilla suggests a short rostral type like that found in Kogia rather than the more elongate type of Phy- 
seter. Granting the correctness of the rostrum as restored, there is still a slight disparity between the relative anterior extension of the maxillae and premaxillae, and the same elements in the skulls of Physeter and Kogia. Measuring from the level of the antorbital notches in the young Physeter skull gives a relative proportion of lengths between the rostral and cranial portions of the skull as $12: 9$. In Kogia the rostrum has become relatively shortened, a distinctive feature of the specialized Kogiidae, the proportional lengths being as $9: 9$. The proportional lengths of the rostrum and cranium of this fossil skull as restored are also $9: 9$.

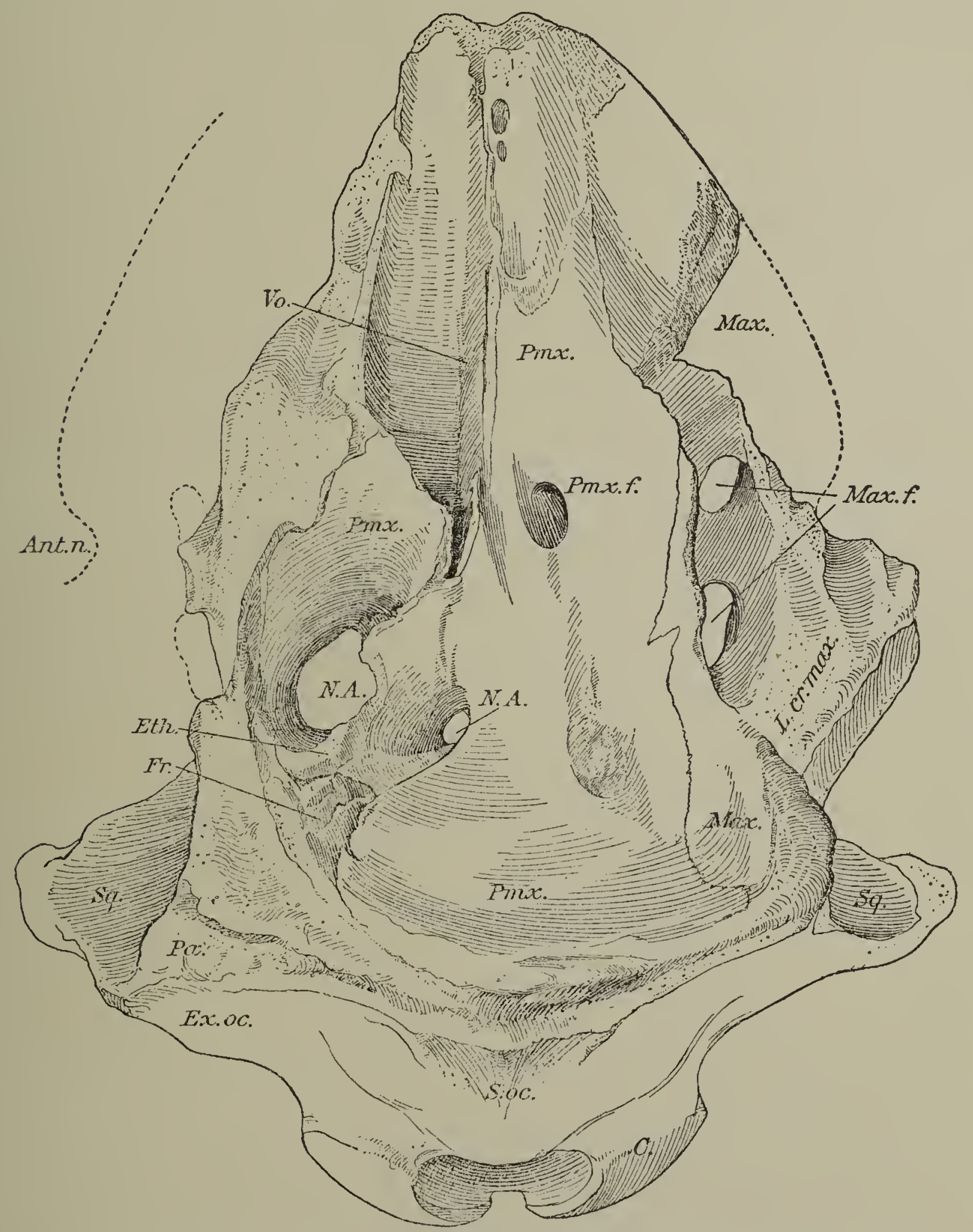

FIG, 1.-Dorsal view of type skull of Idiophyseter merriami. Cat. No. 24287, Palaeont. Mus., Univ. Calif. Ant. n., antorbital notch; $C$., condyle; Eth., ethmoid; Ex. oc., exoccipital; Fr. frontal; L. cr. max., lateral crest of maxilla; Max., maxilla; Max. $f$., maxillary foramen; $N$. A., nasal passage; Pa., parietal; $P m x$. premaxilla; $P m x$. f., premaxillary foramen; $S$. oc., supraoccipital; $S q$., squamosal; Vo., vomer.

This aspect of the skull (text-fig. I) is interesting because it tends to confirm the allocation given above. Skulls of Kogia are characterized by a prominent sagittal crest between the nares and the vertex, while this crest is lacking on those of Physeter, and the supracranial basin is greatly developed. The curvature and outlines of those 
elements which are preserved afford a basis for computing and restoring the original outlines of the skull. In this restoration, some allowance must be made for possible differences in the degree of elevation or projection of the free edge of the maxilla above the maxillary foramina. With this exception, the relations and peculiarities of the various bones comprising the dorsal face of the braincase of this fossil skull are essentially the same as in the Physeter skull.

The maxillae are the very large and massive bones which form the major portion of the rostrum and whose ascending processes slide backward over the upper surfaces of the supraorbital plates of the frontals. They expand in width in front of the deep antorbital notches. Their flat upper surfaces are formed by a thin outer plate of dense bone, but the internal structure is cancellous as in Physeter, with distinct cells which were probably filled with oil in life as in the latter. On the dorsal surface there is a broad groove leading forward from the maxillary incisure. The internal margin of each maxilla embraces the corresponding border of the premaxilla. Judging from the section of the right maxilla which is preserved, there are but slight differences in contour as well as in relative proportions from Physeter. The lateral border of the maxilla is thick anteriorly, but as the maxilla approaches the antorbital notches, in consequence of the upward slope of the ventral surface from the median line, it becomes progressively thinner, decreasing until it is less than half of its maximum depth, and at the widest point probably exhibiting a tendency to curve downward.

As seen from dorsal view, the median portion of the rostrum is formed by the premaxillae, in the shape of rather broad bands of varying width with very thin edges overhanging the mesorostral gutter, and by the anterior extension of the vomer which constitutes the floor of the gutter. With the exception of a short interval at the extremity, the vomer in Kogia and Physeter extends the whole length of the gutter. On the outside, the vomer meets the inner borders of the premaxillae laterally, and internally forms the floor and walls of the gutter. The same relations are maintained in this fossil skull. The floor of the mesorostral gutter increases in width posteriorly, but is shut off from the left nasal passage by the overspreading left premaxilla as in Orycterocetus.

In Physeter, the upper surface of the cranium (pl. 6, fig. 1) is concave, the facial depression in which the fat or spermaceti cushion lies being limited posteriorly by the transverse crest and continued laterally to the elevated ridges of the broadly expanded maxillae. The latter curve upward and outward from their internal borders toward the external margin of the cranium. The great breadth of the maxillae in front of the antorbital notches adds another distinctive feature to the rostrum. Asymmetrical modifications in the cranium are carried to an extreme stage in Physeter and in this fossil skull. The left nasal passage of this fossil skull is enormously developed, the other reduced in a corresponding degree. The distortion thus occasioned is not confined to the bones immediately concerned with the formation of the nasal passages, but affects the entire surface of the great supracranial basin.

On comparing this fossil skull with that of the young Physeter, the arrangement of the various bones was found to be essentially the same. Most of the left side of this skull is lost. On the right side the supraorbital process of the frontal is imperfect and portions of the outer margin of the maxilla are missing. The great semicircular wall which rises behind the nasal passages to form the supracranial basin is constituted by the thin plate-like posterior extremities of the premaxillae, the maxillae, the nasal, and by the underlying frontals. On the right side of the skull, the greatly thickened and sloping lateral edges of the crest are formed by the maxilla, but this bone apparently does not meet the opposite one in the middle line. The internal border of the maxilla is very thin. No especial asymmetry is presented by either of the maxillae. The maxillary foramen is represented by a fissure placed between the nasal passages and the antorbital notch, but nearer the latter, and into which a pair of passages from the infraorbital system opens. This incisure gives passage to the great branches of 
the trigeminal nerve which supply the upper lip and face. A thin lamina projecting upward and outward from the maxilla on the internal side in conjunction with the longitudinal thickening of the latter on the outside partially inclosed this incisure from above.

Posteriorly, the maxilla is thickest behind the maxillary incisure. The outer margin follows the corresponding border of the frontal and, with the possible exception of the anterior extremity on the supraorbital process, does not project beyond the latter. The temporal fossae are very short. Superiorly, in the young Physeter skull they are roofed over by the frontals and the maxillae are excluded from their borders. In this fossil skull, the upper lateral margins of the frontals have been destroyed. That portion of the maxilla which overlies the right supraorbital process suggests the restoration which has been made for this structure. The indications are that the preorbital projection of the maxilla rolls over the supraorbital process of the frontal and the dorsal border of the lachrymal as in Physeter. This inference, also, is indicated by the curvature of the fragment of the original surface of the right maxilla and by the direction of the longitudinal ridge which parallels the groove leading backward from the antorbital notch.

The premaxillae, however, are dissimilar in form. Anterior to the antorbital notches, the premaxillae lie on each side of the mesorostral gutter and it is reasonable to assume that they were more or less symmetrical in outline. The right premaxilla passes backward along the upper surface of the cranium and posterior to the nasal passages expands into a broad, thin plate applied to the upper surface of the frontal and overlapping the maxilla along its outer borders. On the right premaxilla at the level of the nasal passage there is a deep ovoidal depression larger than the right nasal passage. The right premaxilla is much longer than the left, extending posteriorly to the transverse crest; while the left, in Physeter at least, neither reaches beyond the nares nor comes in contact with the frontal. The right premaxilla is also broader than the left one, and the horizontal expansion reaches its greatest development posterior to the nares. The postnarial process of the right premaxilla may have been in contact with the nasal, but this is rather unlikely. The left premaxilla as stated above is turned out of its course by the enlargement of the corresponding nasal passage and apparently terminates suddenly at the level of the posterior margin of this aperture. In the right premaxilla, $86 \mathrm{~mm}$. in front of the nasal passage, there is an oval foramen, $32 \mathrm{~mm}$. in diameter, leading into a canal which is directed outward, and which communicates with the infraorbital system. There is no corresponding opening on the left side.

On the left side of the young Physeter skull there is a large thin plate of bone overlying the frontal, meeting the left maxilla along its external margin and extending forward to the ethmoid, which appears to be the nasal. No trace of a nasal can be found on this fossil skull, for the corresponding region is eroded.

In an adult Physeter skull, the left nasal passage is approximately a foot in diameter and in the young specimen it measures $85 \mathrm{~mm}$. In this fossil skull it is approximately $60 \mathrm{~mm}$. The left passage is also considerably larger than the right. The upper margin of the left nasal passage is formed by the vomer on the inner side, the premaxilla in front, on the outer side, and on the back, and postero-internally by a rough spongy mass growing out from the left side of the ethmoid which is twisted over to the left side. Inferiorly the vomer curves around the back of each passage, while the pterygoid forms the remainder of the inferior border. In the anterior and outer wall, a small slip of the palatine appears.

The ethmoid is an irregular mass of bone which is placed in front of the frontal fontanelle and which inferiorly is continuous with the presphenoid. The latter is embraced in the narrow groove of the vomer. Part of the dorsal margin of the ethmoid is missing. No trace of small foramina which would afford passage to the nasal branches of the ophthalmic division of the trigeminal nerve can be found. 
From a dorsal view, the frontals are almost entirely hidden by the modifications which have resulted from the development of the great supracranial basin. The posterior and external borders of the frontals will be visible on a better preserved skull, but the remainder of their upper surfaces are concealed by the plate-like posterior extremities of the premaxillae mesially and by the maxillae laterally. A small strip of the right frontal is visible above the right nasal passage. Postero-mesially, the frontals are broadly sutured to the upper margin of the supraoccipital. Laterally, the frontals are shut off from the supraoccipital by the wedge-like plates of the parietals. The supraorbital processes of the frontals are relatively short and thick. The most obvious peculiarity of this aspect of the skull as compared to that of the young Physeter is the abruptness with which the supraoccipital descends to the condyles.

\section{POSTERIOR VIEW}

The outer borders of this face of the skull (text-fig. 2) had been weathered away before the skull was discovered. Computations of the relative proportions of the elements in a skull of a living cetacean when applied to a fossil for purposes of restoration (pl. 3, fig. 2) are always attended with a certain amount of error, but nevertheless it seems desirable to make some attempt in this direction.

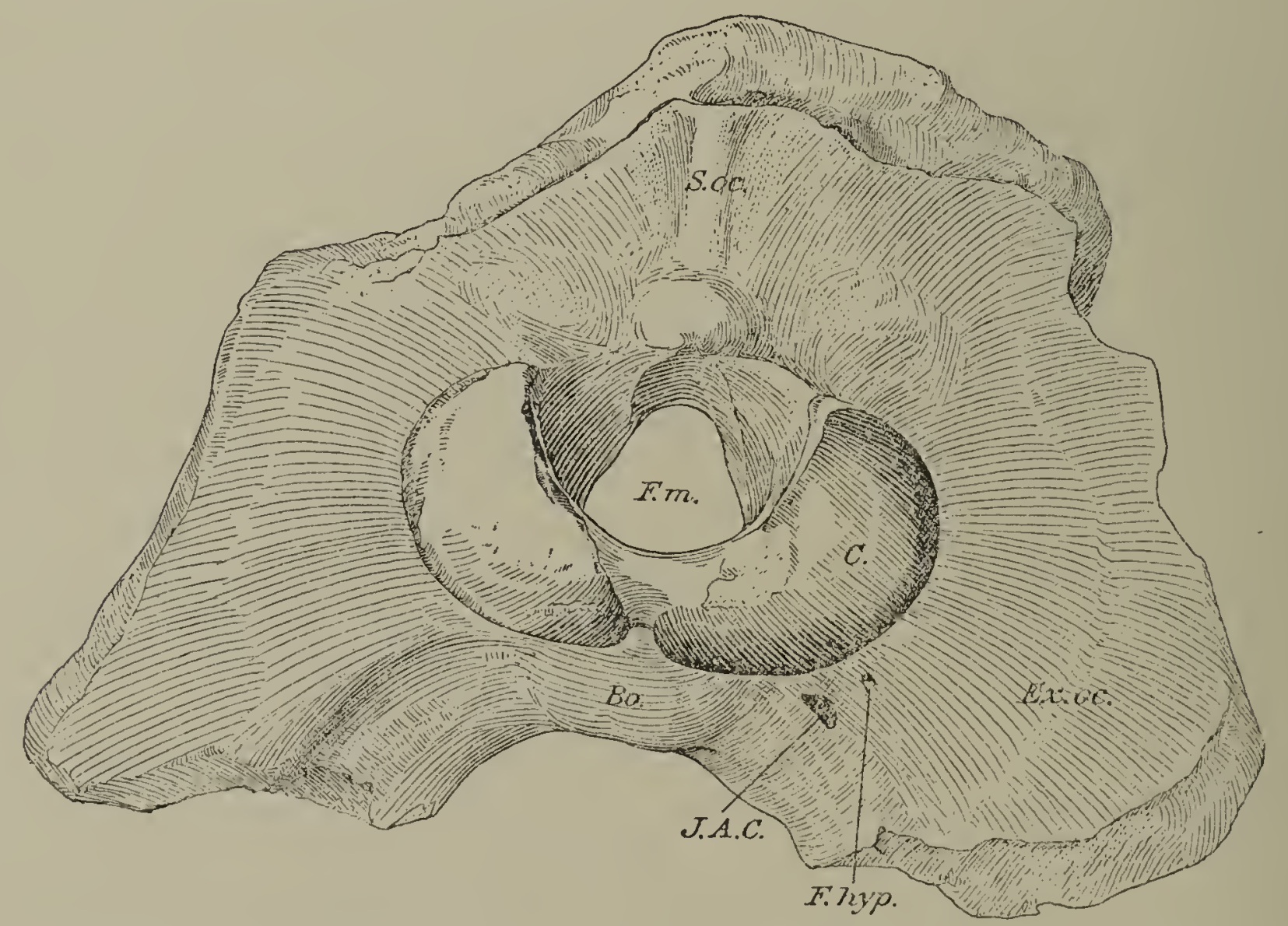

FIG. 2.-Posterior view of type skull of Idiophyseter merriami. Cat. No. 24287, Palaeont. Mus., Univ. Calif. Bo., basioccipital; $C$., condyle; $E x$. oc., exoccipital; $F$. hyp., hypoglossal foramen; $F$. $m$., foramen magnum; J. A. C., jugulo-acoustic canal; $S$. oc., supraoccipital.

As seen from the occipital view, the large projecting condyles are the only structures which have not suffered from erosion. The opening for the foramen magnum is subtriangular in outline. The condyles are semielliptical in outline, considerably broader near the middle than at either end, and slightly convex from side to side. They are borne on short condylar processes and are set off from the exoccipitals by shallow concavities. The internal margins are concave and sharply defined, converging inferiorly, but separated by a narrow sulcus. The peculiarities of the condyles correspond more closely with Physeter than with Kogia. In Diaphorocetus poucheti, the condyles are relatively smaller. The large condyles, taken in conjunction with the broad mastoid region for muscular attachments, indicate a certain amount of mobility for the head and lead further to the conclusion that the cervical vertebrae were separate and not fused. 
The exoccipitals were evidently rather large, coalesced with the supraoccipital above and projected outward as in Physeter, concealing the zygomatic processes for the most part when viewed from behind. Laterally and anteriorly they are in contact with the squamosals, while inferiorly they are fused with the basioccipital. The supraoccipital is broad, with a low median carina superiorly, on either side of which the surface is depressed.

Below the right condyle, the jugulo-acoustic canal is exposed, but the orifice lies in front of the incisure between the falcate process of the basioccipital and the exoccipital. The hypoglossal foramen pierces the exoccipital and its ectal orifice may be seen external to this fracture and below the right condyle.

\section{LATERAL "VIEW.}

In some respects, the full extent of the damage which has resulted to this skull is more apparent when viewed from the side (text-fig. 3) than from any other aspect. The zygomatic process, the preorbital and postorbital projections of the supraorbital plate, the jugal, and the projecting processes of the pterygoid are missing. The broken edges of the exoccipital, frontal, and maxilla further distort this aspect of the skull. Even though the skull at first glance may appear to be too badly damaged for accurate description, such is really not the case for, when these missing borders are restored (pl. 2, fig. 2), the fundamental resemblances to Physeter as indicated by the relations of the component parts become more apparent.

Aside from whatever uncertainty may exist as to the correctness of the restoration, it is evident that this skull is characterized by a relatively small temporal fossa. This fossa has been shortened in an anteroposterior direction, and is bounded by the frontal above and the squamosal below. The chief point of interest in this region on the young Physeter skull (pl. 2, fig. 1) is the fate of the parietal. In this young Physeter skull, a thin T-shaped plate of bone is inserted in the vertical interval between the squamosal and the frontal, and also in the horizontal interval between the supraoccipital on the upper side and the frontal and squamosal on the lower. In more mature skulls, the squamosal and frontal unite in a vertical suture. It can not be demonstrated with certainty from the material at hand, that a parietal is present in a Physeter skull as a separate element. Some writers maintain that it has fused with the supraoccipital. This may be the true solution because there is a fissure, more distinct in some places than in others, which separates this lower temporal process from the main body of the plate-like supraoccipital. By following this fissure it becomes evident that if this portion does represent the parietal, then a thin plate of this bone reaches the vertex, being inserted between the supraoccipital and the frontal. On its external face this element receives an ascending process of the squamosal into a deep triangular fossa, posteriorly it is in contact with the supraoccipital above and the exoccipital below, and anteriorly the frontal is deeply mortised into its anterior margin.

Returning to this fossil skull, some significance may attach to the fact that a parietal is present in the same relative position as in the young Physeter skull, although much larger. Within the temporal fossa, the sutures bounding the parietal are well-defined and there is also some evidence for believing that a thin plate-like dorsal extension of this bone extends at least part way to the vertex, being inserted between the supraoccipital and frontal. If this interpretation is correct, then it corroborates in part what appears to be the true position of the parietal in the Physeter skull during early stages in its growth. The parietal is suturally united with the squamosal posteriorly and with the frontal and alisphenoid anteriorly.

In this fossil skull, the alisphenoid occupies essentially the same position as in Physeter and is broadly expanded, extending forward to the supraorbital process of the frontal and sheathing the posterior borders of the latter for a short distance, and in the temporal fossa projects upward, being bounded on its upper margin by the frontal, posteriorly by the parietal, and inferiorly by the squamosal. 


\section{Tertiary History of Pelagic Mammals of Pacific Coast.}

Although the orbit is small in the restoration, it is possible that it may have been wider. The supraorbital process is shorter than in most dolphins, but what remains of its outer margin indicates that it was relatively thick. In Physeter, the supraorbital process is largely uncovered by the maxilla externally; the extremity is relatively shallow, and the whole structure is distinctly arched. The postorbital projection extends farther backward, but does not quite come in contact with the zygomatic process of the squamosal. In Kogia, the postorbital projection overlaps the zygoma for an inch or more. In Physeter, the lachrymal is wedged in between the preorbital margin of the supraorbital process and the maxilla. Below the antorbital projection of the maxilla and ankylosed to the lachrymal there is a narrow curved strip of bone, the styliform process of the jugal, which forms the lower boundary of the orbit. There is nothing peculiar about the structure of the fossil skull in this region which would suggest a lachyrmal of the Kogia type (pl. 3, fig. 1), but the relations of the bones do favor one of the Physeter type.

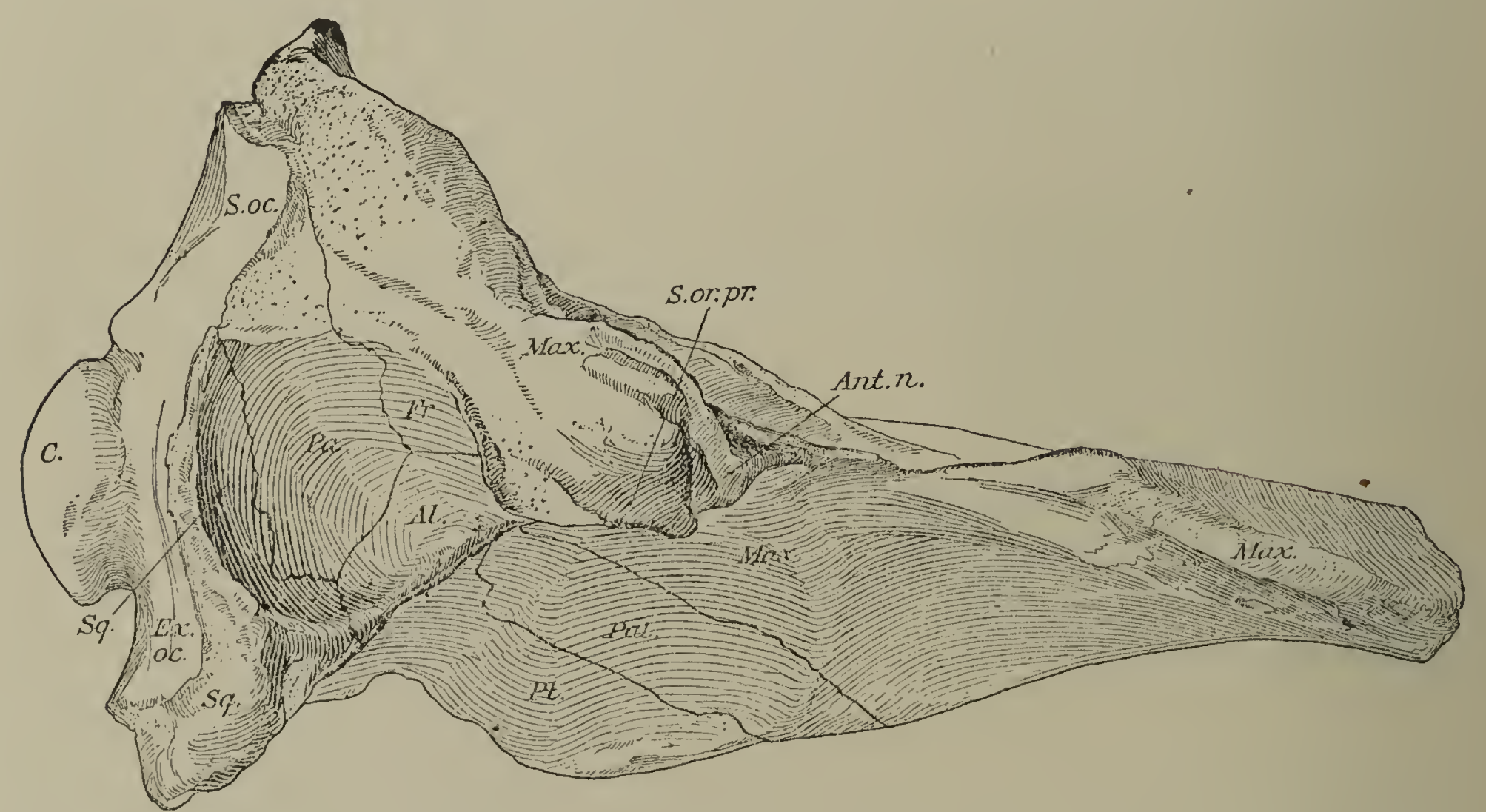

F1G. 3.-Lateral view of type skull of Idiophyseter merriami. Cat. No. 24287, Palaeont. Mus., Univ. Calif. Al., alisphenoid; Ant. n., antorbital notch; $C$., condyle; Ex. oc., exoccipital; Fr., frontal; Max., maxilla; $P a$., parietal; $P a l$., palatine; Pt., pterygoid; S. oc., supraoccipital; S. or. pr., supraorbital process of frontal; $S q$. , squamosal.

The original outlines of the zygomatic process can only be surmised since the major portion of both processes are missing. The zygomatic portion of the squamosal in a Kogia skull is drawn out into a rather slender process, with a small concave fossa for the condyle of the lower jaw, and with the anterior end produced downward although it does not meet the styliform process of the jugal. In Physeter, the zygomatic process is bluntly pointed anteriorly, thickened dorso-ventrally, and the upper surface slopes downward and forward; the postglenoid process is scarcely developed as such. Although the major portion of the right zygoma is missing, the surface of the lower antero-external corner shows that this process must have been of moderate size. Whether or not the zygoma projected as far forward as the postorbital projection of the supraorbital plate will remain a matter of doubt until a skull is found with these structures intact.

The skull as a whole is rather heavy and the slope of the dorsal and ventral surfaces imparts a peculiar sub-triangular appearance to the lateral profile. In front of the antorbital notches, the upper surface of the maxilla is nearly horizontal, but from this point posteriorly it is deflected upward to conform with the peculiar modifications 
which have been brought about in the frontal during the development of the supracranial basin.

The extremity of the rostrum is missing, and, as before indicated, there are some grounds for assuming that it was relatively shorter than in Physeter. The lateral aspect of the rostrum as far as preserved is formed entirely by the maxilla. Between the last alveolus and the antorbital notch the thin outer margin of the maxilla has been destroyed. The alveoli are visible from a side view and the last one is placed $225 \mathrm{~mm}$. in front of the antorbital notch. This view best illustrates the great depth of the rostrum in the region of the palatines.

Viewed from the side, the condyles project beyond the plane of the exoccipitals and are borne on distinct necks. Alterations in the proportions or outlines of the restored portions of the hamular and vaginal processes of the pterygoids would not materially affect the typically physeteroid appearance of the basicranium.

VENTRAL VIEW.

The general contour as restored (pl. 1, fig. 2) is irregularly pentagonal, the greatest width being across the zygomatic processes. In this feature, the restored skull agrees more closely with conditions found in a skull of a very young Physeter catodon ( $\mathrm{pl}$. 6, fig. 2) than with a skull of an adult Kogia breviceps. In Kogia, the greatest width of the skull is across the postorbital projections of the supraorbital processes. Although the relations of the various elements which form the ventral face of the skull agree in some respects with Kogia and in others with Physeter, there are a number of important differences.

Skulls of Physeter lack functional teeth in the maxilla. In Kogia, however, there is a well-defined alveolar sulcus. Authorities differ in regards Physeter, although all agree that the upper tooth row is atrophied. It appears that some skulls do have as many as 8 teeth on each side but the teeth appear to be implanted in the gums. Two alveoli, however, are present on the right maxilla of this fossil skull and the terminal portion probably contained additional alveoli. Internally each maxilla is produced downward to form a narrow, crest-like ridge which anteriorly gradually merges into the convex portion of the maxilla and posteriorly increases in width to agree with a corresponding surface of the palatine. The internal margins of the maxillae approximate each other so closely in front of the palatines that only a slender strip of the vomer is visible. The axial ridge of the vomer first appears on the ventral surface of the skull between the maxillae and about midway between the second alveolus and the anterior infraorbital foramen. External to these medial longitudinal crests, the maxilla is hollowed out, forming a large concave area in front of the infraorbital foramen. Similar concavities are present on the Kogia skull but are either ill-defined or absent on the young Physeter skull.

On each side extending from the alveoli to the condyles is a series of elevations and depressions which contribute to the formation of the maxillary concavities, orbits, tympano-periotic recesses, and glenoid fossae. In this region there appear portions of the maxilla, lachrymal, frontal, palatine, vomer (in part covered by the forward extension of the pterygoid), pterygoid, alisphenoid, basioccipital, exoccipital, and squamosal. In Kogia there is but a single depressed inferior opening for the infraorbital system, and this is bounded by the maxilla and lachrymal. The orifice is situated at the level of the posterior wall of the nasal passage. On the ventral surface of the maxilla are two openings for the infraorbital system in this fossil skull. The anterior orifice is entirely inclosed by the maxilla. The posterior orifice is bounded by the maxilla, frontal, and lachrymal. From the posterior orifice a canal extends upward through the maxilla and opens on the dorsal face of the skull in the maxillary incisure. The canal leading upward from the anterior orifice is continuous posteriorly with the previously mentioned canal and anteriorly with the canal which passes through the substance of the maxilla above the tooth row; it also has a dorsal orifice 
in the maxillary incisure. The wall intervening between these two foramina has disappeared in the young Physeter skull and a single orifice occupies approximately the same position and area as the two foramina in the fossil skull.

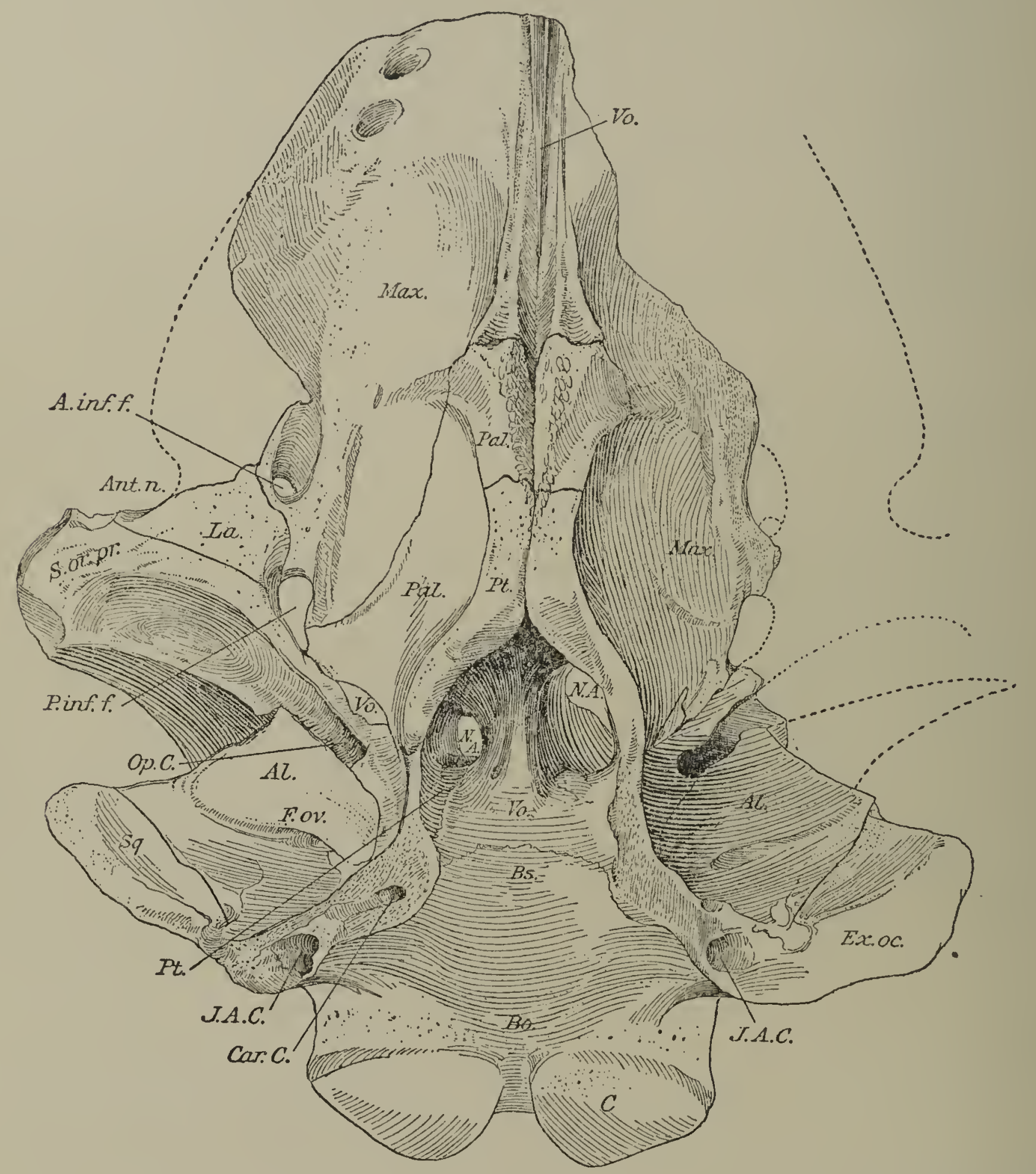

FIG. 4.-Ventral view of type skull of Idiophyseter merriami. Cat. No. 24287, Palaeont. Mus., Univ. Calif. Al., alisphenoid; Ant. n., antorbital notch; Ant. inf. f., anterior infraorbital foramen; Bo., basioccipital; Bs., basisphenoid; C., condyle; Car. C., carotid canal; $E x$. oc., exoccipital; $F$. ov., foramen ovale; $J . A . C$., jugulo-acoustic canal; La., lachrymal; Max., maxilla; $N$. A., nasal passage; Op. c., optic canal; Pal., palatine; $P$. inf. f., posterior infraorbital foramen; Pt., pterygoid; S. or. pr., supraorbital process of frontal; $S q$., squamosal; Vo., vomer.

Thin, wedge-like lachrymals, which are inserted between the supraorbital plates of the frontals and the maxillae, extend inward beyond the internal walls of the orifices for the infraorbital canals in the Physeter skull. In Kogia, the lachrymals are greatly enlarged and on the ventral face of the skull are equally if not more conspicuous than the supraorbital processes of the frontals. The right lachrymal in this fossil skull occupies approximately the same relative position as in Physeter, excepting a narrow, slit-like process which is not developed and hence the lachrymal terminates at the level of the external walls of the ventral orifices for the infraorbital system. In this respect, the lachrymal of this fossil skull is unlike either Kogia or Physeter. The right lachry- 
mal is incomplete, but notwithstanding its position on the ventral surface, it was not visible from a dorsal view. The slender internal process of the lachrymal which is so conspicuous in skulls of Kogia and Physeter is not present, and the most produced portion lies between the two inferior openings of the infraorbital system. It does contribute the lower boundary of the antorbital notch as in Physeter. No primitive characters are apparent, unless the intimate relation the lachrymal bears to the maxilla and the supraorbital process of the frontal be considered one. Both jugals are missing. In the restoration they are patterned after those on the young Physeter skull.

The bones of the palatal region have suffered some from erosion and breakage, but on the right side the palatine is essentially perfect and the vaginal processes of the pterygoid alone are missing. On the right side, the optic canal is so well preserved that the relations of all the contributing bones can be made out; the sutures are indistinct in places, but can be traced. The physeteroid characters can be seen in the relations of the palatines, pterygoids, and vomer, and in the position of the infraorbital openings. In a Kogia skull, the pterygoids are broadly expanded anteriorly, overspreading the narrow palatines, meeting the opposite bone along the median line of the palate, and extending forward beyond the palatines to reach the maxilla. The exposure of the palatines is thus reduced to a small area represented by their anterior extremities which make their appearance in front of the concave anterior borders of the pterygoids. On the other hand, in a young Physeter skull, the palatines are expanded horizontally and are overridden posteriorly by narrow tongue-like processes of the pterygoids, which in some young skulls project forward beyond the ventral orifice of the infraorbital canal. As near as can be determined from a close examination of this fossil skull, the relations between the pterygoids and the palatines appear to correspond more closely to conditions in the young Physeter skull than to an adult Kogia skull. The palatines of this fossil skull are relatively narrow, but they do not project forward noticeably beyond the limits of the grooves leading forward from the anterior infraorbital orifices.

With the exception of the basal portion, the hamular processes of the pterygoids are for the most part missing. They appear to have been produced backward into long processes as in Physeter and thus internally form the floor for the nasal passages. The anterior margins of the pterygoids apparently slide under the palatines and thus contribute the major portion of the outer lower wall of each nasal passage. In restoring this portion of the fossil skull a condition approximately halfway between the Kogia and Physeter type of architecture was more nearly in agreement with the length of the vaginal processes of the pterygoids.

On the anterior wall of the optic canal and near its origin there appears the small splint-like extremity of the orbitosphenoid which projects laterally upon the ventral face of the supraorbital process of the frontal. By making comparisons with skulls of Kogia and Physeter, it has been possible to work out most of the structural peculiarities of this region. The large size and horizontal expansion of the alisphenoid in this fossil skull is also a conspicuous feature of the Physeter skull. It is quadrangular in outline, bounded anteriorly by the optic canal and limited posteriorly by the squamosal. The large foramen ovale is directed obliquely through the alisphenoid and its ectal orifice lies considerably posterior to the anterior margin of the squamosal and opens into a broad groove which terminates near the postero-external angle of the alisphenoid as in Physeter. In Kogia, this foramen is rather small and is situated at the level of the anterior margin of the squamosal, and the direction of the groove leading from the foramen ovale is almost at right angles to the long axis of the skull. The optic foramen is confluent with the sphenoidal fissure as in skulls of young individuals of Kogia and Physeter. In some adult skulls of Kogia, a taenia metoptica is present which separates the optic canal from the sphenoidal fissure. This fissure is closed ventrally by the vaginal process of the pterygoid, anteriorly is limited by the supraorbital plate of the frontal, and is also bounded posteriorly by the alisphenoid. As in Kogia, the foramen 
rotundum appears to be situated in the angle formed by the alisphenoid and frontal, nearest to the sphenoidal fissure.

In the young Physeter skull, the canal for the carotid artery is rather large (18 $\mathrm{mm}$.), piercing the alisphenoid near the base and separated from the foramen ovale by an intervening strip of bone less than $10 \mathrm{~mm}$. wide. The combined jugulo-acoustic funnel is bordered posteriorly by the exoccipital, internally by the basioccipital, and anteriorly by the alisphenoid. A process of the exoccipital in the Kogia skull extends forward to meet the alisphenoid and bounds this funnel internally, thus excluding the basioccipital from its lower margin. Otherwise these canals are very similar. In this fossil skull the carotid canal passes through the alisphenoid (text-fig. 4, Car. C.) above the vaginal process of the pterygoid and thence through the substance of the falcate process of the basioccipital for a total distance of $100 \mathrm{~mm}$. or more and opens ectally in front of the jugulo-acoustic canal. The jugulo-acoustic canal, on account of a median constriction appears to represent two foramina. This canal lies entirely within the exoccipital and pierces this bone in an oblique direction for a distance of 90 $\mathrm{mm}$. The greatest diameter of the jugulo-acoustic foramen at the point where it is exposed on the right side is $22 \mathrm{~mm}$.; that for the carotid canal is $10 \mathrm{~mm}$. The hypoglossal foramen begins internally on the posterior wall of the jugulo-acoustic funnel and opens ectally on the posterior face of the exoccipital above the jugular incisure in skulls of Kogia and Physeter. It is present in the same position on the right exoccipital of this fossil skull.

The median region of the basicranium is bounded laterally by the great flanges or falcate processes of the basioccipital and by the pterygoids. It narrows slightly anteriorly and probably was partially inclosed by the hamular processes of the pterygoids. The ventral edges of the vaginal processes of the pterygoid and the extremities of the falcate processes of the basioccipital are missing. The general course and direction of certain foramina are thus revealed. On the right side (text-fig. 4) the small carotid canal is exposed on the lateral border of the basioccipital, some $28 \mathrm{~mm}$. posterior to the margin of the vomer.

The basioccipital is a rather large bone terminated posteriorly by the paired condyles and synostosed anteriorly with the basisphenoid. Between the basisphenoid and basioccipital the medial region is noticeably swollen transversely. The same region is flattened on skulls of Kogia and Physeter. In the skull of the young Physeter, the sides of the basioccipital descend obliquely outward and form the falcate processes, each of which posteriorly abuts against a similar plate formed by the exoccipital and anteriorly limits the posteror extension of the corresponding process of the pterygoid. In the Kogia skull the pterygoids project much farther backward and are also in contact with the falcate processes of the basioccipital.

In this fossil skull, the outer extremities of the basioccipital have been broken off, but nevertheless the relations of the surrounding bones do not indicate that the falcate processes were produced any farther downward than in Physeter. Anterior to the occipital condyles, the lower surface of the basioccipital is somewhat convex, and the outer edges are produced downward as free plates. Each of these falcate processes forms the internal boundary for the corresponding tympano-periotic recess. It appears more probable that this region of the fossil skull resembled Kogia more closely than Physeter and for that reason the restoration represents a compromise between the two types of construction. The suture between the basioccipital and the basisphenoid is not visible; it is possible that the basisphenoid is not entirely covered on its ventral face by the overlying plate of the vomer.

Because of the concavity of the internal borders of the maxillae, the exposed surface of the vomer has the shape of a boat in the skulls of a young Physeter and an adult Kogia. As remarked before, only the axial ridge of the vomer is visible anteriorly in this fossil skull because of the close approximation of the maxillae. The vomer forms the internal and posterior wall for each nasal passage and extends upward to meet the 
ethmoid. In this region the vomer is very thin, and, following the deviation of the ethmoid and the asymmetrical conditions produced by the disparity in size of the nasal passages, turns to the right. At the point where these thin wings of the vomer are

Measurements of the skull.

\begin{tabular}{|c|c|c|}
\hline & $\begin{array}{c}\text { Idiophyseter } \\
\text { merriami } \\
\text { No. } 24287 \\
\text { Univ. Calif. }\end{array}$ & $\begin{array}{c}\text { Physeter catodon } \\
\text { (embryo) } \\
\text { No. } 49488, \\
\text { U. S. Nat. Mus. }\end{array}$ \\
\hline Total length (condyles to tip of premaxillae). & $\begin{array}{l}m m \\
1735.0\end{array}$ & $\begin{array}{l}m m . \\
851.0\end{array}$ \\
\hline 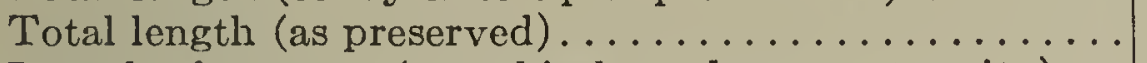 & 615.0 & \\
\hline Length of rostrum (antorbital notches to extremity)... & 1388.0 & 520.0 \\
\hline 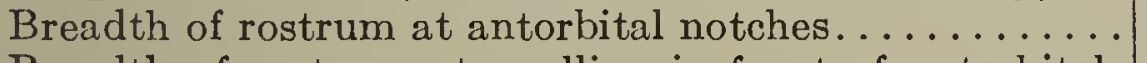 & ${ }^{1} 368.0$ & 315.0 \\
\hline $\begin{array}{l}\text { Breadth of } \text { rostrum at swelling in front of antorbital } \\
\text { notches } \ldots \ldots \ldots \ldots \ldots \ldots \ldots \ldots \ldots \ldots\end{array}$ & 1405.0 & 347.0 \\
\hline Greatest breadth of skull across supraorbital processes. & 1502.0 & 472.0 \\
\hline 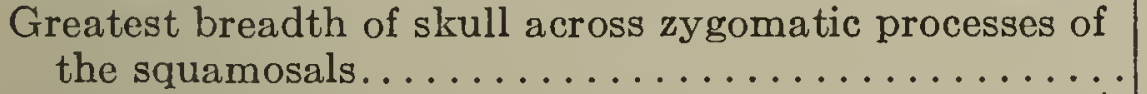 & ${ }^{1} 555.0$ & 487.0 \\
\hline Vertical height of skull (basioccipital to transverse crest). & 273.0 & 285.0 \\
\hline $\begin{array}{l}\text { Vertical height of rostrum at base (level of antorbital } \\
\text { notches) } \ldots \ldots \ldots \ldots \ldots \ldots \ldots \ldots \ldots \ldots \ldots \ldots \ldots \ldots \ldots \ldots\end{array}$ & 135.0 & 111.0 \\
\hline $\begin{array}{l}\text { Greatest width of right maxilla (inside margin to the } \\
\text { apophysis) } \ldots \ldots \ldots \ldots \ldots \ldots \ldots \ldots \ldots \ldots \ldots \ldots \ldots\end{array}$ & 137.5 & 168.0 \\
\hline $\begin{array}{l}\text { Length of frontal plate of right maxilla (antorbital notch } \\
\text { to supraoccipital) } \ldots \ldots \ldots \ldots \ldots \ldots \ldots \ldots \ldots \ldots \ldots\end{array}$ & 245.0 & 250.0 \\
\hline Greatest length of right premaxilla, as preserved...... & 490.0 & 725.0 \\
\hline Greatest breadth of right premaxilla at level of nares... & 105.0 & 68.0 \\
\hline Greatest breadth of right premaxilla posterior to nares. & 190.0 & 99.0 \\
\hline Least breadth of premaxilla in front of antorbital notches & 75.0 & 24.0 \\
\hline Greatest length of supraorbital process of right frontal.. & 1118.0 & 97.5 \\
\hline 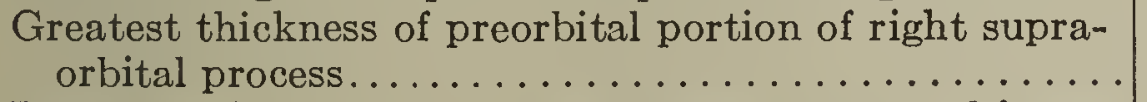 & & 18.5 \\
\hline $\begin{array}{l}\text { Least breadth of supraoccipital between temporal fossae. } \\
\text { Distance from summit of transverse crest to upper }\end{array}$ & 355.0 & 314.0 \\
\hline 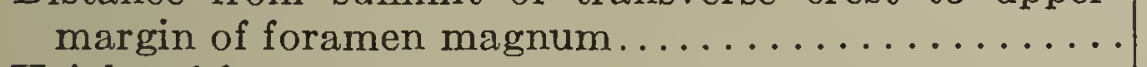 & 177.5 & 167.5 \\
\hline 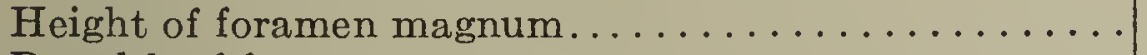 & 73.0 & 66.0 \\
\hline Breadth of foramen magnum......... & 71.0 & 80.0 \\
\hline Greatest breadth across occipital condyles........... & 216.5 & 197.0 \\
\hline Greatest vertical diameter of right condyle... & 129.0 & 123.5 \\
\hline Greatest transverse diameter of right condyle........ & 78.0 & 66.2 \\
\hline 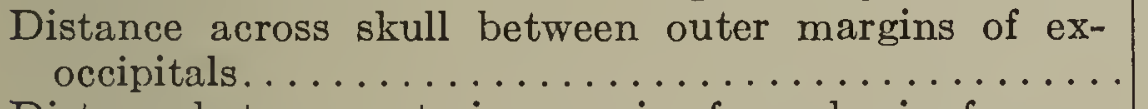 & 540.0 & 433.0 \\
\hline $\begin{array}{l}\text { Distance between anterior margin of apophysis of supra- } \\
\text { orbital process of right frontal and posterior margin } \\
\text { of right condyle } \ldots \ldots \ldots \ldots \ldots \ldots \ldots \ldots \ldots \ldots \ldots\end{array}$ & 425.0 & 380.0 \\
\hline Distance across basicranium between foramina ovale... & 191.0 & 158.0 \\
\hline 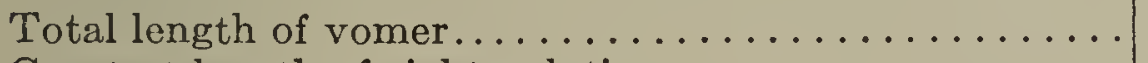 & 470.0 & 535.0 \\
\hline 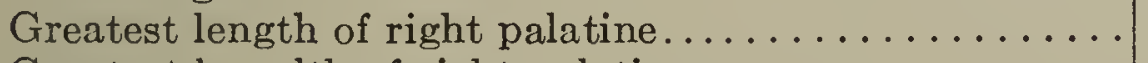 & 194.5 & 180.0 \\
\hline Greatest breadth of right palatine............ & 60.0 & 116.5 \\
\hline Greatest transverse diameter of right lachrymal....... & $110+$ & 147.0 \\
\hline Greatest antero-posterior diameter of right lachrymal. . & 62.5 & 61.8 \\
\hline Greatest antero-posterior length of right pterygoid..... & $245+$ & 175.0 \\
\hline 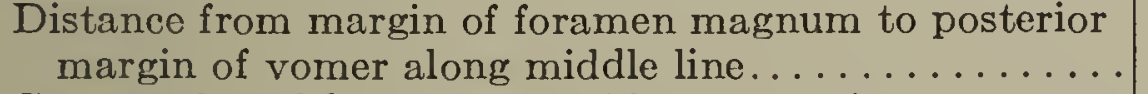 & 149.0 & 2191.0 \\
\hline Greatest breadth of alisphenoid at extremity........ & 110.0 & 72.0 \\
\hline Greatest depth of alisphenoid at extremity ......... & 55.0 & 32.5 \\
\hline Least distance between optic canal and foramen ovale.. & 60.0 & 105.0 \\
\hline $\begin{array}{l}\text { Least distance between optic canal and jugulo-acoustic } \\
\text { foramen. } \ldots \ldots \ldots \ldots \ldots \ldots \ldots \ldots \ldots \ldots \ldots \ldots \\
\end{array}$ & 135.0 & 149.0 \\
\hline Greatest diameter of right nasal passage........ & 37.0 & 28.5 \\
\hline Greatest diameter of left nasal passage. . & 60.0 & 85.0 \\
\hline
\end{tabular}

${ }^{1}$ Estimated. $\quad 2$ To anterior margin of basisphenoid. 
applied to the presphenoid in the young Physeter skull (pl. 6, fig. 2) they are broad and project laterally, sheathing the anterior face of the orbitosphenoid, touching the supraorbital process of the frontal, and projecting laterally beyond the level of the pterygoids. The extremities of these wings appear above the pterygoid, between the posterior margin of the palatine and the optic canal. If the relations of the various bones surrounding the nasal passages of this fossil skull have been correctly interpreted then the structural peculiarities are in entire agreement with the young Physeter skull. Furthermore, the extremity of the lateral wing of the vomer may be seen between the palatine and the optic canal on both sides in this fossil skull.

The vomer, which embraces the presphenoid below, expands horizontally behind the nasal passages and sheathes the basisphenoid. It meets the vaginal plates of the pterygoids along its lateral margins. A pair of narrow, slit-like apertures which expose the presphenoid appear on either side of the ridge between the nasal passages. The posterior margin of this bone is concave.

The squamosal bone is firmly mortised into the side of the braincase, extending upward to the dorsal margin of the temporal fossa as a narrow wedge between supraoccipital and parietal, meeting the alisphenoid anteriorly, and abutting against the exoccipital postero-inferiorly. From an external view, the squamosal embraces the alisphenoid from behind in the temporal fossa and a long oblique suture marks their contact on the ventral face of the skull.

The zygomatic surfaces were not preserved and until these parts are found any restoration will be a matter of personal opinion. In Physeter, the fossa for the reception of the condyle of the mandible is an ill-defined concavity. The postglenoid process is short and round. Anteriorly, the zygomatic process does not come in contact with the postorbital projection of the supraorbital plate of the frontal. In Kogia the post glenoid process is hardly discernible and little more than a projecting angle is present

\section{Ontocetus oxymycterus Kellogg.}

Comparative measurements indicate that a complete skull of this species will measure between 12 and 15 feet in length. If this estimate is correct, then the skull of this species is more than twice as long as that of Idiorophus patagonicus (Lydekker) from a lower Miocene tuff formation on the coast of Chubut Territory, Patagonia, and probably represents the largest Miocene physeteroid thus far described. This specimen $^{1}$ is tentatively referred to the genus Ontocetus of Leidy.

Type Specimen.-Cat. No. 10923, Division of Vertebrate Palaeontology, United States National Museum. The material includes the distal end of the rostrum, the extremities of both mandibles with the roots or portions of 10 or 11 teeth in place, as well as several imperfect teeth which were found in the adjoining matrix.

Type locality.-The occurrence is as follows: Near latitude $34^{\circ} 20^{\prime} 12^{\prime \prime}$ North, and longitude $119^{\circ} 43^{\prime} 20^{\prime \prime}$ West, in the sea-cliff which follows the beach north of the Santa Barbara lighthouse, Santa Barbara County, California. Range 27 West, Township 4 North, Santa Barbara Special Map, U. S. Geological Survey.

Horizon.-The specimen was discovered by Mr. Charles O. Roe about 35 years before he finally removed it to his home in Santa Barbara during the year 1909. The rostrum and mandibles were found projecting from the sea-cliff at an elevation of about 12 feet above the high-water mark. The sea-cliff is nearly 80 feet high at the point where the skull was found, but the writer can not give any estimate as to the thickness of the stratum or as to the relative position of the specimen within it. I am indebted to Mr. Earl V. Shannon, Assistant Curator of Geology, for the following report on the matrix:

"The specimen submitted for examination consists of a dense, almost aphanitic laminated rock of medium olive-buff color. Superficially it resembles a rhyolite

${ }^{1}$ R. Kellogg, A fossil physeteroid cetacean from Santa Barbara County, California, Proc. U. S. Nat. Mus., vol. 66, Publ. 2564, pp. 1-8, pls. 1, 2, 1925. 
with flow structure more than a sedimentary rock and this resemblance is heightened by scattered nearly spherical cavities a millimeter or two in diameter, which, under a binocular microscope, are seen to be lined with minute, sparkling, rhombohedral, colorless, or slightly yellowish crystals. In $1: 1$ hydrochloric acid the rock effervesces slowly in the manner characteristic of a dolomite and upon warming in the acid large pieces are completely dissolved, leaving little residue and with the separation of a considerable amount of oily matter. The solution, after removal of iron, lime, etc., in the usual manner, reacts copiously for magnesia with microcosmic salt. The rock is evidently a fairly pure bituminous dolomite."

No direct reference to the strata which comprise the sea-cliff west of the Santa Barbara lighthouse can be found and Arnold" states that "the structure of the coast west of Punta del Castillo was not studied." This stratum of bituminous dolomite, however, probably represents one of the calcareous deposits which alternated with siliceous deposits to form the thick series known as the lower division of the Monterey

formation. In the report by Arnold and Anderson, ${ }^{2}$ reference is made to "massive beds of peculiar sand-colored limestone with characteristic lamellar weathering." Again in referring to a bituminous limestone [a bituminous dolomite as shown by No. 11 in the table of analyses, op. cit., p. 45] from Redrock Mountain, ${ }^{3}$ northeast of Lompoc, Santa Barbara County, they report as follows: "The last analysis (No. 11) represents a limestone typical in lithologic appearance of the limestone of the Monterey." The age of this formation is Middle Miocene, Helvetian, or later.

\section{Rostrum.}

As the base of the rostrum and the braincase still remain in the sea-cliff near Santa Barbara, an exact idea of this physeteroid's relation to previously described skulls can not be given at present. The general outlines of the skull, however, were probably similar to Idiorophus and Scaldicetus. According to the figures of Scaldicetus mortezelensis given by Abel, ${ }^{4}$ the extremity of the rostrum of that species is not characterized by a lateral compression. This is the most apparent difference between the rostrum of the Santa Barbara cetacean (pl. 7, fig. 1) and that of Scaldicetus. The size of the teeth and the general appearance of their dentinal axes indicate some relationship with Ontocetus. With the possible exception of Idiophyseter merriami, all previously described skulls of fossil physeteroids, in so far as can be judged from the imperfectly preserved specimens now known, were characterized in part by the presence of 3 teeth in the extremity of each premaxilla. In these forms the extremity of the rostrum is formed by the premaxillae alone. In this Santa Barbara skull (pl. 7, fig. 2), also, the premaxillae take part in the formation of the extremity of the rostrum and 3 of the teeth on each side are implanted in the premaxilla. The lateral compression of the distal portion of the rostrum is quite noticeable in certain genera, particularly so in Idiorophus patagonicus and Oryclerocetus mediallanticus. The extremity of the rostrum of this fossil physeteroid was constricted from side to side and the inner margins of the premaxillae are in contact along the median line as in Idiorophus patagonicus, forming a roof for the mesorostral gutter. On comparing the dorsal view of this Santa Barbara rostrum with that of Physeter, ${ }^{5}$ other peculiarities become apparent. In the latter, the rostrum is more or less attenuated anteriorly, but the abrupt constriction or lateral compression of the distal portion of the rostrum has disappeared with the horizontal expansion of the rostrum as a whole.

1 R. Arnold, Geology and oil resources of the Summerland District, Santa Barbara County, California, Bull. No. 321, U. S. Geol. Surv., p. 38, 1907.

${ }^{2}$ R. Arnold and R. Anderson, Geology and oil resources of the Santa Maria Oil District, Santa Barbara County, California, Bull. No. 322, U. S. Geol. Surv., p. 34, 1907.

${ }^{3}$ R. Arnold and R. Anderson, op. cit., p. 44.

4 O. Abel, Mém. Mus. roy. d'hist. nat. de Belgique, Bruxelles, tome 3, p. 67, text fig. 5, 1905.

¿ P. J. Van Beneden and P. Gervais, Ostéographie des Cétacés vivants et fossiles, Atlas, pl. 19 , figs. $5,6,1880$. 
While removing the matrix, it became evident that this skull had partially decayed before it was completely buried in the sediments which preserved it. Furthermore, some of the teeth were broken off in the alveoli previous to its burial, for on removing the matrix which covered the right mandible (pl. 8, fig. 2), the roots of the teeth were exposed to view. Other teeth dropped out of the alveoli in the upper jaws after the skull was covered with sediments as several were found in the matrix. The outer surfaces of the maxilla are worn, more in some places than in others. Nevertheless, it appears that the anterior alveoli in the maxilla are separated from the outer surface by a very thin plate, hardly more than $15 \mathrm{~mm}$. in thickness. The lateral border of the maxilla overhangs the alveoli more noticeably posteriorly than anteriorly. The alveoli in the maxillae agree in size with those for the corresponding teeth in the mandibles. At least 8 alveoli are present in the distal end of each maxilla and a complete skull may have carried 18 or more teeth in each jaw. From the inferior margin, the maxilla (pl. 8, fig. 2) curves upward to the premaxilla in a gradual curve which becomes more pronounced as the maxilla attains a greater depth posteriorly. Apparently, the horizontal, plate-like, inwardly projecting portions of the premaxillae do not roof the mesorostral gutter to the extremity of the rostrum, but this can not be stated with any degree of certainty, for although they taper rapidly their extremities are clearly mutilated. The maxillae gradually increase in breadth toward the base of this section of the rostrum and then appear to suddenly expand as would be expected in a skull characterized by a lateral compression of the extremity of the rostrum. From a lateral view the maxillae increase in depth as they approach the base, whereas the premaxillae decrease.

The mesorostral gutter extends the full length of the rostrum. Its distal extension is made up entirely by the premaxillae which meet mesially on the floor in a linear suture. Posterior to the third pair of alveoli is the distal extremity of the vomer which contributed the floor of the gutter for most of its length, and on each side is mortised into the ventral extensions of the premaxillae, and they in turn are applied to the inner borders of the maxillae. From its extremity posteriorly, the vomer increases in width and eventually gains a position on the walls. The dorsal wall or roof of the vomerine gutter is formed, as mentioned above, by the overhanging platelike portions of the premaxillae. From the level of the third pair of alveoli posteriorly, the premaxillae retain a nearly uniform breadth.

\section{MANDIBLES.}

Since this specimen projected from the face of the cliff and was exposed to the action of the elements for 35 years at least, it is not surprising that the inferior surfaces of the mandibles should exhibit evidence of considerable erosion. From a ventral view (pl. 8, fig. 1), numerous branching canals are now visible, although they are filled with matrix, which afforded passage for nerves and blood-vessels. In places, this wear has amounted to an inch or more in thickness. The extremities of the mandibles are relatively large in comparison to the rostrum and in general conformation are somewhat similar to those of Physeter. Pressure or other factors resulted in the separation of the mandibles at the symphysis. The left mandible does not lie in its normal position and its inner face is appressed against the ventral surface of the rostrum. The proximal portions of the mandibles were not collected and, as the inner faces of distal sections commence to diverge some $170 \mathrm{~mm}$. in front of the point where they were broken off, it is evident that all of the symphysial region is represented; if this is the case, then the symphysis of the mandible is co-extensive with the first 8 pairs of teeth. Both mandibles curved upward from the posterior end of the symphysis forward. The distal extremity of each mandible is obliquely truncated in a dorso-ventral direction, while the external and internal faces of the mandible descend abruptly from the dorsal surface which is relatively flat.

The tooth-bearing portion of the mandible is relatively massive and the bone itself is rather dense. The alveoli (pl. 8, fig. 2) are large and the posterior ones occupy more than half of the width of the mandible. In this fossil, the series of teeth in each 
mandible consists of more than 11 slightly curved and conical teeth. The first and third teeth are the smallest of the mandibular series. The roots of all the teeth avail-, able for examination from the upper jaw are terminated obtusely and no doubt those of the mandible are similar in appearance. Two teeth, the inner one much smaller than all of the following with the exception of the third, project obliquely forward from the extremity of each mandible.

\section{TEeth.}

Turning to the teeth, we find that they are all very large and that some may have projected 4 or 5 inches beyond the jaws. They are separated by intervals or septa narrower than the thickness of the cement. In respect to their mode of implantation in the jaw, the teeth differ from those of Physeter in that they are lodged in distinct alveoli and the septa extend the full depth of the alveolus. These alveoli are too large to hold the teeth in place independently of a dense ligamentous gum which accounts for their absence from the alveoli in the upper jaw. The position of the mandibles prevented the teeth from falling out of the alveoli and in some instances the matrix in the alveolus which encircles the root attains a width of $20 \mathrm{~mm}$. or more. This interval affords another indication of how loosely the teeth were implanted in the jaws. All the crowns of the teeth, with the exception of the third in the right mandible, either were broken off at the time the specimen was removed from the sea-cliff or were destroyed before burial. The summit of the crown of this tooth is abraded or broken and the enamel is ornamented with coarse longitudinal striae.

The crown of the third mandibular tooth is broken off obliquely in an internoexternal direction. The enamel forms a band encircling the crown of the tooth, about $1 \mathrm{~mm}$. in thickness and approximately $35 \mathrm{~mm}$. in depth when complete. The crown and upper part of a tooth, which broke away from the end of the root in the mandible at the time the specimen was removed from the sea-cliff, measures $153 \mathrm{~mm}$. in length. The greatest transverse diameter of the base of this apical section of the tooth equals $78 \mathrm{~mm}$. and the maximum thickness of the cement is $9.5 \mathrm{~mm}$. At the level of the superior face of the mandible, the outer coat of cement of these teeth varies from 10 to $19 \mathrm{~mm}$. in thickness. From these measurements it is evident that a short section of the tooth which intervenes between this apical portion and the distal extremity or root is missing. A large mandibular tooth will measure at least $300 \mathrm{~mm}$. in length. The roots of these teeth are fusiform, remarkably robust, and very large in proportion to the crown. They are almost straight at the basal two-thirds, but curved toward the crown so that the latter appears to be obliquely placed upon it. The enamel on the crown does not form an enlargement at the base and passes into the cement on the root without any perceptible increase or decrease in the diameter of the neckhence there is no distinct neck and no constriction at this point can be observed on any of the teeth which are sufficiently preserved to offer any data. The distal extremities of all the teeth are present in the left mandible. At the point where they are broken off, a small pulp cavity is exposed in the second and ninth teeth, measuring 3.5 and 7.5 $\mathrm{mm}$. respectively in diameter. This indicates that the lower portions of the roots were pervaded by a slender pulp cavity, irregular in diameter because of the presence of nodosities on the sides.

As seen in cross-section, the teeth consist of an internal cone of ossified pulp and dentine which is covered externally by a thick layer of cement. This outer coat of cement is usually brownish in contrast to the light cream-colored dentine, and on the eighth tooth of the right mandible is equal to about one-fourth of the transverse diameter of the root. The dentinal axis is formed in concentric layers while the cement on the other hand appears to be composed of thin and narrow longitudinal strips or lamina. In cross-section, the ends of these lamina are so arranged that their axes correspond to lines radiating from the center of the pulp cavity.

The most obvious distinction between these teeth and that of Ontocetus emmonsi is the relative thickness of the outer layer of cement. In cross-section the central axis of dentine appears to be more or less ovoidal in the anterior mandibular teeth in con- 
trast to the circular outlines of the posterior ones, but this may be due in part to differences in the direction of the teeth in the alveoli, the former being implanted more obliquely than the latter. Thin ridges which encircle the dentinal axis and which have been referred to as annular lines of growth are present. Longitudinal grooves or fluting, varying in number and in depth among the several teeth at hand, further characterize the external surface of the dentinal axis. The teeth of Scaldicetus caretti, a physeteroid whale from the Anversian of Belgium, agree with those of this Californian species in size.

All of the teeth are imperfectly fossilized and the dentine especially is rather soft and pithy. In their present state, difficulties which are familiar to anyone who has attempted to preserve tusks of mastodons, are encountered when the teeth are freed from the matrix. The teeth fracture and crumble even when every precaution is taken for their preservation.

\section{Measurements on the rostrum and mandibles.}

Total length of rostral section along the median line................ 845

Width of right premaxilla at proximal end of rostral section. . . . . . . . . . . . 97

Width of right premaxilla at level of second alveolus................... 91

Depth of right premaxilla at proximal end of rostral section $\ldots \ldots \ldots \ldots \ldots \ldots \ldots \ldots \ldots 190$

Depth of right premaxilla above maxillary suture at level of fifth alveolus.......... 69

Breadth of rostral section at proximal end (left maxillary surface worn) . . . . . . . . 405

Breadth of rostral section at point $100 \mathrm{~mm}$. posterior to distal end............. 170

Breadth across combined premaxillae at proximal end of rostral section...........213

Breadth across combined premaxillae at level of fifth alveolus ............... 211

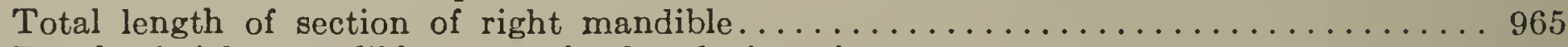

Depth of right mandible at proximal end of section..................... 192

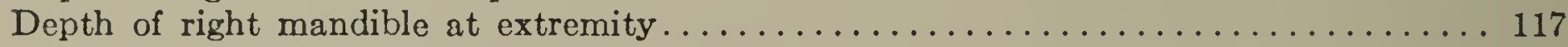

Breadth of right mandible at proximal end of section. . . . . . . . . . . . . 175

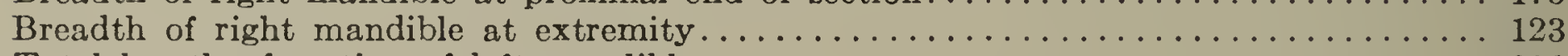

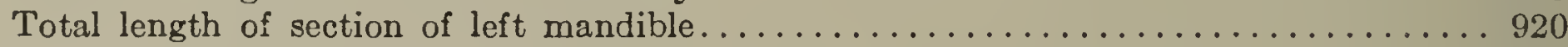

Depth of left mandible at proximal end of section $\ldots \ldots \ldots \ldots \ldots \ldots \ldots \ldots \ldots \ldots \ldots$

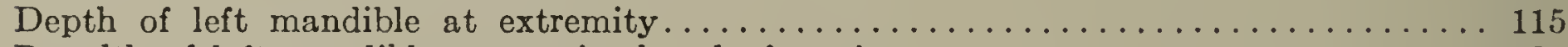

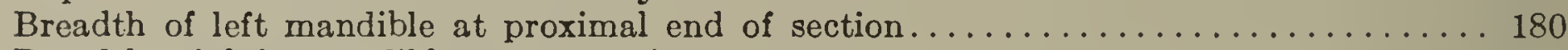

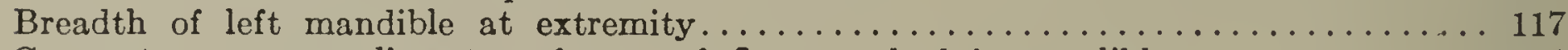

Greatest transverse diameter of root of first tooth, left mandible............ 54

Greatest transverse diameter of root of second tooth, left mandible........... 74

Greatest transverse diameter of root of third tooth, left mandible................. 70

Greatest transverse diameter of root of fourth tooth, left mandible........... 66.5

Greatest transverse diameter of root of fifth tooth, left mandible........... 67.5

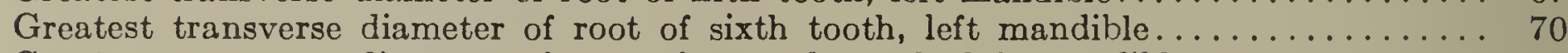

Greatest transverse diameter of root of seventh tooth, left mandible............... 78.5

Greatest transverse diameter of root of eighth tooth, left mandible .............. 89

Greatest transverse diameter of root of ninth tooth, left mandible.................. 90.5

Greatest transverse diameter of root of tenth tooth, left mandible............... 71

Length of enamel crown of third tooth, right mandible (apex missing or abraded) ......... $30+$

Greatest antero-posterior diameter of enamel crown of third tooth at base, right mandible 32

Eighth tooth, right mandible.

Transverse diameter of tooth at level of superior face of mandible......... 82

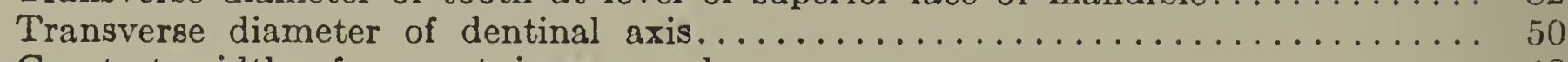

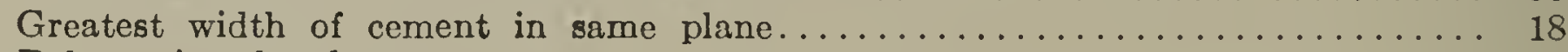

Pulp cavity closed.

Eighth tooth, left mandible.

Transverse diameter of tooth at level of superior face of mandible......... 93

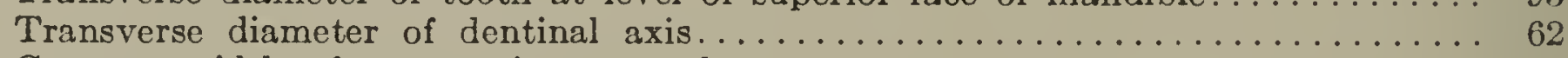

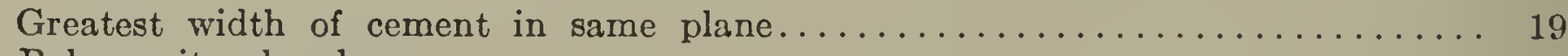
Pulp cavity closed.

Ninth tooth, right mandible.

Transverse diameter of tooth at level of superior face of mandible......... 80

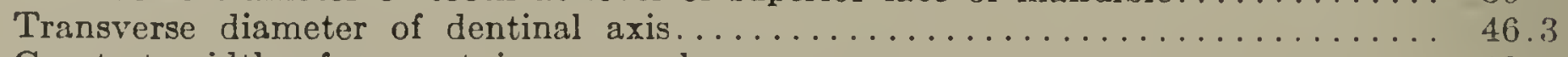

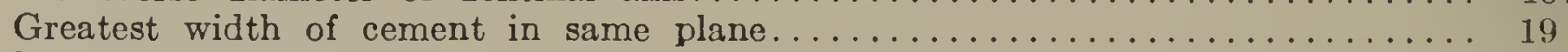

Transverse diameter of pulp cavity at same plane................... 7.5 


\section{FOSSIL CETOTHERES FROM CALIFORNIA.}

Since Edward D. Cope published, in 1872, the description of the mandible of Eschrichitus davidsonii, several specimens from Miocene formations on the Pacific Coast of North America belonging to the group of cetaceans known as whalebone whales have found their way into collections. Some of these specimens furnish considerable additional information regarding the structural peculiarities of the skull and skeleton. The material discussed in the present paper includes three skulls, one of which was associated with a nearly complete skeleton. All of the skulls are more or less distorted from crushing, with different elements missing at the time of collection or misplaced during the long interval which has elapsed since their discovery. They also differ in size; the one preserved in the block of matrix in association with vertebrae and ribs is the largest; the other two are of approximately the same size and appear to be conspecific, notwithstanding certain minor differences in the illustrations.

Many hours have been spent in an endeavor to reach an understanding of the relations of these specimens to previously described cetotheres. The types of practically all of the North American Tertiary forms have been examined and actually compared with these specimens. Thirty-five genera of Tertiary mysticetes have been proposed, but not all of these are valid. A careful perusal of the literature will convince anyone that the generic allocations of many of the described species are inconsistent with the structural peculiarities of the skulls. A discussion of these species would entail a general revision of the whole group, but this is beyond the scope of the present paper. It seems, therefore, proper that all comparisons should be limited to those forms which obviously have some bearing on the relationships of these California cetotheres.

Various writers have discussed these Miocene cetotheres, but each writer appears to have a somewhat different conception of their relationships. Attempts have been made to base generic distinctions upon different features in cranial architecture. It was Cope ${ }^{1}$ who classified the cetotheres upon the mandibles, True ${ }^{2}$ on differences in the slope of the supraorbital plate of the frontal and the relations of the parietal bones to the adjoining elements, Winge ${ }^{3}$ on the position

1 E. D. Cope, Fourth contribution to the marine fauna of the Miocene Period of the United Strtes, Proc. Amer. Philos. Soc., Philadelphia, vol. 34, No. 147, pp. 139-154, pl. 6, May 29, 1895.

2 F. W. True, The genera of fossil whalebone whales allied to Balaenoptera, Smithson. Misc. Coll., vol. 59, No. 6, Publ. 2081, pp. 1-8, April 3, 1912.

H. Winge, Udsigt over Hvalernes indbyrdes Slaegtskab. Vidensk. Medd. fra Dansk, naturh. Foren., Kjøbenhavn, Bd. 70, pp. 73-80, 1918; A review of the interrelationships of the Cetacea, Smithson. Misc. Coll., vol. 72, No. 8, Publ. 2650, pp. 16-22. 1921. 
and extent of the glenoid articular surface for the condyle of the lower jaw, but Van Beneden ${ }^{1}$ was the first to point out the importance of the ear bones for purposes of classification, although in later years he attributed considerable importance to the position and relations of the condyle of the mandible.

In only one of these skulls from California is there anything of the rostrum preserved. This skull also shows the proportions and shape of the supraorbital processes of the frontals. Nevertheless, the degree of forward thrust of the supraoccipital shield and the backward thrust of the mesial portion of the rostrum, the unusually slender supraorbital processes, the position of the nasals, as well as the relations of the bones in the intertemporal region are so definitely like Cetotherium rathkii, that there appears to be little doubt but that this specimen should be allocated to that genus. The other skulls, in so far as can be determined by comparisons with figured specimens and descriptions, appear to be referable to the genus Plesiocetus. In this genus, however, the relations between the rostrum and the cranium are not fully known. Another genus, Mesocetus, should be mentioned in this connection, because of the confusion which still exists as to the structural peculiarities of the skull which distinguish this genus from Plesiocetus. According to the illustrations given by Van Beneden, the degree of interdigitation between the rostral and cranial portions of the skull in species of the genus Mesocetus represents an advanced stage in the general trend toward telescoping. The periotics of the species from the Antwerp Basin, Belgium, referred to Mesocetus, as compared to that of Plesiocetus hupschii, present features which may indicate a generic difference.

One gathers the impression that the skulls of the species referable to the Miocene genus Cetotherium were characterized by curved supraorbital processes, by the facial position of the nasals, by long, slender, zygomatic processes with peculiar, elongated, glenoid articular surfaces, as well as by long, slender mandibles, a conception that is strengthened by a comparison of the various described species. The backward thrust of the mesial portion of the rostrum has carried the ascending processes of the maxillae and premaxillae, as well as the nasals, beyond the level of the preorbital angles of the supraorbital processes. In consequence of this backward movement, the facial portion of the skull is dished in mesially, the anterior borders of the supraorbital processes curving forward and outward. These supraorbital processes slope gradually outward from the dorsal surface of the interorbital region and are never abruptly depressed

1 P. J. Van Beneden, Observations sur les caractères spécifiques des grands cétacés, tires de la conformation de l'oreille osseuse, Ann. Sci. Nat., Paris, ser. 2, tome 6, Zoologie, pp. 158-159, 1836; Description des ossements fossiles des environs d'Anvers, Ann. Mus. Roy. d'Hist. Nat. de Belgique, Bruxelles, Cétacés, tome 4, pp. 1-83, 1880, pls. 1-39, 1878; op. cit., tome 7, pp. 1-90, pls. 40-109, 1882; op. cit., tome 9, pp. 1-40, pls. 1-30, 1885; op. cit., tome 13, pp. 1-139, pls. 1-75, 1886. 
below the level of the latter as in the living balaenopterine whales. Cetotherium appears to be the only Miocene mysticetacean in which the supraorbital processes are slender and noticeably narrower at the base than at the extremity. If we take the features seriatum, we find first of all that the skulls of these cetotheres retained a welldefined intertemporal region which was constituted entirely by the parietals which meet mesially along the median line in front of the supraoccipital shield. In most species, the braincase is short and broad, and the apex of the supraoccipital shield lies behind the level of the orbit. So far as known, the rostrum is never laterally compressed. The ascending process of the maxilla is narrow and is suturally united with the frontal. It does not overspread the supraorbital process of the frontal. The general arrangement of the bones which form the nasal passages is more nearly in agreement with the typical structure of terrestrial mammals than with the toothed whales. The nasals and mesial projections of the frontals completely roof over the ethmoid region, and in addition the palatine is excluded from the anterior wall of the corresponding nasal passage. The choanae lie behind the anterior narial apertures and the orbital plate of the maxilla is retained.

During the early stages in the development of the embryonic whalebone whale skull, teeth are present in each jaw, but they are absorbed long before the birth of the animal. The evidence afforded by embryological studies suggests toothed ancestors for the Mysticeti, although it does not show what type of cetacean may have been ancestral. The Upper Eocene and Oligocene toothed whales, especially Patriocetus, were held by $\mathrm{Abel}^{1}$ to be the predecessors of the living whalebone whales. This derivation has been questioned by Miller ${ }^{2}$ and he calls attention to the restoration given by Abel for Patriocetus in which the premaxilla is shown extending backward to the parietal and the maxilla terminating in front of the orbit. Furthermore, one of the characteristic features of the Mysticeti, the orbital plate of the maxilla, appears to be missing on the Patriocetus skull. At any event, the specimens now known do not support the derivation of the cetotheres from the archaic toothed whales grouped under the family Agorophiidae.

The undiscovered predecessors of the cetotheres may some day be found in Eocene formations; at least by the close of the Upper Oligocene, the cetotheres were already well established. In case of the mysticetes, the interdigitation of the rostral and cranial portions of the skull, in so far as substantiated by described specimens, is observed only in genera which make their appearance after

I O. Abel, Die Vorfahren der Bartenwale, Denkschr. Kais. Akad. Wiss. math.-naturw. Kl., Wien, Bd. 90 , pp. 28-34, 57-68, pls. 1-4, 6, 11, 12, 1913.

2 G. S. Miller jr., The telescoping of the cetacean skull, Smithson. Misc. Coll., vol. 76, No. 5, Publ. 2720, pp. 23, 42-44, 1923. 
the close of the Burdigalian stage. These early cetotheres had lost their teeth and acquired two rows of bladelike plates of baleen depending from the roof of the mouth which served as a sieve when the animal was feeding. Small crustaceans or fish constitute the food of the living whalebone whales and the cetotheres no doubt subsisted on the same types of food. In the case of the living balaenopterine whales, numbers of small fish are engulfed in the oral cavity when feeding, along with a large quantity of water which necessarily must be expelled before such small prey can be swallowed. Hence these plates of baleen with internal marginal fringes of intermatted bristle-like fibers form a strainer remarkably well adapted for taking surface swimming crustaceans or for impounding the small fish which are scooped up when the cetacean plunges through a shoal with an open mouth. It is well known that herrings, anchovies, and the like are often found in exceedingly large shoals in the seas at the present time. Small fish abounded in the waters along the coast of southern California during Monterey time, as is evidenced by the presence of a small herring-like fish (Xyne grex) in the diatomaceous shales at Lompoc, California, in such enormous numbers that their remains at one level in this horizon are spread like a blanket over an area which can only be estimated by acres. But as Jordan ${ }^{1}$ states, these small delicate fish were inhabitants of shallow bays, and inasmuch as remains of whalebone whales are found in this same deposit, it is evident that they were accustomed to frequent such places in search of food and for bringing forth their young.

Unfortunately, the skeleton of the cetothere hereinafter described suffered considerable breakage during shipment to Washington and, in consequence of a longitudinal fracture, some of the centra of the thoracic vertebrae shown in the accompanying illustration were destroyed.

\section{Cetotherium furlongi, new species.}

Type specimen.-Cat. No. 26521, Museum of Palaeontology, University of California. The skeleton of this cetothere is remarkably complete in comparison to previous discoveries. The skull has suffered from erosion and weathering. The back and top of the braincase have been eroded away, exposing a natural brain cast; the extremity of the rostrum is missing; the right supraorbital process is incomplete. The major portion of the left mandible and the proximal end of the right are present. 7 cervical, 12 dorsal, and 10 lumbar, and 9 caudal vertebrae are preserved in the slab of sand stone. The whole or portions of 17 ribs are intermingled with the vertebrae. The left scapula, humerus, radius, and ulna, although articulating, have been washed backward and are overlain by three of the lumbar vertebrae.

Type locality.-The occurrence is as follows: near latitude $36^{\circ} 1^{\prime}$ North, and longitude $120^{\circ} 32^{\prime}$ West, in Stone Canyon, southeast of the town of King City, Monterey County, California. Section 14, Township 22 South, Range 13 East, Priest Valley Quadrangle, U. S. Geological Survey.

${ }^{1}$ D. S. Jordan and J. Z. Gilbert, Fossil fishes of the Miocene (Monterey) formations, Leland Stanford Junior Univ. Publ., Univ. Series, pp. 14, 25, 1919. 
Horizon.-A fine-grained, impure, calcareous sandstone of a greenish-gray color which underlies the coal strata in Stone Canyon. According to Mr. W. N. Nichols, a graduate student in the Department of Geology; University of California, this region shows considerable evidence of faulting and the sandstone-coal formation is a block lying between serpentines of Franciscan age. Vaqueros formation, Middle Miocene or Helvetian stage.

From long-continued exposure in the canyon, the upper part of the braincase is missing, having been destroyed by weathering. By making due allowance for the missing caudal vertebrae and for the intervertebral cartilages, it was found that the complete skeleton of this cetothere, including the skull, measures approximately 16 feet. Numerous specimens of cetotheres have been collected in various formations in other countries and there is some difference of opinion regarding their validity. For the purposes of the present paper, only those based on fairly complete skulls will be considered in making comparisons.

\section{SKULL.}

In general form, the skull (text-fig. 1) of this species agrees in many details with that of Cetotherium rathkii, ${ }^{1}$ although it is nearly twice the size of the latter. Detailed comparisons of many structures will be impossible on account of circumstances connected with the preservation of the specimen. The ventral surface of this skull is crushed and the outlines of most of the elements and their sutures are obliterated. Close scrutiny failed to reveal any points of interest. From a ventral view in its present condition, the skull presents a flat surface without any indication of distinct elements. The various bones were telescoped into one another, compressed together by the great weight of the overlying strata, and solidified or fossilized into a compact more or less homogeneous mass. Even the tympanic bones were not visible, but after removing some of the overlying bone which had shifted from its original position by forturtous circumstances, the flattened involucrum of the right tympanic was discovered and removed. The horizontal ventral surface of each maxilla was marked by shallow curved grooves for lodging the bases of the blades of baleen which depend from the roof of the mouth. These ridges may be observed on the matrix, although the corresponding portion of the rostrum is missing.

Compared with Cetotherium moreni, ${ }^{2}$ the cranium is relatively longer and narrower, with a more rounded intertemporal region, a more noticeable interdigitation of rostral and cranial elements, and apparently with a supraoccipital shield which is not so strongly triangular in outline or at least is shorter. The lateral crests of the triangular supraoccipital shield are well developed in Cetotherium moreni. In this last-mentioned species, the distance between the nasal aperture and the condyles is more than onethird of the total length of the skull, while in furlongi it is somewhat less than onethird. Lydekker estimates the length of the nasals in the skull of moreni to be 8 or 9 inches, while those of the present specimen were no doubt less than 5 inches. In general appearance, this skull agrees more closely with Cetotherium rathkii than with Cetotherium moreni. The bases of the nasals in $C$. rathkii are in the same level as the most anterior portion of the curved posterior margin of the supraorbital processes.

The form and dimensions of the rostrum are not fully known. From the impressions in the matrix and the outlines of the bones comprising the base of the rostrum it is fairly certain, however, that the maxillae were very large bones. They formed the

1 J. F. Brandt, L'Institut, Paris, No. 502, p. 270, August 10, 1843; Bull. Acad. Sci. St. Petersbourg, vol. 1, p. 146, 1843; Untersuchungen ueber die fossilen und subfossilen Cetaceen Europa's, Mem. Acad. Imp. Sci. de St. Petersbourg, ser. 7, vol. 20, No. 1, pp. 68-85, pls. 1-4, 1873; P. J. Van Beneden and Paul Gervais, Ostéographie des Cétacés vivants et fossiles, Paris, Atlas, pl. 17, figs. 6-7, 1880.

${ }^{2}$ R. Lydekker, Contributions to a knowledge of the fossil vertebrates of Argentina: II. Cetacean skulls from Patagonia, Anales del Museo de La Plata, vol. 2 for 1893, pp. 2-4, pl. 1, figs. 1, $1 a, 1 b, 2$, April 1894. 
major portion of the rostrum. On their dorsal aspect the maxillae are slightly depressed in front of the supraorbital processes; the postero-mesial or ascending processes are narrow and are suturally united with the frontals. These processes of the maxillae are separated from each other by the corresponding processes of the premaxillae and by the nasals. Posteriorly, the narrow ascending processes of the maxillae do not extend beyond the base of the nasals. The internal margin of each maxilla was in contact with the premaxilla for practically the entire length. An antorbital process can be observed on the left maxilla, but it has been largely destroyed on the opposite bone. The lateral border of the maxilla is thin and blade-like, differing here but slightly in contour as well as in general proportions from Cetotherium moreni.

Of the premaxillae little can be said. They extend backward as far as the posterior margins of the nasals; they are widely divergent in the region of the nasal apertures and, although they converge anteriorly without any marked horizontal increase in thickness, there is nothing peculiar about them to suggest that the extremities were unlike those of Cetotherium moreni. Posteriorly, the premaxillae are narrow as viewed from above, with their greatest diameter in a dorso-ventral direction and presenting a slight sigmoid curve. They probably projected anteriorly beyond the maxillae as in the last-mentioned species. Along its entire external border, the premaxilla is closely applied to the corresponding surface of the maxilla. They are separated from each other at the widest point of their curved internal margins by an interval of 96.5 $\mathrm{mm}$.

The supraorbital processes are relatively narrow at the base and slope gradually downward and outward from the level of the interorbital region. Each process exhibits a slight sagittal arch, posterior to which the surface is depressed and as a whole slopes backward in a moderate curve. The anterior border of this process curves downward and forward in a more or less regular curve. The preorbital projection is short and rounded while the postorbital is rather massive, thick, and projects backward above the zygomatic process of the squamosal. The frontal bones are relatively deep and meet in a vertical plane behind and below the nasal bones. They do not contribute any of the outer surface of the braincase in the intertemporal region. The frontals, as remarked above, are overridden in the interorbital region by the extremities of the maxillae, premaxillae, and nasals. There are no definite grooves for lodging the extremities of the nasals, but, from the shape of the sinus, it is evident tlat they were relatively narrow and closely approximated, and their actual length is more or less problematical.

In front of the supraoccipital shield, the parietals meet mesially in a linear suture and comprise the intertemporal region. Although the surfaces of the parietals are worn in this region, there are no indications which would suggest the presence of a sagittal crest. The parietals are suturally united with the supraoccipital posteriorly and override the frontals anteriorly. The relations between the parietal and frontal below the supraorbital process are not clear. In most balaenopterine whales, the parietals override the frontals at the base of the supraorbital processes and small projections of the former underlap the latter at the same level below these processes. No doubt similar relations of these two elements characterized this Miocene cetothere.

The apex and upper portion of the supraoccipital is missing, but the curvature of the posterior borders of the temporal fossae and the shape of this element at the base indicate that its sides curved obliquely upward, but whether the apex was pointed or rounded can not be determined. In a back view of the skull it is seen that the supraoccipital slopes obliquely forward and upward. The supraoccipital probably was concavo-convex, and its slanting lateral margins meet the parietals and probably overlap them to some extent. It is evident that the most anterior point of the supraoccipital shield lies considerably behind the level of the orbit and probably also behind the level of the foramen ovale. The condyles are missing and the lateral margins of the exoccipitals are imperfect. 

FIG. 1.-Dorsal view of type skull and mandibles of Cetotherium furlongi. Cat. No. 26,521 Palaeont. Mus., Univ. Calif. Ant. pr., antorbital process of maxilla; Cer., natural cast of lobe of cerebellum; $E x$. oc., exoccipital; $F r_{\text {., }}$ frontal; $L . M_{\text {., left man- }}$ dible; Max., m $R$. M., right mandible; $S q$., squamosal; S. or. $p r$. supraorbital process of frontal; Zgg., zygomatic process of squamosal.
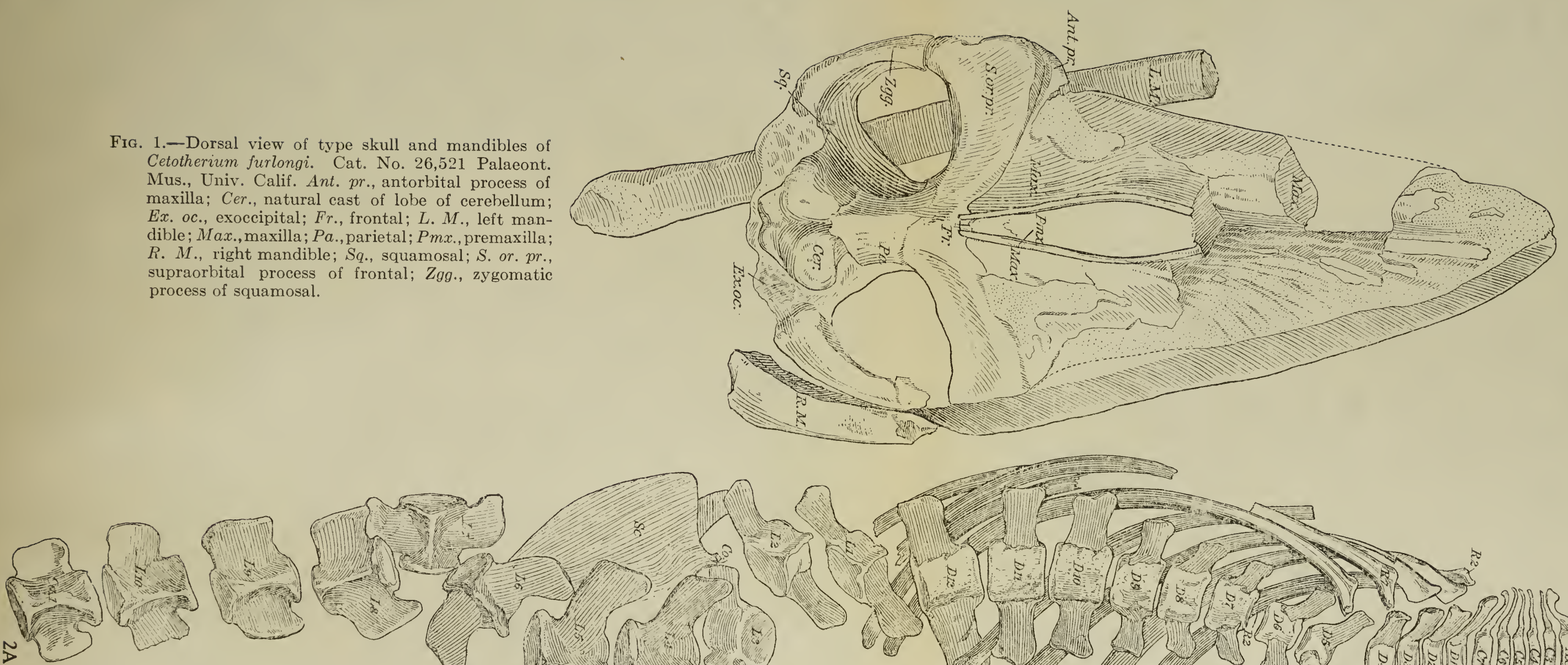

8.

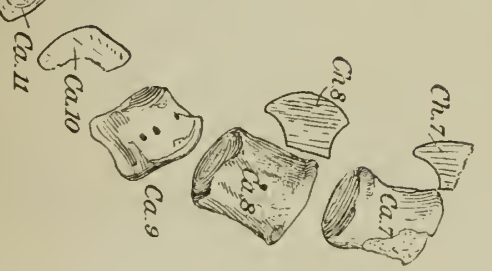

$\tilde{\varpi}$
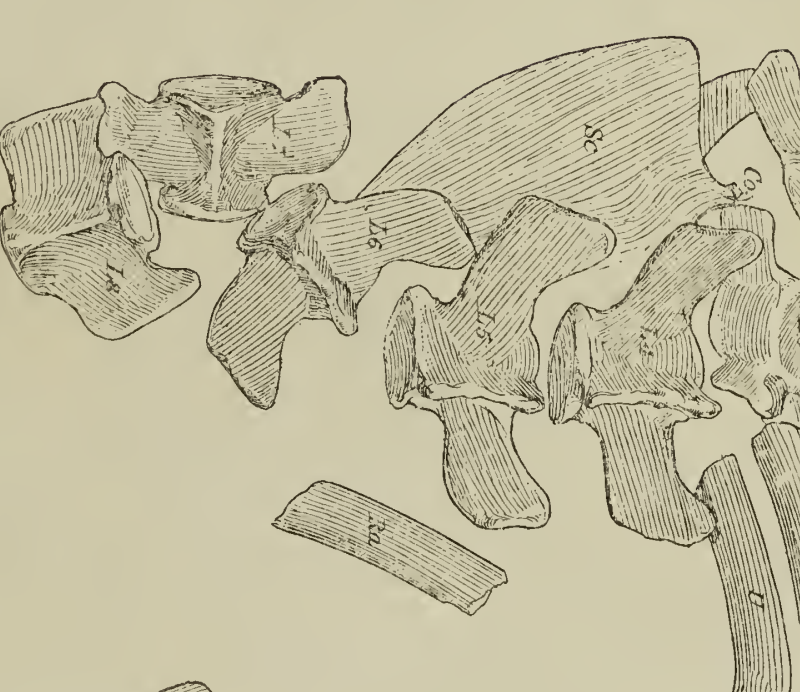

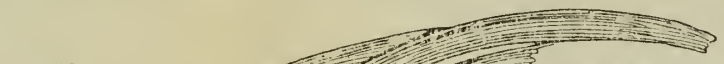
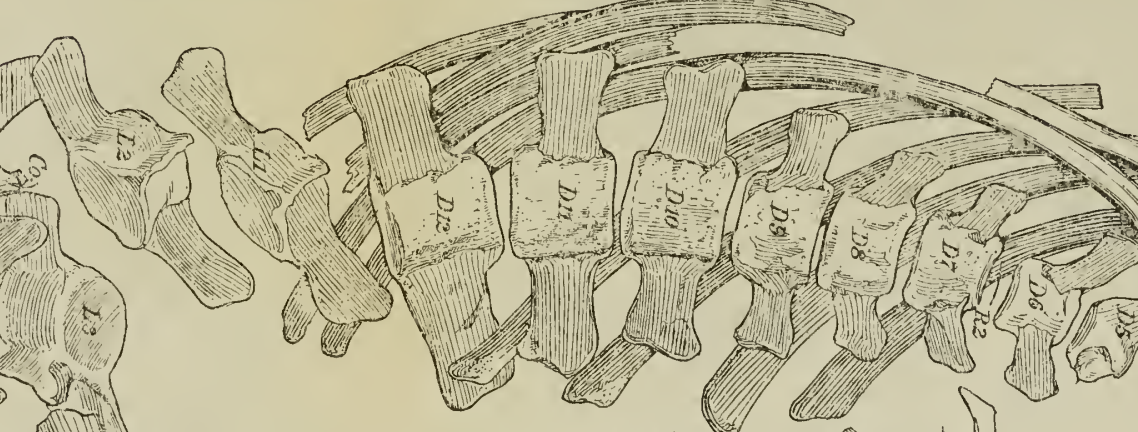

1.1
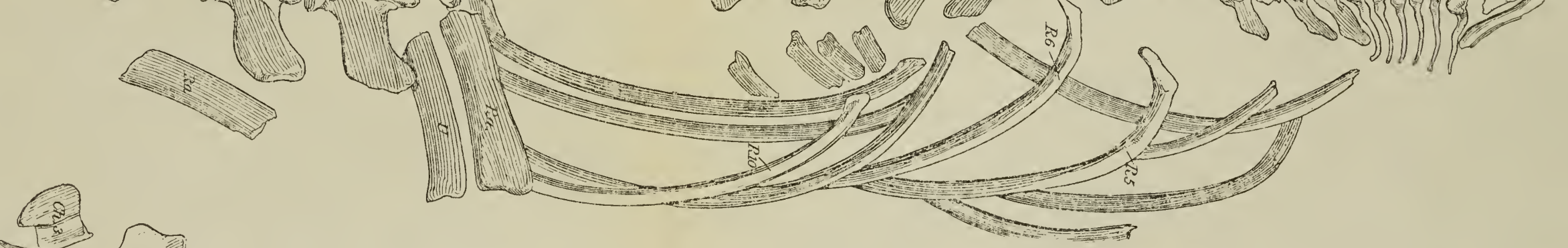

4

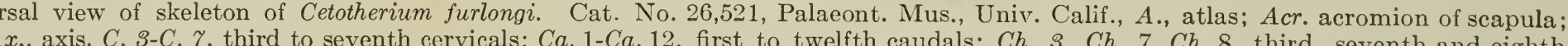
chevrons; $C o$., coracoid process of scapula; $D .1-D .12$, first to twelf th dorsals; $L .1-L$. 10 , first to tenth lumbars; $R .2$, second eighth left side; $R$. 5, fifth (?) rib, right side; $R .6$, sisth (?) rib, right side; $R .7$, seventh (?) rib, left side $R .10$, tenth (?) rib, right side;
$R a$., radius; Sc., left scapula; Sty., stylohyoid (?); $U$., ulna. 
The squamosals were rather large bones, which were suturally united with the parietals above and the pterygoids in front. Their zygomatic processes are relatively long and narrow, curving outward and forward. The squamous portion of this bone is thick and apparently meets the parietal edge to edge; it is possible, however, that the squamosal overlaps the posterior part of the ventral edge of the parietal. The anterior extremity of the squamous portion is prolonged forward, inward, and slightly downward as the bifid pterygoid process. The upper fork of the latter overlaps the upper part of the pterygoid, posterior to and below the alisphenoid; the lower fork, the falciform process, meets that portion of the pterygoid which forms the external boundary of the pterygoid fossa. Between the two forks of the squamosal and the above-mentioned portions of the pterygoid is a notch which represents the foramen ovale. The squamosals and their processes form the posterior and outer borders of the temporal fossae. The left zygomatic process is complete and abuts against the postorbital projection of the supraorbital process. The zygomatic process tapers anteriorly, with the external margin as seen from above, curving forward in a regular curve in marked contrast with the bi-convexity of the same surface on that of Cetotherium rathlii. The glenoid articular surface extends over upon the outer face of the zygomatic process. In direction the anterior portion of this surface is strongly oblique. The postglenoid process is long, directed more downward than backward.

The jugal is missing and the lachrymal can not be recognized if present. The extremity of the vomer is missing, and the proximal portion takes the form of an open V-shaped trough as far backward as the nasal passages, beyond which in all mysticetes known to the writer it flattens out on the ventral face of the basicranium to sheath the basisphenoid.

The exposed natural brain-cast gives some idea of the original appearance of the posterior portion of the brain. The lobes of the cerebellum are large and bulging, separated mesially by a sinus, and bounded posteriorly by the medulla oblongata. These lobes helped to mould the lateral contour of the braincase.

\section{MaNDIBLES.}

Comparison of the type mandible of Eschrichitus davidsonii Cope ${ }^{1}$ with the mandibles of this cetothere unfortunately will not prove very satisfactory for several reasons. In the first place, the nature of the formation from which Cope's specimen was obtained was not given. According to the label on the specimen it was found in digging a well at San Diego at a depth of 74 feet below the surface. The type of Eschrichitus davidsonii Cope consists of a section of the left mandible $327 \mathrm{~mm}$. in length, and the greatest depth of this fragment is $99 \mathrm{~mm}$. It now bears Cat. No. 12922 in the collection of the Academy of Natural Sciences of Philadelphia. In general proportions it agrees fairly well with those of this cetothere, but so do others from Miocene formations on the Atlantic Coast. The characters used by Cope, such as the point of termination of the external foraminal series and the peculiarities of the canalis mandibularis can not be ascertained from either of these mandibles. The angle and condyle of all three of the mandibles are missing; so also is the coronoid process. Approximately threefourths of the left mandible (text-fig. 1) of this cetothere is preserved. At the broken extremity, the mandible measures $85 \mathrm{~mm}$. in depth, the greatest depth of the mandibular canal being $74 \mathrm{~mm}$. and the greatest breadth $30 \mathrm{~mm}$. The internal surface of the mandible is plane on the proximal half, but distally it becomes more convex. Externally, the mandible is more or less convex, being broader below the middle than above. The mandible is bowed to a slight extent and the inferior margin is nearly straight. The internal foramina are relatively small, about an inch apart, and form a series which follows the upper margin. The foramina in the external series are large and separated by rather wide intervals. Behind the coronoid the anterior end of the

1 E. D. Cope, On an extinct whale from California, Proc. Acad. Nat. Sci. Philadelphia, pp. $29-30,1872$. 
cavity on the internal face of the mandible is filled-in with matrix, and the loss of the posterior extremity prevents accurate comparison with European specimens.

Table of measurements.

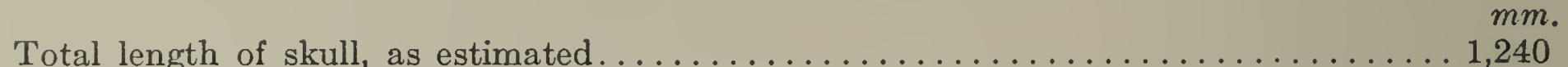

Breadth of skull across anterior ends of zygomatic processes............. 545

Greatest breadth of skull across lateral margins of exoccipitals estimated......... 370

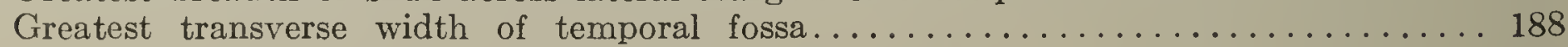

Greatest antero-posterior diameter of temporal fossa................. 150

Least breadth of braincase in intertemporal region................... 154

Greatest breadth of skull across supraorbital processes................. 540

Greatest antero-posterior diameter of left supraorbital process at extremity........ 213

Distance from base of nasals to condyles, estimated.................... 387

Depth of rostrum at point where broken off . . . . . . . . . . . . . . . 107

Greatest breadth of premaxilla at level of external nasal apertures............ 15

Breadth of left maxilla in front of antorbital process of that bone . . . . . . . . . 185

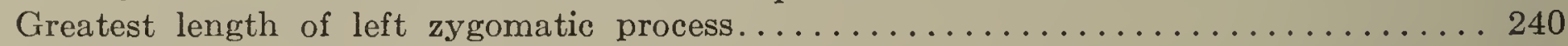

Depth of left zygomatic process at extremity.................... 36.9

Distance from preorbital portion of supraorbital process to postglenoid process of squa-

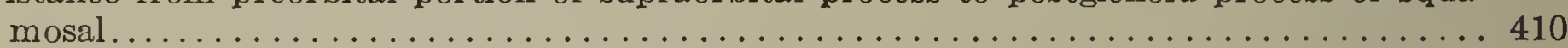

Distance from postorbital projection of left supraorbital process to base of corresponding

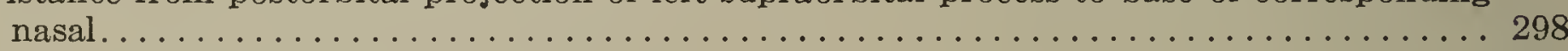

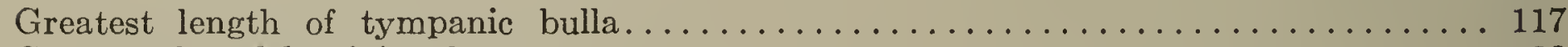

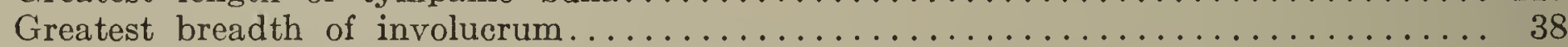

Total length of left mandible as preserved..................... 974

Greatest depth of left mandible at point where broken off $\ldots \ldots \ldots \ldots \ldots \ldots \ldots \ldots \ldots \ldots \ldots$

Greatest breadth of left mandible at point where broken off . . . . . . . . . . . . 56.2

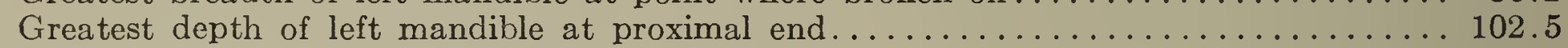

Least breadth of left mandible at proximal end..................... $25+$

\section{VERTEBRAE.}

All of the cervical vertebrae (text-fig. 2) of this fossil cetothere are free and distinct. They are exceedingly thin in an antero-posterior direction and this peculiarity is accentuated by the relative lengths of the slender transverse processes. In the living Bowhead Whale, Balaena mysticetus, and the North Atlantic Right Whale, Eubalaena glacialis, the 7 cervical vertebrae are normally fused together to form a single mass and are so modified by this telescoping that it is not easy to recognize their identity. Occasionally the seventh cervical is free. The pedicles of the neural arches of all of the cervicals are usually distinct, but the spines and upper portions of the arches of the second to sixth inclusive are fused into a solid mass. The balaenopterine whales, however, differ in having all of the cervicals free and distinct. As an individual peculiarity, two or more cervicals may be irregularly ankylosed together.

The ankylosis of the cervical vertebrae and their fusion into a compact immovable mass is considered to be the culmination of an evolutionary trend toward the shortening of the neck. The increase in the size and proportions of the skull, the out-bowing of the lower jaws, and the development of long blades of baleen depending from the roof of the mouth, require a firm axis upon which the skull can rotate and which at the same time will support an enormous increase in the weight of the skull suspended from it. This support could be secured by the development of massive cervicals or by the shortening of the neck, and ultimately by the fusion of the 7 cervicals. In the case of any pelagic mammal having feeding habits similar to those of the whalebone whales, flexibility of the neck is not absolutely necessary to its welfare; hence the short neck appears to fulfill the necessary requirements for cetaceans with relatively large skulls.

In these Miocene cetotheres in which the cervical vertebrae are separate, it is apparent, from the dorsal extension of the opposing articular facets on the atlas and axis, that any rotary movement about the odontoid is very limited. On the other hand, the articular surfaces of the two occipital condyles are convex and taken together form a sub-hemispherical protuberance which fits into the basin-like atlas. The crescentic 
shape of the two articular facets on the atlas which comprise the basin and bound the spinal cord allows some freedom of movement for the head, chiefly in an up-and-down or side-to-side direction, and also permits a limited rotary movement. Some side-toside movement is permitted in most mammals by the flexure of the cervical series as a whole but, inasmuch as all of these vertebrae are excessively shortened, any movement of this kind is effectually restricted.

The atlas is incomplete, the upper portion having been weathered away until nothing more than a shell-like strip of the inferior region remains. While agreeing with certain specimens from the Calvert formation in size, this atlas differs in some details of form. Attention should be directed to the presence of a short, lower, transverse process (parapophysis) and to the curvature of the anterior and posterior borders. The atlas is relatively deep antero-posteriorly in comparison to the succeeding cervicals, the length being less than one-fifth of its greatest breadth. In comparison to an atlas from the Calvert formation near Plum Point, Maryland, it is about equal in size, but the transverse processes are deflected more strongly backward and the concave articular surfaces for the occipital condyles are nearly confluent at their inferior edges, or at least are not separated by a mesial depression or elevation. The posterior border of the atlas as viewed from above is distinctly concave and there is no trace of a triangular projection which would fit under the odontoid process of the axis. The posterior margin of the atlas from Maryland is slightly convex and there is a distinct triangular projection mesially on the inferior margin. The last-mentioned atlas has short, stout, tapering, imperforate transverse processes. From a posterior view, the body of this atlas is seen to be much deeper than in front, and the flattened articular surfaces for the axis are more nearly crescentic in outline. In front of the atlas is a slender bone which appears to be the right stylohyal.

At this point, attention should be directed to the fact that the illustration (text-fig. 2) accompanying this description shows the outlines of the vertebrae only in so far as they have been exposed by the preparator. For this reason, the transverse processes of the cervical vertebrae especially appear to be more asymmetrical than they would if the vertebrae had been freed from the matrix and arranged in accordance with their normal position in the series. At first glance the axis of this specimen appears to be somewhat asymmetrical, the transverse process of the left side being more strongly twisted, directed obliquely backward and then curving forward, but this condition unquestionably has resulted from crushing. The transverse process of the right side also presents an irregular curvature. The axis has a broad triangular body, a short, thick odontoid process, and wide, perforated, wing-like transverse processes, the perforation being rather large; the high massive arch and spine are missing.

The other cervical vertebrae have thin sub-rectangular centra, and very long, slender, transverse processes composed of an upper bar (diapophysis) and a lower bar (parapophysis), which are widely separated at the base and inclose a space somewhat smaller than the centrum. The extremities of these 2 above-mentioned bars are not united on the last 3 cervicals. The neural arches and spines of all of these cervicals have been eroded away. The neural canals of most cetotheres are exceedingly low in comparison to their breadth. The transverse processes of the seventh cervical are directed forward throughout most of their length but recurved near the extremity. This curvature indicates a somewhat restricted flexibility of the neck, that is from a side to side direction, for the long transverse processes of the first dorsal are also directed obliquely forward. The centra of the third to seventh cervical vertebrae inclusive progressively increase in thickness, that of the last being almost one-third greater than that of the third.

Some variation in the total number of thoracic and caudal vertebrae exists in certain of the living Mysticeti, but the vertebral formulae of the several species now recognized show an even greater range of variation. As yet, we do not know what to expect in the various fossil forms which already have been made known from incomplete skele- 
tons or skulls. For convenience in comparison, the vertebral formulae of the whalebone whales, living and extinct, are assembled in the following table, together with the total lengths of adults of these cetaceans.

\begin{tabular}{|c|c|c|c|c|c|c|c|}
\hline & $\begin{array}{c}\text { Total } \\
\text { length } \\
\text { (in flesh). }\end{array}$ & C. & D. & L. & $\mathrm{Ca}$. & $\begin{array}{c}\text { Total } \\
\text { number } \\
\text { verte- } \\
\text { brae. }\end{array}$ & Authority. \\
\hline Balaena mysticetus. & $\begin{array}{l}\text { ft. } \\
65\end{array}$ & 7 & 14 & 10 & 23 & 54 & Gray, 1866. \\
\hline Balaenula balaenopsis. . & 164 & 7 & 13 & 10 & 21 & 51 & $\begin{array}{l}\text { Van Beneden, } \\
1878 .\end{array}$ \\
\hline Eubalaena australis. & ${ }^{2} 68$ & 7 & 15 & 11 & 21 & 54 & Hector, 1872 . \\
\hline Eubalaena glacialis. . & $48-54$ & 7 & 14 & 11 & 24 & 56 & Allen, 1908. \\
\hline Neobalaena marginata..... & 320 & 7 & 18 & 1 & 14 & 40 & Oliver, 1922. \\
\hline Mesocetus hungaricus. ..... & 204 & 7 & 12 & 11 & 14 & 46 & Kadic, 1907. \\
\hline Cetotherium furlongi....... & 16 & 7 & 12 & 10 & 12 & 41 & Kellogg. \\
\hline Rhachiancctes glaucus..... & 432.4 & 7 & 14 & 12 & 23 & 56 & Andrews, 1914. \\
\hline Mcgaptera nodosa...... & 47 & 7 & 14 & $10-11$ & $19-22$ & $51-54$ & True, 1904 \\
\hline Balaenoptera cortessii. . & 224 & 7 & 12 & 11 & 10 & 40 & Cuvier, 1836. \\
\hline Balaenoptera acuto-rostrata. & $\left\{\begin{array}{l}{ }^{4} 2710.5 \\
333\end{array}\right.$ & 7 & 11 & $12-13$ & $17-20$ & $47-49$ & True, 1904. \\
\hline Balaenoptera borealis... & 413.75 & 7 & 14 & 13 & 23 & 57 & Andrews, 1916. \\
\hline Balaenoptera physalus. & $\begin{cases}387 & \\
570 & 8\end{cases}$ & 7 & 15 & 15 & 25 & 62 & Oliver, 1922 \\
\hline Sibbaldus musculus. & $\begin{array}{ll}572 & 7\end{array}$ & 7 & 15 & 14 & 28 & 64 & Oliver, 1922. \\
\hline
\end{tabular}

1 Most of these measurements are taken from tip of upper jaw to notch of flukes; one or two may have been taken in a different way, $i$. $e$. , to tip of fluke, and in that case are "over all" measurements.

${ }^{2}$ Gray, $1866 . \quad 3$ Oliver, 1922a. $\quad$ Turner, $1892 . \quad 5$ True, 1904.

This specimen has at least 11 dorsal vertebrae and possibly 12 , for 11 have more or less well-marked articular facets at the distal ends of the transverse processes for the reception of the tubercula of the corresponding ribs. The extremities of the transverse processes of the twelfth thoracic vertebra are slightly thickened and this may indicate the attachment of a pair of ribs. The heads of the last pair of ribs, which in some of the living balaenopterine whales do not articulate with a corresponding surface on the transverse process of the last dorsal vertebra, may also be unattached to the vertebral column of this skeleton. Hence the actual number of dorsal vertebrae can not always be determined from the total number of vertebrae bearing rib facets.

The first dorsal resembles a posterior cervical more closely than do the following dorsals, the centrum being broad and depressed. From the beginning to the end of the series, the centra of the dorsals increase in length and this increase is especially marked between the fifth and sixth. The centra of the more posterior dorsal vertebrae are rather cylindrical and distinctly elongated. The epiphyses of these vertebrae are fully ossified and completely coalesced with the centra. On the first dorsal of most cetotheres, the neural canal is wider in proportion to its height than in any of the others. No neural spines are preserved, but no doubt they were high, thin, bladelike processes with the truncated extremities. The neural canal of the second dorsal measures $61 \mathrm{~mm}$. in breadth at the base, and its greatest height anteriorly is $37 . \mathrm{mm}$. The transverse processes of the first 8 dorsals are directed obliquely forward, those of the first more so than the following ones, and those of the last 4 outward. From before backwards, these processes increase in breadth and tend to become shorter as they approach the seventh dorsal vertebra. From this dorsal posteriorly, the transverse processes gradually lengthen.

Beginning with the sixth dorsal, the transverse processes appear to be constricted mesially, or rather their distal ends expand in an anteroposterior direction; those of 
the eleventh dorsal are more than twice as broad as those of the first. The ends of the transverse processes of the eighth to tenth dorsals inclusive are deeply excavated. These articular facets lie horizontal to the long axis of the centrum while those of the anterior dorsals incline obliquely upward.

The lumbars resemble the posterior dorsals in general appearance, but differ in that the ends of their transverse processes do not bear ribs. As usual in these cetaceans, the centra become more massive toward the caudal series. The transverse processes of the anterior lumbars are directed outward while those of the posterior lumbars curve forward. On the inferior face of these thoracic vertebrae, there is a mesial longitudinal carina. This keel increases in height toward the end of the series. Furthermore, attention should be directed to the fourth to eighth lumbars inclusive, in which the centrum is distinctly constricted behind the transverse processes.

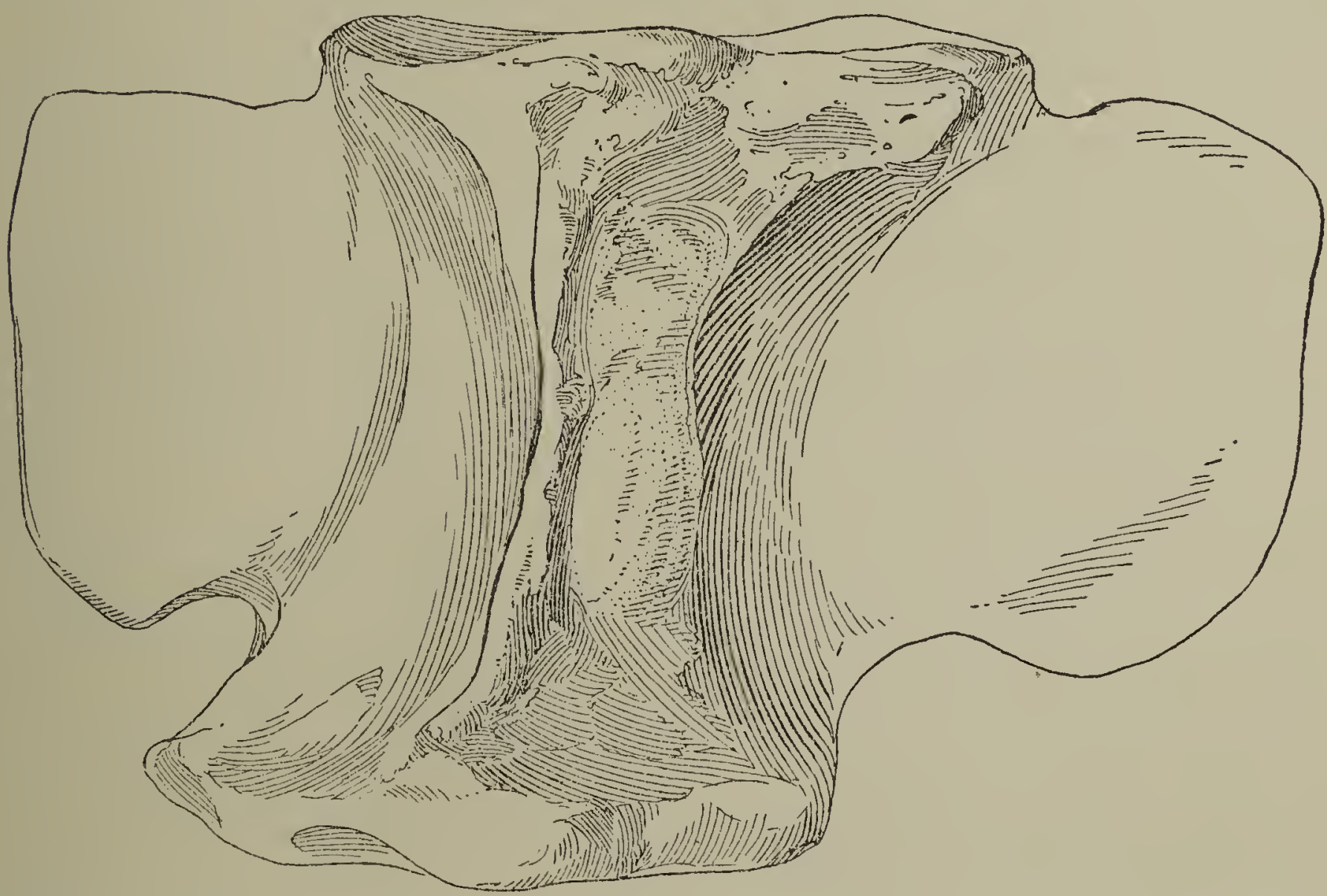

Fig. 3.-Dorsal view of tenth lumbar vertebra of Cetotherium furlongi. Cat. No. 26521, Palaeont. Mus. Univ. Calif.

Turning again to the first three lumbars, it will be noted that the transverse processes are proportionately narrower and longer than those of any of the following vertebrae, and that the extremities of these processes do not project forward beyond the level of the anterior epiphyses. Beginning with the fourth lumbar, the anterior and posterior margins of the transverse processes are characterized by a strong curvature which carries the anterior angle of the extremity beyond the level of the anterior epiphysis. With the broadening of the transverse process, an indentation is produced anteriorly at the base. This indentation is well marked on the seventh lumbar, and increases in depth on each succeeding vertebra and apparently reaches its maximum development on the first caudal. The seventh and tenth lumbars were freed from the matrix and may serve to illustrate the extent and direction of the distortion which characterizes all of these vertebrae. To a still greater degree, the sixth lumbar is compressed in a dorso-ventral direction, the maximum thickness of the centrum as preserved being about $80 \mathrm{~mm}$. This lumbar lay above the scapula. The seventh and tenth lumbars were not superimposed on any other bones but nevertheless they have been flattened to some extent. From a dorsal view (text-fig. 3), the transverse processes of the tenth lumbar appear asymmetrical and the distortion of the centrum is from right to left. The extremities of these transverse processes are not complete 
and the anterior angles are missing. The upper portion of the neural arches and all of the spine are missing, but some idea of the narrowness of the neural canal is afforded by this view. There is a single longitudinal mesial carina on the inferior face of the centrum (text-fig. 4), but this also is distorted by crushing. On the posterior margins, the notches at the bases of the transverse processes are especially well marked. The anterior view (text-fig. 5) does not show any features of especial interest. A lateral view (text-fig. 6) is given to illustrate the depression of the lateral face of the centrum above and below the transverse process.

The vertebral formulae of many cetaceans are often incorrectly given, the discrepancies noted usually being attributed to the inaccurate determination of the last lumbar and the first caudal vertebra. The caudal series begins with the first vertebra which bears chevron facets on the posterior end of the centrum inferiorly. The first and second chevrons are usually small, but the third bears a haemal spine. Regardless of the actual preservation of the corresponding chevron, the first caudal usually can be determined by the posterior bifurcation of the median inferior carina. On the preceding lumbars, this carina progressively increases in width and depth posteriorly. Here again some difficulty is encountered because the ventral surfaces of these vertebrae have not been exposed. Fortunately, the tenth lumbar has been freed from the matrix. An examination of the inferior face of the centrum shows a widening of the longitudinal carina posteriorly, but in view of the imperfect condition of the vertebra it appears best not to lay too much stress upon this feature. Nevertheless, this vertebra appears to be either the last lumbar or the first caudal, and in view of the lumbar series of Mesocetus hungaricus, ${ }^{1}$ it is here given as the tenth lumbar.

Since the whalebone whales propel themselves through the water by upward and downward strokes of the flukes, the tail usually is well developed and consists of several vertebrae. In the living Sulphurbottom Whale (Sibbaldus musculus) there are occasionally as many as 30 caudals, but on the other hand only 14 caudals comprise the tail of the Pigmy Right Whale (Neobalaena marginata). It is not surprising that the caudal series of this cetothere is incomplete, for a number of the thoracic vertebrae are displaced, but it is difficult to determine the original number; 9 more or less complete caudal vertebrae are preserved, 1 or 2 of the terminal caudals may be missing and possibly 2 or more intermediate ones. A computation of the original series of caudal vertebrae based upon the relative lengths of the centra of those available indicates a series of 12 to 14 vertebrae. The centra of the anterior caudals are massive with short, broad, transverse processes directed outward; the neural arches probably had high spines. The centra of the posterior caudals tend to become more nearly cylindrical up to the transitional caudal. This transitional caudal, apparently, is the fourth one counting forward from the terminal one shown on text-figure 2 . It is considerably shorter than the preceding caudal vertebrae, and in most cetaceans it is longer than the antero-posteriorly flattened terminal caudals. The anterior margin of the transverse process of the first caudal is deeply notched near the base and the lateral face of the centrum above and below this process is excavated. The second caudal has been damaged and most of its peculiarities are unknown. It possessed broad, transverse processes perforated near the center of the base by a foramen, but the anterior basal notch is shallower. Only the cylindrical centrum remains of the next caudal. An imperfect chevron which belongs no doubt with this caudal is embedded in the matrix on the left side. The anterior 2 of the remaining 6 caudals likewise have cylindrical centra, but lack transverse processes. On the left side of these 2 caudals and near the anterior margin, the corresponding chevrons were found. The lateral faces of the eighth and ninth caudal vertebrae were transversed by a blood-vessel or nerve which followed the usual course. There is no indication of a groove, however,

${ }^{1}$ O. Kadic, Mesocetus hungaricus Kadic, eine neue Balaenopteridenart aus dem Miozän von Borbolya in Ungarn, Jahrb. kgl. Ungar. Geol. Anstalt, Budapest, Bd. 16, H. 2, pp. 21-91, 3 pls., 70 text figs., 1907. 
Fossil Cetotheres.

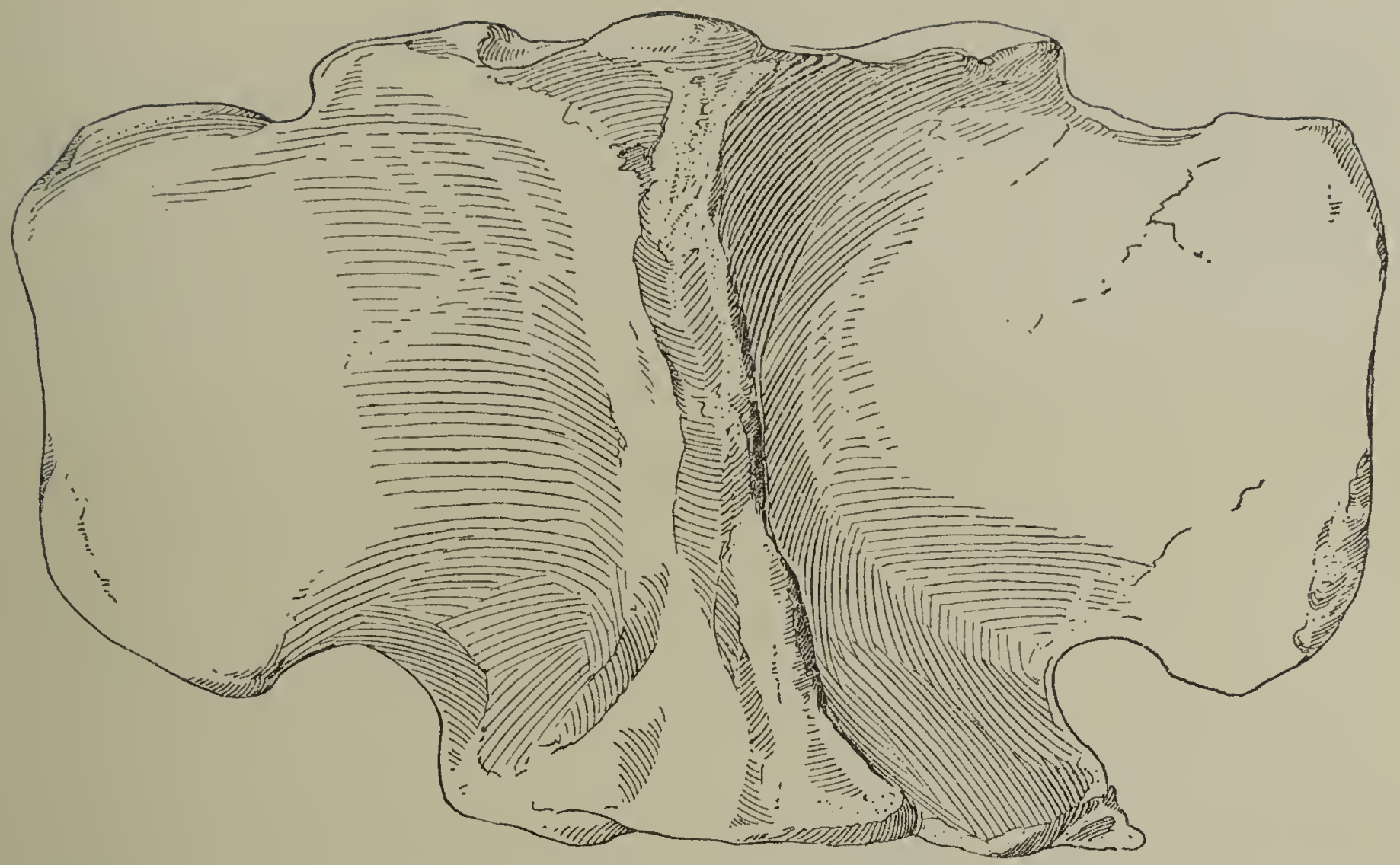

FIG. 4.-Ventral view of tenth lumbar vertebra of Cetotherium furlongi. Cat. No. 26521, Palaeont. Mus. Calif.

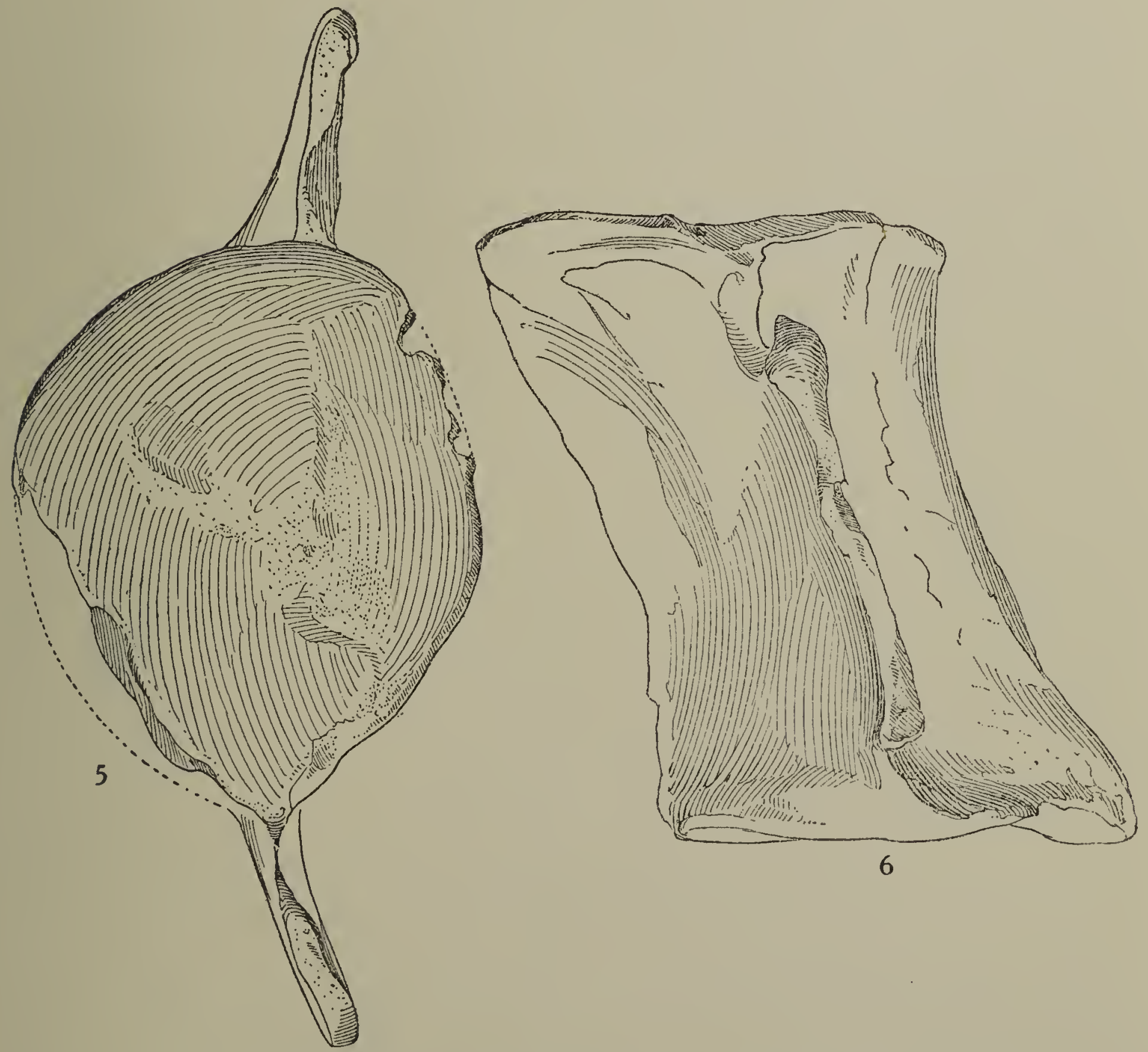

Figs. 5, 6.-Tenth lumbar vertebra of Cetotherium furlongi. Cat. No. 26521, Palaeont. Mus. Univ. Calif. Fig. 5 anterior view; fig. 6, lateral view. 
on the lower portion of the lateral face, but near the middle there is a short vertical canal which passes through the substance of the centrum. Above the dorsal orifice of this canal, no groove can be found, although it is fairly certain that the blood-vessel or nerve passed into the neural canal through the small foramen which pierces the base of the neural arch. The neural arches and processes of the caudal vertebrae of all of the living balaenopterine whales decrease in size gradually and never abruptly, and no doubt similar gradations were exhibited by the caudals of this cetothere. According to the assumed number of vertebrae in the caudal series, the neural arches disappear on the eighth caudal.

Measurements of the vertebrae in (millimeters).

\begin{tabular}{|c|c|c|c|c|c|}
\hline & $\begin{array}{l}\text { Length of } \\
\text { centrum. }\end{array}$ & $\begin{array}{l}\text { Width of } \\
\text { anterior face } \\
\text { of centrum. }\end{array}$ & $\begin{array}{l}\text { Height of } \\
\text { anterior face } \\
\text { of centrum. }\end{array}$ & $\begin{array}{l}\text { Distance be- } \\
\text { tween outer } \\
\text { ends of } \\
\text { transverse } \\
\text { processes. }\end{array}$ & $\begin{array}{l}\text { Greatest antero- } \\
\text { posterior diam- } \\
\text { eter of transverse } \\
\text { process at } \\
\text { extremity. }\end{array}$ \\
\hline Atlas............. & 37 & $x$ & $\mathbf{x}$ & 220 & $x-$ \\
\hline 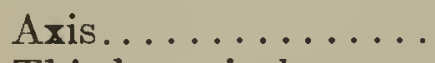 & 161.2 & $x$ & $x$ & 242 & $\mathrm{x}$ \\
\hline Third cervical..... & 21 & $x$ & 64.5 & 232 & $x$ \\
\hline Fourth cervical.... & 23.2 & $x$ & 65 & 232 & $\mathrm{x}$ \\
\hline Fifth cervical...... & $23+$ & $x$ & 66 & 237 & $\mathrm{x}$ \\
\hline Sixth cervical...... & 25.5 & $x$ & 68 & 244 & $x$ \\
\hline Seventh cervical.... & 30.5 & 97 & 68 & 274 & $\mathrm{x}$ \\
\hline First dorsal ....... & 38.5 & $x$ & 73.5 & 224 & 26 \\
\hline Second dorsal....... & 45 & $\mathrm{x}$ & 74 & 210 & 35 \\
\hline Third dorsal........ & 51 & $x$ & 80 & $x$ & 35.5 \\
\hline Fourth dorsal....... & 61 & $x$ & 81 & 194 & 40.5 \\
\hline Fifth dorsal. ....... & 62.5 & $x$ & $\mathrm{x}$ & $x$ & 31 \\
\hline Sixth dorsal....... & 71 & $\mathbf{x}$ & $x$ & 211 & 45 \\
\hline Seventh dorsal...... & 77 & $\mathrm{x}$ & $\mathrm{x}$ & 208 & 46 \\
\hline Eighth dorsal....... & 82 & $x$ & $\mathrm{x}$ & 237 & 49 \\
\hline Ninth dorsal........ & 89 & $x$ & $x$ & 265 & 60 \\
\hline Tenth dorsal....... & 92 & $x$ & $x$ & 304 & 72 \\
\hline Eleventh dorsal.... & 93 & $x$ & $x$ & 350 & 80 \\
\hline Twelfth dorsal...... & 93 & $x$ & $x$ & 360 & $x$ \\
\hline First lumbar....... & $90+$ & $x$ & $x$ & $x$ & $x$ \\
\hline Second lumbar...... & 103 & $x$ & $78+$ & $\mathbf{x}$ & $x$ \\
\hline Third lumbar....... & $100+$ & $x$ & $x$ & $x$ & $\mathbf{x}$ \\
\hline Fourth lumbar...... & 110 & 102 & 85 & $300+$ & $x$ \\
\hline Fifth lumbar....... & 120 & $\mathrm{x}$ & $\mathbf{x}$ & 335 & $x$ \\
\hline Sixth lumbar....... & $x$ & $97+$ & $80+$ & 320 & $x$ \\
\hline Seventh lumbar.... & 120 & 113 & 94 & $\mathrm{x}$ & $x$ \\
\hline Eighth lumbar...... & 130 & 116 & 87 & 238 & $x$ \\
\hline Ninth lumbar...... & 138 & $113+$ & $x$ & 226 & $x$ \\
\hline Tenth lumbar. ..... & 137 & 116.5 & 95 & $224+$ & $101+$ \\
\hline First caudal........ & 140 & 113 & 105 & $188+$ & $76+$ \\
\hline Second caudal...... & 135 & 106 & $x$ & $x$ & $x$ \\
\hline Third caudal....... & 130 & 100 & $x$ & $x$ & $x$ \\
\hline Seventh caudal..... & 110 & 92 & $x$ & $x$ & $x$ \\
\hline Eighth caudal...... & 105 & 89 & $x$ & $x$ & $\mathbf{x}$ \\
\hline Ninth caudal. ...... & 76 & 88 & $101+$ & $\mathbf{x}$ & $x$ \\
\hline Eleventh caudal .... & 29 & 69 & 40 & $x$ & $x$ \\
\hline Twelfth caudal..... & $x$ & 60 & 38 & $\mathbf{x}$ & $x$ \\
\hline
\end{tabular}

1 Including odontoid process.

\section{SCAPULA.}

In contour and general size, the left scapula (text-fig. 2) agrees very closely with we left scapula of Cetotherium klinderi. ${ }^{1} \quad$ The ventral or internal surface has been exposed along its suprascapular or vertebral margin, but, unfortunately, the fourth,

${ }^{1}$ J. F. Brandt, Mem. Acad. Imp. Sci. de St. Petersbourg, ser. 7, vol. 20, No. 1, p. 92, pl. 5 i.g. $14 a, 1873$. 
fifth, and sixth lumbars are superimposed over the lower portion. The axillary margin and inferior angle are thus hidden from view. The vertebral margin of the scapula is regularly convex in contrast to the flattening which characterizes the central portion of this border in most of the living species of the genus Balaenoptera. Most of the slender cylindrical coracoid process has been destroyed. The acromion is well developed, rather broad, and directed more nearly outward than downward. The neck of this scapula is relatively broad and the glenoid cavity for the head of the humerus is rather large. Above the acromion, the anterior margin is nearly vertical or inclined very slightly forward. Consequently, the supra-metacromial notch is lacking.

Measurements of the scapula.

Distance from anterior angle to inferior angle, measured in a straight line......... $380+$ Distance at widest point from vertebral margin to head of scapula ........... $210+$ Distance from anterior (coracoid) margin of scapula to tip of acromion.......... $80+$

\section{HUMERUS.}

Unfortunately the humerus lies beneath the third and fourth lumbars and is crushed in such a way that little can be learned regarding its peculiarities. In comparison to humeri from the Calvert formation of Maryland, it presents no striking differences. The head is large and rounded without any apparent neck, and the lesser tubercle projects dorsad above it. The total length of the humerus was approximately $200 \mathrm{~mm}$. and the greatest breadth of the proximal end as preserved is $116 \mathrm{~mm}$.

\section{Radius and Ulna.}

The proximal ends of the long slender radius and ulna also underlie the third and fourth lumbars. The extremities, however, exhibit a closer agreement with the balaenopterine whales than with Balaena. The shaft of the ulna is slightly narrower than that of the radius. Both are characterized by expanded distal extremities. The olecranon process of the ulna lies beneath the transverse process of the fourth lumbar, and it was thought advisable not to attempt any further removal of the maxtrix to facilitate a study of this process. The estimated total length of the ulna including the olecranon process is $282 \mathrm{~mm}$. and the breadth of the distal extremity is $70 \mathrm{~mm}$. The anterior face of the shaft of the ulna is rounded; the external and internal faces converge posteriorly to form a thin margin. The shaft of the radius is rather stout, slightly thicker than that of the ulna, and measures $273 \mathrm{~mm}$. in length, while the distal extremity measures $83 \mathrm{~mm}$. in breadth. Some of the carpals of this flipper and the right scapula underlie the radius and ulna in the matrix.

RIBS.

Nine of the ribs on the right side and 8 of those on the left side are embedded in the matrix (text-fig. 2). As will become apparent, the ribs do not lie in their normal position, although those on opposite sides supplement each other to some extent and by utilizing both series a composite description can be given. The possibility of incorrectly allocating the tangled mass of ribs on both sides is especially great because of obvious differences in the curvature of the shafts and in the presence of a distinct angle on some of the anterior ribs. Three of the ribs on the right side show a welldefined angle, while none of those on the left side exhibit an angle.

In so far as our present knowledge extends, the first pair of ribs in the Mysticeti are relatively short and noticeably expanded at their distal extremities. From this peculiarity, it may be inferred that the first rib is not represented on either side. In regard to length, the first rib shown on the left side, in comparison to the following ribs, fulfills the requirements for the second of the series. The proximal end of this rib is concealed by the matrix. The tubercula of the two ribs that oyerlie the abovementioned rib are exposed, but the capitula are buried in the matrix. The shafts of all the foregoing ribs are rather slender and the curvature regular. Turning to the rib touching the fourth dorsal which appears to be the seventh rib, it will be observed that the neck is more elongated than the others on the left side, while the curvature is 
reduced. This is the longest rib preserved. Since this rib measures $920 \mathrm{~mm}$. in length and the second $580 \mathrm{~mm}$., it is evident that the ribs rapidly increase in length from the second to the rib which appears to be the seventh. The convex external curvature of the ribs on the left side is rather regular, and this curvature is more pronounced in the rib which touches the fifth dorsal than in any of the preceding or following ribs. All of the extremities of the ribs on the left side are roughened for the attachment of ligaments. The capitula of 2 of the ribs on the right side are borne upon long necks; they may be the fifth and sixth ribs. Beyond this point, the identification of those that remain is rather uncertain; one of these ribs is single headed and may represent the tenth rib on the right side. The shafts of the anterior ribs are noticeably flattened while those that follow tend to become narrower and thicker.

\section{Plesiocetus occidentalis, new species.}

Type specimen.-Cat. No. M.1551; Paratype, Cat. No. M.1350, Museum of Palaeontology, University of California. The type consists of an imperfect weathered skull; the rostrum, supraorbital and zygomatic processes, periotics, tympanics, as well as some of the bones bounding the nasal passages are missing. The skull of the paratype is also incomplete and, although greatly eroded, supplies some additional structural details.

Type locality.-No record of the accession of these specimens can be found in the museum catalogues. The donor and occurrence are unknown.

Horizon.-The matrix which has formed the natural brain cast in each of these skulls is a hard fine-grained magnesian limestone or dolomite and in lithologic appearance agrees with certain limestones in the Monterey formation. Mr. W. F. Foshag, of the United States National Museum, has made a laboratory examination of these natural braincasts and reports that the dolomite in skull Cat. No. 1350 is more siliceous than that of Cat. No. 1551. Mysticetes with this type of skull had a rather widespread distribution during the latter part of the Miocene period; Upper Miocene, probably Tortonian or later.

As mentioned in the introductory remarks, the degree of likeness between these skulls cranially is so marked that they appear to be conspecific. Despite certain structural peculiarities which appear in the illustrations herewith given, the size and relations of the elements are in close agreement and it is believed that whatever differences are exhibited may be explained on the basis of different degrees of wear. These skulls, both in the architecture of the basicranium and in the form of the temporal fossae, bear some resemblance to the skull described by Strobel ${ }^{1}$ from the Lower Pliocene of Cortandone, Italy, as Cetotherium gastaldii, but are distinguished from the latter by sloping supraorbital processes and a narrower intertemporal region. In some respects they agree with the incomplete skull obtained from the upper sedimentary deposits on the Cape of Espichel beyond the Tejo River at the site of Adica about 4 leagues from Lisbon, Portugal, and described by Van Beneden ${ }^{2}$ as Cetotherium vandelli. If the illustrations used by Vandelli, Van Beneden, and Brandt are accurate, the skull from Portugal presents some unusual features for a cetothere. The outer margin of the maxilla may be incomplete which may account for the remarkable constriction of the rostrum anteriorly, and likewise the peculiar appearance of the interorbital and intertemporal regions on the right side may require a similar explanation.

In order to demonstrate the validity of the various species which have been proposed it will be necessary to show differences between corresponding structures. Such comparisons, unfortunately, can not be made from the material which has been described and figured. Unless future discoveries or undescribed specimens supply such

1 P. Strobel, Notizie preliminari zu le Balenoptere fossili subapennine del Museo Parmense, Boll. R. Com. Geol. d'Italia, Roma, vol. 6, Nos. 5-6, p. 136, 1875; A. Portis, Catalogo descrittivo dei Talassoterii rinvenuti nei terreni Terziarii del Piemonte e della Liguria, Mem. Reale Accad. Sci. di Torino, ser. 2, vol. 37, p. 17, pl. 1, figs. 3-5, 1885.

2 P. J. Van Beneden and P. Gervais, Ostéographie des Cétacés vivants et fossiles, Paris, pp. 273-274, Atlas, pl. 17, fig. 8, 1872 [Based upon: A. A. Vandelli, Hist. ct Mem. Acad. Real. d. Sci. de Lisboa, vol. 11, pt. 1, pp. 290, 304, pl. 4, figs. 1-12, 1831]. 
data, the relationships of many of these forms will remain unsettled. Certain structures have been considered by those interested in this subject as being more important than others. Of these, the peculiarities of the supraorbital and zygomatic processes, the contour of the temporal fossa, and the size and shape of the supraoccipital shield are thought to be especially diagnostic. Certain portions of the skull are preserved more frequently than others and in consequence many species have been based upon variations in structures which may or may not be of specific importance. In view of the present inadequate knowledge of the structural peculiarities of the skulls and skeletons of these cetotheres and the imperfect preservation of the parts which are known, it is not possible at the present time to attempt a revision of the species.

There is a strong possibility that one or more genera of cetaceans allied to Plesiocetus are now included among the species which have been referred to Cetotherium. That these species are not all congeneric is borne out to some extent by differences observable in the ear bones. Unfortunately, the periotic and tympanics are not known for many of the described species, or at least they have not been figured. Brandt ${ }^{1}$ has figured the periotic and tympanic of Cetotherium rathkii and unless there was a wider range of variation among these Miocene cetotheres than may be observed between species of the same genus in case of living mysticetaceans, which is extremely unlikely, all species of the genus Cetotherium should possess periotics of the same general type. The structural peculiarities of the periotic in the type skull of Cetotherium megalophysum Cope do not correspond with those of the periotic of Cetotherium rathkii figured by Brandt, nor do they fall within the range of specific variation as understood by the writer. The skull and periotic of Cetotherium megalophysum does exhibit a remarkable resemblance to that of Plesiocetus hupschii Van Beneden. ${ }^{2}$

In order to clarify the discussion which follows, the species hupschii ${ }^{3}$ is here designated as the type of the genus Plesiocetus. Furthermore it seems advisable to change the generic allocation of Cetotherium megalophysum Cope, and as it possesses all the diagnostic characters of Plesiocetus, it will be referred to as Plesiocetus megalophysum (Cope).

\section{SKULLS.}

DORSAL VIEW.

On account of the loss of the supraorbital processes on one skull and their imperfect preservation on the other, critical comparison of these structures with other species is impossible. The zygomatic processes are also missing on both of these skulls and there is some uncertainty about the original shape of the supraoccipital shield. In certain important details, these two skulls differ from all previously figured species, and in most respects they appear to resemble Plesiocetus megalophysum (Cope) ${ }^{4}$ more closely than Cetotherium rathkii Brandt or Cetotherium vandelli Van Beneden. The supraorbital processes of the frontals are unusually broad at the base and slope gradually downward from the interorbital region. They also differ from Cetotherium furlongi in the relative breadths of the supraorbital processes at the base, in the position of the nasals, in the curvature of the posterior margins of the temporal fossae, and in the breadth of the intertemporal region.

Inasmuch as considerable importance has been attributed to the forward thrust of the supraoccipital shield, it is unfortunate that this structure is so poorly preserved on both skulls. Very little of the original surfaces of the bones comprising the dorsal aspect of either skull is preserved, and on one skull (Cat. No. 1551) a natural braincast is exposed. On the other skull (text-fig. 8), the contour of the supraoccipital shield

$1 \mathrm{~J}$. F. Brandt, Untersuchungen ueber die fossilen und subfossilen Cetaceen Europa's, Mém. Acad. Imp. Sci. de St. Petersbourg, ser. 7, vol. 20, No. 1, pp. 74, 79-80, pl. 3, figs. 1-5, 1873.

2 P. J. Van Beneden and P. Gervais, Ostéographie des Cétacés vivants et fossiles, Paris, Atlas, pl. 16, fig. 17, 1872-1880.

3 P. J. Van Beneden, Bull, Acad. Roy. Sci. de Belgique, ser. 2, tome 8, No. 11, p. 140, 1859.

4 E. D. Cope, Fourth contribution to the marine fauna of the Miocene period of the United States, Proc. Amer. Philos, Soc. Philadelphia, vol, 34, No. 147, pp. 146-148, May 29, 1895; op. cit., vol. 35. No. 151, pl. 11, fig. 3, August 13, 1896. 
may be traced, although the cranium is badly weathered and on each side of the median line a small portion of a natural cast of the lobe of the cerebrum is exposed. As a whole the supraoccipital appears to slope forward and become narrower toward the vertex. The exact position of the apex of the supraoccipital shield is uncertain. The extremities of the exoccipitals have been destroyed on both skulls. One skull (text-fig. 7) shows the curvature of the wing-like portion of the exoccipital and the other (textfig. 8) the proportions and outlines of the occipital condyles. From a posterior view, the condyles appear semielliptical in outline, considerably broader above the middle than at the base. The articular surfaces are slightly convex, more or less flattened, and set off from the exoccipitals by shallow concavities. The occipital condyles of this cetacean bear a closer resemblance to those of Plesiocetus megalophysum than to any of the other forms from the Atlantic Tertiary deposits described by Cope. The opening for the foramen magnum is almost circular.

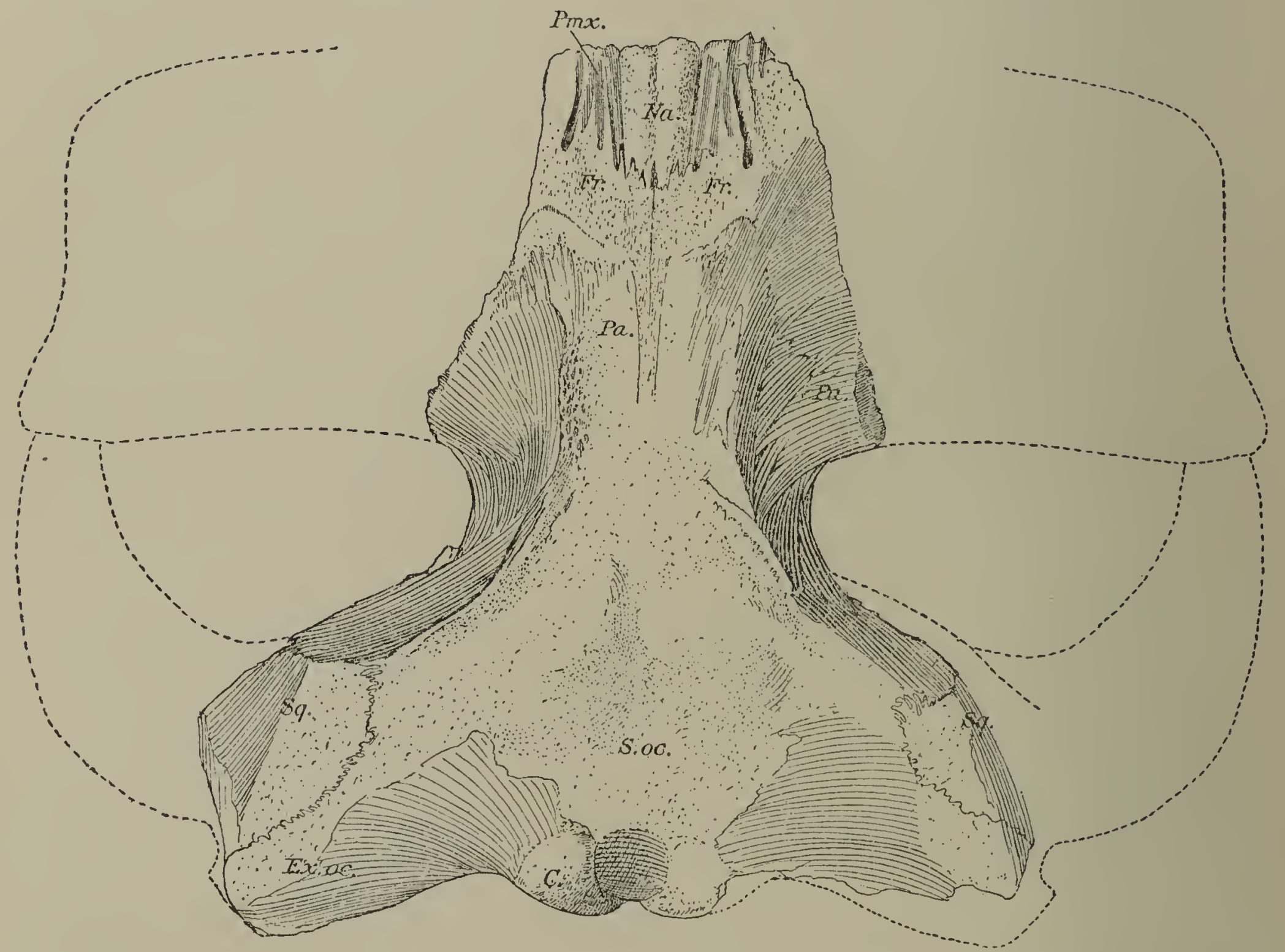

Fig. 7-Dorsal view of type skull of Plesiocetus occidentalis. Cat. No. 1551, Palaeont. Mus. Univ. Calif. C., condyle; Ex. oc., exoccipital; Fr., frontal; $N a .$, nasal; $P a .$, parietal; Pmx., premaxilla; S. oc., supraoccipital; Sq., squamosal.

The form and dimensions of the bones comprising the rostrum are unknown. The sutures on the frontals for the reception of the ascending processes of the premaxillae and for the postero-mesial processes of the maxillae are deep and well defined on both of the skulls. More evidence of erosion in the intertemporal region is shown on one skull (text-fig. 7) than on the other and in addition the anterior projections of the frontals and the distal ends of the nasals have been worn off. The nasals are in place on both of these skulls, although their dorsal surfaces are considerably eroded. As in many of the living balaenopterine whales, the nasals are relatively narrow, but rather deep. They are wedged in between the anterior projections of the frontals, and firmly sutured at their bases. The nasals on skull Cat. No. 1350 are approximately complete, though it is possible that short sections of their anterior extremities are missing. 
The frontals form the rostral wall of the cranial cavity and their lateral projections, the supraorbital processes, roof over the orbit. They are excluded from the vertex by the parietals which meet mesially in the intertemporal region.

From a lateral view, the parietal is seen to be rather broadly expanded, somewhat fan-shaped in general contour, with its greatest diameter along the superior margin. It bounds the temporal fossa internally and descends abruptly from the upper to the lower margin. The most obvious difference between the skull of Plesiocetus megalophysum and these skulls from California is the swollen appearance of the side of the braincase in the former. This swelling is bisected by the more or less horizontal suture between the parietal and squamosal. Furthermore, in the skull of Plesiocetus megalophysum the parietals do not overspread the frontals to any marked extent and terminate at the level of the posterior margins of the supraorbital processes. The superior

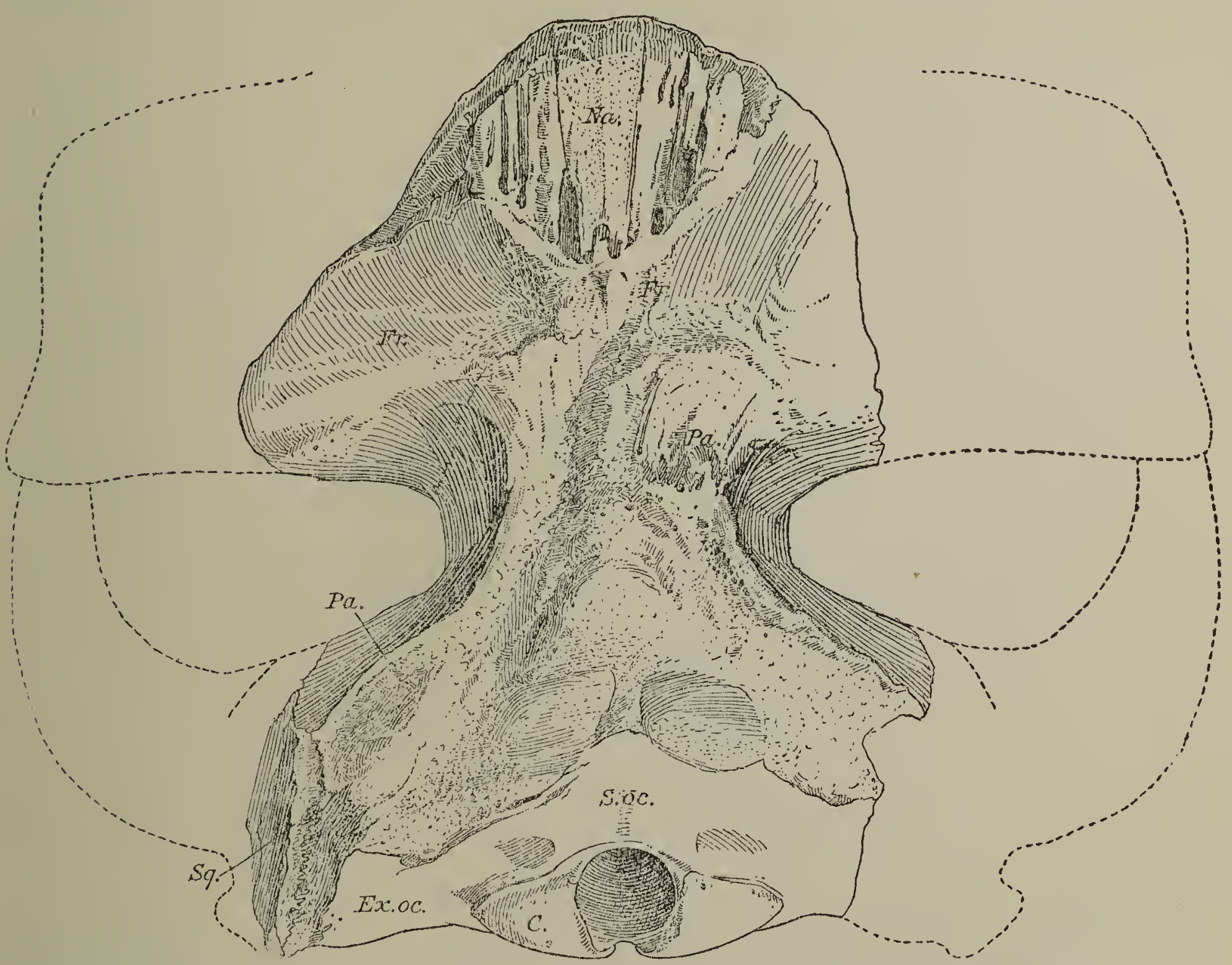

FIG. 8.-Dorsal view of paratype skull of Plesiocetus occidentalis. Cat. No. 1350, Palaeont. Mus., Univ. Calif. C., condyle; Ex. oc., exoccipital; Fr., frontal; $N a .$, nasal; $P a$. parietal; $P m x$. premaxilla; S. oc., supraoccipital; $S q$. , squamosal.

margins of the parietals on the skulls from California are worn down below the level of the supraoccipital suture. In all three of these skulls, the parietal is sutured to the supraoccipital posteriorly, the squamosal, alisphenoid, and pterygoid inferiorly, and the frontal anteriorly. The eroded surfaces of these California skulls show that the parietals overspread the frontals in the interorbital region to a point about halfway between the extremities of the nasals and the posterior margins of the supraorbital processes. In the temporal fossa, the pterygoid lies below the parietal and is in contact posteriorly with the squamosal. Between them appears the extremity of the narrow wedge-like alisphenoid. 
VENTRAL VIEW.

On each side the basisphenoid is overridden by the pterygoid (text-fig. 9) and the narrow extremity of the latter abuts against the anterior face of the lateral protuberance on the basioccipital. The ventral face of the other skull (text-fig. 10) has suffered to a great extent from erosion, and all of the left pterygoid as well as the extremity of the right pterygoid are missing. These pterygoid bones bound the medial region of the basicranium on each side and together with the vomer contribute the upper posterior boundary of each nasal passage. No remnant of a hamular process is present on either of these skulls. By referring to the figures given by Brandt ${ }^{1}$ for Cetotherium rathkii one can interpret most of the elements which are exposed on these skulls from California. According to his illustrations, the palatines extend backward as far

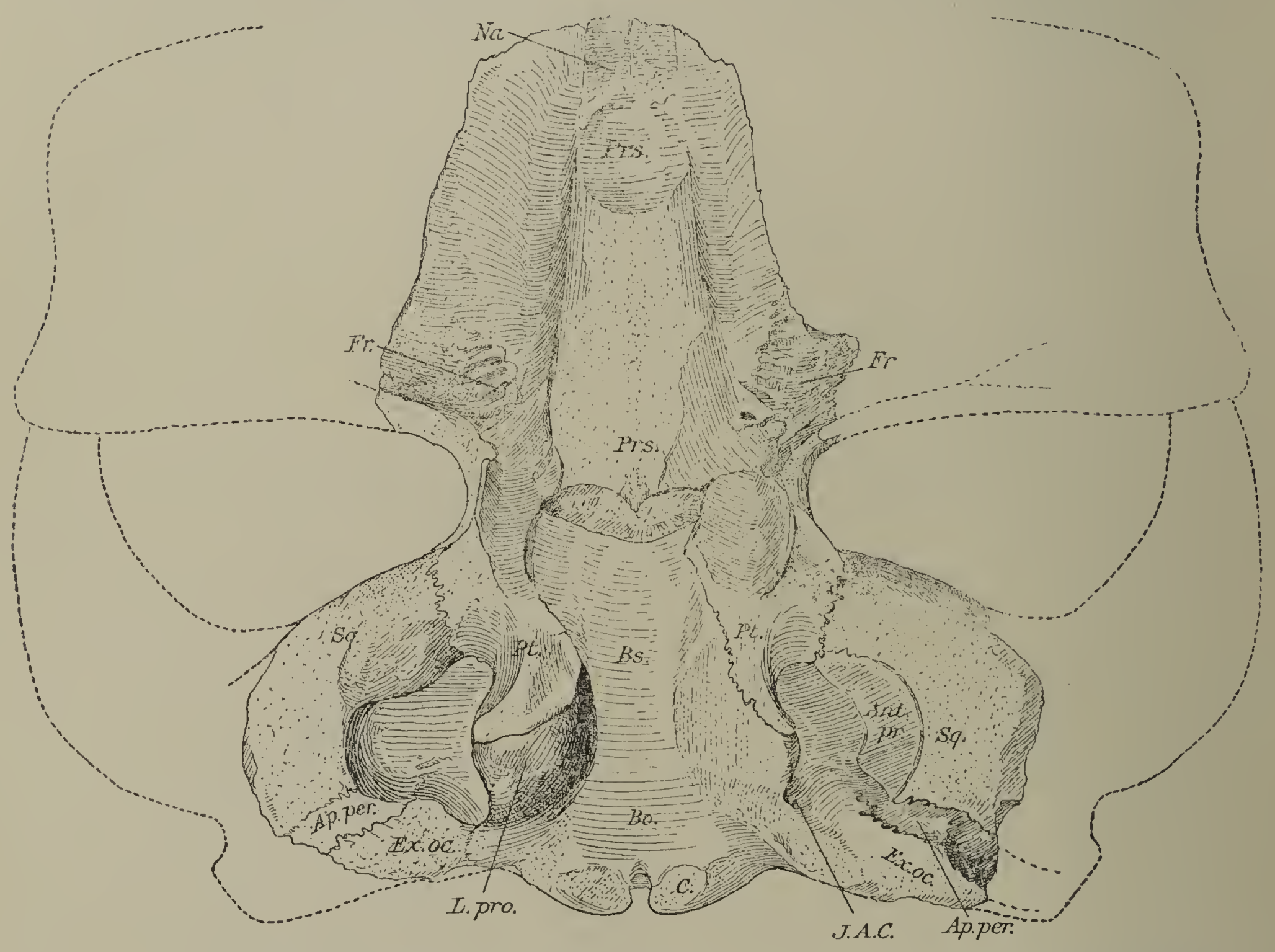

Fıg. 9.-Ventral view of type skull of Plesiocetus occidentalis. Cat. No. 1551, Palaeont. Mus., Univ. Calif. Ant. pr., anterior process of periotic; Ap. per., apophysis or posterior process of periotic; Bo., basioccipital; Bs., basisphenoid; Ex. oc., exoccipital; Fr., frontal; $J . A . C$., jugulo-acoustic canal; $L$. pro., lateral protuberance on basioccipital; $N a .$, nasal; $P r s .$, presphenoid; $P t$., pterygoid, $S q$. , squamosal.

as the anterior margins of the pterygoid fossae. The pterygoids on the skull of Cetotherium rathkii, apparently, have not developed hamular processes. In the temporal fossa (text-fig. 9), the pterygoid is suturally united with the squamosal, and anteriorly forms the posterior wall of the optic canal. The structure of the pterygoid fossa resembles that of Parietobalaena palmeri. ${ }^{2}$ It should be noted that the falciform processes of the squamosals have been eroded away on both skulls. The bell-like contour of the tympano-periotic recess is a characteristic feature of this cetothere. In a better-preserved skull, the inferior outlines of this recess would appear somewhat different. A postero-internal process of the squamosal usually projects into this recess

\footnotetext{
${ }^{1}$ J. F. Brandt, op. cit., pl. 1, fig. 2; pl. 2, fig. 2, 1873.
}

2 R. Kellogg, Description of a new genus and species of whalebone whale from the Calvert Cliffs, Maryland, Proc. U. S. Nat. Mus., vol. 63, art. 15, Publ. 2483, pl. 4, February 5, 1924. 
below the periotic, and in front the falciform process extends across to meet the horizontally expanded pterygoid. This recess is bounded by the squamosal externally, the exoccipital posteriorly, the basioccipital and basisphenoid internally, and by the alisphenoid and the overlying pterygoid anteriorly. As a result of weathering, the pterygoid has been entirely destroyed on one skull (text-fig. 10) and the ventral face of the alisphenoid is exposed to view. The zygomatic processes of both skulls are missing, and the cranial portions of the squamosals are also damaged. With regard to the squamosal, it will be noted that it is a rather large bone, firmly fixed to the side of the braincase and internally forms part of the wall of the cranial cavity.

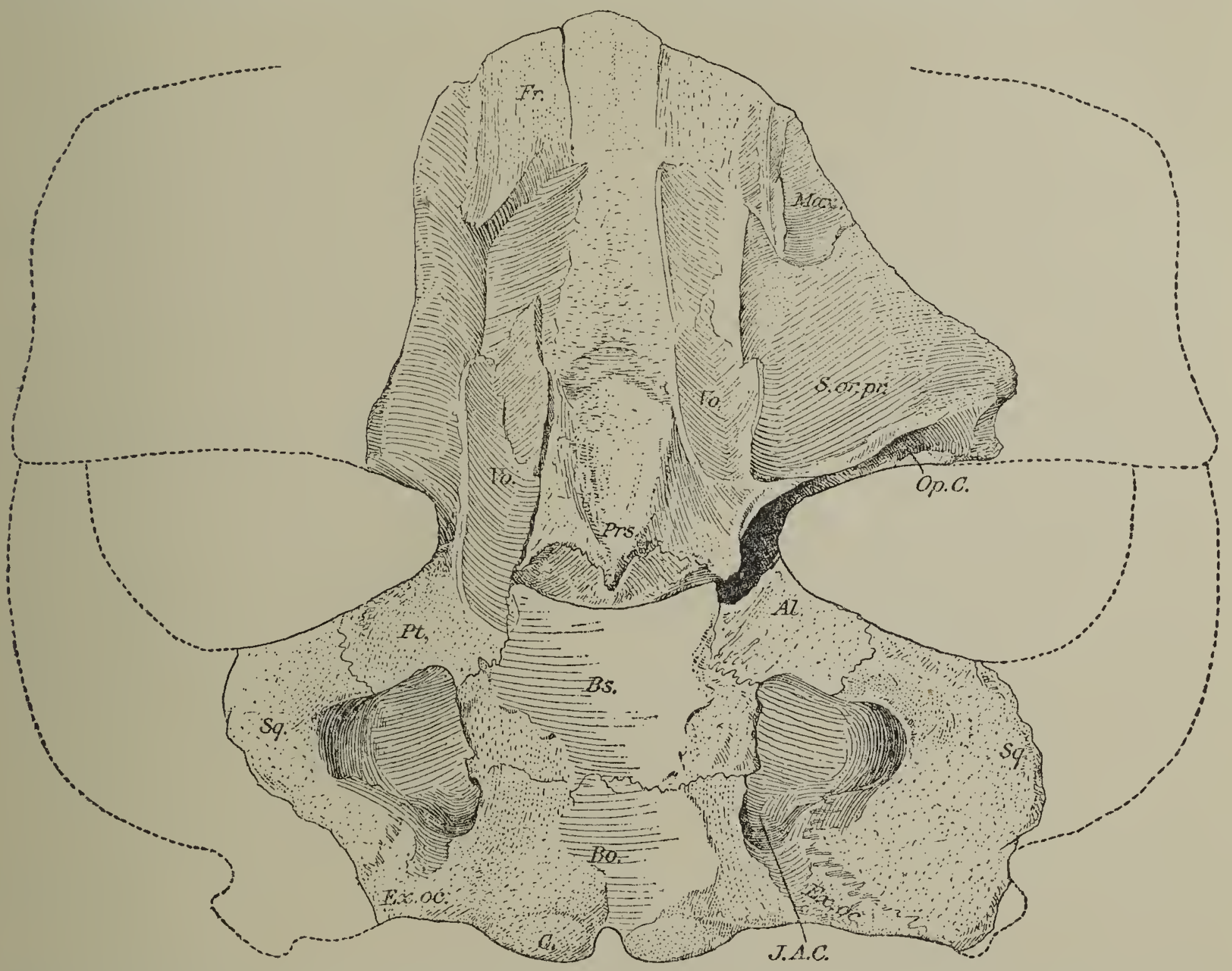

FIG. 10.-Ventral view of paratype skull of Plesiocetus occidentalis. Cat. No. 1350. Palaeont, Mus., Univ. Calif. Bo., basioccipital; Bs., basisphenoid; Ex. oc., exoccipital; Fr., frontal; J. A. C., juguloacoustic canal; Max., maxilla; Op. C., optic canal; Prs., presphenoid; Pt., pterygoid; S. or. pr., supraorbital process of frontal; $S q$. , squamosal; Vo., vomer.

In one of these skulls (text-fig. 9), portions of the apophyses of both periotics are preserved. The apophysis of the periotic is lodged in a narrow trough on the squamosal between the exoccipital suture and the usual position of the transverse groove for the external auditory meatus. The surface of the squamosal in this region has been worn to such an extent that the groove for the meatus has been obliterated. On the other skull (text-fig. 10), the effect of erosion is more noticeable; the exposed surfaces of the exoccipital and squamosal are worn down below the level of the trough for the apophysis of the periotic. The position and course of the jugulo-acoustic canal is fairly well marked on both skulls. This canal originates within the cranial cavity, follows down the external surface of the basioccipital, appears on the ventral face of the basicranium in the angle formed by the exoccipital and the basioccipital, and crosses the former in an oblique direction to its posterior margin.

The basioccipital is considerably wider than long, with ventral surface concave from side to side. The suture between the basioccipital and basisphenoid is not well defined, 
but appears to be in front of the lateral protuberance. On the right side of one skull (text-fig. 9) the lateral protuberance is practically complete; the internal face is obliquely truncated, while the external is vertically truncated. The occipital condyles are low and flattened, and apparently do not project backward beyond the plane of the exoccipitals.

Further mention must be made of the broad basisphenoid, which in a perfect skull may be largely concealed by the horizontally expanded vomer. The anterior margin of this bone is concave and it is separated from the presphenoid by an open transverse fissure. The presphenoid is emarginate posteriorly, with a short mesial process, subcylindrical in cross-section, and tapering anteriorly. Normally, the presphenoid rests in the trough of the vomer, and is not visible from a ventral view. On one of these skulls (text-fig. 10), portions of the lateral walls of the vomerine trough are preserved. The vomer also conceals the above-mentioned transverse fissure, and its horizontally expanded wings meet the vaginal plates of the pterygoids along its lateral margins.

Practically the entire course of the optic canal is shown on one of these skulls (textfig. 10). Near its origin, this canal is bounded by the frontal anteriorly, presumably by the palatine inferiorly, and by the pterygoid and alisphenoid posteriorly. This canal is very narrow in comparison to the breadth of the supraorbital process and follows the posterior margin of the latter on the proximal one-half at least of its outward course. The optic canal is thus exposed inferiorly, although there is a noticeable overrolling of the anterior margin.

From a ventral view (text-fig. 10), the supraorbital processes appear to be rather broad at the base. The ventral surface of the base of the left supraorbital process is flattened and no doubt was overspread by the orbital plate of the maxilla. One of the most diagnositic features of a mysticete skull is the shape of the temporal fossa. Since the zygomatic processes and the extremities of the supraorbital processes are missing on both of these skulls, a structural feature of considerable importance is left unsettled. The narrowness of this fossa at the base (text-fig. 10), the curvature of the posterior margin of the supraorbital process, and the anterior border of the squamosal impart a characteristic contour to the internal portion of the fossa, and in this respect it agrees rather closely with Balaenoptera gastaldii.

Measurements of the skulls.

\begin{tabular}{|c|c|c|}
\hline & $\begin{array}{l}\text { Cat No. } \\
\text { M. } 1350 .\end{array}$ & $\begin{array}{l}\text { Cat. No. } \\
\text { M. } 1551 .\end{array}$ \\
\hline Least breadth of braincase in intertemporal region..... & $\begin{array}{c}m m \\
177\end{array}$ & $\begin{array}{c}m m \\
172.5\end{array}$ \\
\hline Distance from base of right nasal to right occipital condyle.......... & 375 & 387 \\
\hline Length of right nasal. & 110 & 85 \\
\hline 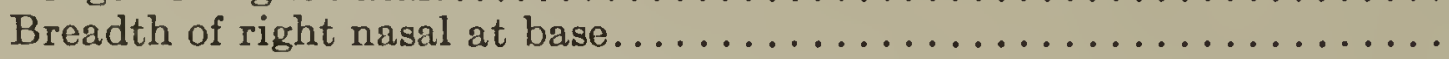 & 15 & 14 \\
\hline 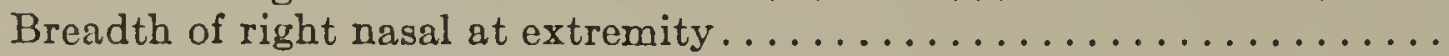 & 24 & 22.5 \\
\hline 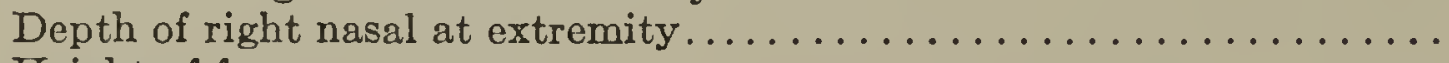 & $\mathrm{x}$ & 46 \\
\hline 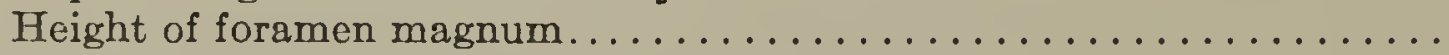 & 60 & $x$ \\
\hline 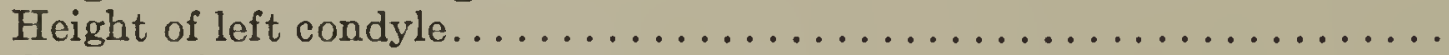 & 98 & $\mathbf{x}$ \\
\hline 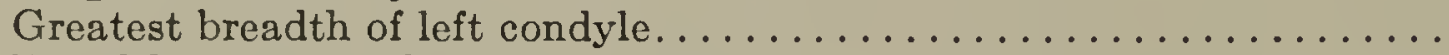 & 61 & $x$ \\
\hline 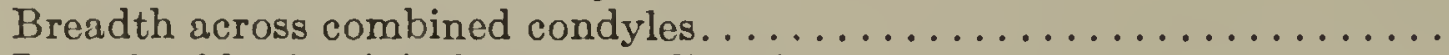 & 157 & $\mathbf{I}$ \\
\hline Length of basioccipital along median line.............. & 86.5 & 94 \\
\hline Breadth of basioccipital between jugulo-acoustic canals............. & 141 & 150 \\
\hline Length of right tympano-periotic recess.................... & 81 & $x$ \\
\hline 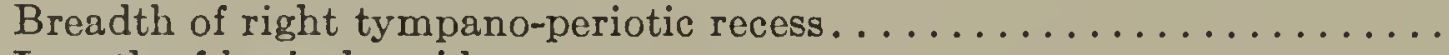 & 91 & 88 \\
\hline 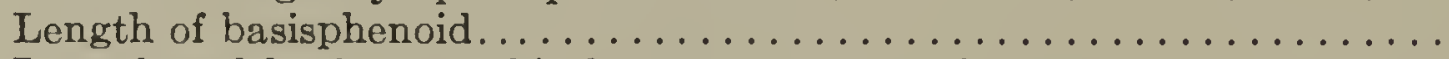 & 91.5 & 94 \\
\hline Least breadth of supraorbital process, ventral side............... & 248 & $\mathbf{x}$ \\
\hline Distance from condylar notch to anterior margin of basisphenoid..... & 178 & 188 \\
\hline 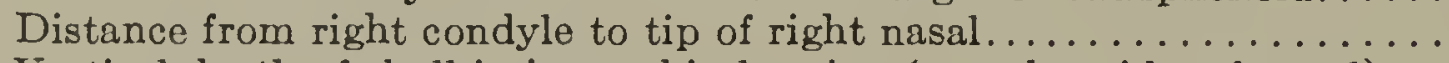 & 458 & 449 \\
\hline Vertical depth of skull in interorbital region (presphenoid to frontal)... & $\mathbf{x}$ & 180 \\
\hline $\begin{array}{l}\text { Vertical depth of skull in occipital region (basisphenoid to apex occipital } \\
\text { shield) estimated. } \ldots \ldots \ldots \ldots \ldots \ldots \ldots \ldots \ldots \ldots \ldots \ldots\end{array}$ & $170+$ & $160+$ \\
\hline
\end{tabular}




\section{A NEW FOSSIL SIRENIAN FROM SANTA BARBARA COUNTY, CALIFORNIA.}

An unusually large sirenian recently submitted to the writer for study by Dr. David Starr Jordan is of special interest on account of the fact that it constitutes the first reported occurrence on the Pacific Coast of North America of a representative of the suborder Trichechiformes. The skull was covered with an encrustation of soda and compact diatomaceous shale; the ribs and dorsal vertebrae were embedded in a laminated opal. Some difficulty was encountered in preparaing the material, for the matrix clings very closely to the bones.

Aside from the sirenians now living, the skulls either in whole or in part are known for one extinct and at least 12 Tertiary genera. One of these genera appears to have had a rather wide geographic range during the Miocene and its geologic range as now understood extends from the Lower to the Upper Miocene. This is the genus Metaxytherium, a widely spread, migratory sirenian, for specimens referable to this genus have been found not only in Europe, but also in Florida, and with this discovery in California as well. This sirenian no doubt was fairly abundant in many parts of the world during that period, frequenting bays and the mouths of rivers, and feeding upon the succulent aquatic vegetation of that time.

The molariform series of Metaxytherium consists of four or five teeth. Turning to this fossil skull, it is to be regretted that the rostrum and palate are missing. The fractures are fresh and indicate that portions at least of these structures were present when the skull was first discovered in the Celite quarry. The specimen was found by workmen who were unfamiliar with the importance of such objects, and the teeth, if present, were not saved when the specimen was removed from its resting place. Disregarding for the present the possibility that this sirenian may have been endentulous, it is sufficient to state that in all other features the skull is in entire agreement with skulls found in France which have been referred to Metaxytherium. The Miocene sirenians of the genus Metaxytherium differ from the extinct Hydrodamalis in their method of feeding in that they masticated their food, thus requiring molariform teeth, the functional use of the temporal and masseteric muscles, the enlargement of the coronoid process of the mandible, and the development of temporal ridges on the braincase. The surfaces of the molariform teeth are not so well adapted for grinding as some of the terrestrial ungulates, but they are suited for cutting aquatic vege- 
tation. The articulation of the jaw is so as to limit the process of mastication and would seem to indicate that the breaking up of the vegetable tissues was accomplished by up and down movements of the jaws rather than by any lateral or side to side movements. There may have been some movement in a fore-and-aft direction or even a slight rotary motion which would account for the worn teeth which have been discovered in Europe. Differences in the type of vegetation sought for as food would unquestionably be reflected in the degree of attrition exhibited by the molariform series at any given age. Judging from the worn molars of some of the species of Metaxytherium one would be led to conclude that their food consisted of aquatic vegetation which contained a certain amount of coarse fibers. Some of the Eocene sirenians possessed the typical Eutherian dentition. Since the trend of evolution as exhibited by the fossil species has been toward the loss of the anterior teeth and reduction of the molariform series from in front and from behind. This process reached its culmination in the edentulous Hydrodamalis stelleri.

The skeletons of many of the Tertiary sirenians have never been discovered; composite skeletons have been assembled for some and in a few instances fairly complete specimens have been found. Deperet's observations would indicate that sufficient material has been assembled to furnish the size of at least four of the European sirenians, the total lengths of which he estimates as follows: the Stampian Halitherium schinzi, 8 feet 5 inches; the Vindobonian Metaxytherium cuvieri, 10 feet 5 inches; the Pontian Miosiren kocki, 11 feet 6 inches; and the Plaisancian Felsinotherium serresii, 8 feet. The sirenian found in California appears to have been considerably larger than any of the above mentioned species. A reasonable estimate of the total length of the skeleton would be about 15 feet. Estimates for the skeleton of the Holocene sirenian Hydrodamalis stelleri, which became extinct about 1768 according to Stejneger, vary considerably, the lengths given ranging from 26 to 34 feet.

Turning to Miosiren kocki from the Upper Miocene of Belgium, the detailed description of which has not been published as yet by Dollo, one may infer from published statements that it does not resemble the sirenian found in California. The enlargement of the posterior portion of the braincase, the reduction or absence of temporal crests, and the rounded appearance of the top of the cranium of Miosiren kocki suggest a relationship with Hydrodamalis rather than with Metaxytherium. As regards the contour of the cranium and development of the temporal crests, the lengthening of the pre-maxilla, the outlines of the mesorostral fossa, and the shape of the mandible, the Pliocene Felsinotherium resembles the Miocene Metaxytherium. In view of this resemblance, comparisons with Metaxytherium and Felsinotherium will be made in the following description. 
During the latter part of the Miocene period, sirenians frequented the Atlantic Coast of North America at least as far north as the Chesapeake Bay. In the light of the recorded material it is not possible to state whether or not the genus Metaxytherium is represented in all of the following occurrences. Case ${ }^{1}$ records the occurrence of a fused radius and ulna, and a rib fragment at Fairhaven, Maryland, in the Calvert formation. A fifth cervical vertebra from the same formation has been discussed by William Palmer, ${ }^{2}$ but his view that it was redeposited from an earlier, possibly Eocene, formation does not appear plausible. A fragment of a premaxillary bone with a tusk-like incisor in place from the phosphate beds of the Wando River, northeast of Charleston, South Carolina, in 1883 was described by $\mathrm{Cope}^{3}$ as Dioplotherium manigaulti. According to Cope, two pair of tusk-like incisor teeth were present in each premaxilla, whereas only one pair has been observed in Metaxytherium. This interpretation is probably incorrect. The type specimen, which was loaned to the writer by the authorities of the Charleston Museum, agrees in all essential details with a portion of the rostrum of another individual from the same formation in the collection of Yale University. The premaxilla of this specimen is broken off near the extremity. A single large tusk, measuring $49.5 \mathrm{~mm}$. by $25.5 \mathrm{~mm}$. in cross-section, is present in the premaxilla. There is no indication of an alveolus for a second incisor. Therefore until this animal can be shown to differ from Metaxytherium it seems advisable to refer Cope's species to that genus. More recently remains of Metaxytherium floridanum ${ }^{4}$ have been discovered at several localities in Florida in the land-pebble phosphate deposits.

Some of the most notable anatomical features of the sirenian found at Lompoc are the large size of the skull and vertebrae, the position of the nasal bones, the structural peculiarities of the olfactory bones, and the type of brain as revealed by an endocranial cast.

\section{Metaxytherium jordani, new species.}

Type specimen.-Cat. No. 10, Museum, Stanford University. The material includes an incomplete skull lacking the rostrum, zygomatic arches, and basicranium, as well as four dorsal vertebrae, the proximal ends of two ribs and fragments of four others, and one metacarpal.

Type locality.-The Celite Company's No. 5 Quarry, 600 feet north from northwest corner of the NE. $1 / 4$ of Section 22, Township 6 North, Range 34 West, San

1 E. C. Case, Miocene text. Maryland Geol. Surv., Baltimore, pp. 56-58; Atlas, pl. 26, fig. 1. 1904.

W. Palmer, The fossil sea cow of Maryland, Science, new ser., vol. 45, p. 334, 1917.

E. D. Cope, On a new extinct genus of Sirenia from South Carolina. Proc. Acad. Nat. Sci. Philadelphia, pp. 52-54, 1883; The extinct Sirenia, Amer. Nat., vol. 24, No. 284, p. 698, pl. 25, figs. $1-5,1890$.

1 O. P. Hay, Description of a new fossil sea cow from Florida, Metaxytherium floridanum, Proc. U. S. Nat. Mus., vol. 61, Publ. 2438, pp. 1-4, pl. 1, May 3, 1922; G. M. Allen, Additional remains of the fossil dugong of Florida, Journ. of Mammalogy, vol. 4, No. 4, pp. 231-239, pl. 26, with 1 text fig., Nov. 1923. 
Bernardino Base and Meridian, 2.5 miles south and east of Lompoc, Santa Barbara County, California.

Horizon.-This specimen was first discovered by workmen quarrying diatomaceous earth. Mr. Edward B. Starr, superintendent of the Celite Products Company, communicated the discovery to Dr. David Starr Jordan and arrangements were completed for Mr. Eric Knight Jordan to visit the locality in May 1924, and collect the material for Stanford University. This deposit of diatomaceous earth has a total thickness of 1,400 feet near Lompoc. The sirenian remains were taken from a stratum within 300 feet of the top of the deposit, that is at least 1,100 feet above the base. Sarmatian, or Upper Miocene.

The following analysis of the matrix which enveloped the vertebrae and ribs has been furnished by Mr. Earl V. Shannon, Assistant Curator of Geology, United States National Museum.

"The analysis of the specimen submitted indicates that it is unquestionably opal. This is probably a percolating water deposit. The banding is possibly in part inherited from the parent diatomaceous earth or, more probably, is diffusion banding similar to that characteristic of many deposits of opal or agate. The variation in color is due more to varying texture than to differences in composition and is similar to the variation in many specimens of opalized wood. Under the microscope the material is entirely isotropic with the exception of a few obscure bands of feeble birefringence and a chalceodonic fibrous structure. The average index of refraction is about 1.440 although different layers vary from 1.435 to 1.445. A partial analysis on the material gave the following results:

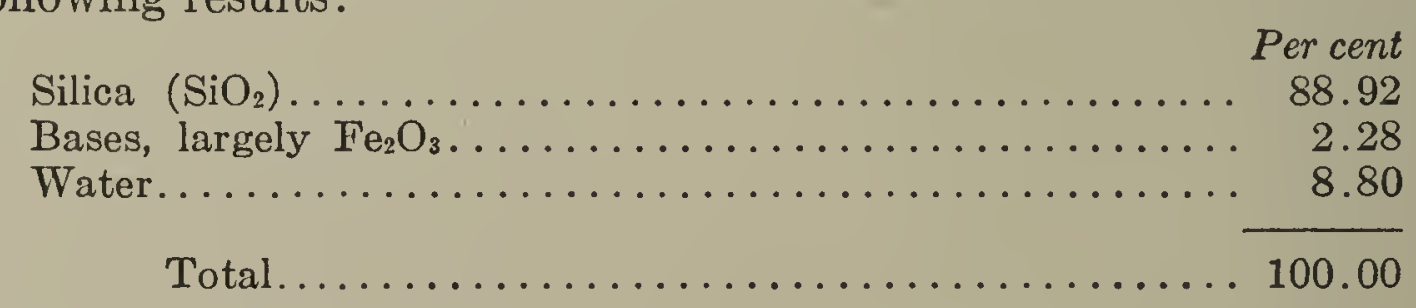

"The hardness of the material is slightly above 5.0; luster waxy; and fracture imperfectly conchoidal. This evidence conclusively proves that the material is not a glassy volcanic rock."

Additional information regarding the deposits of diatomaceous earth just south of Lompoc in the foothills of the Santa Ynez Range, east of the canyon of San Miguelito Creek, will be found in a report by Arnold and Anderson. ${ }^{1}$

\section{SKULl.}

One of the characteristic features of a sirenian skull is the position and shape of the fossa formed by the bones bordering upon the external nasal apertures. Taken together, the nasal passages terminate in a deep meso-rostral fossa which varies in size and shape in the several forms now known. In one Miocene form, Rytiodus capgrand $i,{ }^{2}$ it is considerably longer than wide; in others there is a more evident widening of the meso-rostral fossa. The meso-rostral fossa, in all forms thus far described, is closed anteriorly by the approximation of the premaxillae and extends backward to a point behind the orbits. Practically all of the rostrum of the fossil sirenian skull hereinafter described is missing. The left premaxilla is broken off at a point corresponding to the level of the antorbital notches. A small fragment of the left maxilla is applied to its outer border. Hence the contour of the anterior portion of the mesorostral fossa of this skull is unknown. Judging from the relations of the bones which

1 R. Arnold and R. Anderson, Contributions to Economic Geology 1906; Diatomaceous deposits of northern Santa Barbara County, Cal., Bull. No. 315, U. S. Geol. Surv., p. 440. 1907.

${ }^{2}$ E. Lartet, Note sur deux nouveaux Siréniens fossiles des terrains tertiaires du basin de la Garonne, Bull. Soc. Géol. de France, Paris, ser. 2, tome 23, pp. 673-686, pl. 13, 1866; E. Delfortrie, Découverte d'un Squelette entier de Rytiodus dans le falun Aquitanien, Actes Soc. Linn. de Bordeaux, ser. 4, tome 4, pp. 131-144, pls. 5-8. 1880. 
bound the posterior portion of this fossa, it would appear that it bore some resemblance to that of Felsinotherium serresii. ${ }^{1}$

In the sirenian skulls thus far described, the premaxillae form the greater part of the downwardly directed rostrum; the suture between these bones and the maxillae may be said to commence near the posterior border of the incisive foramina and, after crossing the alveolar border, runs first upward and backward, then nearly backward on the side of the rostrum, terminating at the level of the anterior border of the postorbital processes of the frontals. At the level of the antorbital notch, the facial process of the premaxilla is deflected obliquely inward in this Californian sirenian and is applied externally to the postorbital process of the frontal, with its extremity terminating slightly in front of the posterior border of the meso-rostral fossa. Here, it is suturally united with the nasal and inferiorly abuts against the frontal, thus excluding the maxilla from any share in the superior border of the meso-rostral fossa.

As will be seen from the illustration ( $\mathrm{pl} .10$ ), this cranial fragment exhibits a general resemblance to the corresponding portion of the skull of Hydrodamalis stelleri. In size, the specimen agrees very closely with a skull (Cat. No. 218, 326 U. S. Nat. Mus.) of Steller's sea-cow from Bering Island. Nevertheless, it is very unlikely that this sirenian possesses any close relationship with Hydrodamalis. In the first place, the nasals overspread the frontals on this fossil skull, the parietals and frontals are about equal in length on the top of the cranium, but the olfactory chamber is relatively short. In the Hydrodamalis skull, the nasals are applied to the ventral surfaces of the frontals on the roof and sides of the olfactory chamber, the parietals and frontals likewise are about equal in length on the top of the cranium, but the olfactory chamber is relatively long. Secondly, the premaxillae are in contact with the nasals in both sirenians. Furthermore, the facial processes of the premaxillae retain the same position and relations with the postorbital processes of the frontals and the meso-rostral fossa in both species. Without some alteration or shifting in the position of the bones involved, and there appears to be no such possibility in the types under consideration, it would appear difficult to account for such a migration of the nasal bones," Such a change in the position of the nasal bones appear's unlikely, especially since the component bones of the cranium of these sirenians are essentially the same both in size and in position. To postulate the hypothesis that the edentulous Hydrodamalis is a derivative of this type of sirenian, it will be necessary to account for the shifting of the nasals from a position on top of the frontals to one immediately below and within the olfactory chamber. Following such a line of reasoning it would be necessary to assume that inasmuch as the nasal was already mortised into the dorsal surface of the frontal in these Miocene sirenian skulls, in the course of time the thin edges of the frontal would gradually overspread the nasal until it was no longer visible on the dorsal surface of the cranium. To account for its present condition within the olfactory chamber in the Hydrodamalis skull it would be necessary to assume further that the portion of the frontal which underlies the nasal in Metaxytherium or its allies was correspondingly reduced and finally receded, leaving the nasal appressed to the ventral surface of the frontal. Some support may be given to this line of reasoning by the fact that a fissure had appeared in the underlying frontal in one of the cranial fragments of Felsinotherium serresii ${ }^{2}$ found at Montpellier, France, exposing the ventral face of the nasal in the roof of the olfactory chamber. Another explanation would be that the facial process of the premaxilla receded from the posterior border of the meso-rostral fossa in some stage unknown to us at present, carrying the nasal forward with it. Then after the

${ }^{1}$ P. Gervais, Zoologie et Paléontologie françaises, Paris, ed. 2, Atlas, pl. 6, fig. 3, 1859; C. Deperet, Sur la reconstitution d'un squelette de Felsinotherium Serresi, Sirénien pliocène des sables de Montpellier, Comptes Rendus Acad. Sci. Paris, tome 158, No. 25, pp. 1858-1862, text fig., 1914; C. Deperet and F. Roman, Le Felsinotherium serresi des sables pliocènes de Montpellier et les rameaux phylétiques des siréniens fossiles de l'ancien Monde, Archiv. du Mus. d'hist. nat. Lyon, tome 12 , Mem. 4, pp. 1-56, pls. 1-7, text figs. 1-14, 1920.

2 P. Gervais, Zoologie et Paléontologie françaises, Paris, ed. 2, Atlas, pl.4, figs. 1', 1,"' 1859. 
nasal had migrated forward and dropped to a lower level, the facial process of the premaxilla by further telescoping of the rostral and cranial portions of the skull was again carried backward to the posterior border of the meso-rostral fossa and this in turn forced the nasal backward within the olfactory chamber. For purely mechanical reasons, such an explanation is insufficient, because in so large a skull as that of Hydrodamalis, the interlocking of the rostral and facial portions of the skull would be greatly weakened by a recession of the facial process of the premaxilla. At the same time, it should be noted that the facial process of the premaxilla has receded or at least does not extent backward as far as the hinder border of the meso-rostral fossa in some of the living genera, but it should also be noted that the skulls of these sirenians are relatively small. Neither of the above explanations appear plausible in the light of available data and additional fossil types will be necessary to demonstrate the modifications which have resulted in the Hydrodamalis type of skull.

As shown in the figures of the skull of Hydrodamalis stelleri given by Brandt, ${ }^{1}$ thin plates of the maxillae meet mesially in a linear suture and form the floor of the mesorostral fossa. Laterally, each maxilla is limited in its dorsal extension by the overlying premaxilla. On the sides, the premaxillae bound the meso-rostral fossa superiorly and constitute most of the lateral margins of the rostrum as well as the entire extremity. Posteriorly on the floor of the fossa, a narrow trough-like vomer is exposed, but it does not extend forward to the level of the antorbital notches. No vomer is shown in the figure of a skull of $F$ elsinotherium serresii given by Gervais. These inferior portions of the maxillae as well as the vomer are not preserved on this specimen from California.

With the exception of the nasals, the relations and general appearance of the various elements which comprise the structures within the olfactory chamber of this fossil sirenian skull (pl. 10) are essentially the same as those found in the Hydrodamalis skull. This olfactory chamber lies above the nasal passages as in the latter species. On each side of the olfactory chamber, a thin hook-shaped nasoturbinal is appressed to the upper border of the lateral wall. The left nasoturbinal is approximately $108 \mathrm{~mm}$. long and $53 \mathrm{~mm}$. deep at the extremity. At the level of the anterior margin of the nasal, this nasoturbinal is $20 \mathrm{~mm}$. deep and its maximum width in this region is 10.2 $\mathrm{mm}$.; the extremity or processus hamatus exhibits a dorso-ventral groove and is somewhat rugose. The perpendicular plate of the mesethmoid occupies a sagittal position in the olfactory chamber and divides the latter into two cavities, each of which contains a turbinated bone-the ethmoturbinal - with at least three folds; posteriorly this perpendicular septum merges into the transversely placed cribriform plate which closes the frontal fontanelle. In its present imperfect condition, the anterior extremity of the mesethmoid measures $50 \mathrm{~mm}$. in depth and $8 \mathrm{~mm}$. in width in the most expanded portion. It terminates some $36 \mathrm{~mm}$. below the roof of the olfactory chamber. Originally, the mesethmoid may have extended further forward. As seen from a frontal view, the mesethmoid in the Hydrodamalis skull is expanded between the level of the inferior borders of the ethmoturbinals and the nasal passages, but is relatively narrow above and below this swelling. Superiorly, it terminates $20 \mathrm{~mm}$. below the roof of the olfactory chamber; the dorso-ventral diameter of the mesethmoid is $93 \mathrm{~mm}$. at the extremity and its greatest width is $23 \mathrm{~mm}$. In so far as can be determined from the extremities and the other fragments of the ethmoturbinals which are preserved, they resemble those of Hydrodamalis. Their maximum length appears to have been about $60 \mathrm{~mm}$. The crista galli measures $60 \mathrm{~mm}$. in depth and $21.5 \mathrm{~mm}$. in width. It resembles that of Trichechus in that it is swollen inferiorly and narrowed superiorly. In the Hydrodamalis skull the crista galli does not appear to be developed and if present is merely a flat structure which does not project posteriorly beyond the level of the cribriform plate. In Metaxytherium jordani it projects approximately $35 \mathrm{~mm}$. beyond the cribriform plate. The bones which contribute the walls for the nasal passages are for

${ }^{1}$ J. F. Brandt, Symbolae Sirenologicae, Fasciculus II et III, Mem. Acad. Imp. Sci. de St Petersbourg, ser. 7, tome 12, No. 1, pl. 1, May, 1868. 
the most part missing; the pair of thin bones known as the lamina terminalis of the ethmoid which form the roof above the nasal passages are incomplete.

In general outlines, the braincase of this fossil sirenian agrees very closely with that of Felsinotherium serresii. Comparative measurements indicate that the ratio between the lengths of the corresponding portions of the skull of this sirenian and that of Felsinotherium serresii is as $6: 5$. The anterior part of the roof of the cranium is formed by the frontals. Above the olfactory chamber, the anterior borders of the frontals are overlain by the comparatively large nasals, between which a narrow strip of each bone is exposed which extends forward to the meso-rostral fossa, thus completely separating the nasals in the middle line. Outside the nasals, the postorbital processes of the frontals are in contact with the facial processes of the premaxillae, which in turn define the borders of the meso-rostral fossa. Along the mid-line, from before backward, the dorsal surface of the skull is elevated between the nasals, depressed on each side in the intertemporal region, and set off from the sides of the braincase by well-defined temporal ridges. These temporal ridges extend backward as far as the occiput and disappear anteriorly on the postorbital processes of the frontals.

In front of the lambdoidal crest the roof of the cranium formed by the parietals is slightly convex both from side to side and from before backward. In front of these bones the surface is slightly depressed below the somewhat prominent temporal ridges which form the angles between the roof and the nearly vertical sides of the temporal fossae. Along the median line, as mentioned above, the surface in the intertemporal region is elevated, but laterally there are longitudinal depressions which parallel the temporal ridges. The narrowest part of the skull roof is about $60 \mathrm{~mm}$. in front of the lambdoidal crest; at this point the width is $72 \mathrm{~mm}$., but behind this the roof widens slightly to its posterior border, where it measures approximately $105 \mathrm{~mm}$. across. Anteriorly it attains a greater width, and at the level of the antero-mesial portions of the frontals it is $138 \mathrm{~mm}$. wide. The sides of the cranium immediately in front of the supraoccipital slope to the base of the zygomatic processes, but further forward are nearly flat and, as already remarked, almost vertical; in the latter region the walls of the cranium are somewhat thinner than in the middle of the skull roof where the parietals attain a thickness of $27 \mathrm{~mm}$. or more.

The margins of the left nasal are so smoothly mortised into the corresponding frontal, that its presence was not noted until the skull was thoroughly cleaned in preparation for illustration. In position the left nasal agrees more closely with that of Metaxytherium cuvieri ${ }^{1}$ than with Felsinotherium serresii. In the latter, the nasals are almost in contact on the mid-line of the skull, concealing the antero-mesial portions of the frontals, while in Metaxytherium cuvieri the nasals are separated by an interval equivalent to the maximum width of either nasal. This interval may possibly decrease with age. The width of the exposed antero-mesial portion of the left frontal on this skull from California is slightly less than one-half of the maximum width of the left nasal. The greatest antero-posterior diameter of the left nasal is $47 \mathrm{~mm}$. and transversely it measures $28.5 \mathrm{~mm}$. It is somewhat thinner posteriorly, but measures at least 12.5 $\mathrm{mm}$. in depth laterally near the anterior margin. Internally, there is a distinct line of cleavage between the nasal and the frontal, but posteriorly and laterally it is overridden by the thin edge of the frontal and in places appears to be irregularly fused with the latter. Anteriorly, about $15 \mathrm{~mm}$. of the internal margin of the nasal appears on the upper rim of the meso-rostral fossa between the frontal and the premaxilla. Antero-externally, an oblique suture defines the contact between the nasal and the extremity of the premaxilla.

On the top of the braincase, each frontal is relatively narrow (about $60 \mathrm{~mm}$.) and extends backward from the meso-rostral fossa to the middle of the cerebral fossa. Anteriorly, the frontals form a roof above a relatively short olfactory chamber as com-

H. M. D. Blainville, Ostéographie ou description iconographique, Paris, fasc. 15, pp.13, 138139. Atlas, pl. 8, No. 1, 1843. 
pared to that of Hydrodamalis and are applied inferiorly to the upper and lateral edges of the proximal ends of the nasoturbinals. Their anterolateral extensions, the postorbital processes, are produced forward in an oblique direction. The postorbital processes of the frontals are robust as in Hydrodamalis, but are triconvex at the extremity, the mesial swelling being more than three times as large as either of the other two. The orbits apparently were anterior to the postorbital processes of the frontals, although this can not be determined with certainty because the jugal and that portion of the maxilla which form the lower rim of the orbit are missing. This is the position of the orbit in Hydrodamalis stelleri and Felsinotherium serresii. Each frontal is overspread posteriorly by a thin process of the corresponding parietal. The shape of the suture is shown on plate 10. The parietals and squamosals contribute the major portion of the upper and lateral walls of the braincase. The longest antero-posterior diameter of either parietal $(171 \mathrm{~mm}$.) is along the temporal ridge, as they are separated anteriorly and mesially by the frontals. Posteriorly, the parietals abut against the upper margin of the supraoccipital. The left squamosal with its lateral process is missing. The right squamosal is imperfectly preserved and all of the zygomatic process has been lost. For the purposes of comparison, the description of the external boundaries of the squamosal may start at the anterior margin of the tympano-periotic recess where the squamosal meets the alisphenoid edge to edge as far forward as the posterior margin of the temporal fossa and, after overlapping the hinder margin of the alisphenoid to its upper extremity on the side of the cranium, turns sharply backward and overspreads the parietal, with the suture running upward in a general oblique direction to the lambdoidal crest; the suture which defines the posterior limits extends downward between the squamosal in front and the supraoccipital and exoccipital on the rear to the tympano-periotic recess.

On comparing Trichechus latirostris and Felsinotherium serresii with this fossil, certain features in the supraoccipital shield were found to be common to all three. The apical portion alone of the occipital shield is preserved on this cranium from California and this fragment measures $65 \mathrm{~mm}$. in depth. With regard to the occipital shield, it is unfortunate that the inferior portions, including the exoccipitals and condyles, are missing from the skull of this fossil sirenian. In so far as the occipital shield is shown on skulls of Metaxytherium, there is no close resemblance to the condition of the shield in Hydrodamalis. The lambdoidal crest formed by the upper margins of the supraoccipital resembles that of Trichechus. There is a narrow median carina, $10 \mathrm{~mm}$. in width, on the apical portion of the supraoccipital and on each side there is a small concavity. Below the level of the top of the braincase, the course of the lambdoidal crest can not be determined for the posterior extremities of both squamosals are damaged. In Trichechus the lambdoidal crest passes downward across the squamosal and behind this crest a portion of the periotic makes its appearance on the lateral face of the cranium in a fontanelle between the squamosal and exoccipital.

The cerebral cavity is similar to that of Trichechus in most respects, but differs in some minor details. In shape, it is rather elongated, laterally compressed, truncated anteriorly by the frontals which constitute the rostral wall of the braincase and posteriorly by the supraoccipital. From an inferior view, it will be noted that the posterior extremities of the parietals taken together form a narrow transverse shelf at a level about $26 \mathrm{~mm}$. below the roof of the cerebral fossa. Turning to the roof of the fossa for each cerebral hemisphere, we find that the parietal constitutes a somewhat larger area than the frontal, although as regards length these two elements are about equal. The longitudinal median carina which separates the temporal lobes of the cerebrum does not extend forward to the crista galli as in Trichechus, but flattens out at a point approximately $15 \mathrm{~mm}$. posterior to the suture between the parietals and frontals. Along the suture between the frontals there is a median longitudinal depression and on each side of this there is a curved ridge. In Trichechus, the part of the 
roof contributed by the parietals is much shorter than that contributed by the frontals.

The endocranial cast (pl. 9) here discussed is not complete for the lower occipital region and basicranium of this skull were missing. It is of considerable interest because it is not unlike that of Trichechus latirostris ${ }^{1}$ and the Upper Eocene Eotheroides aegyptiacum, ${ }^{2}$ but the proportions of the frontal and temporal lobes of the cerebrum are somewhat different from Hydrodamalis stelleri. ${ }^{3}$ It is unlikely that such striking similarities would exist in the absence of some close relationship between Metaxytherium and Trichechus. A cast of the entire cranial cavity of a Metaxytherium skull will of necessity be needed to demonstrate or disprove any filial relationship.

All comparisons will be limited to features observable from a dorsal view. It is to be noted that the small olfactory lobes are attached anteriorly in a nipple-like fashion to the frontal lobes of the cerebrum. The cerebral hemispheres are set off from one another sagittally by a narrow elevation anteriorly and by a sinus posteriorly. Each is divided into an expanded frontal lobe and an elongate temporal lobe by a lateral depression which increases in depth inferiorly. This appears to be the pseudosylvian depression. The breadth of the right frontal lobe of the cerebrum is 49 $\mathrm{mm}$. and the maximum length of the entire right hemisphere is $122 \mathrm{~mm}$. Behind and below the sagittal sinus, there appears a median tentorial depression. The cerebellum is relatively small, but its posterior limits can not be determined with certainty.

Behind the palate in skulls of Trichechus and Hydrodamalis and on each side of the posterior aperture of the nasal passages, there is a rough irregular descending process formed by the fusion of the palatine, pterygoid, and the pterygoid plate of the alisphenoid. On this fossil skull the pterygoid processes of the alisphenoid have been broken off at the base. At this level, the left process measures $64 \mathrm{~mm}$. in length. As a result of the above-mentioned breakage, the basisphenoid was also lost, exposing the entire course of the foramen rotundum. The groove for the foramen rotundum commences at a point about $20 \mathrm{~mm}$. in front of the posterior margin of the pterygoid process of the alisphenoid and curving around the base of that process is continued forward to its ectal orifice within the temporal fossa. This foramen is bounded externally, superiorly, and inferiorly by the alisphenoid, and internally by the orbitosphenoid, paralleling the condition found in the Trichechus skull. In so far as this specimen is preserved, the fissures and foramina within the temporal fossae do not appear to differ from those found in the Trichechus skull.

On the basis of measurements, the periotic of Hydrodamalis is about one-eighth larger than that of this fossil sirenian. The tympanic ring is missing, but in so far as the left periotic is preserved it resembles that of Hydrodamalis very closely. The anterior and posterior processes are heavy and rounded. The cochlear portion of the periotic is missing, but the interior margins of the fenestra rotundum and fenestra ovalis are present. These fenestrae were similar in position to those of Hydrodamalis. Instead of the aquaeductus vestibuli opening into a fissure in a large depression as in Hydrodamalis, the depression lies above the orifice of the aquaeduct. The stapes resembles that of Trichechus more closely than that of Hydrodamalis. It measures $14.8 \mathrm{~mm}$. in length and the perforation is situated $4.4 \mathrm{~mm}$. above the footplate. The malleus and incus are damaged, but exhibit the characteristic sirenian structural peculiarities.

1 J. F. Brandt, Symbolae Sirenologicae, Fasciculus II et III. Mém. Acad. Imp. Sci. de St.Petersbourg, ser. 7, tome 12, No. 1, pl. 9. fig. 1, 1868.

2 O. Abel, Die eocänen Sirenen der Mittelmeerregion, Palaeontographica, Stuttgart, Bd. 59, Lief. 5-6, pl. 33, fig. 4, 1913.

3. F. Brandt, op. cit., pl. 9. fig. 3. 
Measurements of the skull.

\begin{tabular}{|c|c|c|}
\hline & $\begin{array}{c}\text { Metaxytherium } \\
\text { jordani Lompoc, } \\
\text { California Cat. } \\
\text { No. 10, Stanford } \\
\text { University. }\end{array}$ & $\begin{array}{c}\text { Hydrodamalis } \\
\text { stelleri Bering } \\
\text { Island Cat. } \\
\text { No. 218326, } \\
\text { U. S. N. M. }\end{array}$ \\
\hline Condylobasal length of skull. & $m m$. & $m m$. \\
\hline $\begin{array}{l}\text { Left condyle to extremity of left postorbital process of } \\
\text { frontal } \ldots \ldots \ldots \ldots \ldots \ldots \ldots \ldots \ldots \ldots\end{array}$ & & \\
\hline 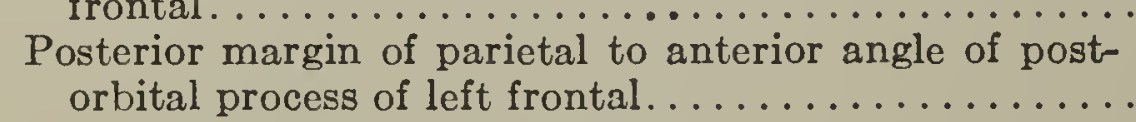 & 316 & 312 \\
\hline Breadth across combined parietals................. & 101 & 138 \\
\hline $\begin{array}{l}\text { Breadth across combined frontals (least intertemporal } \\
\text { breadth) } \ldots \ldots \ldots \ldots \ldots \ldots \ldots \ldots \ldots\end{array}$ & 122 & 95 \\
\hline $\begin{array}{l}\text { Breadth across extremities of postorbital processes of } \\
\text { frontals } \ldots \ldots \ldots \ldots \ldots \ldots \ldots \ldots \ldots \ldots \ldots \ldots \ldots \ldots \\
\end{array}$ & 1198 & \\
\hline Length of left premaxilla............................ & $\mathrm{x}$ & 372 \\
\hline $\begin{array}{l}\text { Greatest transverse diameter of dorsal border of pre- } \\
\text { maxilla along meso-rostral fossa } \ldots \ldots \ldots \ldots \ldots\end{array}$ & 49 & \\
\hline Length of meso-rostral fossa........... & $\mathrm{x}$ & 237 \\
\hline Greatest breadth of meso-rostral fossa. & 172 & 95 \\
\hline Greatest zygomatic breadth. . & $\mathrm{x}$ & 317 \\
\hline Length of zygomatic process of right squamosal. & $\mathbf{x}$ & 180.5 \\
\hline Greatest width of skull across arches below orbits.. & $\mathbf{x}$ & 262 \\
\hline $\begin{array}{l}\text { Posterior margin of zygomatic process to anterior } \\
\text { margin of jugal in rim of orbit............ }\end{array}$ & $\mathbf{x}$ & 285 \\
\hline 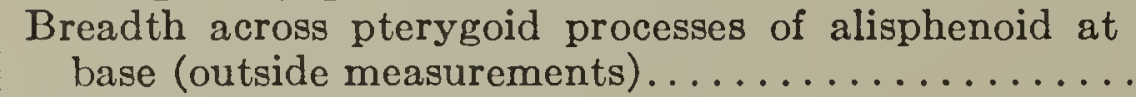 & 118 & 108 \\
\hline Antero-posterior diameter of right parietal. . & 164 & 165.5 \\
\hline
\end{tabular}

${ }^{2}$ Estimated.

Dorsal Vertebrae.

The large number of dorsal vertebrae and the heavy ribs which they support increase the weight of the sirenian skeleton. Dollo has even supposed that these enlarged ribs protected the vital organs against some unknown enemies. According to Abel, a skeleton of Metaxytherium comprises 7 cervical, 19 dorsal, 3 (?) lumbar, and 25 (?) caudal vertebrae. Dr. Zoltan Schreter $^{1}$ has also discussed the skeleton of Metaxytherium, but the writer has been unable to consult this paper. Deperet states that the skeleton of Felsinotherium serresii consists of 7 cervicals, 19 dorsals, 3 lumbars, 1 sacral, and 25 (?) caudal vertebrae. Only four of the dorsal vertebrae of this sirenian are known. Three of these vertebrae were found embedded in their normal position in an irregular mass of opal. The remaining dorsal vertebrae was freed from another block of matrix. The last dorsal in the above-mentioned series lacks the posterior end of the centrum. The exposed surface is weathered and black in color which suggests that the fracture is very old. Some of the skeleton was undoubtedly lost subsequent to the discovery for no contact could be obtained between the several masses of matrix which were included in the shipment.

Although there is some regional differentiation of the dorsal vertebrae in living sirenians, such as the contour and length of the centra, the invariable occurrence of a single facet for the head of the rib on the posterior dorsals and the presence of a pair of demi-facets on the anterior dorsals, allocations made on this basis are always attended with some uncertainty. The centra of the first three dorsals are usually compressed in a dorso-ventral direction. The centra of these vertebrae are also consider-

${ }^{1}$ Z. Schreter, Mediterranes Metaxytherium Skelett, v. Marcyfalva, Földt, Közlöny, Budapest, Bd. 47 , pp. 176-177. 1917. 
ably smaller than those that follow, and a line drawn through the centers of the facets for the tubercula would slope downward and forward from the fifth to the first dorsal. From this point backward, the centra assume a heart-shaped outline, and near the middle of the series a hyapophysis is developed on the inferior face. The centra of the dorsal vertebrae also increase in length from the first to the last.

There appears to be no correlation between the total number of vertebrae in the dorsal series and the number which bear demi-facets for heads of ribs. No differences in the manner of the insertion of the ribs on the dorsal series are apparent, yet the ratios between the dorsals bearing demi-facets and those with single facets in the genera hereinafter mentioned reveal some interesting anatomical details. The skeleton of the Miocene sirenian, Miosiren kocki, ${ }^{1}$ contained 20 dorsals, of which 17 had demifacets and 3 single facets. On the other hand, the Oligocene sirenian, Halitherium schinzi, ${ }^{2}$ had only 19 dorsals, and of these 12 possessed demi-facets. The Pliocene Felsinotherium serresii also had 19 dorsals, but only 9 of these possessed demi-facets. Turning to the recent sirenians, we find that Halicore australis and Hydrodamalis stelleri have 19 dorsals, but only 7 of these have demi-facets. Yet in the case of Trichechus latirostris which has only 18 dorsals, there are 13 with demi-facets.

The isolated dorsal appears to be the fourth. The three which were found associated together belong in the column somewhere between the sixth and ninth and there appears to be some justification for referring to them as the sixth, seventh, and eighth dorsals. After comparing the recent types, it became apparent that within genera there were definite limits to the number of dorsal vertebrae bearing a hyapophysis and whereas a hyapophysis was present on the sixth dorsal of Trichechus latirostris, it did not appear in the skeleton of Hydrodamalis stelleri anterior to the eleventh dorsal. No indication of a hyapophysis is present on the centra of these dorsals and this may be cited as an additional reason for the above-mentioned allocations. The posterior dorsals of Metaxytherium krahuletzi do possess a hyapophysis. Aside from their larger size, these vertebrae do not differ structurally from those of Felsinotherium serresii. ${ }^{3} \quad$ They are also considerably larger than those of Metaxytherium cuvieri, ${ }^{4}$ Metaxytherium krahuletzi, ${ }^{5}$ and Metaxytherium floridanum.

The dorsal which is considered to be the fourth in the series, although strikingly different in proportions, presents the majority of the features which characterize the same vertebra of Trichechus latirostris. It was situated anterior to the others for the following reasons: the centrum is smaller and shallower; the anterior and posterior demi-facets on the lateral face of the centrum are nearly equal in size and are separated by an interval of less than $5 \mathrm{~mm}$.; the neural canal is higher; and the internal borders of the prezygapophysial facets are higher than the external. Compared with the same vertebra in a Hydrodamalis skeleton, the principal differences are as follows: the diapophyses are relatively shorter; the upper portions of the neural arches are thicker, more robust, and much shorter; and the lateral demi-facets are relatively larger.

Of the three remaining dorsals, the middle one is the most complete. This dorsal (pl. 11, fig. 2), which will be referred to as the seventh, is characterized by a broad heart-shaped centrum, a nearly circular neural canal with a slit-like apex, and by the presence of a pair of demi-facets, the anterior of which is the largest. The anterior demi-facet (pl. 11, fig. 5) extends upward from the level of the widest part of the

${ }^{1} \mathrm{~L}$. Dollo, Premiére note sur les Siréniens de Boom (Résumé), Proces-Verbaux Soc. Belge Géol. Paleont. et d'Hydrol., Bruxelles, tome 3, p. 418, 1889; C. Deperet and F. Roman, Archiv. du Mus. d'hist. nat. Lyon, tome 12, Mem. 4, text fig. 8, No. III, 1920.

${ }^{2}$ G. R. Lepsius, Halitherium schinzi, dic fossile Sirene des Mainzer Beckens, Abhandl.

Mittelrhein, geol. Vereins, Darmstadt, Bd. 1, Lief. $1-2$, pp. $4+200+$ viii, pls. $1-10,1881-1882$.

${ }^{3}$ C. Deperet and F. Roman, Le Felsinotherium serresi des sables pliocènes de Montpellier et les rameaux phylétiques des siréniens fossiles de l'ancien Monde, Archiv. du Mus. d'hist. nat. Lyon, tome 12, Mem. 4, pp. 14-16, pl. 6. 1920.

${ }^{4}$ H. M. D. Blainville, Ostéographie ou description iconographique, Paris, fasc. 15, pl. 8, 1843.

$\checkmark$ O. Abel, Die Sirenen der mediterranen Tertiärbildungen Österreichs, Abhandl. k. k. geol. Reichsanstalt, Bd. 19, Heft 2, pp. 91-93, pl. 6, figs. 2-4, 1904. 
centrum almost to the level of the top of the neural canal. This facet is concave and is twisted slightly from the antero-inferior angle to the postero-superior angle. It is elliptical in outline and measures $60 \mathrm{~mm}$. in depth and 31.5 in breadth. Inferiorly, the posterior demi-facet also reaches the widest point of the centrum and extends superiorly above the level of the top of the centrum, giving rise to a postero-lateral protuberance. The facet is obliquely placed on this protuberance and measures 36 $\mathrm{mm}$. in depth and $23 \mathrm{~mm}$. in breadth. An interval of $30 \mathrm{~mm}$. separates the two facets. The margins of both demi-facets are well defined. "The prezygapophysial facets are concave, curving upward and outward. The lateral and inferior faces of the centrum are concave. There is no trace of a hyapophysis. The neural arch is very heavy and on each side gives rise to a short lateral process, the diapophysis. The neurapophysis does not extend the full length of the centrum; the posterior border is curved and is separated from the posterior demi-facet by an interval greater than the maximum breadth of the latter. The neural spines are incomplete on all of the dorsals shown on plate 11, but the extremities of two additional spines were found in another piece of matrix. These extremities are expanded laterally and flattened superiorly. The spines are inclined backward on all four of the dorsal vertebrae.

The sixth (pl. 11, fig. 1) and eighth dorsals (pl. 11, fg. 3) are very similar in appearance to the seventh. The most apparent differences are in the lengths of the centra and in the curvature of the prezygapophysial facets. There is little difference in the sixth, seventh, and eighth dorsals (pl. 11) in the position and proportions of the demi-facets. The presence of these demi-facets shows that the articulation of the head of the rib was divided between two vertebrae. The prezygapophysial facets are somewhat flattened on the sixth dorsal, sloping outward and forward; the internal face of the metapophysis at the outer margin of this facet is excavated. The curvature of the prezygapophysial facets of this dorsal is in sharp contrast to the seventh and eighth on which the facets are concave from side to side and curve upward above the level of the top of the metapophysis. The interval between the inner borders of the prezygapophysial facets apparently increases from the fourth dorsal to the middle of the series, for it is much narrower on the fourth than on the eighth, the measurements for the four vertebrae being $22.5,27.5,33$., and $36.5 \mathrm{~mm}$. A similar condition is present in the skeleton of Trichechus latirostris where the interval between the prezygapophysial facets decreases from the first to the fifth dorsal, then increases to the fourteenth, and decreases slightly from this vertebra to the end of the series. Attention should also be directed to the groove which commences at the base of the neural spine and curves forward below the inner margin of each prezygapophysial facet on all of these dorsals. The metapophyses of the fourth, sixth, seventh, and eighth dorsals project beyond the level of the anterior epiphysis. The postzygapophysial facets of the sixth and seventh dorsals are elongate, quadrangular in outline, and slope obliquely upward from the internal to the external margin.

The anterior and posterior faces ( $\mathrm{pl} .11$ ) of the centra of these dorsal vertebrae are broadly heart-shaped in outline. The epiphyses appear to be thin, though complete and fully ossified. The condition of the epiphysis in the several species of Metaxytherium now known is an interesting subject, for there appears to be a tendency toward the reduction of the epiphyses in some of the species. In the case of Metaxytherium krahuletzi, according to Abel, the central part is thin and pitted, presenting an eroded appearance; the peripheral ring is solid and somewhat thicker. The vertebrae of Metaxytherium floridanum possess epiphyses of the same type. This is interpreted as a partial degeneration of the epiphysis and is also offered as a possible explanation of the condition of the epiphysis in the living genera Trichechus and Halicore. In the living Manatee, Trichechus, the epiphysis is reduced to a narrow and incomplete ring, while in Dugong, Halicore, it has disappeared entirely. On these four dorsal vertebrae, the central part of the epiphysis is depressed, but the pits are minute and indistinct; the peripheral border is marked by concentric rings and the margin is 
raised above the level of the centrum. These dorsal vertebrae differ from those of the above-mentioned species of Metaxytherium in that the epiphyses have not reached the same stage of reduction, although the former are considerably larger than those of the latter.

Measurements of the dorsal vertebrae in millimeters.

\begin{tabular}{|c|c|c|c|c|}
\hline & $\begin{array}{c}4 \text { th } \\
\text { Dorsal. }\end{array}$ & $\begin{array}{c}\text { 6th } \\
\text { Dorsal. }\end{array}$ & $\begin{array}{c}7 \text { th } \\
\text { Dorsal. }\end{array}$ & $\begin{array}{c}\text { 8th } \\
\text { Dorsal. }\end{array}$ \\
\hline 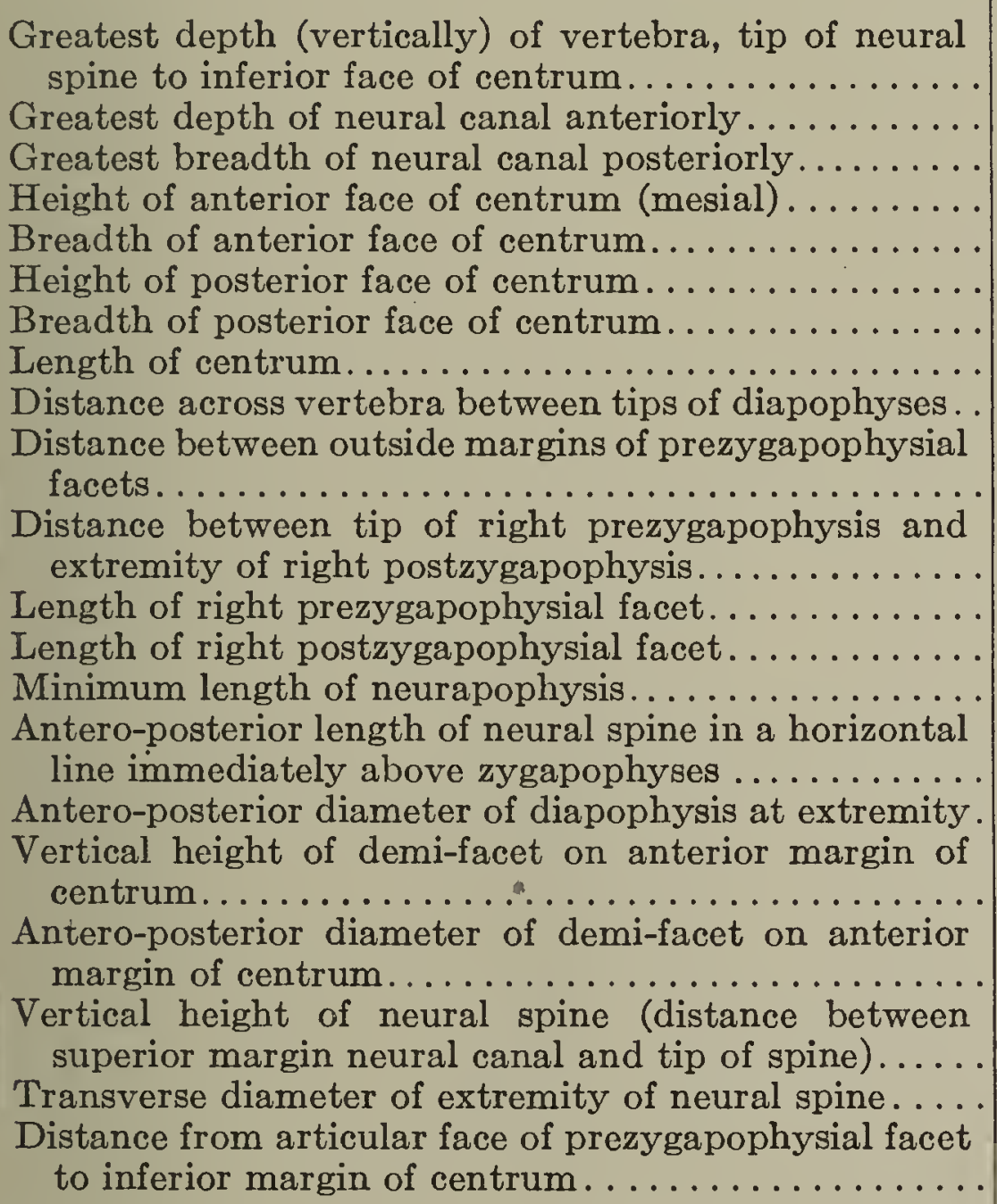 & $\begin{array}{c}199+ \\
55 \\
48.2 \\
64 \\
122 \\
62 \\
x \\
60.5 \\
x \\
81 \\
x \\
31.2 \\
x \\
38.2 \\
x \\
x \\
45.5 \\
30.5 \\
x \\
x \\
112\end{array}$ & $\begin{array}{c}211+ \\
49 \\
42.5 \\
70 \\
124 \\
71.5 \\
139 \\
70.5 \\
171+ \\
90 \\
107 \\
32.5 \\
35 \\
47 \\
71 \\
58 \pm \\
50 \\
\\
26 \\
x \\
x \\
126\end{array}$ & $\begin{array}{c}234.5+ \\
52.3 \\
44 \\
73 \\
134.4 \\
76.5 \\
142 \\
72 \\
173+ \\
82 \\
111 \\
34.5 \\
36.3 \\
53.2 \\
x \\
56 \pm \\
52.1 \\
30 \\
114+ \\
26.2 \\
129.3\end{array}$ & $\begin{array}{r}49 \\
45 \\
80 \\
138 \\
x \\
x \\
x \\
x \\
92 \\
x \\
33 \\
x \\
52.7 \\
x \\
45 \\
51.5 \\
x \\
x \\
x \\
136.5\end{array}$ \\
\hline
\end{tabular}

RIBS.

All of the ribs associated with this specimen are imperfect, but judging from the six fragments represented, they were about as highly specialized as those of Trichechus latirostris. The ribs of this sirenian were very robust; the shafts narrow abruptly near the tuberculum and their curvature is no more pronounced than in Trichechus. One of these fragments measures $67 \mathrm{~mm}$. in width and $43 \mathrm{~mm}$. in thickness below the neck. The proximal end of a left rib (pl. 11, fig. 10) is sufficiently well preserved to show the peculiarities of the tuberculum and capitulum. The capitulum consists of two articular facets separated superiorly by a narrow sinus. The anterior one of these facets is flattened; the posterior one is somewhat convex. They are placed obliquely on the sides and end of the neck, but do not extend inferiorly upon the broad ventral face of the same. The tuberculum is rounded and rolls over upon the side of the neck. The shafts of these ribs appear to be irregularly swollen below the tuberculum, but the contour of the inferior portions is more or less uniform.

\section{Metacarpal.}

The fifth metacarpal (pl. 11, fig. 9) of the left hand resembles that of Halicore in its proportions. The proximal end measures $34.5 \mathrm{~mm}$. in width and $32.5 \mathrm{~mm}$. in depth. Judging from the position of the facets on the proximal end of this bone, the pisiforme and ulnare were consolidated as in Halicore. The facet for this fused carpal is large, 
occupying the major portion of the head, and is moderately concave. On the internal face between this facet and the articular surface for the fourth metacarpal, there is a narrow flattened facet for the unciform. The facet for articulation with the corresponding surface on the fourth metacarpal is convex. Viewed from the side, the dorsal contour of the shaft is nearly straight while the palmar border is curved. The distal extremity is expanded laterally and compressed in a dorso-palmar direction. The total length of this metacarpal is $79 \mathrm{~mm}$. 


\section{NEW PINNIPEDS FROM THE MIOCENE DIATOMACEOUS EARTH NEAR LOMPOC, CALIFORNIA.}

Until quite recently, the pelagic mammalian fauna of the diatomaceous-earth series in California was unknown. While remains of fossil pelagic mammals are encountered in many marine formations, the collection of such material usually depends upon the degree of hardness of the rock they are found protruding from as well as upon the size of the specimen. Exploration and excavation for satisfactory specimens are as uncertain in marine formations as elsewhere. The commercial use of diatomaceous earth has made possible the exploration and excavation of this marine formation to a considerable depth. Through the interest of Mr. Edward B. Starr, superintendent of the Celite Products Company, many specimens which otherwise would have been lost to science have been made available for study. With one exception, all of the fossil pelagic mammals now known from the diatomaceous-earth series in California were preserved through his efforts.

All of the fossil pelagic mammals thus far obtained from the diatomaceous-earth series belong to a fauna which does not appear to occur elsewhere in California. The otarids which occur in this deposit represent a more modernized stock than the archaic types of earlier Miocene stages, such as Allodesmus kernensis and Desmatophoca oregonensis. One of the otarids described in the present paper may be the Miocene prototype of the living fur seal of the North Pacific Ocean. Another larger species, at present very imperfectly known, appears to belong in the limited group which includes the living members of the family Otariidae.

As far as the cetacean fauna of this diatomaceous series is known, it comprises a modernized assemblage of species which is quite different from the fauna which occurs in the limestones, dolomites, and sandstones of the lower division of the Monterey formation. The whalebone whales of the diatomaceous-earth series are unmistakably members of the modernized Mysticeti, while those found in the lower division of the Monterey belong to the more archaic cetotheres. All of the cetaceans thus far obtained from the diatomaceous-earth series, so far as can be judged by their fragmentary remains, exhibit affinities, more or less remote, with species now living in the Pacific Ocean. The little finner, Balaenoptera ryani, ${ }^{1}$ appears to be related

${ }^{1}$ G. D. Hanna and M. E. McLellan, A new species of whale from the type locality of the Monterey Group, Proc. Calif. Acad. Sci., San Francisco, ser. 4, vol. 13, No. 4, pp. 237-241, plates 5 to 9 , June $14,1924$. 
to the living sharp-head finner whale, Balaenoptera davidsoni. The telescoping of the occipital and facial portions of this skull has not advanced as far as in the living species, but otherwise the resemblance is remarkably close. Although Megaptera miocaena ${ }^{1}$ appears to be related to the existing Pacific humpback whale, Megaptera versabilis, the interdigitation of the rostral and cranial elements of the skull is not as far advanced, but the forward thrust of the supraoccipital shield has reached an extreme stage in this process. Remains of only one dolphin ${ }^{2}$ have been described. The relationships of the sirenian Metaxytherium jordani have been discussed in a preceding chapter.

As for Tertiary otarids, none are known from deposits on the Atlantic coast of North America. Differences in climate or lack of. favorable breeding-places may have had something to do with their apparent absence from this region. Several occurrences have already been recorded for the Pacific coast, ${ }^{3}$ and it is possible that some of the European specimens have been correctly allocated in this family.

Living otarids are distinguished from phocids by a number of anatomical differences, and in case of the skeleton the following features may be cited: The otarids have a skull with well-developed postorbital processes and an alisphenoid canal; the mastoid process is conspicuous, distinct from the small auditory bulla. The scapula is large, relatively deep, with high spine near the glenoid border, a distinct acromion process, and large prescapular fossa. The humerus lacks an entepicondylar foramen. The digits of the manus decrease in size from the first to the fifth and do not possess well-developed nails. The pubic bones are unankylosed; the ilium is long and slender, slightly curved outward anteriorly. The femur possesses a fairly well-developed lesser trochanter. Three digits (II, III, IV) of the pes are shorter and more slender than the others, with welldeveloped nails. The hind limbs are capable of being turned forward for terrestrial locomotion.

The phocids have a skull with undeveloped or rudimentary postorbital processes, but lack an alisphenoid canal; the mastoid process is inflated, continuous with the auditory bulla. The scapula is usually falciform, with spine near the middle of the blade, a slightly developed acromion process, and with prescapular fossa rarely larger than postscapular fossa. An entepicondylar foramen is present in the humerus of many of the genera. The digits of the manus are subequal,

I R. Kellogg, Description of the skull of Megaptera miocaena, a fossil humpback whale from the Miocene diatomaceous earth of Lompoc, California, Proc. U. S. Nat. Mus., vol. 61, Publ. 2435 , pp. 1-18, plates 1 to 4 , July 3,1922. [This specimen was found 900 feet nor th from the northeast corner of the SE. $1 / 4$ of Section 15, Township 6 North, Range 34 West, San Bernardino Base and Meridian, 2 miles soutb and east of Lompoc, Santa Barbara County, California.]

${ }^{2}$ D. S. Jordan and J. Z. Gilbert, Fossil fishes of Southern California, Leland Stanford Junior University Publications, Univ. Ser., pp. 59-60, plate 28, figs. 1, 3, 1919. W. Palmer, Journ. Mammalogy, Baltimore, vol. 1, No. 2, p. 100, February 1920.

${ }^{3}$ R. Kellogg, Pinnipeds from Miocene and Pleistocene deposits of California, Bull. Dept. Geol. Sci., Univ. Calif. Publ., Berkeley, vol. 13, No. 4, pp. 23-132, text figs. 1 to 19, April 14, 1922. 
usually decreasing slightly from the first to the fifth; the nails usually are well-developed. The pubic bones are approximated in the females and appressed posteriorly for about one-third of their length in the males; the ilium is short and broad, strongly curved outward anteriorly. The lesser trochanter is undeveloped on the femur. The first and fifth digits of the pes are stouter than the three middle ones. The hind limbs are not capable of being turned forward for terrestrial locomotion.

In attempting to find distinguishing characters in the skeletons of fossil pinnipeds, especially in those from the Antwerp Basin, Belgium, the differences in the humeri and femurs have been found to be fairly satisfactory, inasmuch as most of the described species are very imperfectly known. The vertebral column may contain diagnostic features, but the material available has but little significance unless one could be certain of the position in the column, and in case of the Belgian species, whether the vertebræ have been correctly allocated to the species in question. With few exceptions, the vertebrae of fossil seals resemble one another so closely that accurate indentification is almost impossible. Fortunately, the writer has had access to casts of all the fossil pinnipeds from the Antwerp Basin described by Van Beneden. These casts were acquired by the United States National Museum many years ago and supplement the descriptions and illustrations given by Van Beneden.

Some of the fossil pelagic mammals which have been collected in the diatomaceous earth deposits at Lompoc, California, are well fossilized. For others nothing more than the impressions left by the bones are available for study. Specimens of this character are usually found in blocks of diatomaceous earth which have been quarried in the usual manner by the workmen. Blocks which contain large fossils frequently split at the level of the specimen. At the time the specimen is first exposed many of the bones exhibit their original appearance, but after a few hours' exposure they commence to disintegrate. By using modern methods, an experienced collector could preserve the bones of many of the specimens discovered. The impressions left by the bones in the soft diatomaceous earth, however, are often remarkably complete. Fortunately, many new advances have been made in recent years in the preparation as well as in the methods of study of such palaeontological specimens. In the past, impressions of the original bones were often considered to be inadequate, because it was difficult to make comparisons between impressions and entire bones. By taking a glue mold of these impressions, it is possible to study a cast which reveals the peculiarities of the different parts of the skeleton.

At first it was thought that many of the differences observed in the specimens described on the following pages were of specific value, but 


\section{Tertiary History of Pelagic Mammals of Pacific Coast.}

closer study and comparison with fur seals of different ages has suggested that they may be attributed to age variation. Specimens of fur seals corresponding in size to these fossils have been selected in order to facilitate description and to draw attention to the peculiarities of these pinnipeds.

The writer desires to acknowledge his indebtedness to Dr. David Starr Jordan for the kindly interest which he has shown during the progress of the writer's studies, as well as for the opportunity to describe the fossil pelagic mammals obtained through his efforts. Mr. J. W. Lytle, of the Museum of History, Science, and Arts of Los Angeles, prepared the casts which were used in this study.

Pithanotaria starri, new genus and species.

INDIVIDUAL I.

Type specimen.-Cat. No. 11, Museum Stanford University. A nearly complete impression of the skeleton of a small pinniped showing the outlines of the skull and right mandible, the right fore limb, the ribs, and the vertebral column as far back as the ilium. Impressions of two sternebrae and some of the bones in the left fore limb are also present. The outlines of the ilium are distinct; the remainder of the innominate bone is missing. The femur, patella, and proximal ends of right tibia and fibula are present, but the remainder of the skeleton occupied an adjoining block of matrix.

Type locality.-The Celite Company's No. 9 quarry, 1.4 miles south of the intersection of Ocean Avenue and "C" Street in the town of Lompoc, San Bernardino County, California.

Horizon.-This specimen was found in a block of diatomaceous earth which had been quarried on the property of the Celite Products Company. Mr. Edward B.

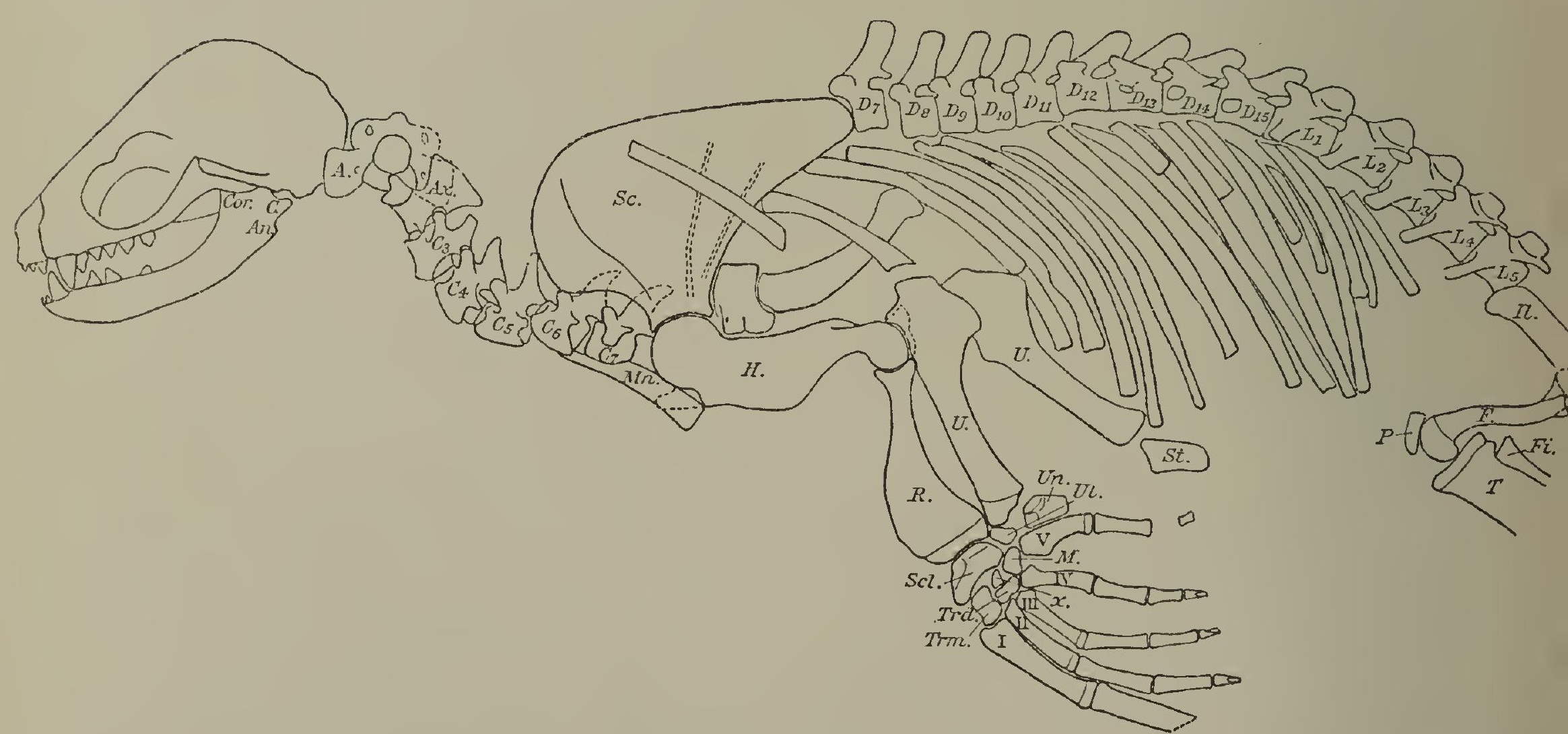

FIG. 1.- Lateral view of skeleton of Pithanotaria starri. Cat. No. 11, Museum Stanford University.

Abbreviations: $A$., atlas; $A n_{\text {. }}$, angle; $A x$., axis; $C$., condyle; $C .3$ to $C .7$, third to seventh cervicals; $C o r$., coronoid process, $D .7$ to $D .15$, seventh to fifteenth dorsals; $F$., femur; $F i$., fibula $H$., humerus; $I l$., ilium; $L .1$ to $L .5$, firsi to fifth lumbars; $M$. ., magnum; $M n$., manubrium; $P$., patella; $R$., radius; Sc., scapula; Scl., scapho-lunar; St. sternebra; T., tibia; Trd., trapezoid; Trm., trapezium; U., ulna; Ul., ulnare; Un., unciform; $X$, either the centrale or the proximal half of the trapezoid; $I$ to $V$, first to fifth metacarpals. 


\section{New Pinnipeds from Vicinity of Lompoc, California.}

Starr, superintendent of the company, at once recognized the importance of the impression and made arrangements with Dr. David Starr Jordan to forward the specimen to Stanford University. The fossil pinniped was taken from a level approximatcly 200 feet above the base of the deposit of diatomaceous earth which at this locality attains a maximum thickness of 1,400 feet. Sarmatian or Upper Miocene.

The vertebral column of this fossil pinniped, judging from the impressions of the vertebrae, does not differ to any marked degree from that of a two-year-old Callorhinus alascanus. In the latter, the vertebral column consists of 7 cervicals, 15 dorsals, 5 lumbars, 3 sacrals, and 10 caudals. The skeleton of a two-year-old male Callorhinus alascanus (Cat. No. 14222, U. S. Nat. Mus.) measures 1,000 mm. in length. Although the posterior extremity of the skeleton of the fossil pinniped from Lompoc is missing, the total length hardly exceeded $950 \mathrm{~mm}$. Following the curvature of the vertebral column, this specimen measures $770 \mathrm{~mm}$. from the tip of the rostrum to the anterior end of the ilium.

The relationships of this pinniped appear to be with Callorhinus and Artocephalus. In most respects, the peculiarities of this skeleton are quite unlike those of living Phocidae, although the radius does resemble that of Phoca in its general outlines. Briefly stated, the following peculiarities of the skeleton of this fossil pinniped appear to indicate an otarid relationship. The slender mandible with inflected angle, the presence of haplodont molariform teeth, the outline and almost vertical inclination of the transverse processes of the atlas, a scapula with a large prescapular fossa, a humerus with a long deltoid crest and no entepicondylar foramen, a rather stout ulna with styloid process directed toward the radial angle, the interdigitation of the upper end of the ulnare between the styloid process of the ulna and the epiphysis of the radius, the fact that the upper end of the trapezoid is not wedged in between the trapezium and the fused scapho-lunar, the absence of modifications for nails on the ungual phalanges of the first and fifth digits in the manus and pes, and the possession of a slender ilium of the typical otarid type.

\section{SKULL.}

From the skull of a two-year-old Callorhinus alascanus, the most apparent distinctions are in the greater depth of the brain-case, the lesser depth of the rostrum, and the more convex curvature of the brain-case as viewed from the side. Some of these differences may not be real and possibly may be attributed to crushing. The rostrum is relatively short, the interorbital region flattened, and the brain-case arched. As regards the rostrum, this fossil skull differs from those of living otarids, with the exception of females of Arctocephalus and Zalophus, in its length and depth. The rostrum of the skull of a young Callorhinus is relatively shorter and deeper. A skull of a young Arctocephalus was not available for comparison. The dorsal outline of the skull of this fossil otarid is quite different from those of young individuals of Callorhinus and Zalophus; the brain-case also is relatively deeper than that of a rather young Otaria byronia from Peru. A small postorbital process seems to be present. The postorbital constriction is not as well marked as in Callorhinus. Hence the brain-case probably was not as quadrangular in outline as in the latter. The antero-lateral angle of the brain-case varies in its sharpness with age and sex; these angles are more conspicuous in a two-year-old male than in an old bull Callorhinus. The orbit of this skull is smaller than that of the fur seal. Sagittal and occipital crests are well developed in old bull fur seals, but are absent on skulls of young individuals. No sagittal crest was present on this fossil skull. The parietal bone appears to correspond in curvature and proportions with that of a young Callorhinus. The anterior and posterior nares open in the same position as in the fur seal. Some of the more conspicuous structures of the skull are not indicated very clearly in the impression. Of these, the zygomatic process, the auditory bulla, and occipital condyle are the most important.

In size and proportions this right mandible also agrees with that of a two-year-old Callorhinus alascanus. The mandible is slender, with inflected angle and narrow con- 
dyle. The interval between the angle and the condyle is about the same as in Callorhinus. The impression of the upper portion of the coronoid process has been obliterated, but the curvature of the anterior border at the base corresponds to that of a young fur seal.

The dentition of this skull agrees with that of a two-year old Callorhinus. As in the fur seal, the outer upper incisor is larger than the others and caniniform; the impressions of the lower incisors are indistinct. The canines are large and sharply pointed; the lower canine is slightly curved, but the upper is nearly straight. As in Callorhinus, the premolars are not sharply differentiated from the molars. All of the molariform teeth have a simple laterally compressed crown and poorly defined cingulum. No accessory cusps were present, or at least none are indicated in the impressions of the upper molariform series. The impression of the fifth upper molariform tooth is not as distinct as the others, and it is possible that it may have had a small posterior accessory cusp. Impressions of 5 molariform teeth are present in the upper jaw. Some of the molariform teeth are missing from the mandible, as only 3 are present.

TABLE 1.-Comparative measurements of the skulls (in millimeters).

\begin{tabular}{|c|c|c|}
\hline & $\begin{array}{l}\text { Pithanotaria starri, } \\
\text { Lompoc, California. } \\
\text { Cat. No. 11, Mus., } \\
\text { Stanford University. }\end{array}$ & $\begin{array}{c}\text { Callorhinus alascanus, } \\
\text { St. Paul Island, Alas- } \\
\text { ka, } 2 \text { year old ơ. Cat. } \\
\text { No. } 14222 \text { U. S. Nat. } \\
\text { Mus. }\end{array}$ \\
\hline Condylobasal length of skull. & 154 & 178 \\
\hline Occipito-nasal length of skull.......... & $x$ & 129 \\
\hline $\begin{array}{l}\text { Vertical depth of brain-case at apex supra- } \\
\text { occipital. } \ldots \ldots \ldots \ldots \ldots \ldots \ldots \ldots \ldots \ldots\end{array}$ & 76 & 67.5 \\
\hline Vertical depth of rostrum at base of nasals... & 38 & 45 \\
\hline Zygomatic breadth of skull............ & $x$ & 103.4 \\
\hline Mastoid breadth of skull................ & $x$ & 88 \\
\hline $\begin{array}{l}\text { Breadth across occipital condyles (outside } \\
\text { measurement) } \ldots \ldots \ldots \ldots \ldots \ldots \ldots \ldots \ldots \ldots\end{array}$ & $\times$ & 50.5 \\
\hline Length of palate (to median notch)........ & $x$ & 61 \\
\hline Base of pterygoid to extremity of premaxilla & $x$ & 105 \\
\hline Interorbital constriction $\ldots \ldots \ldots \ldots \ldots \ldots$ & $x$ & 23.5 \\
\hline Postorbital constriction. .............. & $x$ & 33.5 \\
\hline Length of upper molariform series......... & 141 & 45 \\
\hline $\begin{array}{l}\text { Length of right mandible (extremity to con- } \\
\text { dyle) } \ldots \ldots \ldots \ldots \ldots \ldots\end{array}$ & 112 & 114 \\
\hline $\begin{array}{l}\text { Depth of right mandible at coronoid process } \\
\text { (angle to tip) } \ldots \ldots \ldots \ldots \ldots \ldots \ldots \ldots\end{array}$ & $x$ & 34.6 \\
\hline Depth of right mandible at level of last molar & 15 & 15.5 \\
\hline $\begin{array}{l}\text { Depth of right mandible at level of third } \\
\text { premolar } \ldots \ldots \ldots \ldots \ldots \ldots \ldots \ldots \ldots \ldots\end{array}$ & 18.5 & 21 \\
\hline Length of lower molariform series......... & $x$ & 35.2 \\
\hline
\end{tabular}

${ }^{1}$ Five teeth. 2 Six teeth.

Fore Limb.

The impression of the right fore limb is remarkably complete. Even the ungual phalanges are represented. The total length of the fore limb in its present position as measured from the vertebral margin of the scapula to the distal end of the first phalange of the first digit is $370 \mathrm{~mm}$. The same measurement for the fore limb of a two-year-old Callorhinus alascanus is $470 \mathrm{~mm}$. The illustration (text-fig. 1) which accompanies this description represents the various elements in the position in which they occur on the slab of diatomaceous earth. 
Scapula.

None of the living Holarctic phocids, so far as can be judged by these impressions, possess a scapula of this type. The scapula of Monachus tropicalis bears a slight resemblance to that of this fossil otarid, but the position of the spine is quite different. The coracoid or anterior border of this fossil scapula does not merge into the suprascapular border in a more or less regular curve as in Phoca vitulina; $;$ the outlines of the blade as well as the size and position of the fossae resemble the scapula of a twoyear-old Callorhinus alascanus very closely. The prescapular fossa is relatively large, the postscapular portion is elongated, and the spine extends about seven-ninths the depth of the blade. There is no indication of a hook-like process at the inferior angle. The scapula of this fossil otarid is not as deep as that of a young Callorhinus and the inferior angle is prolonged further backward. In front of the spine the external surface of the scapula is relatively flat and to this was attached the deltoid muscle. Further forward and along the coracoid margin the scapula is depressed as in Callorhinus alascanus. A muscle which assists the deltoid in abducting the humerus arises in this area. Phoca vitulina and Phoca sibirica possess falciform scapulæ which resemble each other, as well as other species of the genus Phoca in a general way, and may be taken as representative of the type characteristic of this genus. In these species the coracoid border curves forward and upward from the neck to the suprascapular border and passes imperceptibly into the latter. A well-developed hook-like process is present below the inferior angle. The coracoid border is not depressed below the area for attachment of the deltoid muscle, the prescapular fossa is not considerably larger than the postscapular fossa, and the spine arises near the middle of the blade. Hence the scapula agrees in all particulars with those of otarids and differs from the phocids in all the features enumerated above.

\section{Homerus.}

The impression of the external face of the right humerus reveals the curvature of the shaft, the proportions of the head and deltoid crest, the shape of the lower trochlear portion, and the outline of the supinator ridge. The lesser tuberosity and internal condyle alone are missing to give a complete picture of this humerus. Compared with the corresponding element of Prophoca proxima, ${ }^{2}$ it is somewhat smaller and agrees very closely in general form, except for the more pronounced over-rolling of the deltoid crest on the external margin, the more flaring supinator ridge, and the absence of an entepicondylar foramen. The supinator ridge is thin and of approximately the same length as in Callorhinus. Comparisons made between the cast of the left humerus of Prophoca proxirna and the same element in skeletons of living phocids revealed some well-marked differences. The deltoid crest is exceptionally long as compared with the same structure on a humerus of Phoca vitulina, and the upper portion of the supinator ridge is directed backward in a plane parallel to that of the deltoid crest. Consequently, the distal portion of the humerus was somewhat narrower than that of Phoca vitulina, on which the supinator ridge is directed more outward than backward. In the direction and length of the supinator ridge and in the large size of the capitulum, the humerus of Pithanotaria starri resembles that of a two-year-old Callorhinus alascanus more closely than any of the previously described fossil phocids. This humerus is also larger than that of Phoca vindobonensis; ${ }^{3}$ the large size of the head and the flaring margin of the deltoid crest further distinguish

${ }^{1}$ H. M. D. Blainville, Ostéographie ou description iconographique, Paris, fasc., Phoca, plate $2,1843$.

2 P. J. Van Beneden, Description des ossements fossiles des environs d'Anvers-Première Partie, Pinnipèdes ou Amphiteriens, Annales du Mus. d'hist. nat. de Belgique, Bruxelles, tome 1 , plate 18 , figs. $12,13,1877$.

${ }^{3}$ F. Toula., Phoca vindobonensis n. sp. von Nussdorf, in Wien. Beiträge z. Paläont. u. Geol. Osterreich-Ungarns u.d. Orients, Wien und Leipzig, Bd. 11, heft 2, pp. 47-70, plates 9 to 11 , 1897. 
this pinniped from the Vindobonian phocid of the Vienna basin. In Prophoca proxima the depth of the humerus through the coronoid fossa is somewhat greater than in this pinniped from Lompoc. In a two-year-old Callorhinus alascanus the depth of the humerus at this point is approximately the same as in this fossil humerus. The curvature of the anterior and posterior borders of the shaft also agree with Callorhinus. Leptophoca lenis ${ }^{1}$ from the Calvert formation of Maryland has a humerus with a shorter deltoid crest, longer shaft, and less flaring supinator ridge. The humerus of Phocanella pumila ${ }^{2}$ has a short deltoid crest which corresponds in a general way with that of Phoca vitulina and Phoca hispida, but the head is smaller and the shaft slenderer than in this fossil otarid.

\section{RADIUS.}

On comparing the external views of this radius and those of Phoca vitulina and Phoca hispida, it is interesting to note how closely they resemble one another in general outlines. The head is somewhat wider than the neck in contrast to the more uniform proportions of the proximal end of the left radius of Prophoca proxima. The posterior border of the radius is rather evenly curved, but the curvature of the anterior border is not as regular. Commencing at the neck, the curvature of the anterior border at first is gradual, but below the middle the expansion becomes very pronounced and imparts a characteristic outline to this element. The curvature of the anterior border of the radius of Callorhinus alascanus as viewed from the side is quite different from this type, being irregularly biconcave; the shaft expands rather suddenly above the rugosity which marks the insertion of the tendon and flexor muscle of the wrist, and below this point the border gradually curves forward to the widest part of the radius, which is just above the insertion of the flexor muscle of the elbow joint. As in living pinnipeds, the lower portion of the radius of Pithanotaria starri is flattened from side to side. On the radius of Phoca vitulina and other living phocids, there is a well-defined notch on the anterior border which extends obliquely upward and backward between the shaft and the distal epiphysis for the insertion of the flexor muscle of the elbow joint. There is a poorly defined groove for this muscle near the same point on the left radius of Prophoca proxima. Close scrutiny of the impression of the right radius of this fossil otarid convinced the writer that the notch, if present, was very shallow, although the surface may have been shightly grooved. The distal extremity of the radius, including the epiphysis, resembles the same element in the fore limb of a two-year-old Callorhinus alascanus more closely than Phoca. There are no ridges in the impression which would indicate the presence of grooves for tendons and muscles as in Phoca, and the entire surface in this region is relatively smooth, as in Callorhinus. In addition to the presence of grooves for tendons and muscles on the external surface of the distal extremity of the radius of Phoca vindobonensis, there are other differences which have a more important bearing upon its relationships with the pinniped from Lompoc. Among these peculiarities, the oblique curvature of the anterior face of the shaft and the wide neck of the radius of the Vienna phocid are the most obvious.

\section{ULNA.}

In its general form, the ulna undoubtedly was very similar to that of a young Callorhinus alascanus. The right ulna of this otarid differs considerably from that of Phoca vindobonensis and those of living phocids in several respects. The most apparent differences are the curvature of the posterior margin of the olecranon process, the greater width of the distal end of the shaft, and the shape and position of the styloid process. In the width of the distal end of the shaft, the position of the styloid process, and the extent of the facets for the radius and ulnare, this ulna resembles

1 F. W. True, Deseription of a new genus and species of fossil seal from the Miocene of Maryland, Proc. U. S. Nat. Mus., vol. 30, Publ. 1475, pp. 835-840, plates 75, 76, 1906.

2 P. J. Van Beneden, Op. cit., plate 14, figs. 1 to $4,1877$. 
that of a two-year-old Callorhinus. The greater sigmoid cavity on the anterior face of the ulna for articulation with the trochlea of the humerus is characterized by an evenly concave curve; its proximo-distal diameter is about equal to that of a young fur seal. The articular surface of the greater sigmoid cavity is continuous with the lesser sigmoid cavity which articulates with the head of the radius. In position and size this facet also agrees with that of a young fur seal. The external surface of the olecranon process appears to have been flattened, while in Callorhinus there is a welldefined triangular concavity for the insertion of the extensor muscle of the elbow joint. The shaft of the ulna is relatively stout.

TABLE 2.-Comparative measurements of the bones of the fore limb (in millimeters).

\begin{tabular}{|c|c|c|}
\hline & $\begin{array}{c}\text { Pithanotaria } \\
\text { starri, Lompoc, } \\
\text { California. Cat. } \\
\text { No. 11, Mus., } \\
\text { Stanford } \\
\text { University. }\end{array}$ & $\begin{array}{l}\text { Callorhinus alas- } \\
\text { canus, St. Paul } \\
\text { Island, Alaska. } \\
2 \text {-year-old } \sigma^{\gamma} \text {. } \\
\text { Cat. No. 14222, } \\
\text { U. S. Nat. Mus. }\end{array}$ \\
\hline 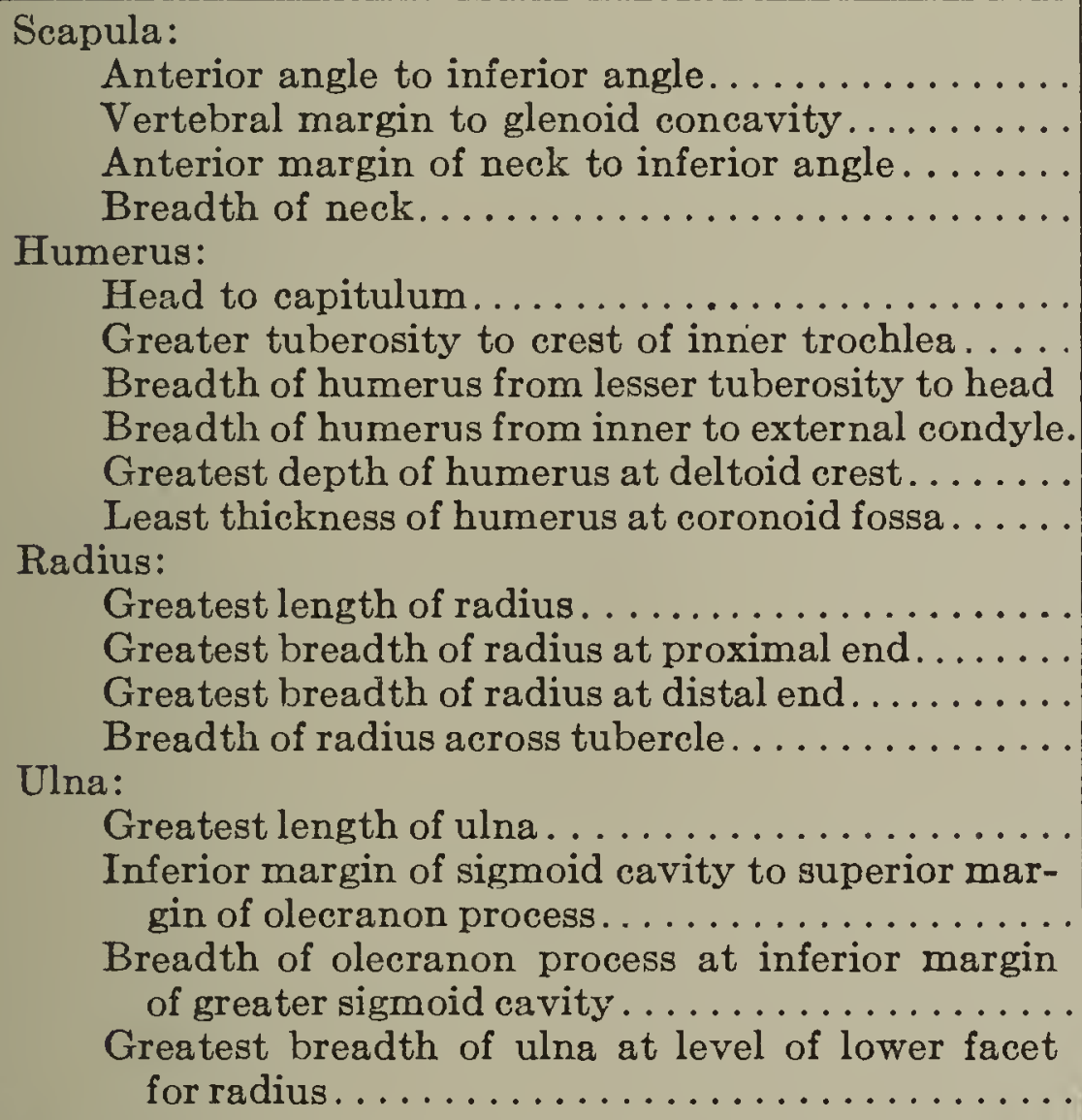 & $\begin{array}{l}143.5 \\
82.5 \\
120 \\
27 \\
106.5 \\
\times \\
\times \\
\times \\
32 \\
11 \\
90.5 \\
23 \\
32 \\
\times \\
111 \\
32 \\
21 \\
19.2\end{array}$ & $\begin{array}{c}141.5 \\
118.5 \\
118 \\
24 \\
105 \\
118.5 \\
39.5 \\
41 \\
32 \\
12 \\
\\
118 \\
19 \\
34 \\
11.2 \\
145.5 \\
45 \\
25 \\
16.5\end{array}$ \\
\hline
\end{tabular}

\section{Carpus.}

The structure of the carpus appears to be rather unusual in several respects. The bones are unequal in size; the magnum and ulnare are nearly equal in the proportions of their anterior faces; the trapezium appears to be relatively small. There are two impressions in the area where the trapezoid should occur, and if they represent the upper and lower portions of the anterior surface, then this element was traversed mesially by a horizontal groove or depression. The trapezoid would then be almost as large as the trapezium. In these respects the relations of these carpal bones approach the conditions existing in Callorhinus alascanus. As viewed from in front, the trapezoid in the carpus of Phoca vitulina and Phoca fasciata is relatively slender and the upper extremity is interposed between the trapezium and the fused scapholunar-centrale. It is barely possible that the upper depression (text-fig. 1, X) may represent the centrale. In that case the larger element, which articulates with the radius, would consist of the scaphoid and lunar alone. The presence of a wholly consolidated scapho-lunar-centrale in the Pinnipedia has been regarded as a highly im- 
portant character. This fusion has been held to preclude their derivation from a form which possesses these as separate elements. No conclusive evidence that this character was acquired during the aquatic adaptation of the group has been presented up to the present time. Hence it is to be regretted that the actual bones of this carpus are not available. The scaphoid and lunar have consolidated, and the only dubious point is the interpretation of the above-mentioned depression. If it does represent the centrale, then aquatic adaptation in this group has resulted in the fusion of the centrale with the scapho-lunar. The question of the consolidation of the scaphoid and lunar would then await the discovery of some earlier form. At present the evidence does not appear to be very conclusive. Under either interpretation the trapezoid differs in position and proportions from the same element in the carpus of Phoca. The displacement of some of the carpal bones is also unfortunate, for it is difficult to recontruct the carpus from impressions of the elements. The ulnare is much smaller than the same element in the carpus of Phoca, but it does resemble that of Callorhinus. Judging from the impression, the upper end of the ulnare may have been interposed between the epiphysis of the radius and the styloid process of the ulna as in the carpus of Callorhinus. In the latter, the articular facets for the radius and ulna are on the external and internal faces of the ulnare. In Phoca vitulina the facet on the ulnare for articulation with the styloid process of the ulna is on the proximal face. The ulnare of this fossil otarid is rather small and the styloid procéss of the ulna rather large. The displacement of the unciform probably took place at the time the head of the fifth metacarpal was thrust upward into the carpus. The large size of the unciform is most unusual for a pinniped. It is as large as or larger than the trapezium.

Measurements of the bones of the carpus (in millimeters).

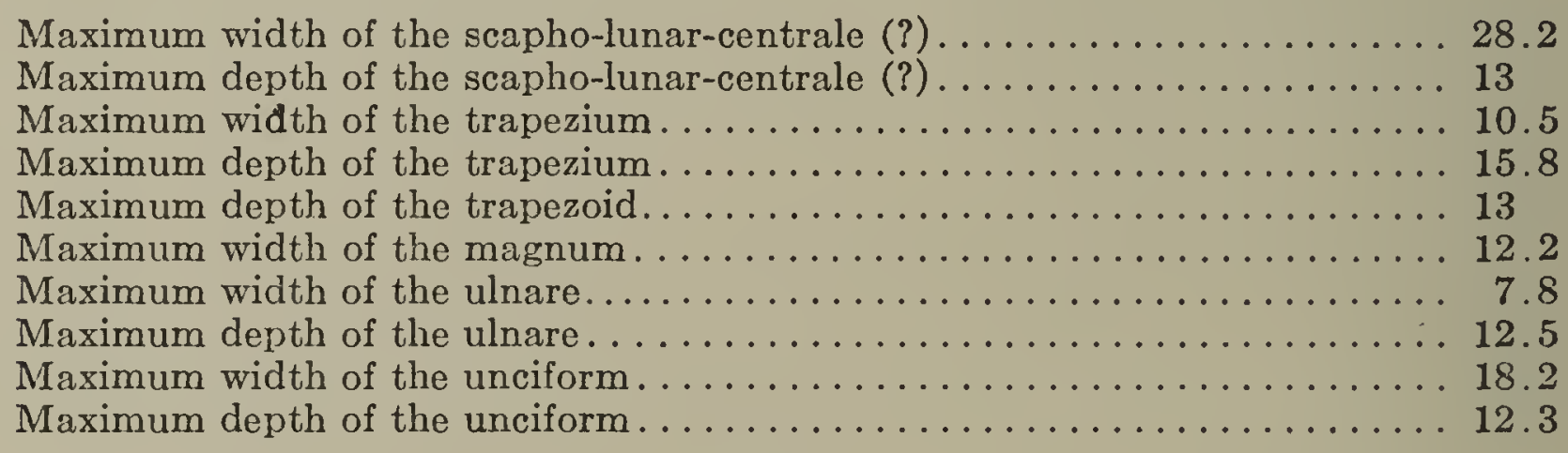

Digits.

In structure the broad flat flipper of this fossil otarid does not differ in any essential detail from that of a two-year-old Callorhinus alascanus. The relative lengths and proportions of the first and fifth digits are remarkably close. The ungual phalanges were rather short, broad, and bluntly pointed. In the living fur seal, the first digit consists of a metacarpal and two phalanges; the other digits have an additional phalange. Unfortunately, the impressions of the first and fifth digits are not complete. The impressions of the first four digits correspond to their normal position; the fifth has been twisted. This shifting of the fifth digit may have caused the disassociation of some of the carpal bones.

The first metacarpal is larger than all the others, both in respect to length and relative proportions. The radial angle of the proximal end of this metacarpal projects beyond the level of the ulnar angle. The distal extremity of this metacarpal is slightly expanded. The second metacarpal is rather slender, with no evident disparity in size between the shaft and the proximal end. The head of the third metacarpal is noticeably expanded. The fourth and fifth metacarpals are slightly shorter and resemble the same element in the flipper of a young Callorhinus alascanus. The first phalange of the first digit is broader and longer than any of the others. All of the second phalanges are slender and taper toward the distal end. The ungual phalanges of the second, third, and fourth digits are modified to support nails. 
TABLE 3.-Comparative measurements of the greatest length of metacarpals and phalanges (in millimeters).

\begin{tabular}{|c|c|c|}
\hline & $\begin{array}{l}\text { Pithanotaria starri, } \\
\text { Lompoc, California. } \\
\text { Cat. No. 11, Mus. } \\
\text { Stanford University. }\end{array}$ & $\begin{array}{l}\text { Callorhinus alascanus, } \\
\text { St. Paul Island, Alas- } \\
\text { ka, 2-year-old ơ. } \\
\text { Cat. No. 14222, U.S. } \\
\text { Nat. Mus. }\end{array}$ \\
\hline First metacarpal. & 55.2 & 67.4 \\
\hline First phalange of first digit. & $45+$ & 64.5 \\
\hline Second phalange of first digit........... & $x$ & 25.5 \\
\hline Second metacarpal. . . $\ldots \ldots \ldots \ldots \ldots$ & 38.2 & 48 \\
\hline First phalange of second digit............ & 32 & 47 \\
\hline Second phalange of second digit. .......... & 25 & 38 \\
\hline Third phalange of second digit........... & 10 & $x$ \\
\hline Third-metacarpal........... & 34.6 & 44.5 \\
\hline 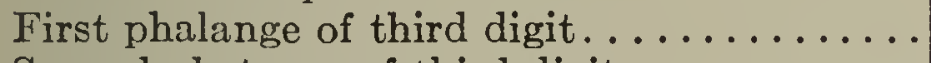 & 25.5 & 37 \\
\hline Second phalange of third digit............ & 20.4 & 30 \\
\hline Third phalange of third digit........... & 9.8 & $x$ \\
\hline 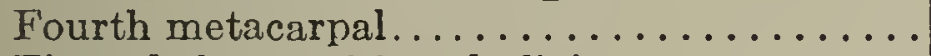 & 30.8 & 37.5 \\
\hline First phalange of fourth digit. . & 25 & 27.5 \\
\hline Second phalange of fourth digit. & 16.5 & 22.4 \\
\hline Third phalange of fourth digit. . & 8.5 & $\times$ \\
\hline Fifth metacarpal.......... & 32 & 36.6 \\
\hline First phalange of fifth digit. . & 23.5 & 25.3 \\
\hline Second phalange of fifth digit. & $x$ & 6.5 \\
\hline Third phalange of fifth digit. . & 9 & $x$ \\
\hline
\end{tabular}

Cervical Vertebrae.

Very little can be said concerning the atlas of this pinniped except that it agrees rather closely with that of the living Callorhinus alascanus. The impression of the atlas is not complete, as only a portion of the posterior surface is represented; the right lateral margin is nearest to the skull. In size it was somewhat smaller than the atlas of a two-year-old Callorhinus alascanus (Cat. No. 14222 U. S. Nat. Mus.); the greatest depth of the neural canal of the last-mentioned vertebra is $23.5 \mathrm{~mm}$. and the breadth across the transverse processes is $73.5 \mathrm{~mm}$. Turning again to this fossil atlas, it appears that the neural canal measured $18 \mathrm{~mm}$. in depth and the estimated breadth across the transverse processes is $60 \mathrm{~mm}$. The size and curvature of the neural canal are very clearly indicated. The posterior articular facets also were similar in size and proportions to those of a young fur-seal atlas. This impression does not include the left transverse process and only a portion of the left posterior articular facet is represented. The peculiarities of the anterior surface of this atlas are unknown.

A lateral view of the axis is afforded by the impression of this element. The neural spine and odontoid process are fairly well defined; the right anterior articular facet and the right postzygapophysis are more or less clearly outlined. This axis does not appear to differ structurally from that of a two-year-old Callorhinus alascanus.

Judging from their impressions, the remaining cervical vertebrae also correspond to those of a young fur seal, although they are slightly smaller. The proportions of the pre- and post-zygapophyses can be determined from the impressions of the fourth and fifth cervicals, and the position of the upper and lower transverse procasses are indicated on the third, fourth, and fifth cervicals. The impressions of the last three cervicals are not as complete as those of the first four.

\section{Dorsal Vertebrae.}

Analysis of the impressions and comparison of the size of the vertebrae with those of a two-year-old Callorhinus alascanus lead to the conclusion that 15 dorsal vertebrae were present in this skeleton. There are impressions of 9 dorsals posterior to the scapula. Impressions of 3 dorsal vertebrae are present on the inner face of the scapula. 
The position of the anterior dorsals and the intervals which separate them show that these vertebrae were disarticulated before the skeleton was covered with sediments. The manubrium or anterior sternebra is in contact with the sixth and seventh cervicals and the impression of the neural spine of the sixth cervical passes beneath the coracoid border of the scapula. This confirms the severance of the vertebral column posterior to the cervical series. The dorsal vertebrae average smaller than those of a two-yearold Callorhinus alascanus.

The following comments on the dorsal series of this skeleton are based upon comparisons between the impressions taken from the same series of a two-year-old Callorhinus alascamus skeleton and those on this slab of diatomaceous earth. Inasmuch as no marked differences could be observed, the peculiarities of these vertebrae have been interpreted from the Callorhinus skeleton. The metapophyses appear to have been low and rounded. Beginning with the fifth in the dorsal series of Callorhinus, the anterior angle of the metapophysis becomes more pronounced. As we go backward along the series as far as the eleventh dorsal, there is relatively little change in the shape of this angle, but on the twelfth it moves inward and assumes a more oblique position. On the thirteenth the metapophysis contributes the outer surface of the prezygapophysial facet. From this dorsal to the end of the series the metapophysis is continuous with the prezygapophysis. There is a distinct anapophysis on the thirteenth dorsal, and it increases slightly in size on the fourteenth and fifteenth. It is absent on the lumbar vertebrae. The neural spines of the anterior dorsal vertebrae were high; those on the posterior dorsals were considerably lower, as in Callorhinus. The centra increase in length toward the end of the dorsal series.

In a skeleton of a two-year-old Callorhinus alascanus, the facets for the tubercula of the ribs are cup-shaped on the first and second dorsals and flattened on the third to fifteenth. Demifacets for the capitula are present on the centra of the third to eleventh dorsals inclusive. The impressions of the transverse processes are distinct, but the position and peculiarities of the facets for the ribs are not sharply defined. On the whole the dorsal series appears to agree very closely with that of the young fur seal. The impression of the centrum of the seventh dorsal of this fossil otarid measures 15 $\mathrm{mm}$. in length and the vertical distance from the tip of the spine to the inferior face of the centrum is $36.5 \mathrm{~mm}$.

\section{Lumbar Vertebrae.}

Five lumbar vertebrae were present in this skeleton. The centra of the first and second lumbar vertebrae are slightly longer than the others and the fifth lumbar has a longer transverse process than the first. The metapophyses were high and projected forward and outward. The neural spines are lower than those of the posterior dorsals. All five of these lumbars were of the Callorhinus type.

RIBS.

Impressions of more than 17 ribs are present, several being nearly complete, but it is a difficult matter to determine how many belong on the right side. Four or five of the anterior ribs, which normally underlie the scapula, are certainly missing. Only one of these ribs has left its impression on the inner face of the scapula. Some evidence of wave action is afforded by the abnormal position of the left scapula, the impression of the internal face of this bone being situated above the vertebral column. Otherwise, the bones in the skeleton rest in the position of a seal lying on its side. All of the ribs are rather long and slender, with expanded extremities. Well-developed tubercula were present on the anterior ribs, but the length of the neck and the size of the capitulum are not shown in any of the rib impressions. All of these ribs appear to be moderately curved from end to end. Eleven vertebral ribs are connected with the sternebrae by cartilaginous sternal ribs in the skeleton of a young Callorhinus alascanus. 


\section{Sternebrae.}

In the living Otariidae, the sternebrae are not fused together to form three elements, but remain distinct. There are 9 sternebrae in the sternum of Callorhinus and Arctocephalus. Impressions of two sternebrae are shown on this slab of diatomaceous earth and one of these is the manubrium. The latter is long and slender and measures $67 \mathrm{~mm}$. in length, exceeding that of a two-year-old Callorhinus alascanus. The other sternebra measures $26 \mathrm{~mm}$. in length and its proportions correspond with those of the fur seal.

\section{Pelvis.}

Of the pelvis, only the impression of the anterior end of the right ilium appears to be represented. This element was slender, as in the living otarids, with the anterior extremity curved slightly outward. In proportions and length the ilium of this fossil otarid is practically indistinguishable from that of a two-year-old Callorhinus alascanus. The length of the ilium of this fossil otarid is about $50 \mathrm{~mm}$., while that of a two-year-old fur seal measures $50.5 \mathrm{~mm}$. It articulated with the first and second sacrals, but furnishes little additional information on the structure of the pelvic girdle of these Miocene otarids. This imperfectly preserved pelvic girdle does show that before the close of the Miocene period the otarids had already acquired the type of pelvic girdle which is characteristic of the family and that in all essential features the pelvis was similar to those of the living otarids.

\section{Hind LrmB.}

Unfortunately, all of the hind limb, with the exception of the femur and the proximal ends of the right tibia and fibula, was destroyed when the adjoining slab of diatomaceous earth was put through the usual processes of manufacture at the Celite Products Company plant at Lompoc.

TABLE 4.-Comparative measurements of the bones of the hind limb (in millimeters).

\begin{tabular}{|c|c|c|}
\hline & $\begin{array}{l}\text { Pithanotaria starri, } \\
\text { Lompoc, California. } \\
\text { Cat. No. 11, Mus. } \\
\text { Stanford University. }\end{array}$ & $\begin{array}{l}\text { Callorhinus alascanus, } \\
\text { St. Paul Island, Alas- } \\
\text { ka. 2-year-old } \sigma^{7} \text {. } \\
\text { Cat. No. } 14222 \text {, U.S. } \\
\text { Nat. Mus. }\end{array}$ \\
\hline 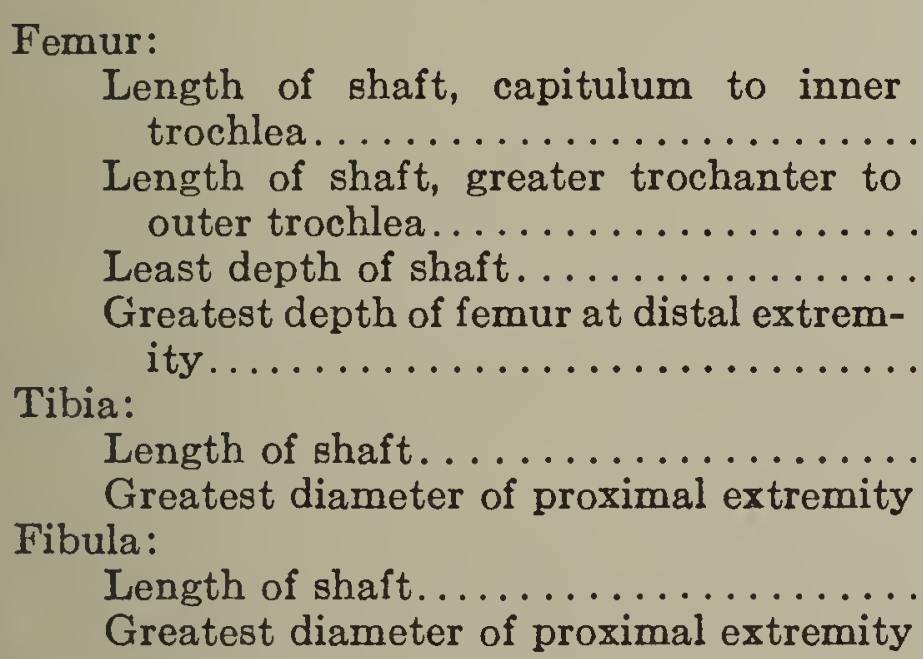 & $\begin{array}{c}\times \\
65 \\
8.5 \\
22.2 \\
\times \\
32.5 \\
\times \\
10\end{array}$ & $\begin{array}{c}77 \\
70 \\
11.3 \\
36.3 \\
145 \\
31.4 \\
122 \\
12\end{array}$ \\
\hline
\end{tabular}

\section{FEMUR.}

The internal half of the shaft of the right femur is represented in the impression shown on plate 12. Except for its slightly smaller size and the more oblique truncation of the greater trochanter, this femur is very similar to the corresponding bone in a two-year-old Callorhinus alascanus skeleton. The principal features of this bone are not indicated by the outline drawing herewith given (fig. 1), as the major portion of the shaft lies below the surface of the matrix. The epiphysis of the greater trochanter 
and the capitulum appear to have separated from the shaft before this impression was formed. Two concavities which are situated between the end of the shaft and the ilium may have originated from these epiphyses. The outer condyle of this femur was nearly flat in contrast to the more or less conical condyle of a two-year-old Callorhinus femur. The curvature of the shaft is practically the same as in a young fur seal. The patella is flat and relatively thin.

\section{Tibia and Fibutia.}

The proximal ends of the left tibia and fibula are represented by impressions of their internal surfaces. The relative proportions of the tibia and fibula of this pinniped correspond to the fur seal, but the anterior face of the proximal extremity of the tibia appears to have been somewhat flatter.

\section{INDIVIDUAL II.}

Referred specimen.-Cat. No. 26784, Museum of Palaeontology, University of California. The specimen consists of a slab of diatomaceous earth with an impression of the left fore limb. The scapula, humerus, radius, and ulna, carpals, metacarpals, and the proximal ends of the first phalanges are represented.

Occurrence.-The Celite Company's No. 15 quarry, 300 feet west from the northwest corner of the NE. $1 / 4$ of Section 22, Township 6 North, Range 34 West, San Bernardino Base and Meridian, 2.5 miles south and east of Lompoc, Santa Barbara County, California.

Horizon.-This specimen was found by laborers in the quarry of the Celite Products Company and was afterwards presented to the Museum of Palaeontology by Messrs. Edward B. Starr and Edward J. Porteous. The exact level at which this specimen was obtained is not known to the writer, but the bed is approximately 1,400 feet thick and quarrying operations were being carried on at several levels at the time of the writer's visit in 1920. Arnold and Anderson stated that this deposit formed part of the upper division of the Monterey formation. Sarmatian or Upper Miocene.

\section{Fore Limb.}

The illustration herewith given (fig. 2) represents a cast taken from the original impression in the slab of diatomaczous earth. Both specimens have been studied and in the following description an attempt has been made to point out the essential features of this fore limb and to describe peculiarities which were not shown on the type specimen.

\section{ScAPULA.}

The imprint of the left scapula (fig. 2) of the fossil pinniped from Lompoc shows that the general conformation of this bone is of the otarid type, although the neck is relatively shorter and the blade wider but not as deep as in Callorhinus and Arctocephalus. The prescapular fossa is very large and the ridge which projects into this fossa is slightly curved. In front of this ridge the coracoid border is depressed below the level of major portion of the fossa. Above the well-marked coracoscapular notch, the coracoid or anterior border of the scapula is first directed obliquely upward and forward, then nearly vertically, and obliquely backward superiorly. The suprascapular border is not complete. The postscapular fossa is relatively narrow. The lower portion of the spine with its acromion process was broken off and displaced at the time this impression was left in the diatomaceous earth. The lower portion of this spine is shown on figure 2 behind the glenoid border of the scapula. The glenoid fossa was rather large and appears to have been shallowly concave.

\section{Humerus.}

The left humerus of this otarid differs in some minor details from those of the living Callorhinus alascanus and Arctocephalus australis. The condition of the lesser tuberosity is the most striking peculiarity of this humerus. In the living Callorhinus 
alascanus and Arctocephalus australis the greater tuberosity is twisted backward to the right side, while the lesser tuberosity is inclined obliquely forward; the two tuberosities, although closely approximated, are separated by a deep sinus. On this fossil humerus the greater tuberosity is likewise twisted toward the right, but the lesser tuberosity is erect and is directed almost at a right angle to the sagittal plane of the deltoid crest.
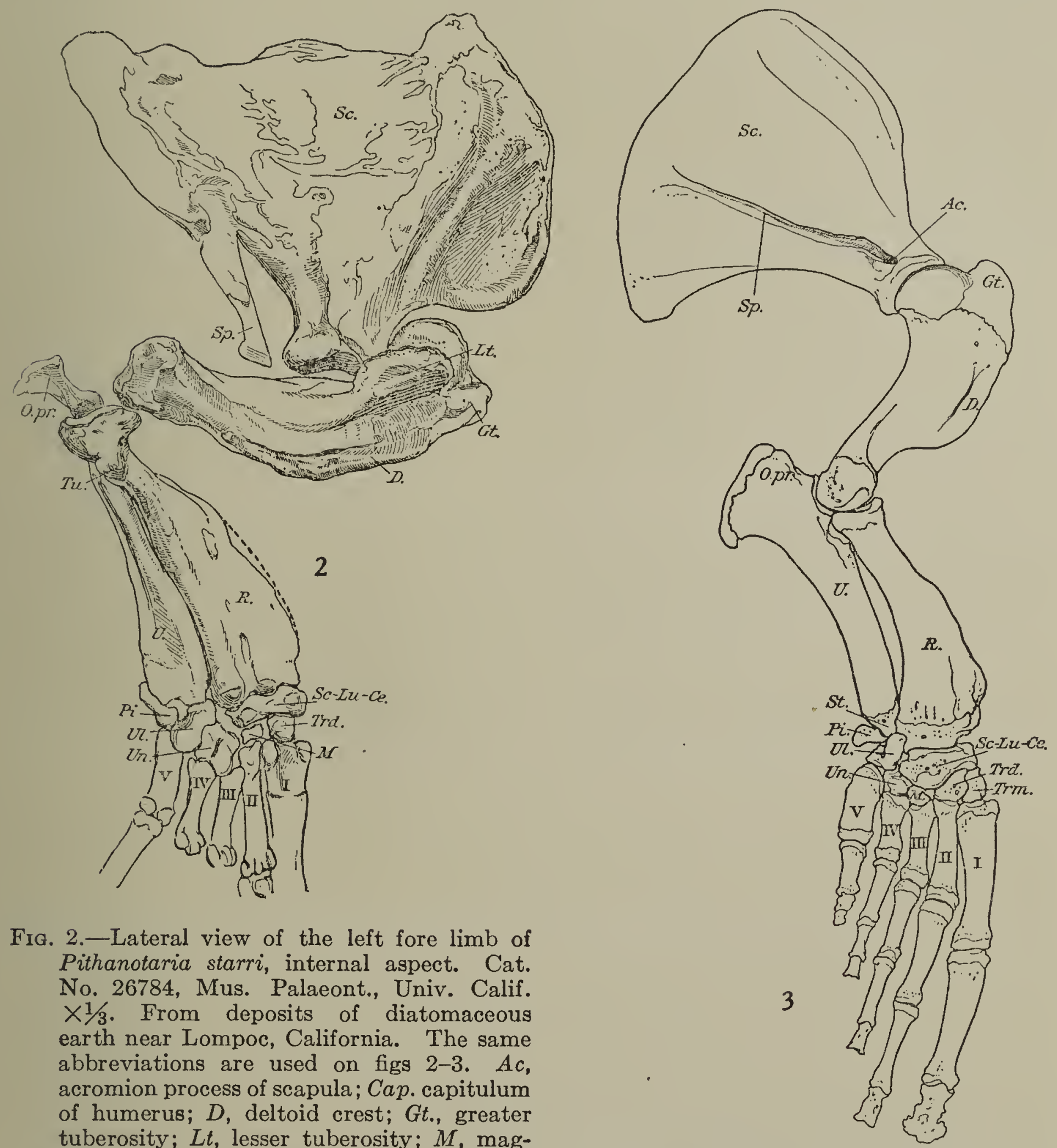

FIG. 2.-Lateral view of the left fore limb of Pithanotaria starri, internal aspect. Cat. No. 26784, Mus. Palaeont., Univ. Calif. $\times 1 / 3$. From deposits of diatomaceous earth near Lompoc, California. The same abbreviations are used on figs 2-3. Ac, acromion process of scapula; Cap. capitulum of humerus; $D$, deltoid crest; $G t$., greater tuberosity; $L t$, lesser tuberosity; $M$, magnum; O. pr. olecranon process; $P i$, pisiform; $R$, radius; $S c$, scapula; $S c-L u-C e$, scapho-lunarcentrale; $S p$. spine of scapula; $S t$. styloid process of ulna; $T r$, inner trochlea; $\operatorname{Trd}$, trapezoid; $T r m$, trapezium; $T u$, tubercle of radius; $U$, ulna; $U l$, ulnare; $U n$, unciform; I to V, first to fifth metacarpals.

FIG. 3.-Lateral view of right fore limb of Eumetopias jubata (Schreber), external aspect. Cat. No. 8821, ơ, Mus. Vert. Zool., Univ. Calif., $\times 1 \%$. Ano Nuevo Island, off San Mateo County, California.

When viewed from the internal side (fig. 2) the anterior border of the humerus is seen to curve strongly upward, though the antero-posterior diameter of the shaft in the deltoid region is not conspicuously greater than the lower trochlear portion. The deltoid crest is well developed and is continued downward as a very prominent ridge for about five-sixths of the length of the shaft and then merges into the coronoid fossa. This crest is characterized by a flaring inner margin and a more or less flattened ante- 
rior face. The lesser tuberosity is thick and strongly rugose, and terminates below the level of the articular face of the head as in the living fur seals. The greater tuberosity projects slightly above the level of the head. The impression of the inner condyle has been destroyed, but the crest of the inner trochlea corresponds to that of Callorhinus alascanus.

\section{RADIUS.}

In its general form the radius of this pinniped agrees with that of Callorhinus and Arctocephalus. The proximal end of the radius is broadly oval in outline, with a large concave facet for the reception of the capitulum of the humerus. The articular surface of the tubercle is continuous with the ulnar facet. This peculiarity distinguishes this radius from those of Callorhinus and Arctocephalus. In the last-mentioned genera there is a distinct interval between the tubercle and the ulnar facet. The shaft is constricted in the region of the tubercle and in cross-section would appear nearly circular. Below this neck-like portion the shaft is compressed from side to side and greatly expanded in an antero-posterior direction, attaining its maximum width near the distal epiphysis. The curvature of the shaft agrees with that of Arctocephalus australis, but it should be noted also that the anterior margin of the radius is missing. There is a longitudinal mesial depression on the internal surface of the distal half of the shaft. The facets on the distal epiphysis for articulation with the fused scapho-lunar-centrale appear to correspond in all essential details with those of the living fur seals.

\section{ULNA.}

The outlines of the ulna are not as clearly shown on this impression as might be desired. Of the olecranon process only the anterior margin is visible and the greater sigmoid cavity is overlain by the proximal end of the radius. The distal extremity of the ulna is wedged in between the ulnare and pisiform. The anterior face of the olecranon process is broad and rather deeply excavated. Unless the olecranon process has been distorted by pressure, the anterior face slopes much more noticeably toward the inner border than in Arctocephalus. The inner face of the distal end of the shaft of the ulna is flattened and not rounded as in the fur seal.

\section{Carpus.}

Though the outlines and peculiarities of the carpal bones are difficult to interpret from the impressions left by their palmar faces, the carpus seems identical with that of the otarids in proportions and in structure. Certain minor differences are to be expected in any genus of this family. In the sea lion, Eumetopias jubata (fig. 3), the ulnare is not interposed between the radius and the ulna, and the last-mentioned elements articulate directly with each other. In the fur seal, Callorhinus alascanus, the ulnare is interposed between the epiphysis of the radius and the styloid process of the ulna, and each of these elements has a facet for articulation with the ulnare. The position of the ulnare appears to agree more closely with the conditions found in the Callorhinus carpus than with that of Eumetopias. The pisiform is relatively slender. The unciform has been shifted from its original position and the ulnar surface apparently is exposed to view. In comparison to Callorhinus and Eumetopias, the consolidated scapho-lunar-centrale appears rather narrow, with well-developed tuberosities near the inner and outer angles. The magnum and trapezoid are rather small elements in this carpus. The trapezium is missing from this carpus if the other elements have been correctly interpreted. All the elements in this carpus are either out of their normal position or tilted one way or another.

\section{Metacarpals.}

Viewed from the palmar side, the metacarpals resemble those of Callorhinus alascanus. The first metacarpal differs from the others in its greater length and in the expansion of the proximal end. The shaft of the second metacarpal is distinctly narrowed; the facets for the third metacarpal and trapezium converge on the palmar 
face and are separated by a narrow crest. The third metacarpal is slightly shorter than the second. The palmar faces of the proximal ends of the third and fourth metacarpals are broader than the second. As in the living otarids, the fifth metacarpal is more robust than the others and the shaft is somewhat wider than the fourth.

TABLE 5.-Comparative measurements of the fore limbs (in millimeters).

\begin{tabular}{|c|c|c|c|}
\hline & $\begin{array}{c}\text { Pithanotaria } \\
\text { starri, Lompoc, } \\
\text { California. } \\
\text { Cat. No. } \\
\text { 26784, Univ. } \\
\text { California. }\end{array}$ & $\begin{array}{l}\text { Arctocephalus } \\
\text { australis St. } \\
\text { Peter \& Paul } \\
\text { Ids., Strait of } \\
\text { Magellan. Cat. } \\
\text { No. 23331, U. } \\
\text { S.N.M. }\end{array}$ & $\begin{array}{l}\text { Callorhinus } \\
\text { alascanus St. } \\
\text { Paul Id., Alas- } \\
\text { ka. } 4 \text { year old. } \\
\text { Cat. No. } \\
\text { 14225, } \\
\text { U.S.N.M. }\end{array}$ \\
\hline 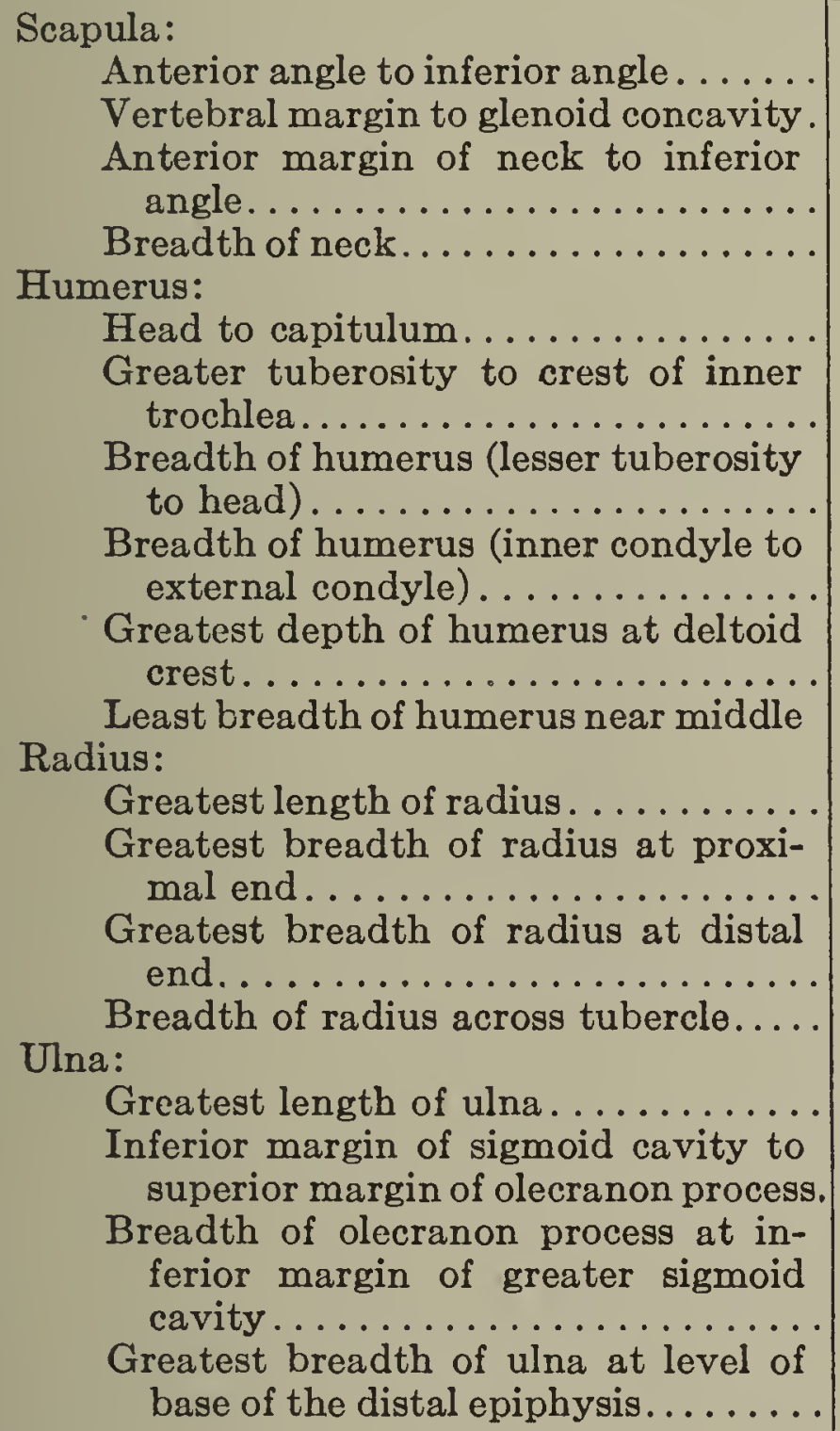 & $\begin{array}{c}187+ \\
130+ \\
155 \pm \\
33 \\
123+ \\
114 \\
\times \\
\times \\
38 \\
\times \\
106 \\
27.5 \\
\times \\
17.2 \\
139 \\
55 \\
\times \\
25\end{array}$ & $\begin{array}{c}216 \\
186.5 \\
186 \\
39 \\
160 \\
\\
174 \\
58.8 \\
58 \\
52 \\
26 \\
175 \\
27.8 \\
55 \\
18.5 \\
220 \\
85 \\
38 \\
22.5\end{array}$ & $\begin{array}{c}175 \\
148 \\
147.5 \\
31 \\
132.2 \\
144.5 \\
51 \\
55.5 \\
39 \\
22.1 \\
145 \\
24.8 \\
47.5 \\
16 \\
172.2 \\
60 \\
36 \\
22\end{array}$ \\
\hline
\end{tabular}

\section{INDIVIDUAL III.}

Referred specimen.-Cat. No. 26785, Museum of Palaeontology, University of California. Consists of impressions of the right and left hind limbs in a slab of diatomaceous earth. All the elements in the digits of both limbs are represented, including the dorsal faces of the digits in the right limb and the plantar faces of the digits in the left limb. Of the tarsal bones in the right limb, the dorsal faces of the cuboid, ectocuneiform, and (?) mesocuneiform, as well as the proximal face of the navicular, are preserved; the other tarsal bones either are missing or their impressions have been defaced. In the left limb the plantar view of the cuboid, the fibular view of the ectocuneiform, the tibial view of the calcaneum, the distal view of the navicular, and the head of the astragalus are shown. Median sections of the shafts of the right tibia and fibula, and a nearly complete left tibia with an unankylosed distal epiphysis are also present. 
Occurrence.-The Celite Company's No. 15 quarry, 300 feet west from the northwest corner of the NE. 1/4 of Section 22, Township 6 North, Range 34 West, San Bernardino Base and Meridian, 2.5 miles south and east of Lompoc, Santa Barbara County, California.
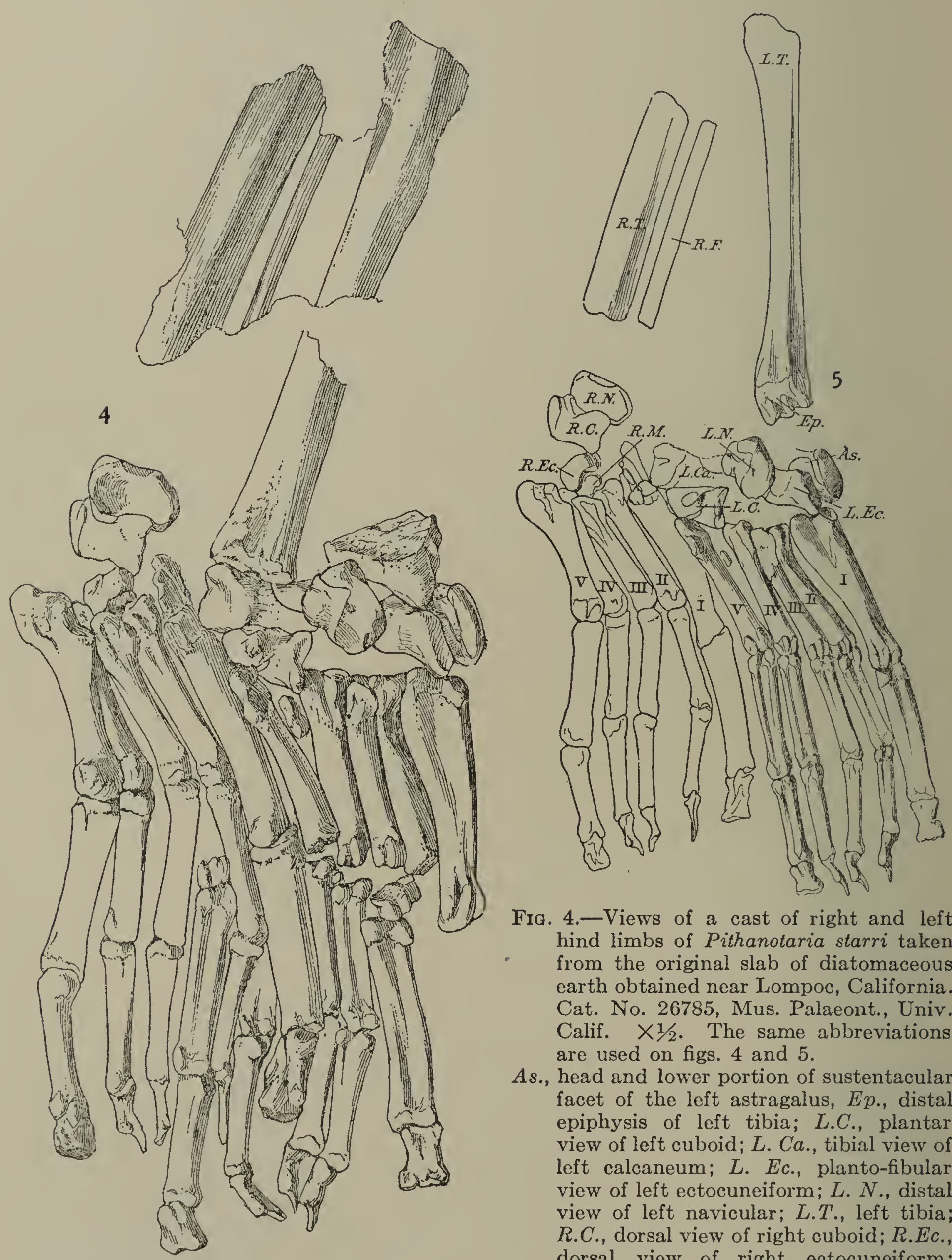

Fig. 4.-Views of a cast of right and left hind limbs of Pithanotaria starri taken from the original slab of diatomaceous earth obtained near Lompoc, California. Cat. No. 26785, Mus. Palaeont., Univ. Calif. $\times 1 / 2$. The same abbreviations are used on figs. 4 and 5 .

$A s .$, head and lower portion of sustentacular facet of the left astragalus, $E p$., distal epiphysis of left tibia; L.C., plantar view of left cuboid; $L$. Ca., tibial view of left calcaneum; $L$. Ec., planto-fibular view of left ectocuneiform; $L$. $N$., distal view of left navicular; L.T., left tibia; R.C., dorsal view of right cuboid; R.Ec., dorsal view of right ectocuneiform; $R . F$. , right fibula; R.M., dorsal view of right (?) mesocuneiform; R.N., proximal view of left navicular; R.T., right tibia; $I$ to $V$, first to fifth metatarsals.

FIG. 5.-Views of right and left hind limbs of Pithanotaria starri with the phalanges transposed to their normal positions. From deposits of diatomaceous earth near Lompoc, California. $\times 1 / 3$. 
Horizon.-These specimens were also acquired by the Museum of Palaeontology from Messrs. Edward B. Starr and Edward J. Porteous of the Celite Products Company at Lompoc, California. Sarmatian or Upper Miocene.

The pinniped to which these hind limbs belonged was a slightly larger individual than the type and may have been either a slightly older individual or a male.

\section{Tibia and Frbula.}

A fairly accurate description of the lower limb bones (fig. 4) can be given as median sections of the shafts of the right tibia and fibula, and the major portion of the shaft of the left tibia with a displaced distal epiphysis are represented in the impressions. On the cast the internal angle of the shaft of the left tibia faces the observer. In

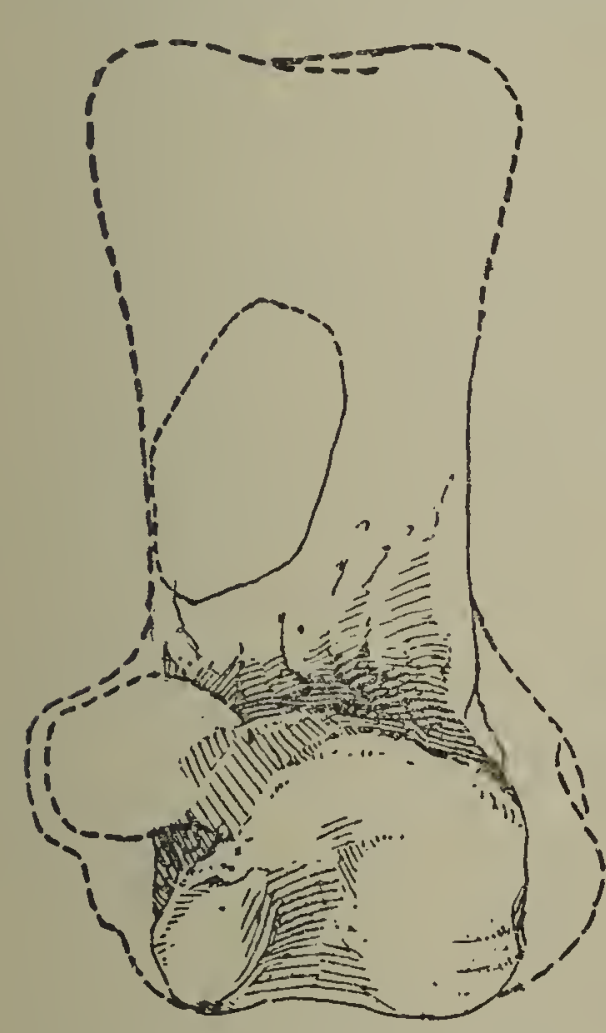

FIG. 6.-Tibial view of left calcaneum of Pithanotaria starri. Cat. No. 26785, Mus. Palaeont., Univ. Calif. $\times 1 \frac{1}{3}$. Diatomaceous earth near Lompoc, California. curvature and proportions it resembles that of Callorhinus alascanus very closely. The distal end of the shaft of this tibia is roughly three-sided, the anterior and internal faces being rounded and continuous, while the posterior and external are flattened and meet at an angle. The shaft of the left tibia measures $125 \mathrm{~mm}$. in length; the width of the distal epiphysis is $26 \mathrm{~mm}$. and the depth $19+$ $\mathrm{mm}$.; the length of this epiphysis is approximately 15.5 $\mathrm{mm}$. A pair of vertical grooves traverses the internal face of the epiphysis. The right fibula is as slender as that of Callorhinus.

\section{Calcanedm.}

Unfortunately, the left calcaneum (fig. 6) alone is represented among these tarsal impressions and a considerable portion of it is hidden from view by overlying bones. Above the greater process, the plantar border of the left calcaneum is overlain by the distal end of the shaft of the left tibia; the peroneal tubercle is hidden by the close approximation of the left cuboid and the first metatarsal of the right limb; the proximal end is overlain by the left navicular; and the major portion of the facet on which the ectal surface of the astragalus articulates is not represented in the impression. This calcaneum differs from those of Arctocephalus australis and Callorhinus alascanus in several respects. The most obvious peculiarity of this tarsal element in comparison to those of the above-mentioned genera is the obliquity of the facet for the cuboid and the less noticeable development on the distal extremity of the tibio-dorsal angle or lesser process. The facet for the cuboid is ovoidal in outline and apparently does not occupy more than one-half of the distal face of the calcaneum. The above-mentioned lesser process is merely a low rounded crest and the surface which articulates with the sustentacular facet of the astragalus is continuous with the facet for the cuboid as in Callorhinus. Only the inferior end of the articular surface for the reception of the ectal facet of the astragalus is shown in this impression. This facet does not extend across the tibial face of the dorsal border as in all of the living otarids and barely crosses the median sagittal plane of the shaft of the calcaneum. In this feature it resembles the calcaneum of Pontolis cf. magnus (see p. 102). The groove for the interosseous ligament appears to be shallow, as in Callorhinus.

\section{Astragalus.}

Neither the plantar nor the dorsal surfaces of the astragalus is included among the impressions of the tarsals. No trace of a right astragalus can be found and only a portion of the head of the left is represented. The internal angle of the head of this astragalus is relatively thicker than in either Arctocephalus or Callorhinus. The 
distal surface of the head is convex in all directions and serves as the articular surface for the proximal facet of the navicular; in outline it is almost kidney-shaped. Turning to the plantar surface of the head, other differences may be pointed out. There is a rather deep groove invading the sustentacular facet from the internal border and ending about two-thirds of the distance across the head on those of living otarids. A similar groove is present on this fossil astragalus, but it is very shallow. The sustentacular facet also approaches nearer to the internal border of the neck than in living otarids.

\section{NAVICULAR.}

Both naviculars are represented in the impressions of the tarsal bones. This tarsal element is extraordinarily broad and subquadrangular in outline. Its proportions are quite different from those of Callorhinus, Zalophus, and Eumetopias, and as a whole bear a much closer resemblance to those of Arctocephalus. The proximal facet of the right navicular (fig. 7) for articulation with the head of the astragalus is deeply concave, with a sudden upward curvature toward the tibial and fibular borders. The curvature of the dorsal margin of this facet is regular in contrast to the medial depression on those of Callorhinus, Arctocephalus, and Zalophus. The fibular border is much shorter than the tibial; the facet for the cuboid is short and obliquely truncated. In outline the distal face of the left navicular (fig. 7) bears some resemblance to that of Arctocephalus. The tuberosity on the plantar face of the navicular, which in living otarids is directed toward the fibular border, is placed nearest to the tibial or posterointernal angle. There are three facets, though continuous with one another, on the distal face of the navicular of Arctocephalus; the largest facet articulates with the entocuneiform and extends about halfway across this face; the other two facets articulate with the meso- and ectocuneiform. The most distal portion of the navicular is at the crest which separates the facets for the ento- and mesocuneiforms. On this fossil navicular the facets for the three cuneiforms are not as distinct; the internal half of this face is nearly flat and horizontal, while the external curves upward toward the fibular and plantar borders. In comparison with that of Arctocephalus, the facet for the entocuneiform is not as wide as it extends less than halfway across the tibial border. In this respect, it agrees more closely with that of Callorhinus than with Arctocephalus. The depressed rugose area, which in living otarids restricts the facets for the cuneiforms from the plantar half of this face, is not developed on this fossil navicular. The tubercle at the tibial or postero-internal angle is more prominent than in Arctocephalus. The dorso-fibular angle is rounded off, but the dorso-tibial angle is nearly square.

TABLE 6.-Comparative measurements of the navicular (in millimeters).

\begin{tabular}{|c|c|c|c|}
\hline & $\begin{array}{c}\text { Pithanotaria starri, } \\
\text { No. 26785, U. C. }\end{array}$ & $\begin{array}{c}\text { Arctocephalus } \\
\text { australis, No. 23331, } \\
\text { U.S.N.M. }\end{array}$ & $\begin{array}{c}\text { Callorhinus alas- } \\
\text { canus, No. 20866, } \\
\text { U.S.N.M. }\end{array}$ \\
\hline $\begin{array}{c}\text { Tibio-fibular diameter...... } \\
\text { Greatest dorso-plantar di- } \\
\text { ameter................. }\end{array}$ & $23.5+$ & 26.1 & 28 \\
\hline
\end{tabular}

\section{Coвord.}

This cuboid is slightly smaller than that of Arctocephalus australis, but the astragalocuboid contact is essentially the same. The dorsal surface of the right cuboid (fig. 8) and the curvature of the proximal facet for the calcaneum are very clearly shown on this cast. From a dorsal view, this cuboid resembles that of Arctocephalus more closely than that of Callorhinus. The upward slope of the calcanear facet is not nearly as oblique as in Callorhinus and corresponds more closely with that of Arctocephalus, 


\section{New Pinnipeds from Vicinity of Lompoc, California.}

but the anterior border is rounded off and not crest-like as in the latter. On the tibial border and about $6 \mathrm{~mm}$. below the summit of the calcanear facet, there is a small projecting ovoidal facet for articulation with the antero-external angle of the navicular. Similar facets are present on the cuboids of Arctocephalus and Callorhinus, but they do not project beyond the level of the tibial border. The proximal and distal portions of this cuboid are nearly equal in diameter in contrast to the proximal expansion of the Arctocephalus cuboid. The curvature of the distal border of the anterior face agrees with that of Callorhinus. Some well-marked peculiarities characterize the plantar face of the left cuboid (fig. 8). The groove for the peroneus longus is sharply defined and curves upward from the tibial border. The tuberosity is small and rounded and does not extend entirely across the plantar face as in Arctocephalus. On the cuboid of Callorhinus the groove for the peroneus longus is shallow and the course of the groove is nearly horizontal; the tuberosity is low, rounded, and poorly defined. On

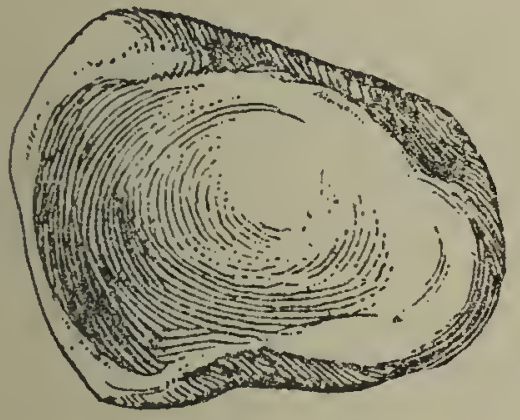

A

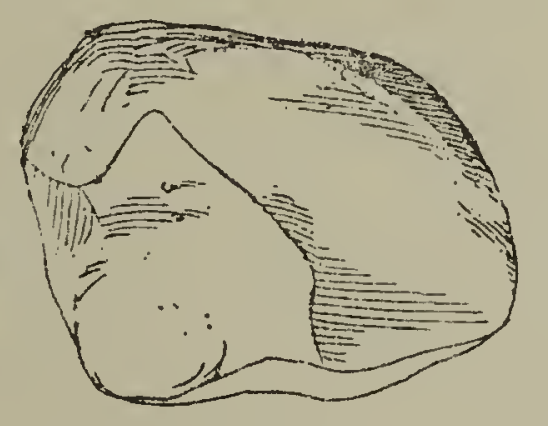

B

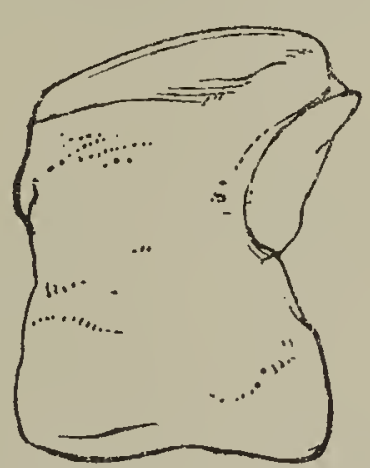

A

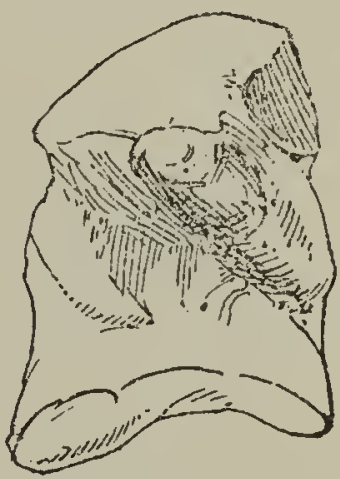

B

FIG. 7.-Navicular of Pithanotaria starri. Cat. No. 26785, Mus. Palaeont., Univ. Calif. Diatomaceous earth near Lompoc, California. $A$, proximal view of right navicular; $B$, distal view of left navicular. $\times 1 \frac{1}{3}$.

FIg. 8.-Cuboid of Pithanotaria starri. No. 26785, Mus. Palaeont., Univ. Calif. Diatomaceous earth near Lompoc, California. $A$, dorsal view of right cuboid; $B$, plantar view of left cuboid. $\times 1 \frac{1}{3}$.

the cuboids of Arctocephalus and Callorhinus there is a deep excavation behind the calcanear facet and above the tuberosity. This excavation is not present on the left cuboid of this fossil pinniped, and this portion of the tarsal agrees more closely with that of Monachus tropicalis, although the cuboid of the latter otherwise is quite different. The distal border of the plantar face of this fossil cuboid is shallowly concave.

TABLE 7.-Comparative measurements of the cuboid (in millimeters).

\begin{tabular}{|c|c|c|c|}
\hline & $\begin{array}{c}\text { Pithanotaria starri, } \\
\text { No. } 26785 \text {, U. C. }\end{array}$ & $\begin{array}{c}\text { Arctocephalus } \\
\text { australis, No. 23331, } \\
\text { U.S.N.M. }\end{array}$ & $\begin{array}{l}\text { Callorhinus alas- } \\
\text { canus, No. } 29866 \text {, } \\
\text { U.S.N.M. }\end{array}$ \\
\hline $\begin{array}{l}\text { Breadth of anterior face of } \\
\text { cuboid at level of lower } \\
\text { margin of proximo-tibial } \\
\text { facet for the navicular..... } \\
\text { Breadth of anterior face of } \\
\text { cuboid at distal extremity. } \\
\text { Length of cuboid from sum- } \\
\text { mit of calcanear facet to } \\
\text { tibio-distal angle......... } \\
\text { Breadth of plantar facet of } \\
\text { cuboid at distal extremity }\end{array}$ & $\begin{array}{l}12.2 \\
13.6 \\
24.5 \\
15\end{array}$ & $\begin{array}{r}17.2 \\
15.3 \\
24.6 \\
17.5\end{array}$ & $\begin{array}{l}16 \\
16.2 \\
30.8 \\
26.3\end{array}$ \\
\hline
\end{tabular}

\section{ENTOCUNEIForM.}

An imperfect impression of what appears to be the right entocuneiform lies immediately above the head of the first right metatarsal. One can not be certain of the surface which is exposed, as a portion of this tarsal has been destroyed. 


\section{MESOCUNEIFORM.}

If the impression which is assumed to be the right mesocuneiform has been correctly identified, then it was relatively smaller than the same element in the tarsus of Callorhinus and of approximately the same proportions as that of Arctocephalus. It is wedged in between the right ectocuneiform and the head of the second metatarsal.

\section{ECTOCUNEIFORM.}

In general appearance, the left ectocuneiform differs from those of Arctocephalus and Callorhinus in many respects. The plantar face is nearly flat and obliquely truncated. The blunt process which is developed on the proximal half of the plantar face of the ectocuneiform of living otarids is absent. The proximal facet for the navicular is slightly convex. An obliquely placed depression is present on the fibular face. Very little additional information can be given for the right ectocuneiform; the anterior face of this tarsal is shown on figure 4.

\section{Digits.}

In the relative lengths of the metatarsals and phalanges, the digits (figs. 4 and 5) of this pinniped are slightly smaller than those of a two-year-old Callorhinus alascanus. These flippers also agree with those of living otarids in that the first and fifth digits did not bear nails and their ungual phalanges are flattened in a dorso-plantar direction, constricted mesially, and expanded from side to side distally. The ungual phalanges of the second, third, and fourth digits are modified to support nails. The general resemblance of these digits to those of a living fur seal is remarkably close.

The first digit consists of a metatarsal and two phalanges; the other digits have a metatarsal and three phalanges. The first metatarsal is quite similar to that of Callorhinus. It is longer than all the other metatarsals. The internal view of the right and the plantar view of the left first metatarsal are shown on figure 4 . The shaft of this metatarsal is relatively thicker nearer the proximal end than in Callorhinus and the distal end is almost circular. There is a shallow longitudinal depression on the proximal half of the plantar face of the left metatarsal. The proximal end is occupied by a large facet and the surface slopes upward toward the fibular margin. The shaft of the second metatarsal is slender and nearly straight. On the tibial surface and along the proximal border there is a narrow facet for articulation with the entocuneiform. As in Callorhinus there is no articular surface for the head of the first metatarsal. The plantar face of the shaft of the left metatarsal is rounded. The head of the third metatarsal is larger than that of the second. The articular surface on the proximal end slopes obliquely from the tibial to the fibular border. A prominent knob-like process or tuberosity is developed on the tibial face of the head. The shaft is nearly circular in cross-section and approximately of equal width throughout its length. The head of the fourth right metatarsal is concealed by the close approximation of the third and fifth metatarsals. A narrow crest on the plantar face of the head of the left fourth metatarsal marks the contact of the facet for the third metatarsal and a similar facet for the fifth. The shaft is slightly longer than the third, but otherwise it is very similar. In general features the fifth metatarsal does not differ from those of Arctocephalus and Callorhinus. A concave facet for the head of the fourth metatarsal occupies the tibial face of the head. The external angle of the head is prolonged upward and on the plantar face attains a much higher level than the dorsal margin of the facet for the cuboid. The shaft is abruptly narrowed below the head, but the distal extremity is slightly expanded.

The plantar surfaces of the shafts of the first phalanges are characterized by a median longitudinal depression and their dorsal surfaces are rounded. The first phalanges of the first and fifth digits are longer and stouter than the others. The second phalanges of the second to fifth digits inclusive have their plantar faces flattened and their dorsal faces rounded; the shafts taper toward the distal end. 
TABLE 8.-Comparative measurements of the greatest length of metatarsals and phalanges (in millimeters).

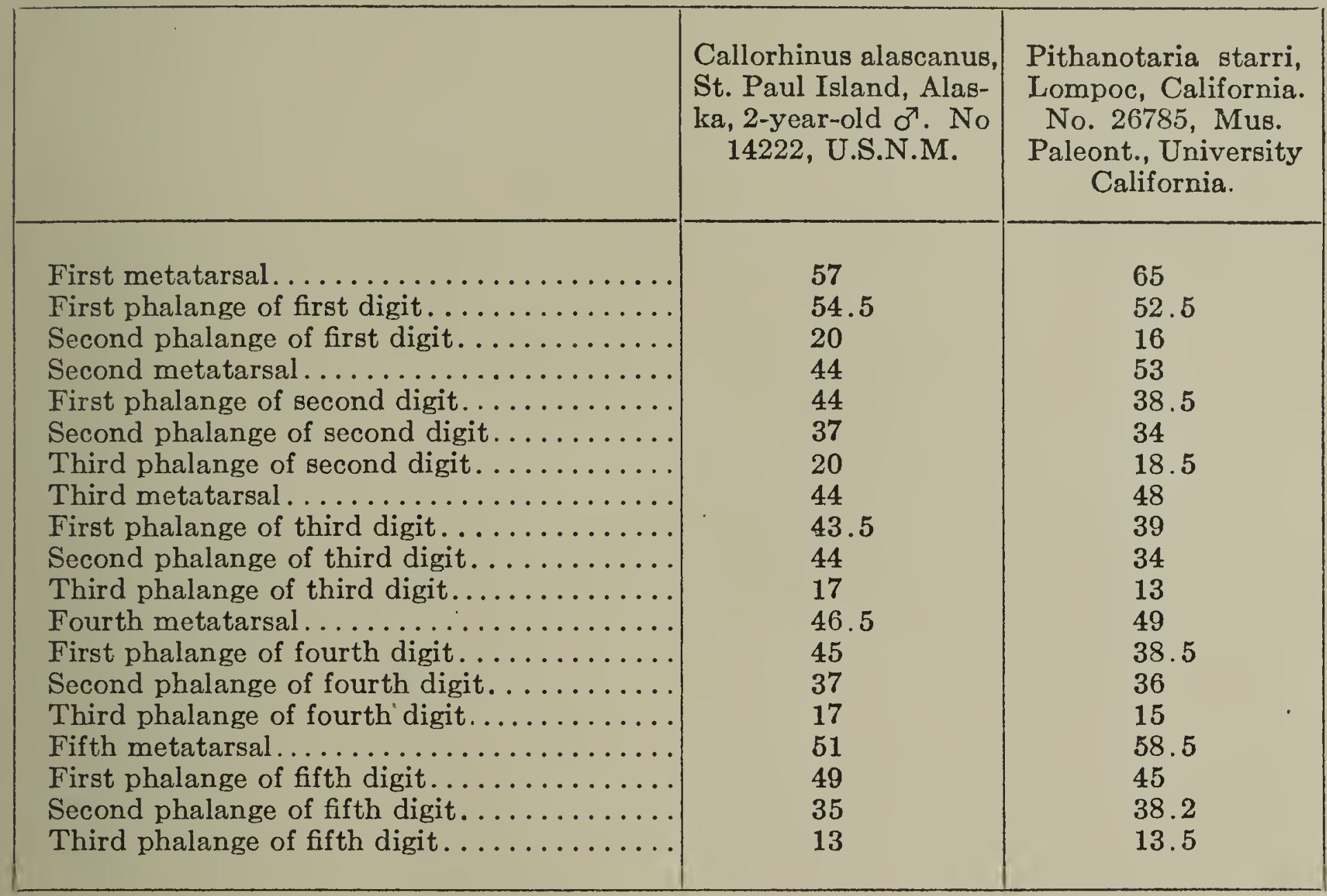

Otarid (?), new genus and species.

From time to time bones of pinnipeds in a more or less perfect state of preservation are found in marine Tertiary deposits on the Pacific Coast of North America. Many of these are discarded by the collectors soon after discovery because of the prevailing impression that it is futile to attempt to determine such fragmentary material. Fortunately, a number of these specimens have found their way into collections on the Pacific Coast and in the course of a rather cursory examination of this material a number of interesting pinnipeds have been discovered. Some of them, in so far as can be determined from the meager skeletal evidence, exhibit resemblances to the family Otariidæ. One of these pinnipeds was obtained from the same formation as Pithanotaria starri, and although the material is too incomplete to warrant the application of a scientific name, it is apparent that it represents a new type.

Specimens.-Cat. No. 24221, distal end of the right tibia, and Cat. No. 24222, four closely appressed ribs from the left side of the body, Museum of Palaeontology, University of California.

Occurrence.-On northeast side of the first canyon entering San Miguelito Creek Canyon from the east and 0.5 mile northeast of 855-foot elevation hill (Lompoc Quadrangle, U. S. Geol. Surv.), and on the opposite side of the canyon from Quarry No. 9 of the Celite Products Company. Southwest 1/4 of section 15, township 6 N., range $34 \mathrm{~W}$. This site is 1.5 miles south and east of Lompoc, Santa Barbara County, California. Locality No. 3545, Museum of Palaeontology. 
Horizon.-The bones were discovered by Mr. Edward J. Porteous during the month of October 1920, while examining the exposure of diatomaceous earth on the opposite side of the canyon from a quarry then in operation. It is impossible to state, at the present writing, the exact level in the beds where these remains were found. Sarmatian or Upper Miocene.

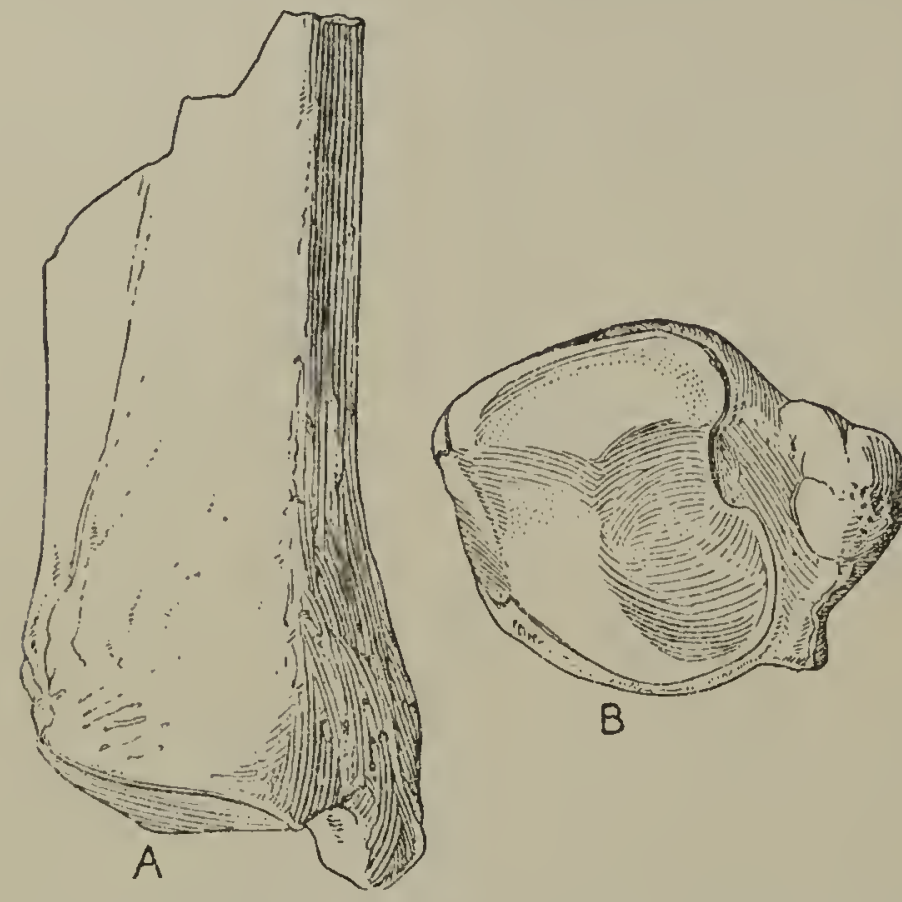

Fra. 9.-Right tibia of an Otarid(?). Cat. No. 24221, Mus. Palaeont., Univ. Calif. Diatomaceous earth near Lompoc, California. $A$, anterior view; $B$, distal view. $\times 1 / 2$.

FIG. 10.-Left rib of an Otarid (?). Cat. 24222, Mus. Palaeont., Univ. Calif. Diatomaceous earth near Lompoc, California. $A$, external view; $B$, internal view. $\times 1 / 2$.
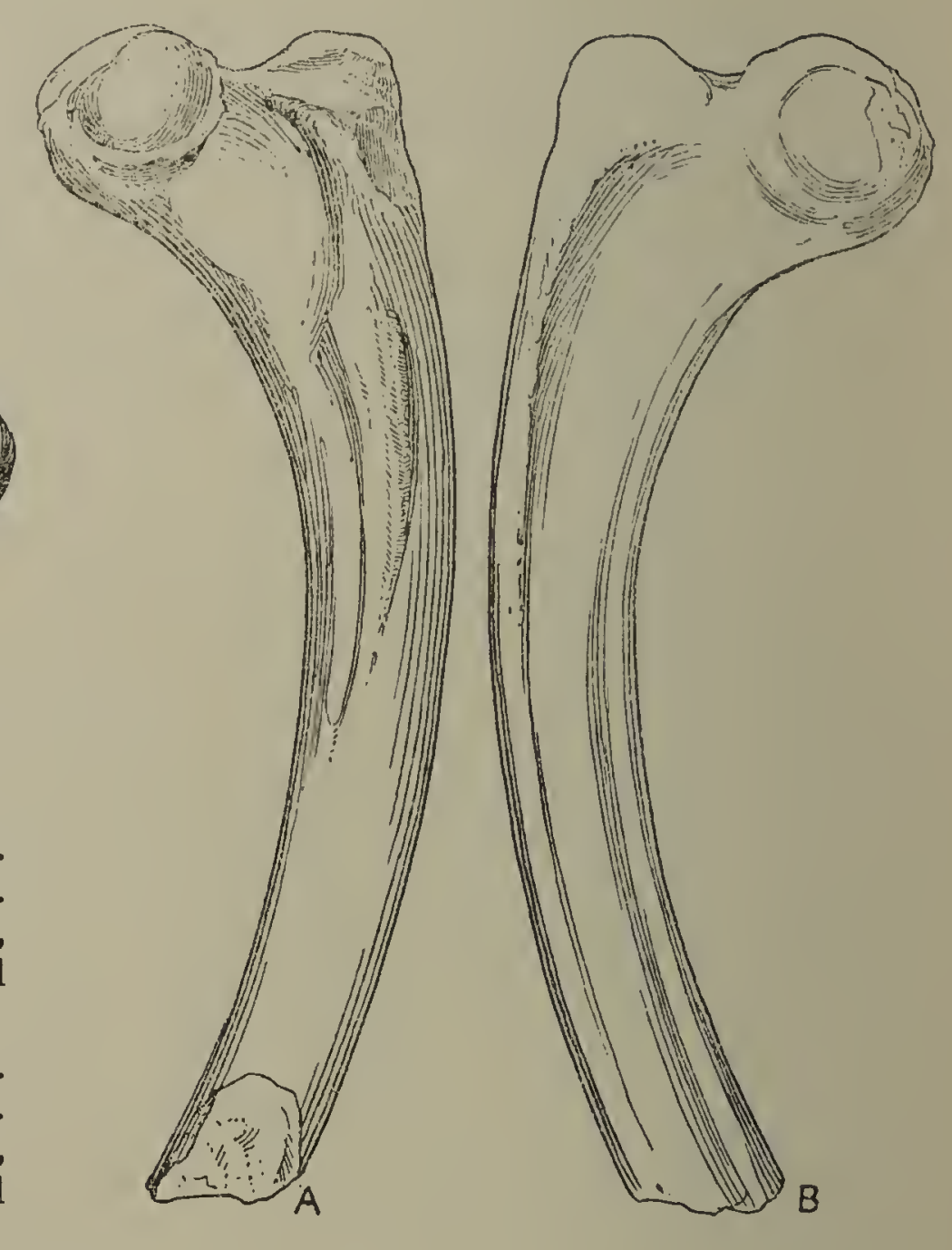

Tibia.

The lower extremity of the tibia is expanded laterally, principally on the internal side. The distal end is thicker as well as broader than the portion of the shaft just above it. The internal surface is continued down beyond the rest of the lower extremity to form the internal malleolus and narrows perceptibly towards the point. The external or fibular surface of the shaft is much broader than the internal and on the lower margin there is an elongated concave facet for articulation with the fibula. The lower margin of the posterior surface of the distal end is strongly convex from side to side in contrast to the flattened appearance of the same portion of the tibia of Eumetopias jubata.

From a distal view (fig. 9) the internal malleolus is observed to terminate in a pointed protuberance and is separated from the astragalar facet by a roughened surface. The main articular facet for the astragalus consists of two surfaces, separated from each other by a slightly curved ridge, the inner one being nearly twice as large as the outer, and concave in both directions; the outer surface is concave from before backwards and is continuous externally with the fibular facet. There is a third surface, however, anterior to these which is directed obliquely upward and articulated with the trochlea of the astragalus.

This fragment of the right tibia (fig. 9) has been compared with all of the living otarid genera and with Odobenus. Of these pinnipeds, the tibia of Odobenus exhibits the closest resemblance. Somewhat similar modifications are present on the tibia of Arctocephalus. The distal articular surface is divided into the same number of facets as in Odobenus and these facets correspond with one another not only in extent but also in position. The presence of a long, narrow facet along the anterior border suggests 
articulation with an astragalus of the Odobenus type. In the latter, the external prolongation of the head of the astragalus is much less developed than in Arctocephalus; the facat on the external face of the head for articulation with the distal extremity of the fibula is more or less flattened, while the sarne surface is deeply concave in the latter. The narrow anterior facet on the distal face of the tibia appears to be correlated with a broad, shallow trochlea on the astragalus.

RiBS.

Four crushed and incomplete ribs from the left side of the body were found associated with the fragment of the right tibia. One of these (figs. 10a, 10b) was selected for illustration. The shafts of all of these ribs are relatively heavy as compared to those of Zalophus. The shaft of the rib figured herewith measures $20 \mathrm{~mm}$. in width and 21 $\mathrm{mm}$. in thickness at a point $70 \mathrm{~mm}$. below the tuberculum. The external, anterior, and posterior faces of the shaft are more or less flattened, but the internal face is depressed, with the posterior margin rounded off and the anterior forming a rather sharp crest. The tuberculum is relatively small, compressed from side to side, and its articular surface slopes obliquely upward. The neck is thin and rather wide. The capitulum consists of two articular facets which are continuous anteriorly although there is a V-shaped indentation inferiorly. These two facets are convex in all directions and are approximately equal in size. 



\section{STRUCTURE OF THE FLIPPER OF A PLIOCENE PINNIPED FROM SAN DIEGO COUNTY, CALIFORNIA.}

The pinniped remains, from the Fernando formation, which form the subject of the present paper, were obtained by Oscar Mitchell in the fall of 1919 in exposures on the south side of Soledad Canyon, San Diego County, California. During the month of November in the same year, Dr. Chester Stock, while engaged in geological work in San Diego County, was informed that a boy had discovered a sandstone nodule containing fossil bones. Dr. Stock obtained permission to examine the nodule, and found that it contained part of the right hind-limb of some pinniped. Through the generosity of the boy's father, Mr. J. W. Mitchell, the Department of Palaeontology of the University of California a short time later came into possession of the specimen.

As recently as 1906, the number of fossil Otariidae known from North America was limited to two more or less doubtfully allocated forms from the coast of Oregon. Important information relative to the exact site of discovery, including the proper horizon, either was not available or was neglected by the original describers, and for this reason the two forms have for some time offered a serious problem in age determination.

Following the discovery of Desmatophoca oregonensis ${ }^{1}$ in sandstone exposures about 8 miles south of Yaquina Bay on the coast of Lincoln County, Oregon, there came to light in the Coos Bay region another pinniped which has been named Pontolis magnus. ${ }^{2}$ More recently a third pinniped of large size, Pliopedia pacifica, ${ }^{3}$ was found near Santa Margarita, San Luis Obispo County, California, and has added some additional information regarding the fossil pinnipeds of the Pacific Coast.

According to Wortman ${ }^{4}$ there is some evidence which supports the assumption that the formation, from which Desmatophoca oregonensis came, may possibly be equivalent in time to the middle Oligocene of our interior series. More recently, Arnold and Hannibal ${ }^{5}$ have referred beds in this area to the Oligocene-Miocene.

Although the skull of Pontolis magnus was found in a formation assumed to be part of the "Empire beds," the exact location is quite

1 T, Condon, Univ. Oregon Bull., Suppl., vol. 3, No. 3, pp. 5-14, pls. 1-2, with 3 text figs., 1905; O. P. Hay, Proc. U. S. Nat. Mus., vol, 49, Publ. 2113, p. 383, 1915.

2 F. W. True, Smithson. Misc. Coll. (Quart. Issue), vol. 48, pt. 1, Publ. 1577, p. 48, 1905;

Prof. Paper, No. 59, U. S. Geol. Surv., pp. 144-147, pls. 21-23, 1906.

${ }^{3}$ R. Kellogg, Journ. Manmalogy, vol. 2, No. 4, pp. 212-226, with 13 text figs., 1921.

4 J. L. Wortman, Science, n. s., vol. 24, No. 603, pp. 89-92, 1906.

${ }^{5}$ R. Arnold and H. Hannibal, Proc. Amer. Philos. Soc., vol. 52, No. 212, pp. 582, 587, pl. 38, 1913; H. Hannibal, Journ. Mammalogy, vol. 3, No. 4, p. 239, 1922. 
indefinite, for True states that the skull was found in a sandstone bluff on the east side of the lower part of Coos Bay, between Empire City and the "north slough." While the exact place of discovery is not definitely known, information from other sources indicates that Pontolis belongs to the Pliocene period. Howe ${ }^{1}$ has brought forth evidence to show that the Empire formation is lower Pliocene. At present the skeleton of Pontolis magnus is unknown, while we have only the right hind-flipper of the skeleton of the present pinniped.

Thus the occurrence of Pontolis magnus in the Pliocene beds of Oregon furnishes additional evidence that this fossil flipper from the Fernando formation in California may possibly belong to the same genus and even to the same species. Judging from the proportions of the skull, which the writer has recently examined, Pontolis magnus was a large pinniped, whose proportions were unquestionably similar to the animal to which the present flipper belonged.

An additional metapodial has recently been placed in the hands of the writer. It represents the first metatarsal, and apparently belongs to the same species as the flipper from the Fernando exposures in Soledad Canyon. This specimen was found during the month of March in 1920 by Mr. Howell Gester, of the geological staff of the Standard Oil Company, in a bed (Museum of Palaeontology, locality No. 3584) of presumably the same age as that from whence the nodule containing the flipper came. Accompanying the metapodial were the following data:

Occurrence: Section 27, township 4 north, range 15 west, near the section line directly west of $2,006^{\prime}$ elevation hill. Bone was found in sandy shale formation immediately below a conglomerate layer about 6 feet in thickness. In the same layer in which metapodial was found, the following shells were also collected: Terebratula n. sp., Phacoides sactaecrucis?, and a pecten which may possibly be Pecten estrellanis. Above the conglomerate are several hundred feet of sandy shale in which a lower Fernando invertebrate fauna was found. (On U. S. Geol. Surv., Fernando Quadrangle, Los Angeles County, California.)

\section{Pontolis cf. magnus True.}

In the nodule from Soledad Canyon (Museum of Palaeontology, locality No. 3585). and associated with the fossil flipper, were fragments of two mollusks, one of which was determined by Dr. Bruce L. Clark as Leda taphra, while the other represents some gasteropod. The occurrence of this nodule is as follows: SW quarter of NE quarter of section 27, township 4 north, range 15 west, on the south side of Soledad Canyon and near the town of Humphreys, San Diego County, California.

This flipper is quite unusual in many respects, and differs in some important features from living pinnipeds. Though at first glance certain features resemble the Cystophorinae, especially the genus Mirounga, these characters are superficial and, apparently, have no important bearing on the relationships of the specimen in question. After a careful comparison with many living pinnipeds, the writer is convinced that this specimen possesses a number of unusual characters, which are quite unlike any other known pinniped, though its relationships are with the sea-lions and the walruses,

${ }^{1}$ H. V. Howe, Univ. Calif. Publ., Bull. Dept. Geol. Sci., vol. 14, No. 3, pp. 85-114, 1922. 
rather than with the true seals. A considerable number of pinnipeds were critically examined, but were found either to be allied to this fossil specimen, or to be so unlike as not to be pertinent in the present study. The following among those examined were found to show certain resemblances: Odobenus divergens, Eumetopias jubata, Arctocephalus australis, Zalophus californianus, and Mirounga angustirostris. In most respects the tarsal elements of the hind-limb of the Phocidae are quite unlike this fossil flipper, while the Odobenidae and Otariidae, which morphologically are closely allied to one another, possess many features in common with this Pliocene pinniped.

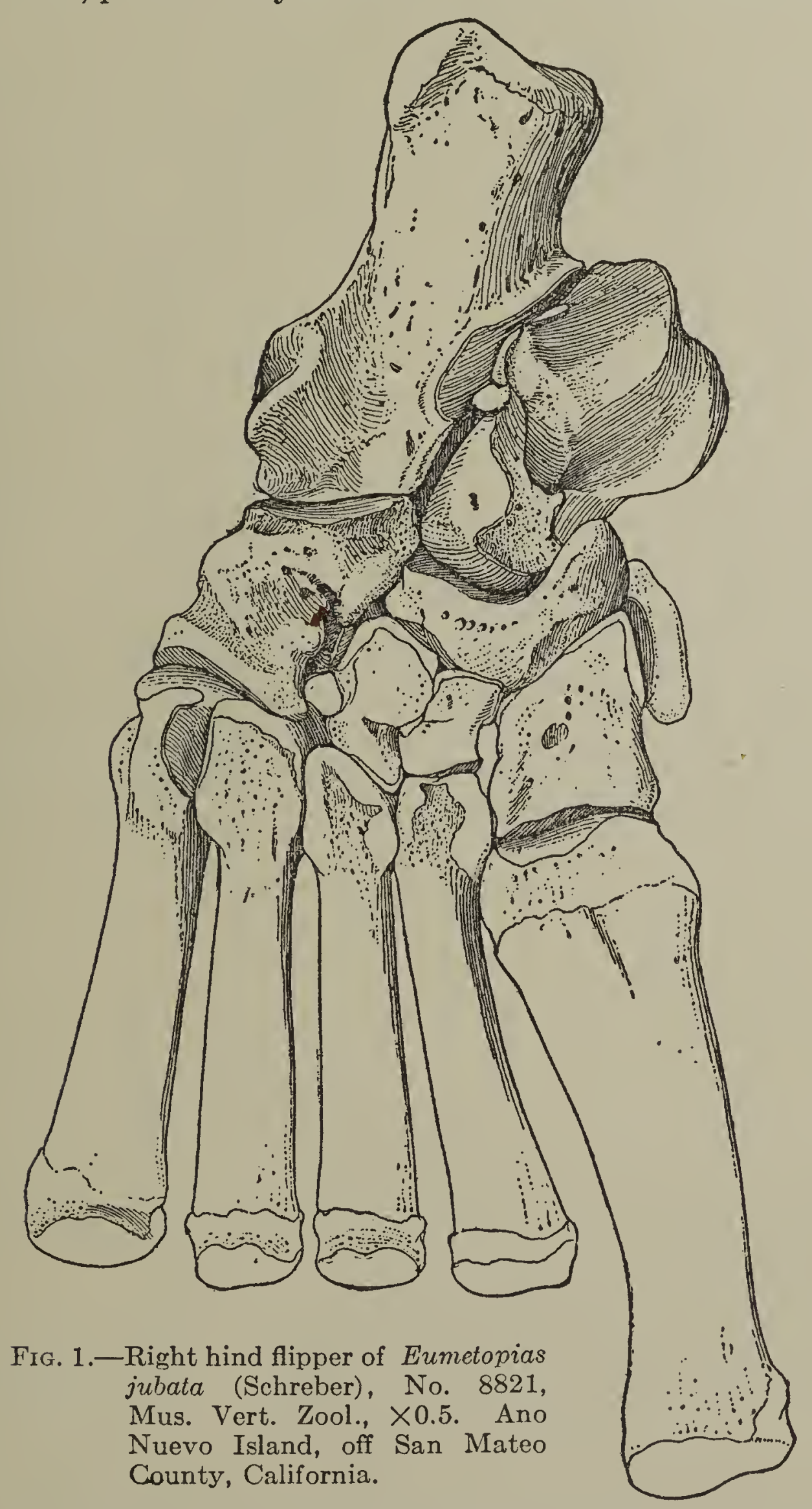

The extension of the fibular facet of the astragalus distally upon the neck is a feature that is not found in any other pinniped. This modification is accompanied by the loss of the external portion of the body of that bone. The astragalo-cuboid contact is smaller than in our living otarids. However, this fossil flipper resembles the sea-lions in so many features, even though some are considerably modified, that it is referred 
tentatively to the Otariidae. Should more of the skeleton become known, it may eventually be allocated to its proper group. It is hardly possible that this Pliocene pinniped is one of the forebears of the living Otariidae, but more probably it represents a somewhat highly modified offshoot which became extinct some time during the Pliocene.

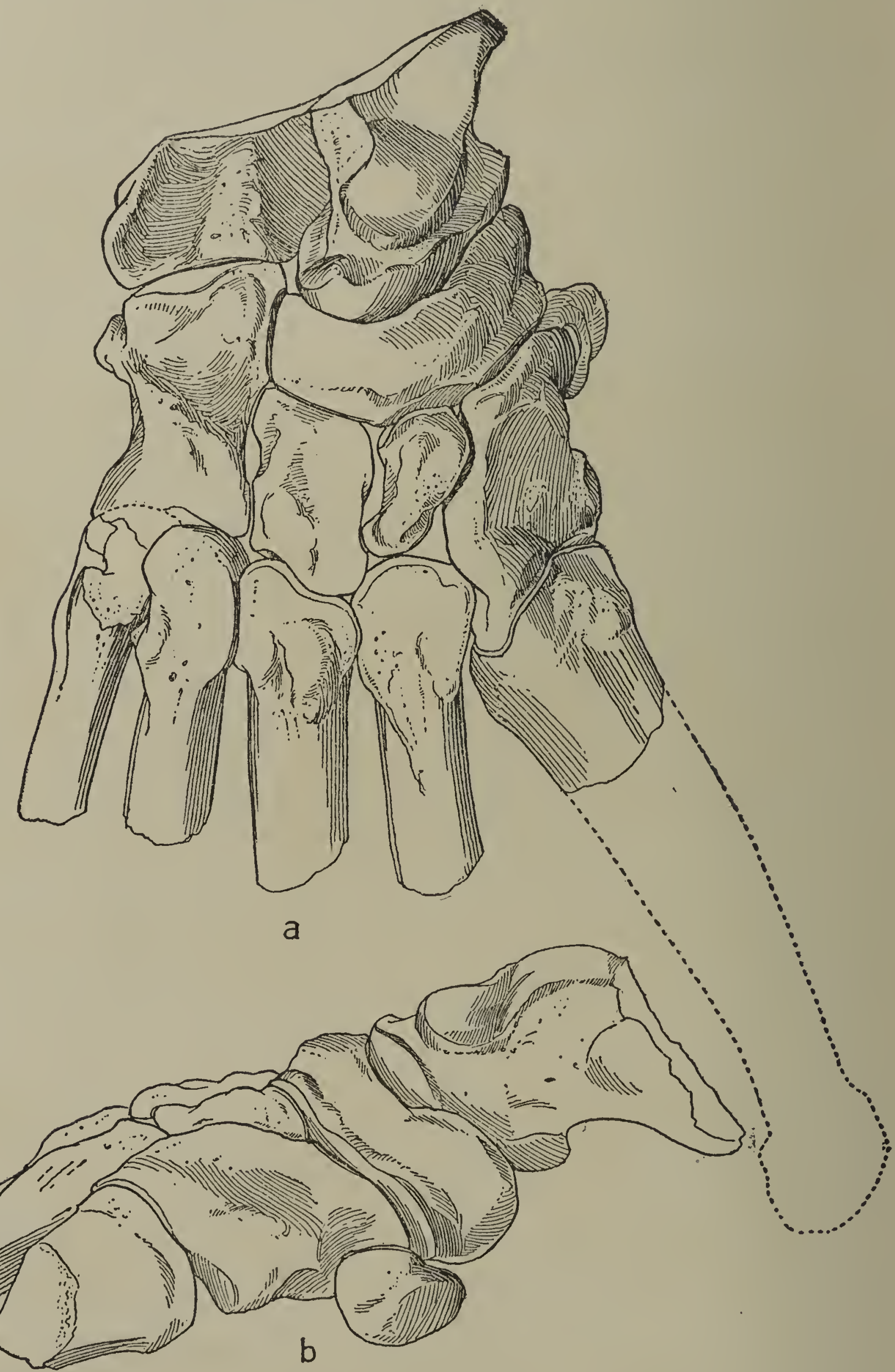

FIG. 2.-Right hind flipper of Pontolis ef. magnus, Nos. 24070-82, Mus. Palaco., Univ. Calif., $\times 0.5$. Exposures on south side of Soledad Canyon, San Diego County, California; $a$, superior view; $b$, lateral view.

On the other hand, the possession by this fossil pinniped of a number of structural modifications peculiar to the Odobenidae is a further indication that fossil walruses may 
be expected in Miocene beds on the Pacific coast, and affords some additional evidence in support of the origin of the Odobenidae in the North Pacific Ocean rather than in the North Atlantic.

I take this opportunity to express my indebtedness to Dr. John C. Merriam for the advice and assistance he has given me in the study of the fossil Pinnipedia; and also to Dr. Chester Stock for help along the same lines. The drawings used in this paper were made by Mrs. Freida Abernathy.

Acknowledgment is made here to Dr. Joseph Grinnell, director of the Museum of Vertebrate Zoology, and Mr. Gerrit S. Miller Jr., United States National Museum, for the loan of skeletons of living pinnipeds for comparison.

\section{TARsus.}

Calcaneum possesses a rounded and produced greater process. Astragalus apparently lacks the external prolongation of the body, while the fibular facet is extended distally on the neck. There is a reduced astragalo-cuboid contact. The navicular is of
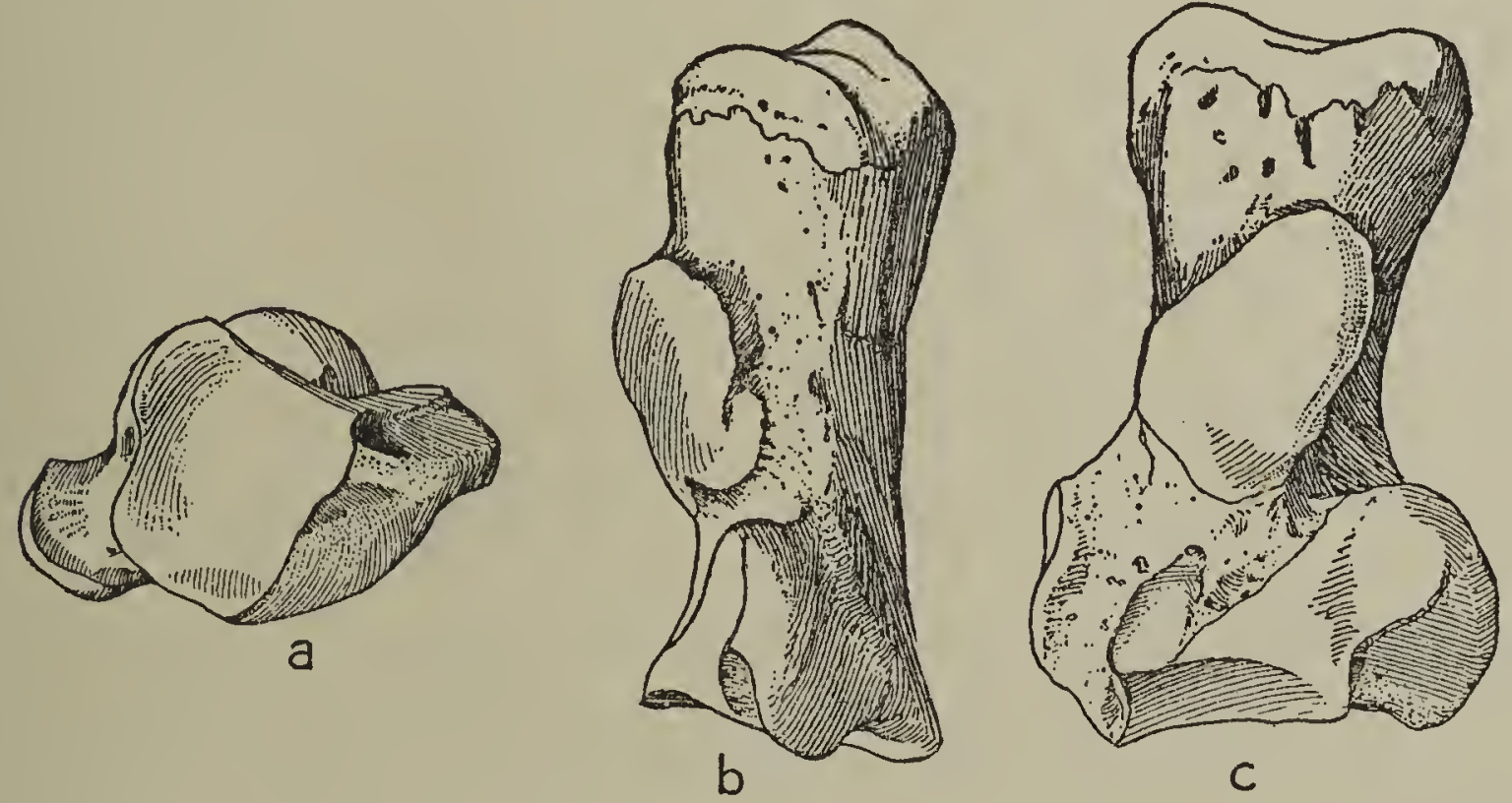

Fig. 3.-Calcaneum of Eumetopias jubata (Schreber), No. 4112, Mus. Vert.

Zool., $\times 0.5$. Ano Nuevo Island, off San Mateo County, California. $a$, distal view; $b$, plantar view; $c$, tibial view.
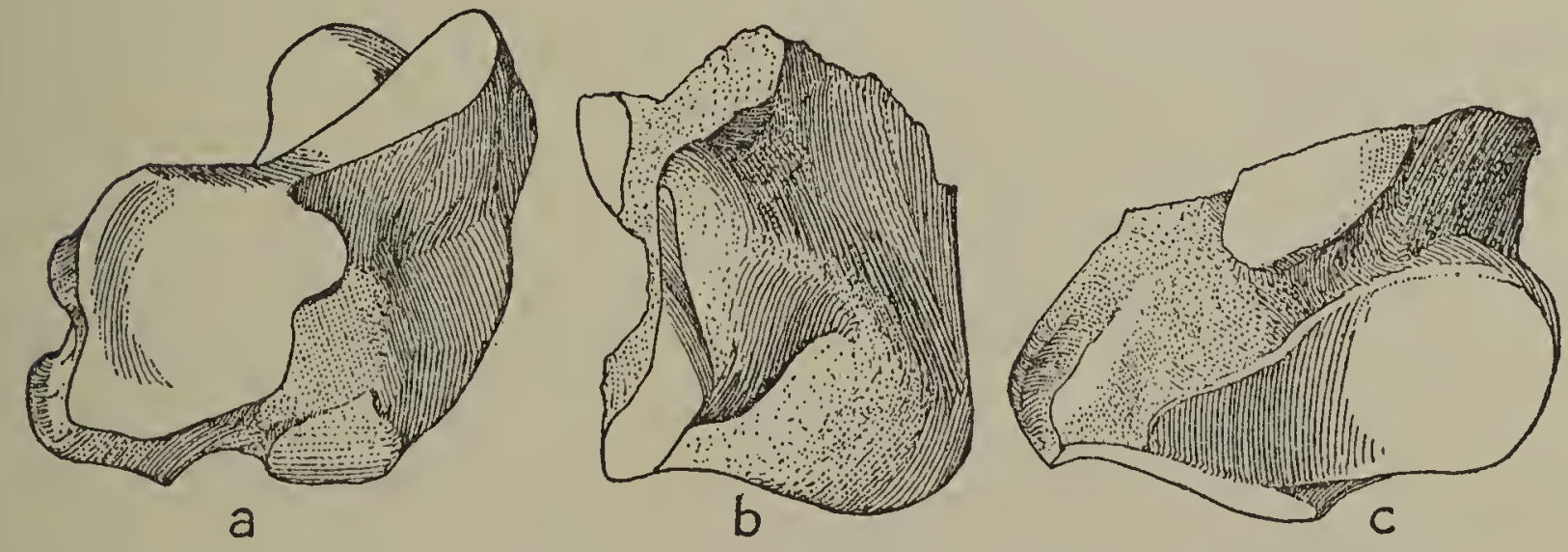

FIG. 4.-Calcaneum of Pontolis cf. magnus, No. 24070, Mus. Palaeo., Univ. Calif., $\times 0.5$. Exposures on south side of Soledad Canyon, San Diego County, California. $a$, distal view; $b$, plantar view; $c$, tibial view.

large proportions; the plantar tuberosity is directed to the tibial side. Calcanear facet on cuboid is somewhat flattened and slopes but slightly upward from fibular side; the tuberosity of the cuboid is restricted to fibular half of plantar face. Ectocuneiform is prismatic, its plantar aspect prolonged into a blunt vertical hook and lacking a proxi- 
mal facet of tibial face. Mesocuneiform is twisted toward the tibial side on plantar half, with no proximal facet on fibular surface. Entocuneiform is prismatic, with V-shaped proximal facet for distal surface of the navicular. Sesamoid is irregularly cone-shaped. Metatarsals are long and robust, with proximal ends expanded, and possessing well-defined facets for articulation with tarsal bones.
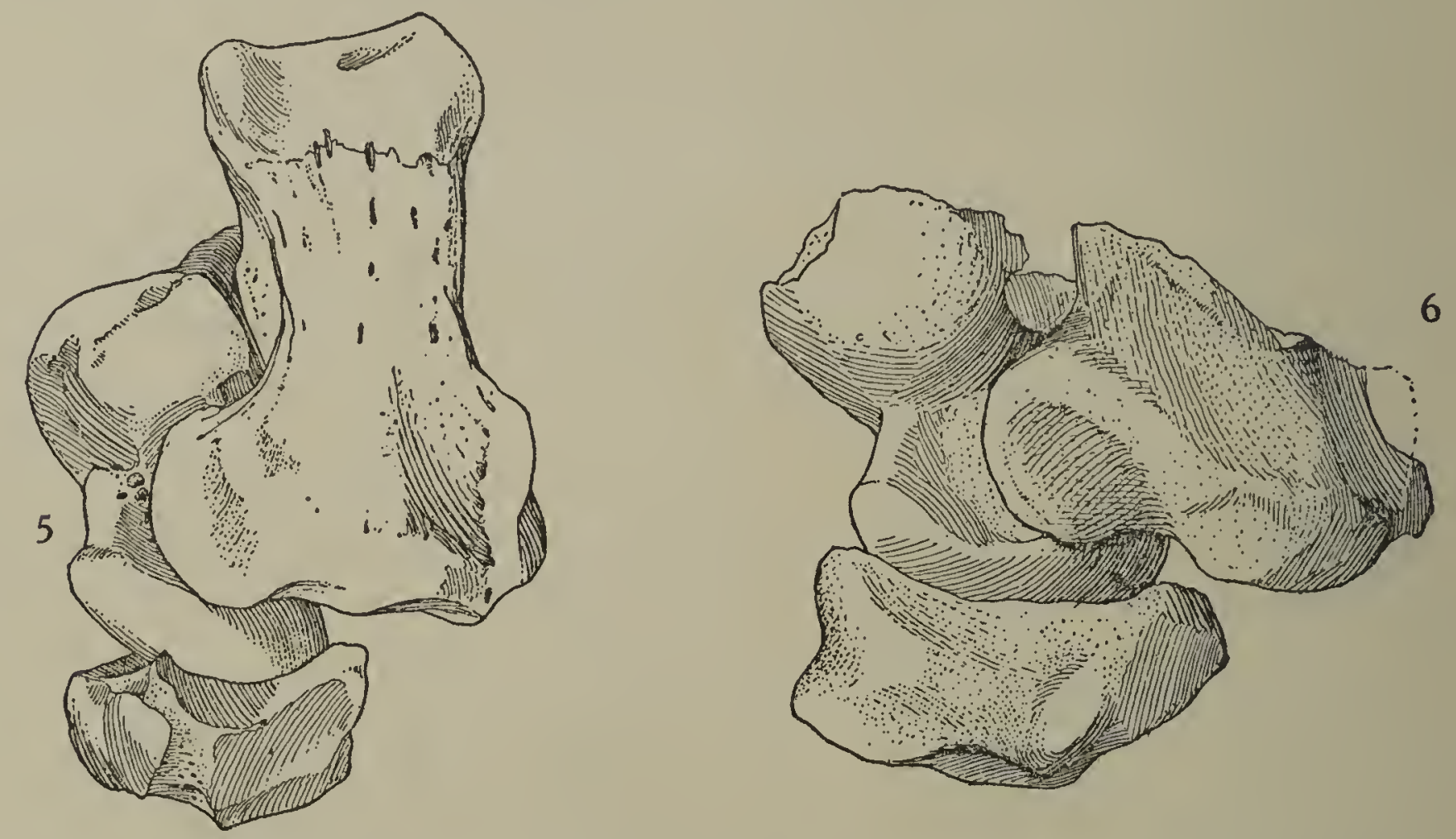

FIG. 5.-Posterior view of calcaneum, astragalus, and navicular of Eumetopias jubata (Schreber) in position, No. 4112, Mus. Vert. Zool., ×0.5. Ano Nuevo Island, off San Mateo County, California.

FIG. 6.-Posterior view of calcaneum, astragalus, and navicular of Pontolis cf. magnus, in position, Nos. 24070, 24071, and 24072, Mus. Palaeo., Univ. Calif., X0.5. Exposures on south side of Soledad Canyon, San Diego County, California.

\section{Calcaneum.}

As in other pinnipeds, the calcaneum was undoubtedly the largest bone of the tarsus. Inasmuch as the proximal portion is missing, its proportions and relations with the astragalus can be surmised only by comparison with the same bones of Eumetopias jubata (fig. 5) and of Odobenus divergens. However, in some respects this particular tarsal element exhibits a closer affinity to Odobenus than to Eumetopias.

Only the outlines of the peroneal tubercle can be distinguished, though in position it is very similar to Eumetopias and Odobenus. This tubercle is considerably mutilated, owing to the fracture of the nodule and the subsequent loss of the adjoining portion. The groove which lodges the ligament for the extensor muscles is shallow and relatively smooth, and not rugose as in Eumetopias.

From an inferior view the relative proportions of the calcaneum of this Pliocene pinniped (fig. 4a), as compared with the living genus Eumetopias (fig. 3a), are best revealed. In the latter, the articular facet for the cuboid has its longest diameter extending from fibular to tibial side, while in this fossil bone the longest axis is just the reverse-that is, from the dorsal to the plantar side.

The fibular face of the calcaneum of Eumetopias (fig. $3 b$ ) is slightly arcuate. The plantar margin of the sustentacular facet is more rounded and less flaring than in this Pliocene fossil (fig. 4b). In this respect the fossil specimen resembles that of Odobenus. On the tibial surface (fig. 4c) is the basal portion of the greater process for articulation with the ectal facet of the astragalus, and below this, separated by the groove for the interosseous ligament, is an extensive subtriangular sustentacular facet for articulation with the corresponding facet on the astragalus. The distal portion of the greater process is more produced and more rounded than same process on calcaneum of Eumetopias (fig. 3c). 


\section{Structure of a Flipper of a Pliocene Pinniped.}

There is a peculiar modification of the greater process of the calcaneum which favors the assumption that the ectal facet of the astragalus was considerably reduced. The distal portion of the greater process is greatly produced, so much so that, when the sustentacular facet of the astragalus is rotated on the corresponding articular surface on tibial face of the calcaneum, the greater process of the calcaneum rests in the groove of the astragalus, which in Eumetopias serves for the reception of the interosseous ligament. This peculiar articulation is impossible in either Eumetopias or Odobenus, for the distal portion of the greater process of the calcaneum is neither rounded nor produced, but instead is flattened.
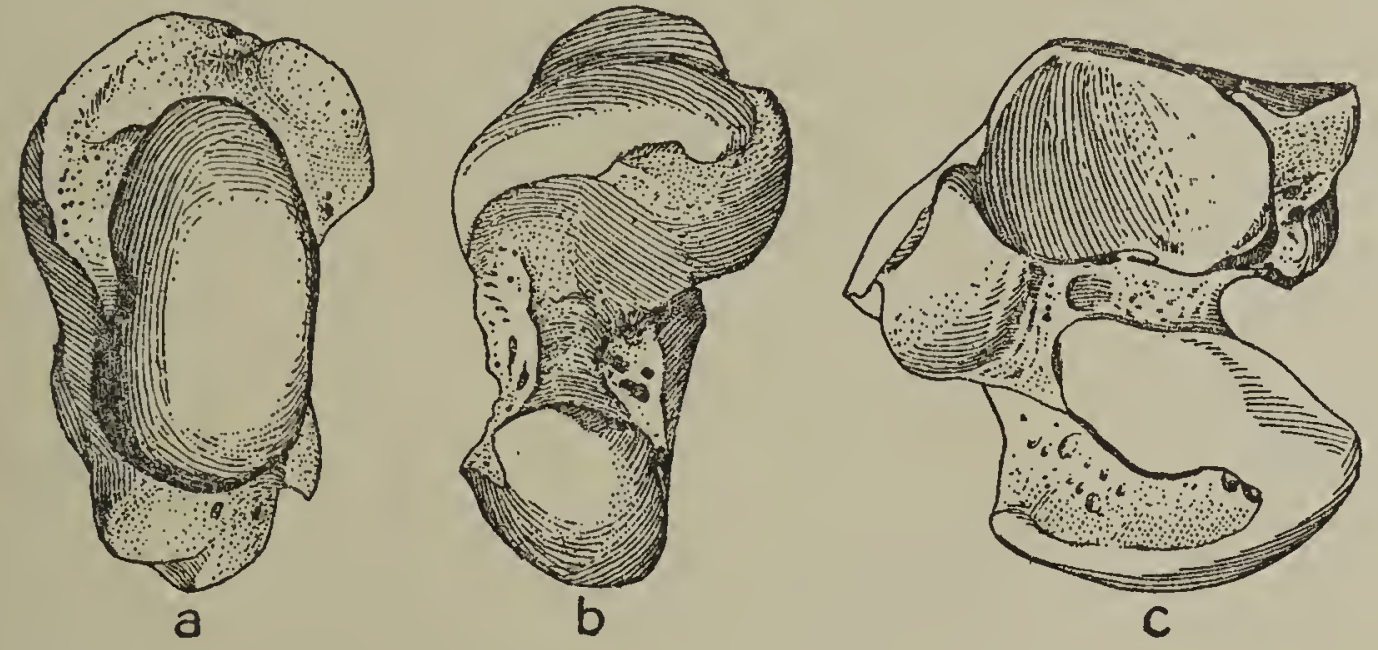

Fig. 7.-Astragalus of Eumetopias jubata (Schreber), No. 4112, Mus. Vert. Zool., X0.5. Ano Nuevo Island, off San Mateo County, California. $a$, distal view; $b$, plantar view; $c$, fibular view.
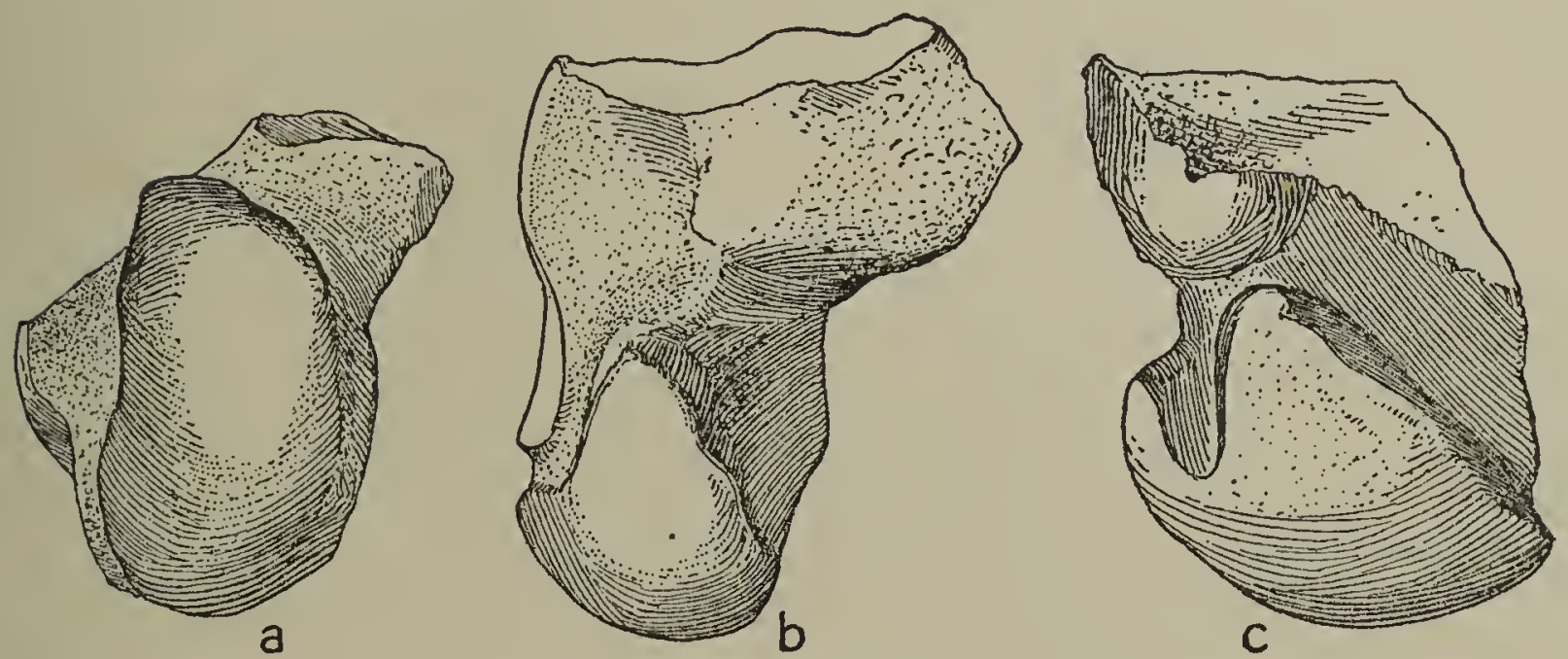

FIg. 8.-Astragalus of Pontolis cf. magnus, No. 24071, Mus. Palaeo., Univ.

Calif., $\times 0.5$. Exposures on south side of Soledad Canyon, San Diego

County, California. $a$, distal view; $b$, plantar view; $c$, fibular view.

The lesser process is relatively longer and narrower than in Eumetopias, and slightly resembles that of Odobenus. The groove for the interosseous ligament is narrow and deep as in Eumetopias, forming a considerable sinus between the articular surfaces when the astragalus and calcaneum are in position.

Measurements of calcaneum (in millimeters).

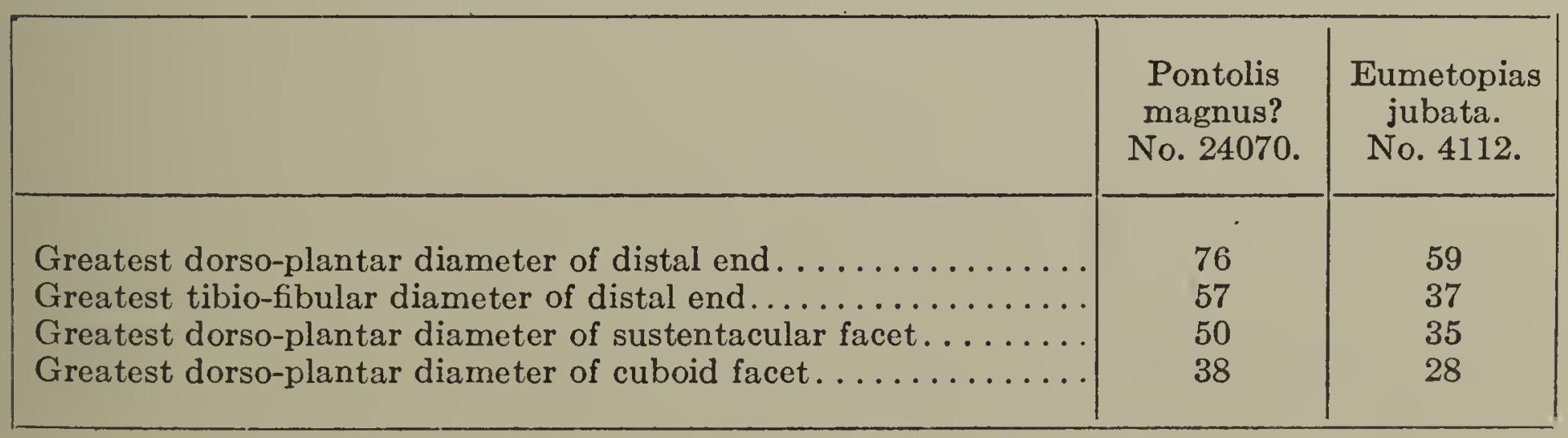




\section{Tertiary History of Pelagic Mammals of Pacific Coast.}

\section{Astragalus.}

On the whole the astragalus is considerably larger than the same element in the tarsus of either Eumetopias or Mirounga. In size, the head of the astragalus approaches that of Odobenus, though in other respects it is quite different. The most characteristic feature is the presence of an exceedingly large fibular facet (fig. 2), with a correlated reduction of the body on the external side. The reduced external prolongation of the body, together with what appears to be a rather prominent internal projection, is most unusual for an otarid and reminds one at once of the phocids, more especially Mirounga angustirostris. This specimen lacks the major portion of the body with its trochlea. That portion of the astragalus is undoubtedly present in the adjoining part of the nodule which was not found at the time the present specimen was collected. The weight of the body was presumably transmitted to this astragalus, largely by the tibia, as in other pinnipeds, though it is also quite certain from the larger fibular facet that the fibula as well had a considerable share in the transmission of the weight.

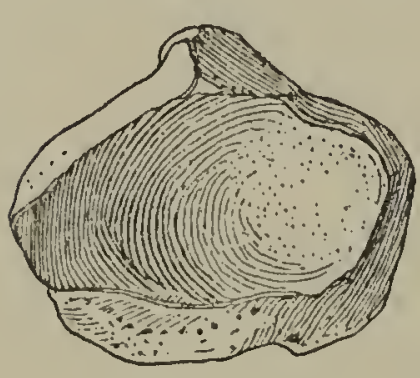

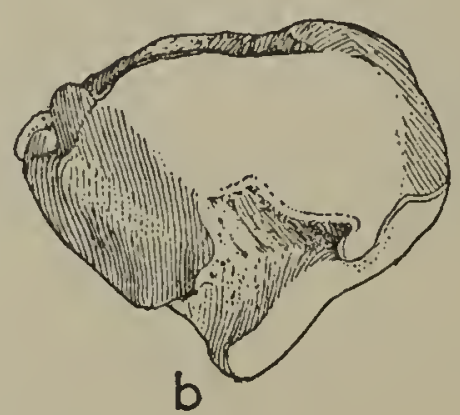

b
FIg. 9.-Navicular of Eumetopias jubata (Schreber), No.4112, Mus. Vert. Zool, $\times 0.5$. Ano Nuevo Island, off San Mateo County, California. $a$, proximal view; $b$, distal view.

The dorsal surface of the neck is somewhat flattened, relatively short and quite wide, with an extensive rugose area for attachment of extensor muscles, which, narrowing into a shallow groove on the external side, separates the fibular facet from the navicular facet.

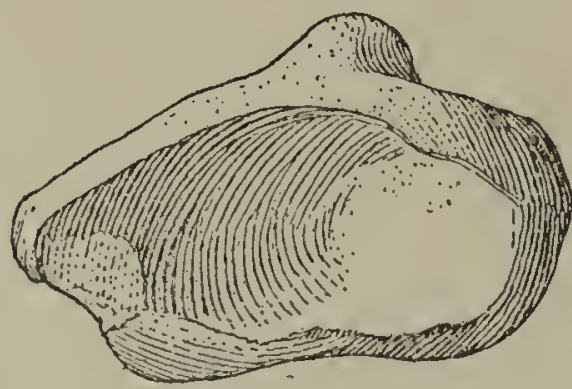

a.

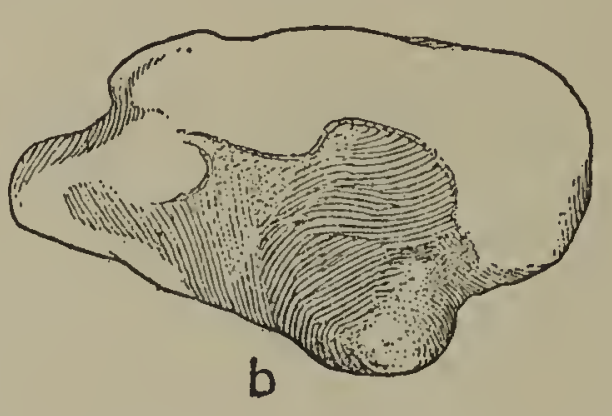

Fig. 10.-Navicular of Pontolis cf. magnus No. 24072 , Mus. Palaeo., Univ. Calif., $\times 0.5$. Exposures on south side of Soledad Canyon, San Diego County, California. a, proximal view; $b$, distal view.

It is interesting to note that the head (fig. $8 a$ ) sets more obliquely on the body than it does in Eumetopias (fig. 7a). Furthermore, the neck is so twisted that the long axis of the head is directed obliquely backward internally, while in Eumetopias the same axis is directed more dorso-ventrally. The distal surface (fig. $8 a$ ) is limited to the front of the head; in outline it is almost kidney-shaped, the main diameter running obliquely from the tibial side dorsally to the fibular side ventrally. The surface is convex in both directions and serves as the articular surface for the proximal facet of the navicular. There is also present a small facet for articulation with corresponding facet on cuboid. In this Pliocene pinniped the long axis of the head rests rather obliquely in the extero-internal axis of the navicular (fig. 2a), while in Eumetopias the long axis rests nearly dorso-ventrally (fig. 1).

The fibular facet (fig. $2 b$ ) is very large and extends distally almost to the navicular facet, being separated from it by the shallow extensor groove. The fibular articulation is more oblique than in Eumetopias (fig. 1). In contrast with other known pinnipeds, this fibular facet is broad, rather elongate, somewhat concave distally, with a prominent crest between it and the tibial surface, and is accompanied by a reduction of the external prolongation of the body of the astragalus. 
The plantar surface (fig. 8b) is not as sharply defined as in Eumetopias (fig. 76).

The fibular surface of the head (fig. 8c) is irregular in outline, and is occupied by a large triangular articular facet for the sustentacular facet of the calcaneum. The groove invading the sustentacular facet from the plantar side is more like that observed in Odobenus, for in the latter, as well as in Mirounga, this groove is continuous dorsally with the groove for the interosseous ligament. In comparing the astragalus of this Pliocene pinniped with the astragalus of Eumetopias, it was observed that there is a similar groove invading the sustentacular facet in both, though it is much shorter in the fossil. In contrast with Eumetopias (fig. 7c), the sustentacular facet of this astragalus was apparently separated from the ectal facet by the deep groove for the interosseous ligament. The groove for this ligament is much deeper and relatively broader than in Eumetopias and is bounded on either side by poorly marked crests, though no astragalar foramen is present.

Measurements of astragalus (in millimeters).

\begin{tabular}{|c|c|c|}
\hline & $\begin{array}{c}\text { Pontolis } \\
\text { magnus? } \\
\text { No. } 24071 .\end{array}$ & $\begin{array}{c}\text { Eumetopias } \\
\text { jubata. } \\
\text { No. } 4112 .\end{array}$ \\
\hline $\begin{array}{l}\text { Greatest dorso-plantar diameter of head } \ldots \ldots \ldots \ldots \ldots \ldots \ldots \\
\text { Greatest tibio-fibular diameter of head } \ldots \ldots \ldots \ldots \ldots \ldots\end{array}$ & $\begin{array}{l}33 \\
58\end{array}$ & $\begin{array}{l}26.5 \\
48\end{array}$ \\
\hline
\end{tabular}

NAVICULAR.

The navicular is extraordinarily long, relatively narrow, and quite thin. Its proportions are quite different from the same bone in Eumetopias, though differences in relative depth and breadth constitute the chief features. Its transverse or tibiofibular diameter is almost twice the vertical or dorso-plantar diameter, while in Eumetopias these two measurements are more nearly equal. In some details, especially the distal face with articular facets for the cuneiforms, the navicular is quite similar. On the plantar face is a prominent tuberosity (fig. 10b), which is, however, directed toward the tibial side and not towards the fibular as in Eumetopias (fig. 9b). The articular facet for the astragalus (fig. 10a) is strongly concave with a sudden upward curvature on both tibial and fibular sides of the navicular.

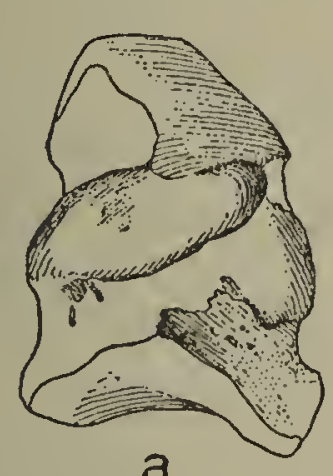

a

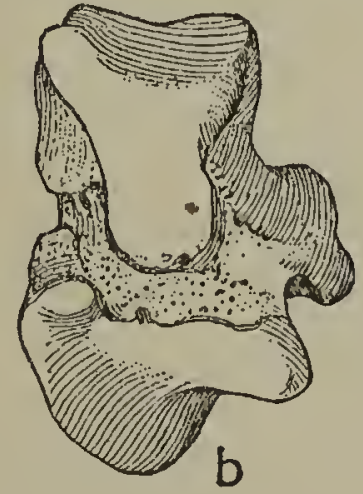

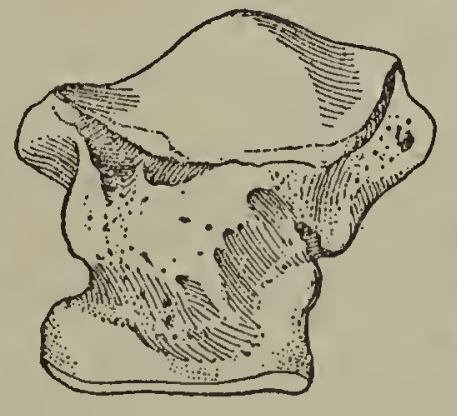

C

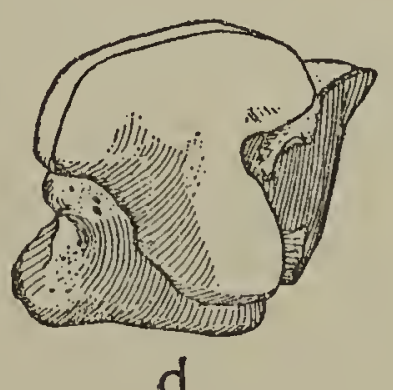

d

FIG. 11.-Cuboid of Eumetopias jubata (Schreber), No. 4112, Mus. Vert. Zool., $\times 0.5$. Ano Nuevo Island, off San Mateo County, California. $a$, plantar view; $b$, tibial view; $c$, dorsal view; $d$, distal view.

On the fibular and plantar borders of the navicular there is a relatively small facet, as compared with same facet in recent otarids, which articulates with corresponding facets on tibial face of cuboid. This fibular facet is quadrangular in Odobenus, long and narrow in both Eumetopias and Mirounga, while it is almost triangular in this fossil specimen.

In appearance the distal surface (fig. 10b), with the extensive rugose area which restricts the facets for cuneiforms from plantar half of this face, most resembles that of 


\section{Tertiary History of Pelagic Mammals of Pacific Coast.}

Eumetopias (fig. 9b). In this respect the fossil is quite unlike either Odobenus or Mirounga, for in these forms the facets cover the entire distal face. In this fossil specimen there are three facets, more or less distinct, though continuous with one another; the largest lies at the dorsal and tibial corner. It is somewhat curved in outline and serves as the articular facet for entocuneiform, although it is not separated from the adjoining slightly concave facet for mesocuneiform. The third facet lies on the dorso-fibular border, just below the preceding, from which it is separated by an elevated line.
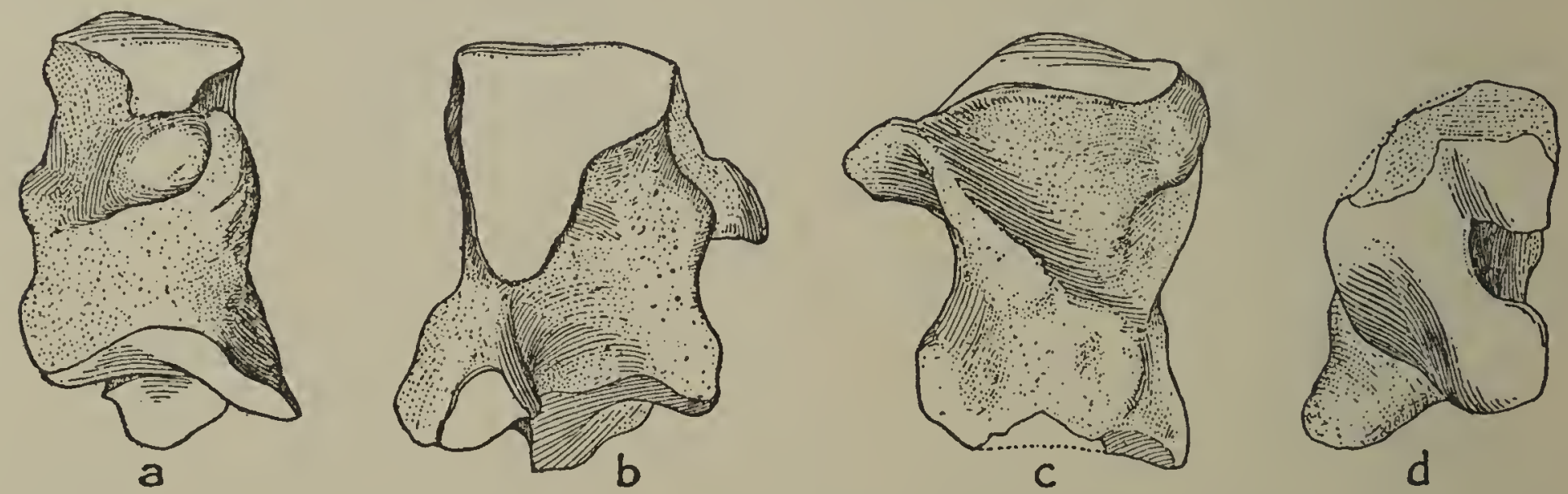

FIg. 12.-Cuboid of Pontolis cf. magnus, No. 24073, Mus. Palaeo., Univ. Calif., $\times 0.5$. Exposures on south side of Soledad Canyon, San Diego County, California. $a$, plantar view; $b$, tibial view; $c$, dorsal view; $d$, distal view.

The tibial corners are rounded off. About half of the distal face, or that area lying between the plantar tuberosity and the facets for the cuneiforms, is depressed and roughened for the interosseous ligament.

Measurements of navicular (in millimeters).

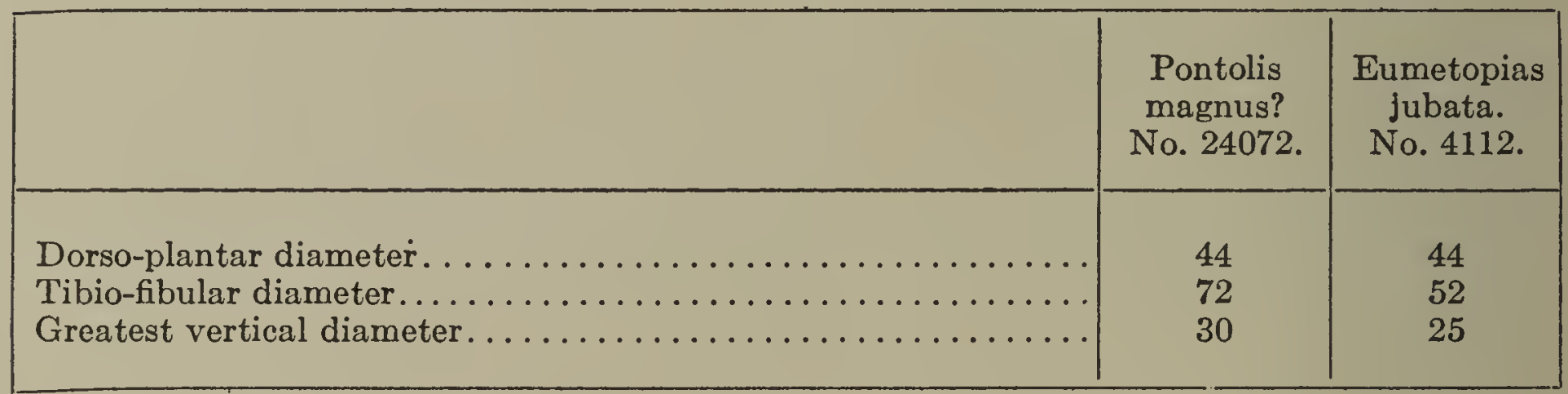

\section{Cubord.}

The cuboid is large, equaling in size that of Odobenus. The reduction of the astragalo-cuboid contact is an important feature of the tarsus of this Pliocene pinniped and in this point it differs from either Odobenus or Eumetopias. In all known pinnipeds the astragalo-cuboid contact is relatively large, the astragalus being more or less supported by the cuboid. It is doubtful if the position of the cuboid in the tarsus of this Pliocene pinniped afforded as much support to the astragalus as it does in living otarids.

Posteriorly this cuboid (fig. 12a) differs from the same tarsal element of Eumetopias (fig. 11a) in the reduction of the tuberosity. In the latter, this tuberosity extends entirely across the plantar face, while in this Pliocene form it is restricted to the fibular half of the face.

Proximally the cuboid exhibits a somewhat flattened three-sided articular facet, strongly deflected externally. In all other otarids the facet for the calcaneum is decidedly oblique, forming a sharp angle with the facet for the astragalus. The tibioplantar angle of this facet is quite sharp, the plantar border is nearly straight, while the dorso-fibular border is evenly convex. The external tuberosity is considerably 
produced as in Eumetopias, its proximal articular surface being cut off from the calcanear facet by an elevated line.

On the tibial face (fig. $12 b$ ) is a large proximal facet with its greatest axis proximodistal, and relatively broad transversely. The superior portion of this facet articulates with the corresponding facet of the navicular and the inferior narrower portion with the ectocuneiform. There is also a small dorsal facet on the distal border of the cuboid for articulation with the lower anterior fibular facet of the ectocuneiform. This facet in Eumetopias (fig. 11b) is reduced to a mere vestige. The pit for the insertion of the interosseous ligament is relatively larger and deeper than in either Odobenus or Eumetopias.
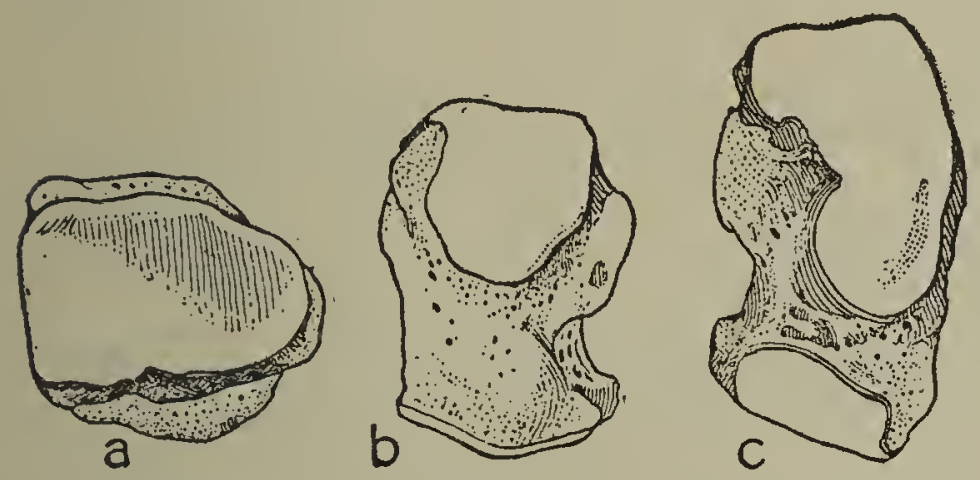

FIG. 13.-Entocuneiform of Eumetopias jubata (Schreber), No. 4112, Mus. Vert. Zool., $\times 0.5$. Ano Nuevo Island, off San Mateo County, California. $a$, distal view; $b$, tibial view; $c$, fibular view.

The dorsal and fibular faces are more or less continuous with one another. The outstanding feature (fig. 12c) is a broad, rugose, and obliquely situated groove for the attachment of ligaments and flexor muscles, which begins near the plantar and proximal borders and extends toward the dorso-distal angle.
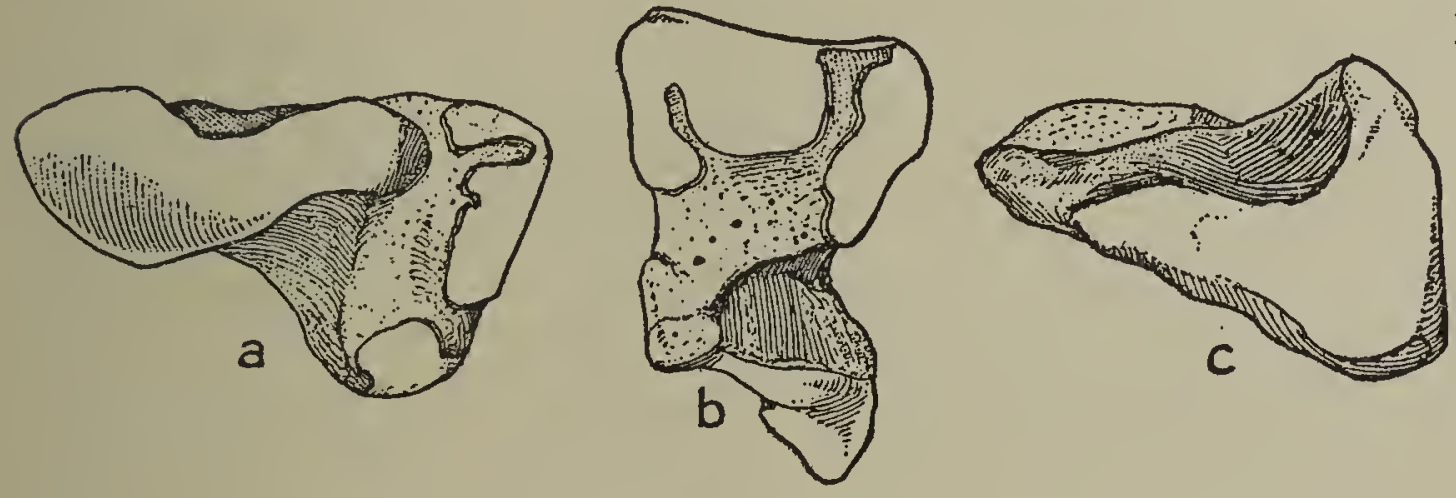

FIG. 14.-Entocuneiform of Pontolis cf. magnus, No. 24074, Mus. Palaeo., Univ. Calif., $\times 0.5$. Exposures on south side of Soledad Canyon, San Diego County, California. $a$, distal view; $b$, tibial view; $c$, proximal view.

Distally there is a curved articular surface (fig. 12d) for the bases of the fourth and fifth metatarsals, nearly U-shaped in outline, with an abrupt downward slope on the dorsal and tibial borders. The facet on the fibular border to articulate with the base of the fifth metatarsal is strongly concave, though it is deflected upward and ventrally. All the borders of the distal face are sharp.

Measurements of cuboid (in millimeters).

\begin{tabular}{|c|c|c|}
\hline & $\begin{array}{c}\text { Pontolis } \\
\text { magnus? } \\
\text { No. } 24073 .\end{array}$ & $\begin{array}{c}\text { Eumetopias } \\
\text { jubata. } \\
\text { No. } 4112 .\end{array}$ \\
\hline Greatest median dorso-plantar diameter. & 36 & 36 \\
\hline Greatest tibio-fibular diameter. & 45 & 35 \\
\hline Greatest proximo-distal diameter. & 61 & 48 \\
\hline
\end{tabular}

\section{ENTOCUNEIFORM.}

A characteristic feature of this fossil entocuneiform, in addition to its prismatic appearance, is the roughly V-shaped proximal facet. The dorsal surface is somewhat flattened and depressed. Centrally, an extensive concavity, strongly rugose, exists for the attachment of a muscle. It differs markedly from the same element in the tarsus 
of Eumetopias by the presence of a strong emargination on the proximo-fibular angle for the corresponding articular surface on the mesocuneiform.

With the exception of the proximal facet, the close resemblance of this tarsal element to the corresponding one in Odobenus is very striking. The distal facet is more nearly like that of the walrus than that of any other pinniped, while the similarity in the strong emargination of the dorso-proximal corner of the fibular face to serve as an articular surface for the mesocuneiform, in both forms, is undoubtedly more than a coincidence. Other features possessed by this fossil flipper closely connect the otarids with the odobenids, and possibly more remotely with the cystophorids as illustrated by Mirounga.
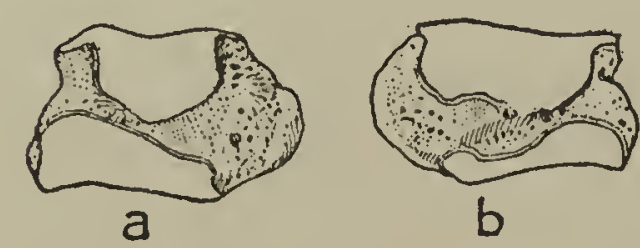

Frg. 15.-Mesocuneiform of Eumetopias jubata (Schreber), No. 4112, Mus. Vert. Zool., ×0.5. Ano Nuevo Island, off San Mateo County, California. $a$, tibial view; $b$, fibular view.

The distal articular surface (fig. 14a) is club-shaped, narrower near the tibial border than at dorso-fibular border; the long axis runs obliquely from the fibular to the tibial side. This facet is also characterized by the strong convexity of the dorso-fibular portion. This same facet in Eumetopias (fig. 13a) is more or less triangular, with its base lying on the fibular border and its two sides meeting in a rounded apex on the tibial border.

On the tibial side, the entocuneiform of this fossil pinniped (fig. 14b) differs from that of Eumetopias (fig. 13b) in the shape of the facet for the sesamoid, in the position of the proximo-plantar articular process, as well as in the reduction of the distal border. The facet for the sesamoid is somewhat quadrangular in outline, with its greatest diameter extending from the dorsal to the plantar side, and continuous with an adjoining articular surface which projects over upon the dorsal face. The borders are sharply defined, and below this facet the surface is depressed and quite rugose. The articular process, which in Eumetopias lies on the plantar face, is directed toward the tibial side and elevated to the proximal border in this fossil specimen.
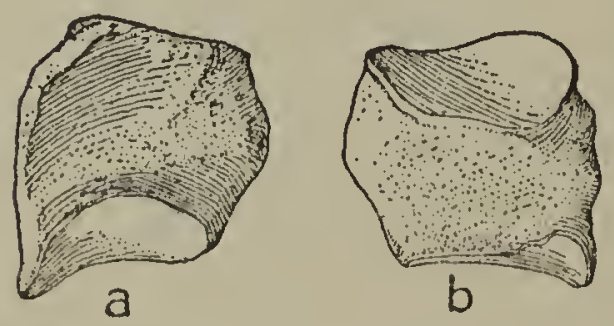

Fig. 16.-Mesocuneiform of Pontolis cf. magnus, No. 24075, Mus. Palaeo., Univ. Calif., $\times 0.5$. Exposures on south side of Soledad Canyon, San Diego County, California. $a$, tibial view; $b$, fibular view.

The fibular surface presents a proximal and a distal half, of which the former is nearly twice the size of the latter. In Eumetopias the two halves are more nearly equal in size. The plantar border of the proximal half of this fossil entocuneiform is curved away from the main axis and is directed to the sole of the foot. The distal border of the fibular face of the entocuneiform of Eumetopias is squarely truncate, and is occupied by an elongate facet (fig. 13c) for articulation with the corresponding facet on second metatarsal. In this fossil bone the distal border is rounded and the facet somewhat reduced in extent. The facet for the navicular does not extend down upon the fibular face in this fossil though it does in Eumetopias.

The facet on the proximal surface of the entocuneiform for articulation with the distal surface of the navicular is nearly kidney-shaped in Eumetopias (fig. 13c); it is slightly concave and slopes toward the fibular side. As remarked previously, this same facet on the fossil bone is roughly V-shaped (fig. 14c). Furthermore, it differ's from Eumetopias in another important feature, in that this facet lies more nearly in a horizontal plane, sloping but slightly toward the fibular side. 
Measurements of entocuneiform (in millimeters).

\begin{tabular}{|c|c|c|}
\hline & $\begin{array}{c}\text { Pontolis } \\
\text { magnus? } \\
\text { No. } 24074 .\end{array}$ & $\begin{array}{c}\text { Eumetopias } \\
\text { jubata. } \\
\text { No. } 4112 .\end{array}$ \\
\hline Greatest vertical diameter. & 48 & 41 \\
\hline Greatest tibio-fibular diameter. & 59 & 37 \\
\hline Greatest dorso-plantar diameter.. & 38 & 31 \\
\hline Greatest diameter of distal articular surface & 43 & 34 \\
\hline
\end{tabular}

\section{MESOCUNEIForm.}

The mesocuneiform is much reduced in size; it is relatively smaller than same element in the tarsus of Eumetopias, though it has a greater vertical diameter than in the latter.

Near the proximal border of the mesocuneiform of Eumetopias (fig. 15a) lies a quadrangular articular facet, occupying a considerable portion of the tibial face, which in turn serves as an articular surface for the entocuneiform. In this fossil bone (figs. $2 a$ and $16 a$ ) the proximal border is considerably produced and shows an obscure facet for articulation with the proximo-dorsal portion of the fibular surface of the entocuneiform.

FIG. 17.-Ectocuneiform of Eumetopiasjubata (Schreber), No. 4112, Mus. Vert. Zool., $\times 0.5$. Ano Nuevo Island, off San Mateo County, California. $a$, fibular view; $b$, tibial view; $c$, proximal view; $d$, distal view.

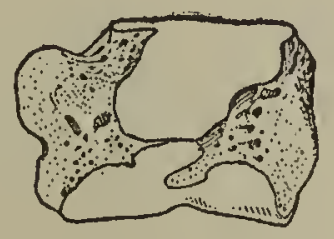

a

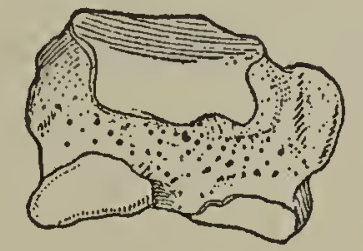

b
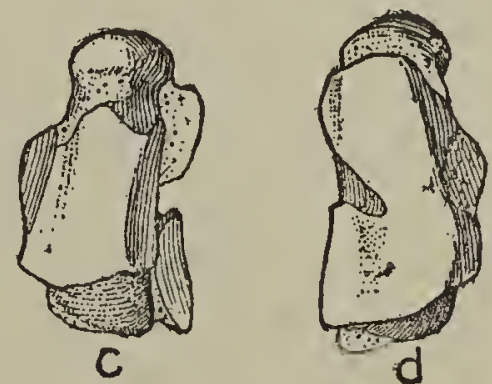

The proximal surface (fig. 16b) is occupied by a large oval facet for articulation with the corresponding facet on distal surface of the navicular; it is strongly concave, with sharply defined borders, and slopes toward the fibular side of the tarsus. On the mesocuneiform of Eumetopias this same facet has a more elongate dorso-plantar diameter and is decidedly more flattened.

A large, proximal, rectangular facet for the ectocuneiform (fig. 15b) is present on the fibular face of the mesocuneiform in Eumetopias, though no trace of the same can be found in this fossil bone (fig. 16b). Almost the entire fibular surface of this fossil mesocuneiform is roughened for an interosseous ligament, while in Eumetopias this area is confined to a narrow space between the small dorso-distal facet for the ectocuneiform and the above-mentioned rectangular facet.

The distal surfaces of the mesocuneiforms of both Eumetopias and this fossil pinniped are essentially the same, the main difference being the degree of concavity, with the latter exhibiting a more strongly marked downward curvature on both dorsal and plantar borders. The plantar surface is not produced distally as much as in Eumetopias (fig. 15a), though in both it is merely a rounded plantar border.

Measurements of mesocuneiform (in millimeters).

\begin{tabular}{|c|c|c|c|}
\hline - & 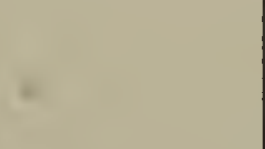 & $\begin{array}{c}\text { Pontolis } \\
\text { magnus? } \\
\text { No. } 24075 .\end{array}$ & $\begin{array}{c}\text { Eumetopias } \\
\text { jubata. } \\
\text { No. } 4112 .\end{array}$ \\
\hline Greatest dorso-plantar diameter & . & 31 & 33 \\
\hline Greatest tibio-fibular diameter. & & 20 & 14 \\
\hline Greatest vertical diameter. . & & 25 & 20 \\
\hline
\end{tabular}




\section{ECTOCUNEIFORM.}

In general appearance, the ectocuneiform of this Pliocene pinniped is quite similar to the same element in the tarsus of Eumetopias jubata. However, it is more prismatic, one side of the prism forming the dorsal surface and the remaining two sides forming the tibial and fibular surfaces, respectively; at the proximal and distal ends it is cut off obliquely; the plantar aspect is produced into a low, blunt hook directed upwards. The concave side of this hook faces toward the fibular surface, thus forming a shallow groove. This same groove (fig. 17a) in the ectocuneiform of Eumetopias is deeper and more rugose. It serves to hold in place the tendon of the peroneus longus.

FIG. 18.-Ectocuneiform of Pontolis cf. magnus, Paleao., Univ. Calif. $\times 0.5$. $a$, fibular view; $b$, tibial view; $c$, proximal view; $d$, distal view.

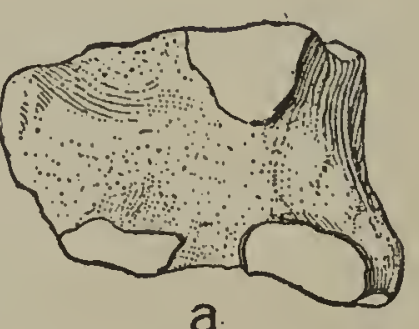

a.
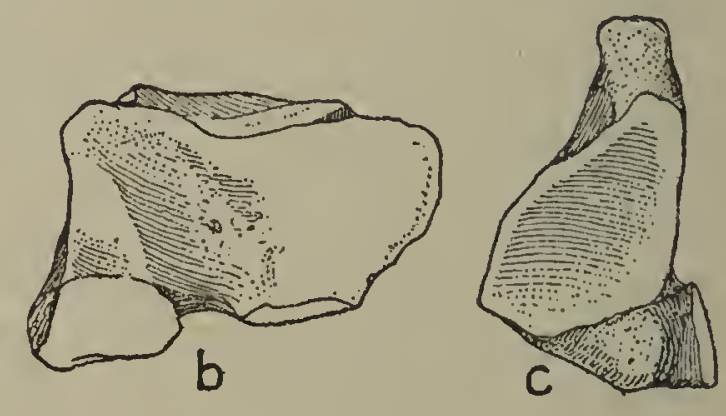

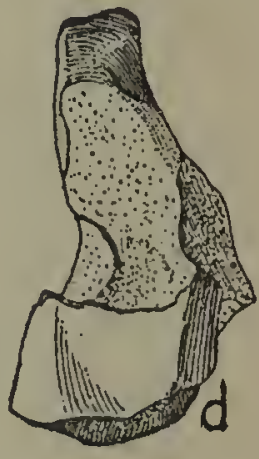

The proximal facet (fig. 18a) on the fibular face is subtriangular in outline; it articulates with the distal portion of an elongated facet near the middle of the tibial surface of the cuboid. There is also an oval facet on the dorso-distal angle of the fibular face of the ectocuneiform for articulation with the corresponding facet on the cuboid.

On the tibial surface (fig. 18b), there are two distal swellings, one dorsal and the other plantar. These swellings are separated by a deep groove which is much broader though relatively shallower than in Eumetopias. No counterpart of the proximal oblong-shaped facet on the tibial surface of the ectocuneiform of Eumetopias (fig. 17b) can be found on this fossil bone.

The proximal surface (fig. 18c) is occupied by a large shallowly concave facet for articulation with the same facet on distal surface of navicular. The corresponding facet on ectocuneiform of Eumetopias (fig. 17c) is more or less flattened, though it is nearly quadrangular and not triangular in outline as on the fossil bone.

The distal surface (fig. 18d) is similar in outline to that of the proximal surface with the exception of a deep indentation on the tibial border. The plantar half of this face is lost. The articular surface of the dorsal half is strongly concave, much more so than in Eumetopias (fig. 17d).

Measurements of ectocuneiform (in millimeters).

\begin{tabular}{|c|c|c|}
\hline & $\begin{array}{c}\text { Pontolis } \\
\text { magnus? } \\
\text { No. } 24076 .\end{array}$ & $\begin{array}{l}\text { Eumetopias } \\
\text { jubata. } \\
\text { No. } 4112 .\end{array}$ \\
\hline Greatest dorso-plantar diameter. & 48 & 38 \\
\hline Greatest tibio-fibular diameter. & 25 & 18 \\
\hline Greatest vertical diameter. & 32 & 24 \\
\hline
\end{tabular}

\section{Sesamoid.}

The sesamoid of this Pliocene pinniped is quite different from that of Eumetopias. The sesamoid of Eumetopias (fig. 19b) is rhomboid in outline and so placed on the tibial side of the entocuneiform that the pointed end is directed distally. The longest diameter of the articular facet (fig. 19a) for corresponding facet on the entocuneiform is proximo-distal. However, the sesamoid of this fossil tarsus has the form of an 
irregular cone (fig. 20b), while the longest diameter of the articular facet (fig. 20a) is dorso-plantar.

19

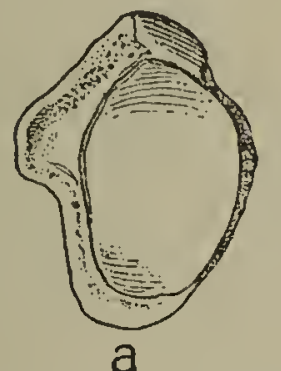

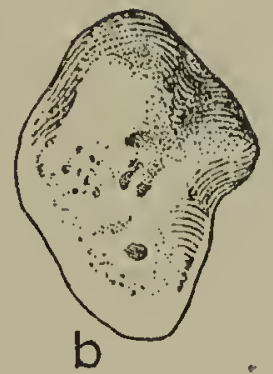

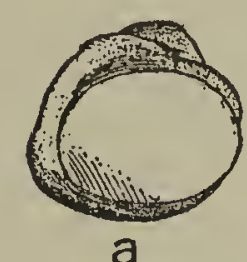

a

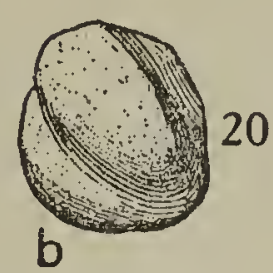

FIG. 19.--Sesamoid of Eumetopias jubata (Schreber), No.4112, Mus. Vert. Zool., $\times 0.5$. Ano Nuevo Island, off San Mateo County, California. $a$, fibular view; $b$, tibial view.

Fig. 20.-Sesamoid of Pontolis cf. magnus, No. 24077, Mus. Palaeo., Univ. Calif., $\times 0.5$. Exposures on south side of Soledad Canyon, San Diego County, California. a, fibular view; $b$, tibial view.

Measurements of sesamoid (in millimeters).

\begin{tabular}{|c|c|c|}
\hline & $\begin{array}{c}\text { Pontolis } \\
\text { magnus? } \\
\text { No. } 24077 .\end{array}$ & $\begin{array}{c}\text { Eumetopias } \\
\text { jubata. } \\
\text { No. } 4112 .\end{array}$ \\
\hline Dorso-plantar diameter. & 26 & 29 \\
\hline Proximo-distal diameter. & 21 & 39 \\
\hline Tibio-fibular diameter. & 18.5 & 19 \\
\hline
\end{tabular}

\section{First Metatarsal.}

The first metatarsal (fig. 21d) of this fossil pinniped is quite unlike that of Eumetopias. It is larger than all the other metatarsals, both with respect to length and to relative proportions. The shaft of this metatarsal is roughly three-sided, the dorsal border forming the base, the fibular and tibial borders meeting in a rounded apex at the plantar angle to form the sides. On the tibio-plantar face (fig. 21e) are two proximal swellings, one dorsal and the other plantar; these swellings are separated by a broad groove. The proximal end is occupied by a concave facet (fig. $21 f$ ) which is strongly curved upwards on the dorsal and plantar borders and slopes towards the fibular side. It articulates with the corresponding facet on distal surface of entocuneiform.

Since only the proximal end of the first metatarsal of this flipper is preserved, it is fortunate that a second great toe was found in southern California, and presumably in the same horizon, by Mr. Howell Gester. This specimen, No. 24083 (fig. 21g), appears to belong to a somewhat older individual. The differences are especially noticeable when the proximal ends are compared with each other. In this second specimen there is a greater development of the proximal swellings or tuberosities on the tibio-plantar face, and accompanied by a narrowing of the intervening groove. The same changes occur during growth in Eumetopias, the oldest individuals possessing the most prominent tuberosities. Otherwise the proximal end (fig. 21i) is very similar to the corresponding portion (fig. 21f) of the above described metatarsal. The main feature wherein it differs from Eumetopias lies in the modification of the proximal facet; in Eumetopias (fig. 21c) this facet is shallowly concave, its fibular and tibial borders slightly upturned, while the articular surface itself slopes towards both dorsal and plantar faces. The facet is roughly four-sided, with slight emargination on the plantar side. In this fossil metatarsal (fig. 21i), the facet is roughly three-sided and is constricted medially on the dorsal and tibial borders. The plantar border of this facet is more strongly upturned than the dorsal. 

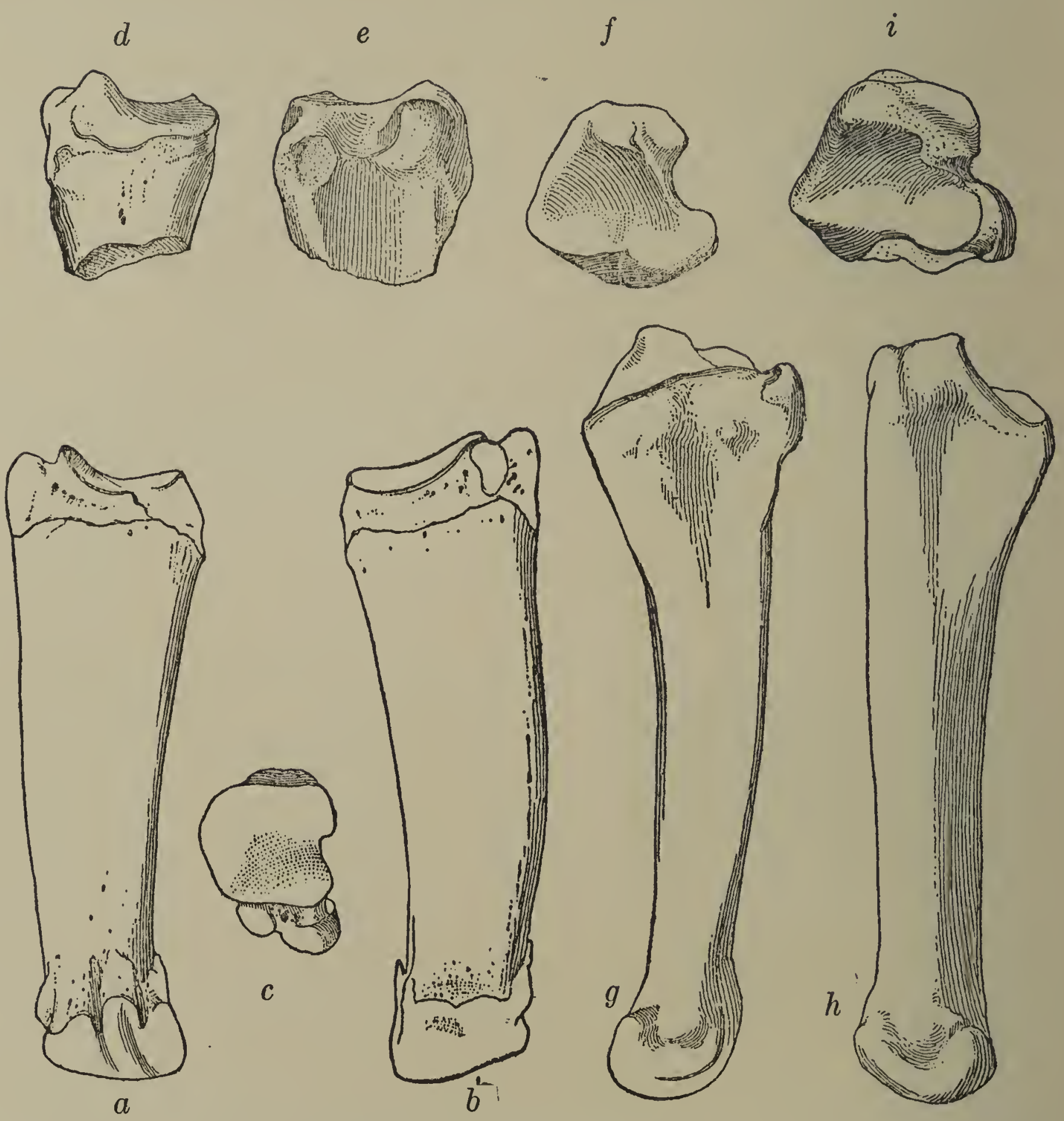

Fra. 21.- $a, b$, $c$ : First metatarsal of Eumetopias jubata (Schreber), No. 4112, Mus. Vert. Zool., $\times 0.5$. Ano Nuevo Island, off San Mateo County, California, a, plantar view; $b$, dorsal view; $c$, proximal view. $d, e, f$ : First metatarsal of Pontolis cf. magnus, No. 24078, Mus. Palaeo., Univ. Calif., $\times 0.5$. Exposures on south side of Soledad Canyon, San Diego County; California. $d$, fibular view; $c$, tibioplantar view; $f$, proximal view. $g, h, i$ : First metatarsal of Pontolis cf. magnus, No. 24083, Mus. Palaeo., Univ. Calif., $\times 0.5$. Sandy shale formation in Section 27, Township 4 North, Range 15 West, near section line directly west of 2,006' elev. hill, Los Angeles County, California. $g$, tibial view; $h$, fibular view; $i$, proximal view.

Measurements of first metatarsal (in millimeters).

\begin{tabular}{|c|c|c|c|}
\hline & $\begin{array}{c}\text { Pontolis } \\
\text { magnus? } \\
\text { No. } 24078 .\end{array}$ & $\begin{array}{c}\text { Pontolis } \\
\text { magnus? } \\
\text { No. } 24083 .\end{array}$ & $\begin{array}{c}\text { Eumetopias } \\
\text { jubata. } \\
\text { No. } 4112 .\end{array}$ \\
\hline $\begin{array}{l}\text { Length.......................... } \\
\text { Dorso-plantar diameter of head..... } \\
\text { Tibio-fibular diameter of head..... } \\
\text { Dorso-plantar diameter of distal end } \\
\text { Tibio-fibular diameter of distal end.. }\end{array}$ & $\begin{array}{c}x \\
38 \\
43 \\
x \\
x\end{array}$ & $\begin{array}{r}165 \\
41 \\
48 \\
28 \\
27\end{array}$ & $\begin{array}{l}127 \\
23 \\
41 \\
17.5 \\
28\end{array}$ \\
\hline
\end{tabular}


The fibular margin of the shaft is slightly arcuate. The entire bone tapers toward the distal end. The distal articular surface is rounded. A shallow depression is present on the fibular face, and a slight tuberosity on the tibial.

\section{Second Metatarsal.}

The shaft is strongly bent toward the tibial side. The tibial surface (fig. 23a) possesses along the proximal edge an extensive facet for articulation with distal portion of fibular articular surface of the entocuneiform. It lacks the lower proximal process which is present in Eumetopias (fig. 22a), for in this fossil flipper there is no articulation with the first metatarsal, as in the recent otarids. The plantar surface is relatively broad and not narrowing to a sharp crest proximally, as in Eumetopias.

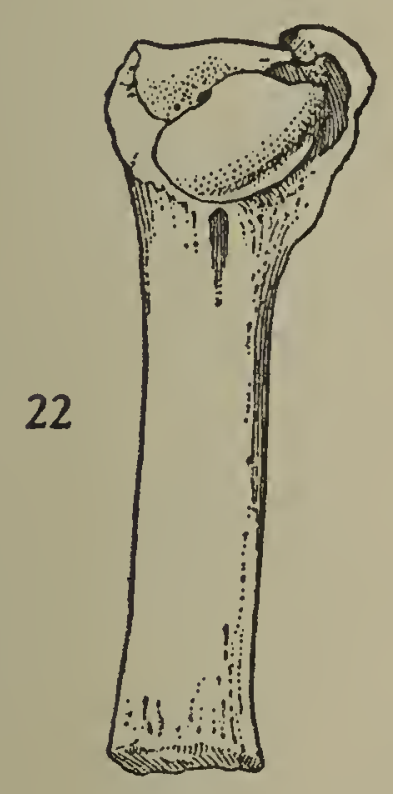

a



b

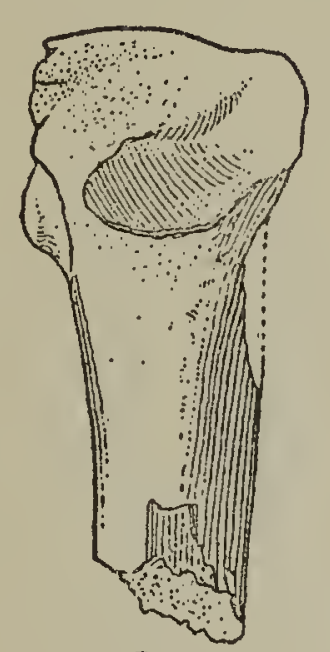

a

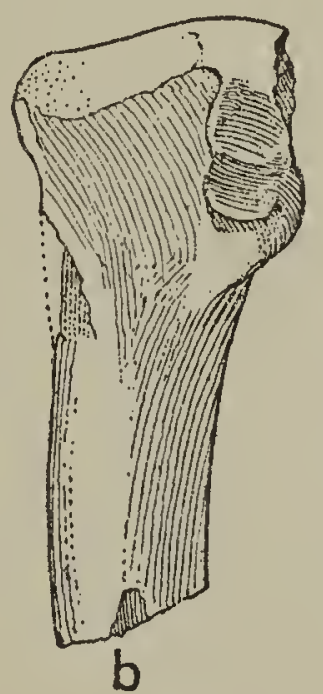

23

FIG. 22.-Second metatarsal of Eumetopias jubata (Schreber), No. 4112, Mus. Vert. Zool., $\times 0.5$. Ano Nuevo Island, San Mateo County, California. $a$, tibial view; $b$, fibular view.

FIg. 23.-Second metatarsal of Pontolis cf. magnus, No. 24079, Mus. Palaeo., Univ. Calif., $\times 0.5$. Exposures on south side of Soledad Canyon, San Diego County, California. $a$, tibial view; $b$, fibular view.

On the fibular surface (fib. 23b) there is a strongly concave facet on the proximal end near the dorsal border for the reception of an articular swelling on the tibial surface of the third metatarsal, and with which it interlocks. Above this concave facet is an oblique articular surface for the distal end of the tibial surface of the ectocuneiform.

The outline of the head is essentially the same as that exhibited by the second metatarsal of Eumetopias, though the facets differ considerably. In Eumetopias, the main facet for the mesocuneiform is shallowly concave with elevated margins on the tibial and fibular sides. In this fossil specimen the facet is somewhat flattened, meeting the proximal margin of the facet for the ectocuneiform in a sharp angle and sloping toward the tibial face.

Measurements of second metatarsal (in millimeters).

\begin{tabular}{|c|c|c|}
\hline & $\begin{array}{c}\text { Pontolis } \\
\text { magnus? } \\
\text { No. } 24079 .\end{array}$ & $\begin{array}{c}\text { Eumetopias } \\
\text { jubata, } \\
\text { No. } 4112 .\end{array}$ \\
\hline Dorso-plantar diameter of head.......... & 36 & 32.5 \\
\hline Tibio-fibular diameter of head........... & 24 & 17.5 \\
\hline
\end{tabular}




\section{Tertiary History of Pelagic Mammals of Pacific Coast.}

\section{Third Metatarsal.}

The head of the third metatarsal is very large, relatively heavy, and more expanded than the head of the second metatarsal. The shaft is large and is twisted toward the tibial side. Notwithstanding the larger size of this metatarsal, it is quite similar, in many respects, to the same bone in the flipper of Eumetopias. The chief modifications exhibited by Eumetopias are the reduction of the interlocking process for the second metatarsal on the tibial face (fig. 24a) and the constriction of the groove separating the facets on dorsal and plantar processes of the fibular face (fig. 24c).

On the tibial surface of the head (fig. 24a) of this fossil, the main facet for second metatarsal is of an interlocking nature. It is situated on a large eminence and fits into a corresponding groove on the fibular face of the head of the second metatarsal, as already described.
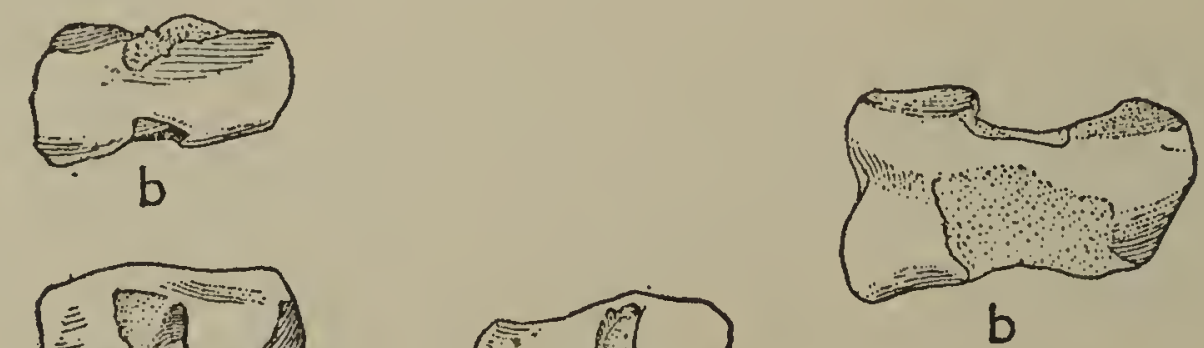

24
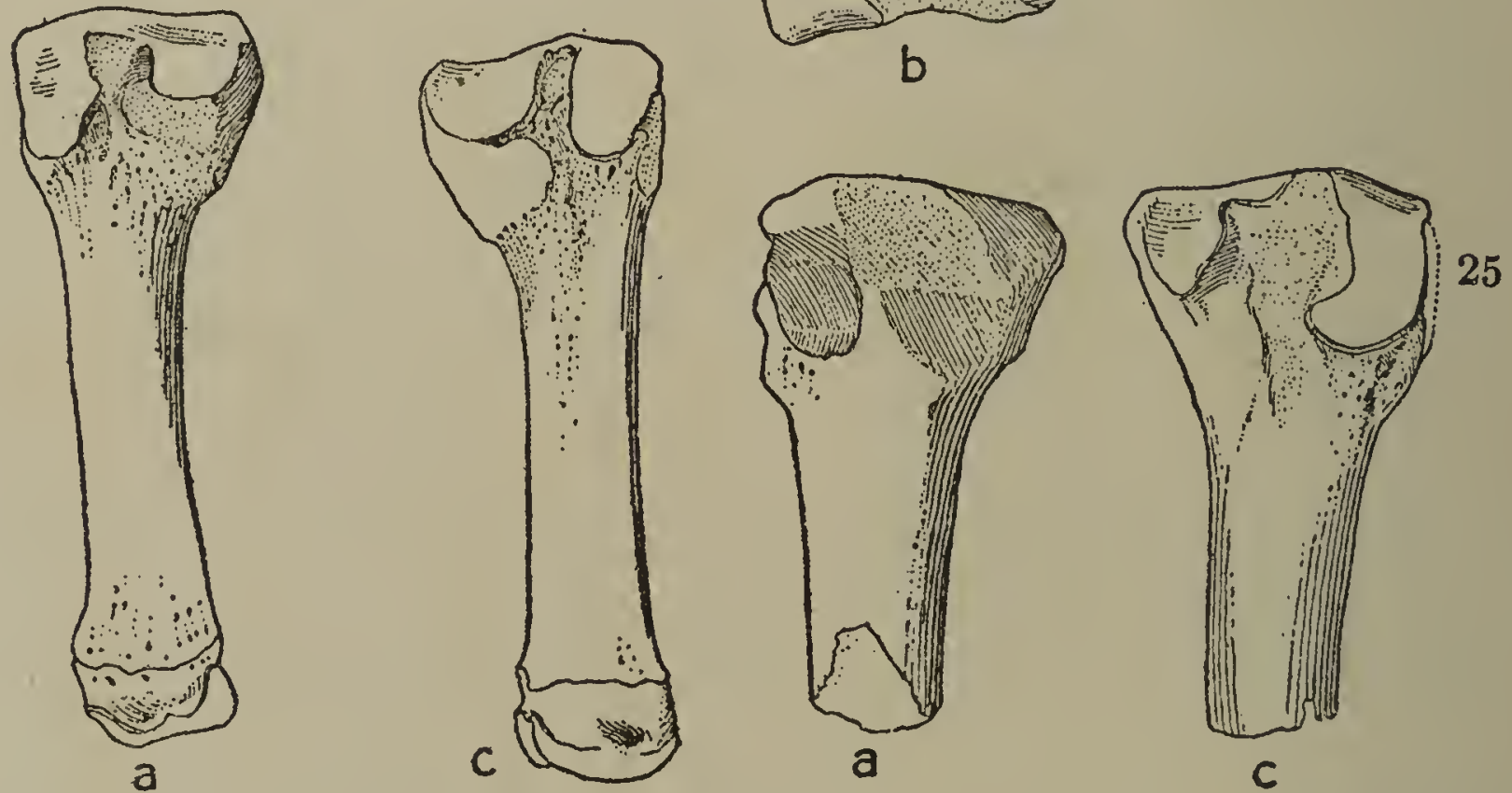

Fig. 24.-Third metatarsal of Eumetopias jubata (Schreber), No. 4112, Mus. Vert. Zool., ×0.5. Ano Nuevo Island, off San Mateo County, California. $a$, tibial view; $b$, proximal view; $c$, fibular view.

FIG. 25.-Third metatarsal of Pontolis cf. magnus, No. 24080, Mus. Palaeo. Univ. Calif., $\times 0.5$. Exposures on south side of Soledad Canyon, California. $a$, tibial view; $b$, proximal view; $c$, fibular view.

The facet for the ectocuneiform on the proximal surface (fig. 25b) is somewhat crescentic in outline, with fibular margin deeply emarginated, and sharply defined. The plantar half of this facet slopes from the fibular margin to the tibial, while the dorsal half slopes two ways, being continuous externally with the dorsal fibular facet and internally with the dorsal tibial facet.

The fibular surface of the head (fig. 25c) has two facets for the head of the fourth metatarsal, which, however, are not of an interlocking nature. The largest one of these is situated on a process near the dorsal face. It is nearly quadrangular and is shallowly concave, while the smaller facet on plantar process is more or less flattened. The two facets are separated by a broad concavity. 
Measurements of third metatarsal (in millimeters).

\begin{tabular}{|c|c|c|}
\hline & $\begin{array}{c}\text { Pontolis } \\
\text { magnus? } \\
\text { No. } 24080 .\end{array}$ & $\begin{array}{c}\text { Eumetopias } \\
\text { jubata, } \\
\text { No. } 4112 .\end{array}$ \\
\hline $\begin{array}{l}\text { Dorso-plantar diameter of head. } \\
\text { Tibio-fibular diameter of head.. }\end{array}$ & $\begin{array}{l}42 \\
26.5\end{array}$ & $\begin{array}{l}32 \\
17.5\end{array}$ \\
\hline
\end{tabular}

\section{Fourth Metatarsal.}

The fibular surface (fig. $27 a$ ) is so badly defaced that an accurate description is impossible. There is, however, an articular strip for the fifth metatarsal which extends along the proximal edge and which is almost complete except for the plantar border. The proximal facet on the dorsal border for articulation with corresponding facet on fifth metatarsal is, however, much narrower than in Eumetopias (fig. 27a).

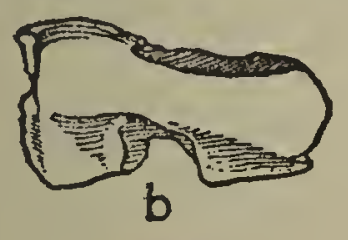

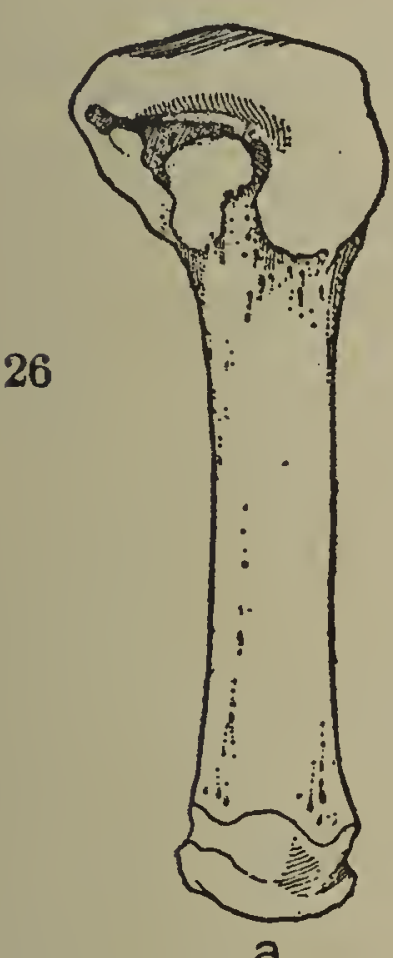

a

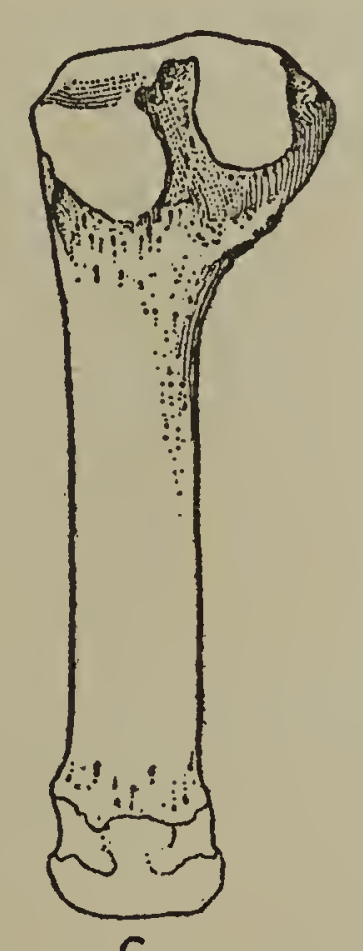

C

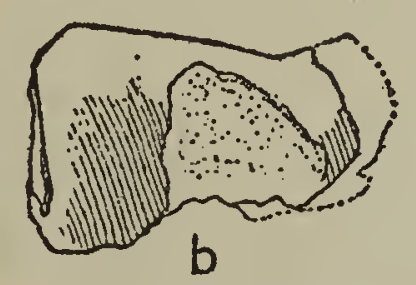

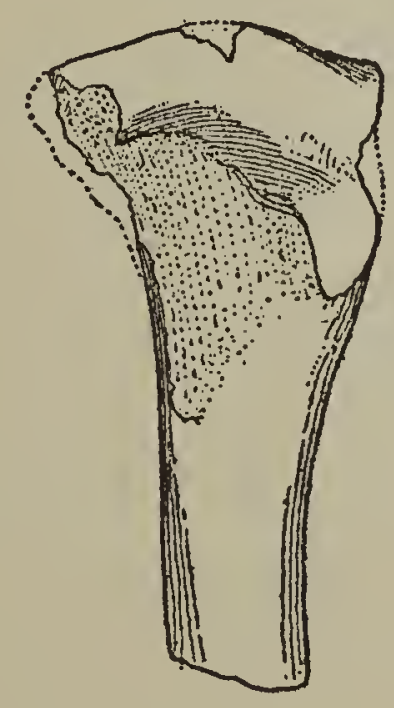

a

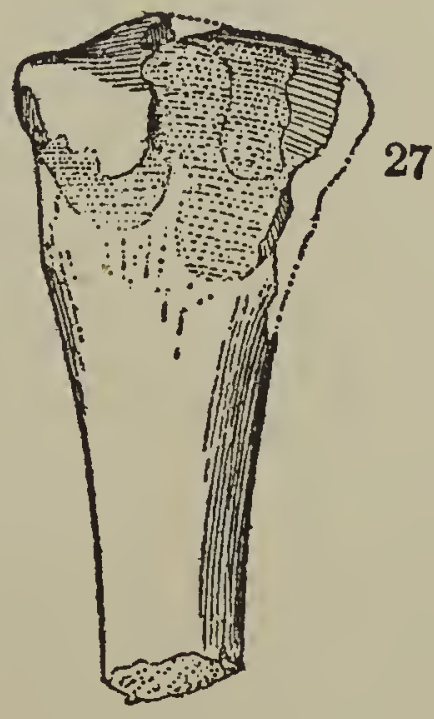

C

FIG. 26.-Fourth metatarsal of Eumetopias jubata (Schreber), No. 4112, Mus. Vert. Zool., X0.5. Ano Nuevo Island, off San Mateo County, California. $a$, fibular view; $b$, proximal view; $c$, tibial view.

Fig. 27. - Fourth metatarsal of Pontolis cf. magnus, No. 24081, Mus. Palaeo., Univ. Calif., $\times 0.5$. Exposures on south side of Soledad Canyon, San Diego County, California. $a$, fibular view; $b$, proximal view; $c$, tibial view.

What remains of the proximal surface (fig. $27 b$ ) indicates that in most respects the facet for the cuboid is similar in outline to that possessed by the corresponding metatarsal of Eumetopias (fig. 26b). There are, however, two features of minor importance which characterize the facet for cuboid on this fossil metatarsal. The dorsal portion of this facet is broader and more evenly convex, while the dorsal margin is sharply defined and not rounded as in Eumetopias. The sharp crest on the plantar half of the proximal surface, which marks the contact of the facet for the third metatarsal and the proximal facet for the cuboid in Eumetopias, is lacking in this fossil. The plantar portion of the head is twisted on the long axis of the shaft toward the fibular side as in Eumetopias. 


\section{Tertiary History of Pelagic Mammals of Pacific Coast.}

Part of the head on the tibial side is missing, though a groove can be distinguished (fig. 27c) which is similar in position to that in Eumetopias (fig. 26c). Only a small part of the proximal facet on the plantar margin remains. The dorsal facet for the third metatarsal does not extend as far down on tibial face as it does in Eumetopias.

Measurements of fourth metatarsal (in millimeters).

\begin{tabular}{|c|c|c|}
\hline & $\begin{array}{c}\text { Pontolis } \\
\text { magnus? } \\
\text { No. } 24081 .\end{array}$ & $\begin{array}{c}\text { Eumetopias } \\
\text { jubata, } \\
\text { No. } 4112 .\end{array}$ \\
\hline $\begin{array}{l}\text { Dorso-plantar diameter of head } \ldots \ldots \ldots \ldots \ldots \ldots \ldots \ldots \ldots \\
\text { Tibio-fibular diameter of head } \ldots \ldots \ldots \ldots \ldots \ldots \ldots \ldots\end{array}$ & $\begin{array}{l}42 \\
31\end{array}$ & $\begin{array}{l}37 \\
21\end{array}$ \\
\hline
\end{tabular}

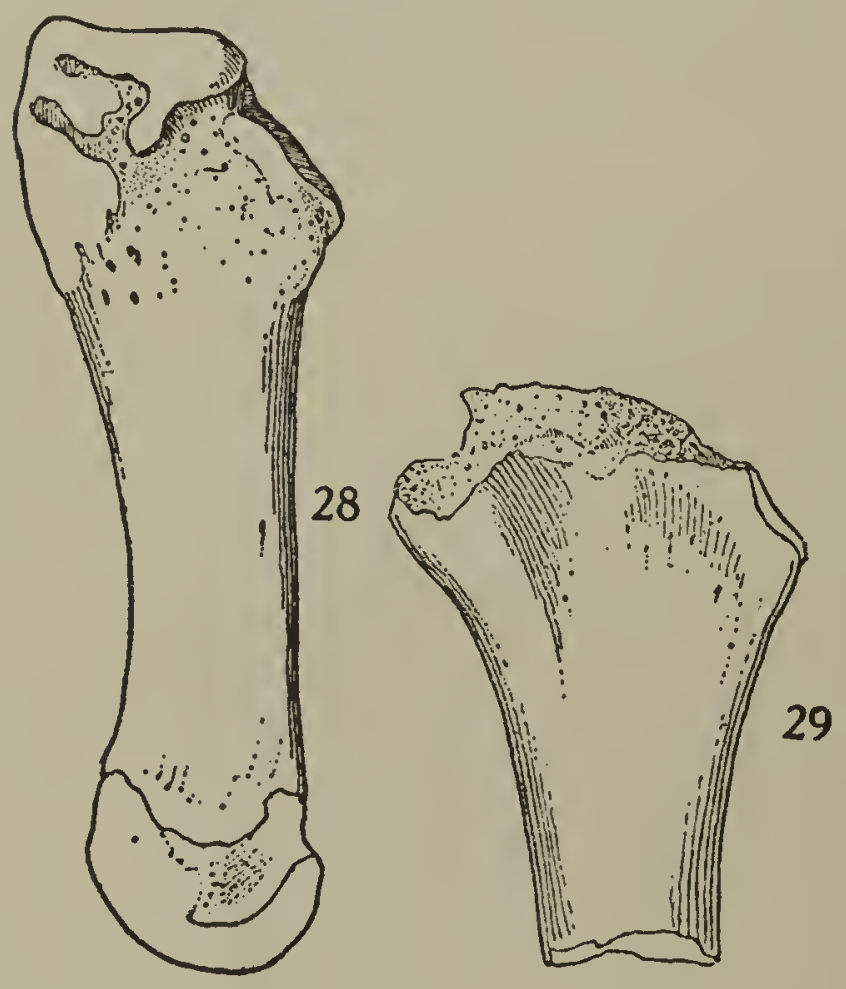

Frg. 28.-Tibial view of fifth metatarsal of Eumetopias jubata (Schreber), No. 4112, Mus. Vert. Zool., $\times 0.5$. Ano Nuevo Island, off San Mateo County, California.

FIg. 29.-Tibial view of fifth metatarsal of Pontolis cf. magnus, No. 24082, Mus. Palaeo., Univ. Calif., $\times 0.5$. Exposures on south side of Soledad Canyon, San Diego County, California.

Fifth Metatarsal.

A typical feature of this Pliocene pinniped is seen in the flattened shaft of the fifth metatarsal. It is relatively much narrower and deeper than in any known otarid. Inasmuch as only a small portion of the shaft (fig. 29) is known, it is not advisable to make any comparisons with the same bone of Eumetopias (fig. 28). The following are the measurements of fifth metatarsal:

Pontolis cf. magnus, No. 24082: $\mathrm{mm}$

Greatest dorso-plantar diameter of shaft...................... 52

Greatest tibio-fibular diameter of shaft. . . . . . . . . . . . . . . . . . . . . . 14 Eumetopias jubata, No. 4112:

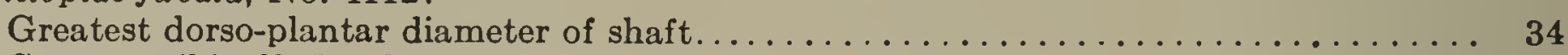

Greatest tibio-fibular diameter of shaft. . . . . . . . . . . . . . . . . . 17 


\section{INDEX.}

The following index contains the names of the families, genera, and species, which occur in this series of papers. Two kinds of type are used for the names, roman and italic; the former indicates valid names, the latter synonyms. When a species name follows a genus name that is synonymous with another genus name, both the genus and species names of the combination are italicized, although the species name may be valid. Two kinds of type are used in the figures referring to the pages, the heavy-faced type indicates the pages on which descriptions may be found.

acuto-rostrata, Balaenoptera........ PAGF aegyptiacum, Eotheroides.......... 65 Agorophiidae................ 37 alascanus, Callorhinus, $75,76,77,78,79,80,81$ $82,83,84,86,89,92$ Allodesmus kernensis.................... 71 angustirostris, Mirounga........... 99, 104 antwerpiensis, Thalassocetus. . . . . . 16 Arctocephalus, 75, 83, 84, 85, 86, 89, 90, 91, 92 ,

94,95

Arctocephalus australis... 84, 86, 89, 90, 99 australis, Arctocephalus....84, 86, 89, 90, 99 australis, Eubalaena............... 44 australis, Halicore. . . . . . . . . . . . . . 67

Balaena....................... 49 mysticetus.............. 42,44

Balaenodon............... 1, 2 balaenopsis, Balaenula............... 44

Balaenoptera.................... 49 acuto-rostrata....... 44 borealis............ 44 cortessii.............. 44 davidsoni................... 71 gastaldii............ 56 physalus............ 44 ryani............... 71

Balaenula balaenopsis............. 44 borealis, Balaenoptera.............. 44 byronia, Otaria ................. 75 californianus, Zalophus............. 99 Callorhinus, $75,76,77,78,79,80,82,83,84,86$ $89,90,91,92$ Callorhinus alaścanus, $75,76,77,78,79,80,81$, $82,83,84,86,89,92$ capgrandi, Rytiodus, ............ 60 caretti, Scaldicetus...........7, 8, 16, 34 carolinensis, Dinoziphius. . . . . . . . . 8,9 catodon, Physeter..........11, 17, 25, 29 Cetotherium................36,37,51

furlongi.........38,44,51

Skull............. 39

Tympanic............. 39

Endocranial cast....... 41

Mandibles........... 41

Stylohyal........... 43

Cervical vertebrae...... 42

Dorsal vertebrae....... 44

Lumbar vertebrae...... 45

Caudal vertebrae....... 46

Chevrons........... 46

Ribs.............. 49

Scapula........... 48

Humerus. . . . . . . . . 49

Radius............. 49

Ulna.............. 49

Cetotherium gastaldii.............. 50

Cetotherium klinderi............... 48
Cetotherium megalophysum.......... 51

Cetotherium moreni.............39,40 rathkii. .....36, 39, $41,51,54$ vandelli...........50,51 coronatus, Palaeodelphis.............. 6 cortessii, Balaenoptera............. 44 crassidens, Hoplocetus. . . . . . . . . . . . 5 cuvieri, Metaxytherium.........58,63, 67 Cystophorinae.................. 98 davidsoni, Balaenoptera............ 71 davidsonii, Eschrichitus. . . . . . . . 35, 41

Delphininae.................. 4

Desmatophoca oregonensis. . . . . . . 71,97 Diaphorocetus. . . . . . 1, 2, 4, 6, 9, 10, 13, 17 poucheti... $2,3,6,7,9,15,22$

Dinoziphius............... 1,2 carolinensis......... 8,9

Dioplotherium manigaulti. . . . . . . . . . 59

divergens, Odobenus.............99, 102 dubusii, Physeterula . . . . . . . . . . .4, 14, 15 emmonsi, Ontocetus. . . . . . . . 11, 12, 33 Eumetopias, 86, 90, 102, 103, 104, 105, 106, 107, $108,109,110,111,113,114,115,116$ Eumetopias jubata...... .86, 94, 99, 102, 110

Eotheroides aegyptiacum.......... 65 Eschrichitus davidsonii. . . . . . . . . 35,41

Eubalaena australis............... 44 glacialis............42, 44

Eucetus................... 1,2

Eudelphis...................... 1, mortezelensis........... 7

fasciata, Phoca.................. 79

Felsinotherium................. 58 serresii, 58, 61, 62, 63, 64, 66, 67

floridanum, Metaxy therium......59, 67, 68 furlongi, Cetotherium..........38,44,51 gastaldii, Balaenoptera............ 56 gastaldii, Cetotherium............. 50 glacialis, Eubalaena..............42, 44 glaucus, Rhachianectes............. 44 grandis, Scaldicetus.............6, 7, 16 Graphiodon....................... 1,2 grex, Xyne.................... 38 Halicore. . . . . . . . . . . . . 12, 68, 69 australis . . . . . . . . . . 67

Halitherium schinzi. . . . . . . . . . . 58, 67 hispida, Phoca................. 78

Homoeocetus. . . . . . . . . . . . . . 1, 2

Hoplocetus.................. 1, 2, 5 crassidens.......... 5 obesus............. 8, 9 hungaricus, Mesocetus............44, 46 hupschii, Plesiocetus..............36, 51 Hydrodamalis. . .......57, 61, 62, 64, 65, 67 stelleri. . . .58, 61, $62,64,65,67$

Hypocetus. . . . . . . . . . . . . . 1, 2,

Idiophyseter. . . . . . . . . . 13, 16,17 
Idiophyseter merriami. . . . . . . 16, 18, 29,31

Skull.

Idiorophus. . . ............. $\ldots, 7,9,14,31$

jordani, Metaxy therium . . . . . . . . . 59, 72

jubata, Eumetopias. . . . . . 86, 94, 99, 102, 110

kernensis, Allodesmus.............. 71

klinderi, Cetotherium. . . . . . . . . . 48

kocki, Miosiren................58, 67

Kogia, 13, 18, 19, 20, 22, 24, 25, 26, 27, 28, 30

Kogiidae

13

krahuletzi, Metaxytherium. . . . . . . .67,68 latirostris, Trichechus.......64, 65, 67, 68, 69 leccense, Physodon............... 4 lenis, Leptophoca. . . . . . . . . . . . . . . 78

Leptophoca lenis.................. 78 magnus, Pontolis...............97, 98 manigaulti, Dioplotherium. . . . . . . . . . 59 marginata, Neobalaena............44,46 mediatlanticus, Orycterocetus. . . . . . 11, 13, 31 mediatlanticus, Paracetus..............9, 10 megalophysum, Cetotherium............. 51 megalophysum, Plesiocetus. ......51,52,53 Megaptera miocaena.............. 72 nodosa.............. 44 versabilis.............. 72

merriami, Idiophyseter. . . . . . . 16, 18, 29, 31 Mesocetus...............1, 2, 3, 36 hungaricus...........44, 46 Metaxytherium, $57,58,59,61,64,65,66,68,69$ cuvieri........58, 63,67 floridanum . . . . . 59, 67, 68 jordani.........59, 72 Skull........... 60

Periotic........... 65

Endocranial cast..... 65

Dorsal vertebrae..... 66

Ribs............. 69

Metacarpal.......... 69 krahuletzi........667,68 minutus, Palaeodelphis................ 6 miocaena, Megaptera.............. 72 Miosiren kocki................ .58, 67 Mirounga...........98, 104, 105, 106, 108 angustirostris..........99, 104

Monachus tropicalis............77, 91 moreni, Cetotherium..............39, 40 mortezelensis, Eudelphis.............. 7 mortezelensis, Scaldicetus. . . . . . . . 7, 16, 31 mortselensis, [Scaldicetus]............. 7 musculus, Sibbaldus............44,46 mysticetus, Balaena. ............42,44 Neobalaena marginata . . . . . . . . . . .44,46 nodosa, Megaptera................ 44 obesus, Hoplocetus. . . . . . . . . . . . 8, 9 occidentalis, Plesiocetus............. 50 Odobenidae................99, 100, 101 Odobenus, $12,94,95,102,103,104,105,106$, 107,108

Odobenus divergens. . . . . . . . . . .99, 102 Ontocetus.............. 1, 2, 12, 13, 30 emmonsi............11, 12,33 oxymycterus........... 30 Rostrum.............. 31 Mandibles............. 32 Teeth............... 33
PAGE

oregonensis, Desmatophoca..........71, 97

Orycterocetus...........1, 2, 12, 13, 14, 20 mediatlanticus......11, 13, 31 quadratidens.........10, 11

Otaria byronia................. 75

Otarid (?), new genus and species...... 93

Tibia................. 94

Ribs................. 95

Otariidae................71,99, 100

oxymycterus, Ontocetus............. 30

pacifica, Pliopedia................ 97

Palacodelphis................. 1,2

Palaeodelphis.................. 1,2

Palaeodelphis coronatus.............. 6

Palaeodelphis minutus.............. 6

palmeri, Parietobalaena............. 54

Paracetus ........................ 2,3

Paracetus mediatlanticus. . . . . . . . . . .9, 10

Parietobalaena palmeri............ 54 patagonicus, Idiorophis. . . . .6, 7, 9, 14, 30, 31 patagonicus, Physodon...........4,5,6 Patriocetus.................. 37

Phoca...................... $4,78,80$

fasciata................... 79

hispida.................... 78

sibirica............... 77

vindobonensis.............. 77,78

vitulina..........77, 78,79,80

Phocanella pumila............... 78

Physeter, 4, 6, 10, 11, 12, 13, 15, 16, 17, 18, 19, $20,21,22,23,24,25,26,27,28,30,31$, 32,33

Physeter catodon...........11, 17, 25, 29

Physeteridae........................ 3,4

Physeterula . . .............. 2, 4, 13

dubusii............ 14, 15

Physetodon.................. 1,2

physalus, Balaenoptera............ 44

Physodon................. 2, 3,5

Physodon leccense.................... 4

Physodon patagonicus...........4,5, 6

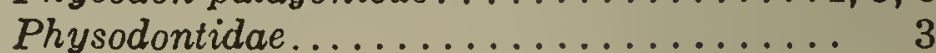

Pithanotaria starri..............74,93

Skull ..............

Mandible........... 75

Cervical vertebrae..... 81

Dorsal vertebrae....... 81

Lumbar vertebrae...... 82

Ribs............... 82

Sternebrae.......... 83

Scapula..........77,84

Humerus. . . . . . . . . 77, 84

Radius............78,86

Ulna. .............78,86

Carpals............79,86

Metacarpals........88,86

Phalanges............ 80

Ilium............ 83

Femur............. 83

Patella............ 84

Tibia .............. . . 84,89

Fibula........... 84, 89

Tarsals............ 89

Metatarsals............ 92

Phalanges............ 92 


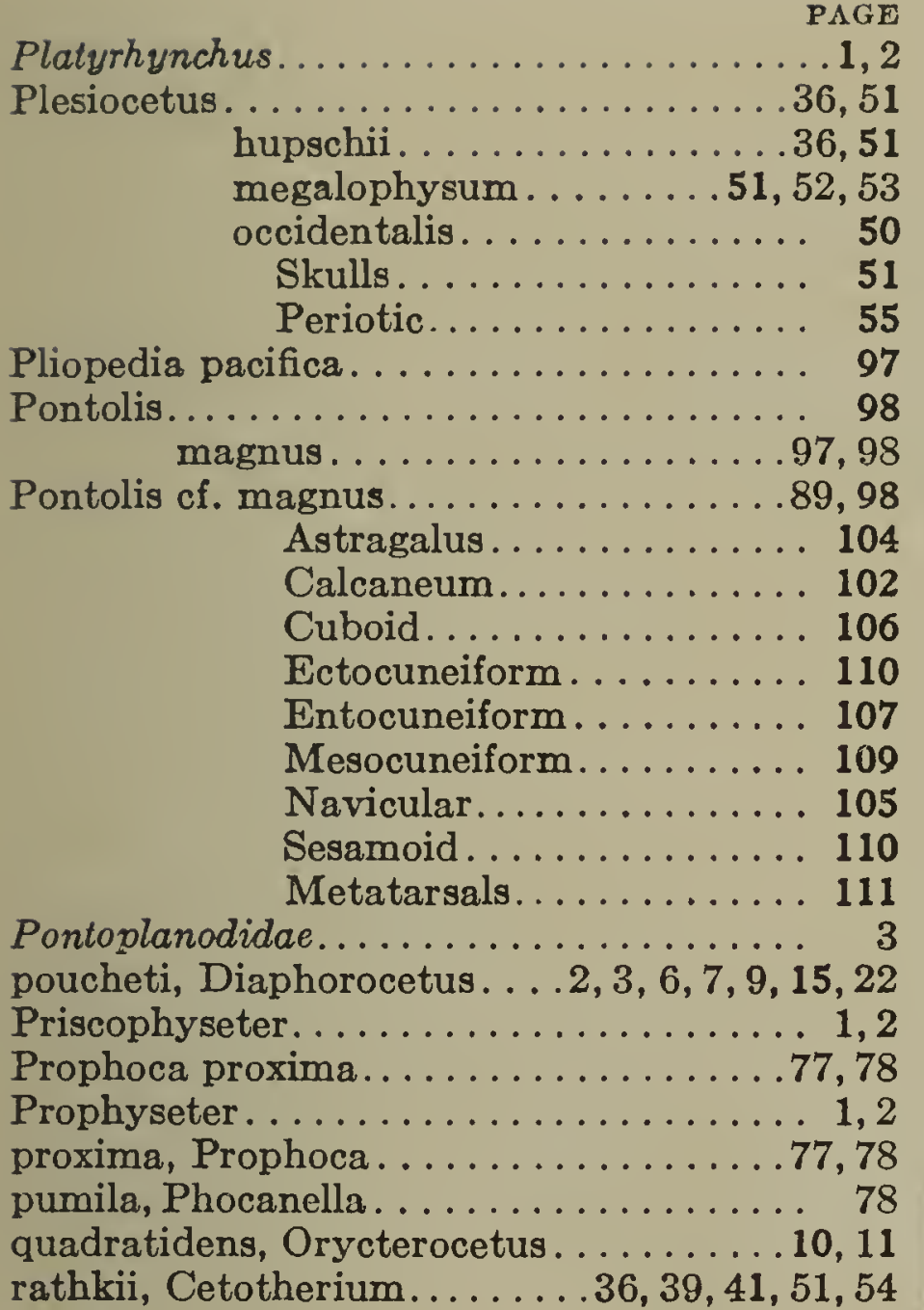

PAGE

Rhachianectes glaucus............ 44 ryani, Balaenoptera.............. 71 Rytiodus capgrandi............... 60 Scaldicetus.......... $1,2,3,5,6,7,13,31$ caretti.......... $7,8,16,34$ grandis...........6, 7, 16 mortezelensis.......... $7,16,31$ mortselensis........... 7

Scaptodon.................. 1, 2 schinzi, Halitherium . . . . . . . . . 58, 67 serresii, Felsinotherium, 58, 61, 62, 63, 64, 66, 67 Sibbaldus musculus............44,46 sibirica, Phoca.............. 77 Squalodon................. 7 starri, Pithanotaria...........74, 93 stelleri, Hydrodamalis, . . . .58, 61, 62, 64, 65, 67 Thalassocetus............. $1,2,11,13$ antwerpiensis........ 16

Trichechus..............64, 65, 68 latirostris.....64,65,67,68,69

tropicalis, Monachus............77, 91 vandelli, Cetotherium............50,51 versabilis, Megaptera............. 72 vindobonensis, Phoca . . . . . . . . .77, 78 vitulina, Phoca. . . . . . . 77, 78, 79, 80

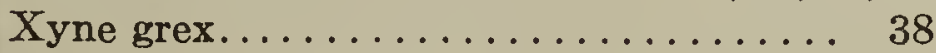

Zalophus............... 75, 90,95 californianus........... 99 


\section{ABBREVIATIONS FOR PLATES 1 to 6.}

The same abbreviations are used on plates 1 to 6 for the following structures:

Al., Alisphenoid.

A. inf. f., anterior infraorbital foramen.

Ant. max. f., anterior maxillary foramen.

Ant. n., antorbital notch.

Ap. max., apophysis of maxilla.

Bo., basioccipital.

Bs., basisphenoid.

$C$. , condyle.

Eth., ethmoid.

Ex. oc., exoccipital.

Fal. pr., falcate process of basioccipital.

F. hyp., hypoglossal foramen.

$F$. m., foramen magnum.

$F$. ov., foramen ovale.

$F r$, frontal.

H. pr. pt., hamular process of pterygoid.

Inf. $f_{\text {., }}$ infraorbital foramen.

Inf. max. f., inferior maxillary foramen.

$J$. A. C., jugulo-acoustic canal.

$J u$. , jugal.

$L a$., lachrymal.

L. cr. max., lateral crest of maxilla.
Max., maxilla.

Max. $f .$, maxillary foramen.

Max. inc., maxillary incisure.

$N$. A., nasal passage.

$N a$., nasal.

$O p$. c., optic canal.

$P a$., parietal.

Pal., palatine.

$P$. inf. f., posterior infraorbital foramen.

$P$. max. $f$. , posterior maxillary foramen.

$P m x$., premaxilla.

Pmx. f., premaxillary foramen.

$P$. oc. $p r$. , paroccipital process.

Prs. presphenoid.

Pt., pterygoid.

S. max. f., superior maxillary foramen,

S. oc., supraoccipital.

S. or pr., supraorbital process of frontal.

$S q$. , squamosal.

Vo., vomer.

Zyg., zygomatic process of squamosal. 


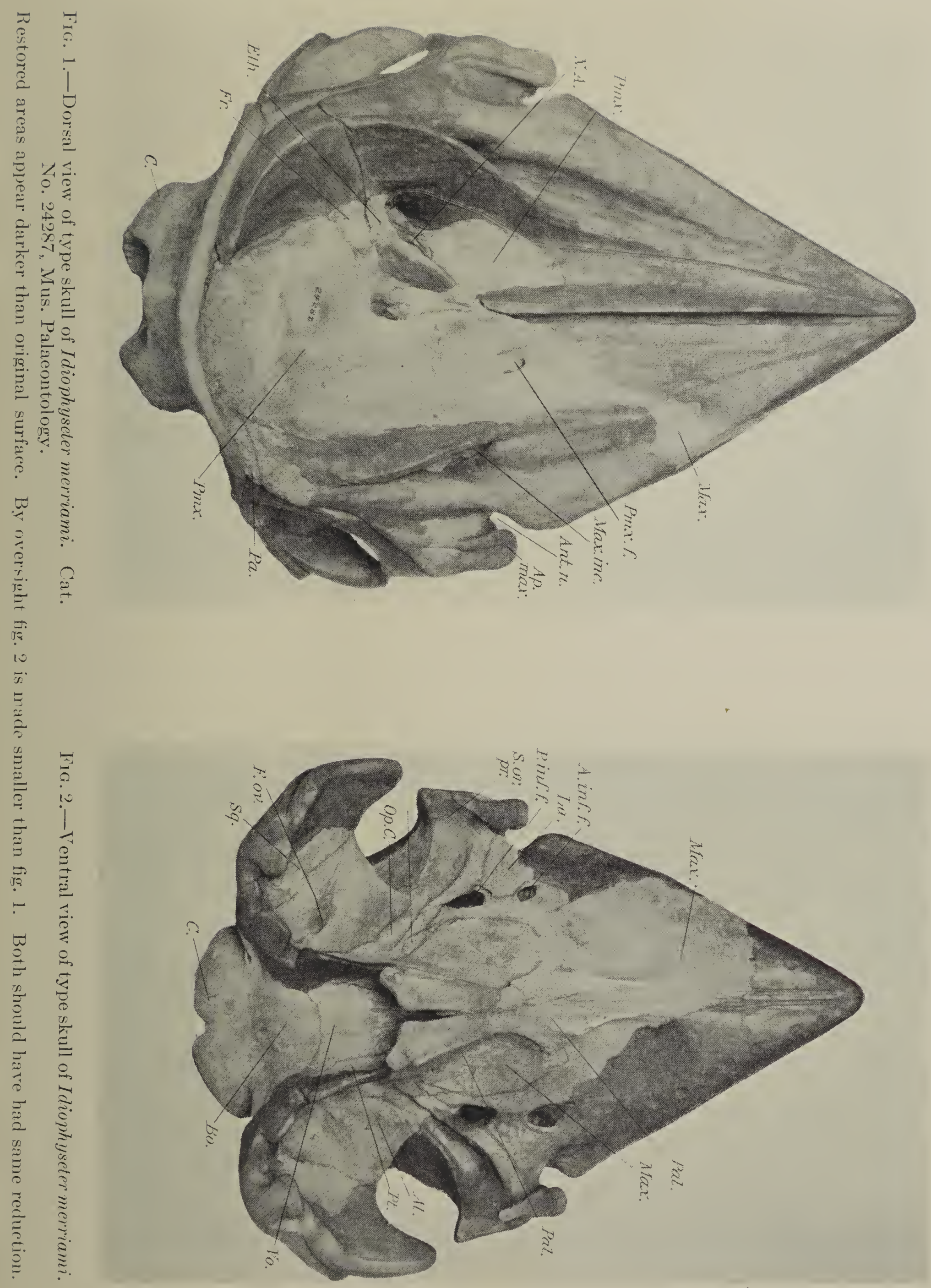





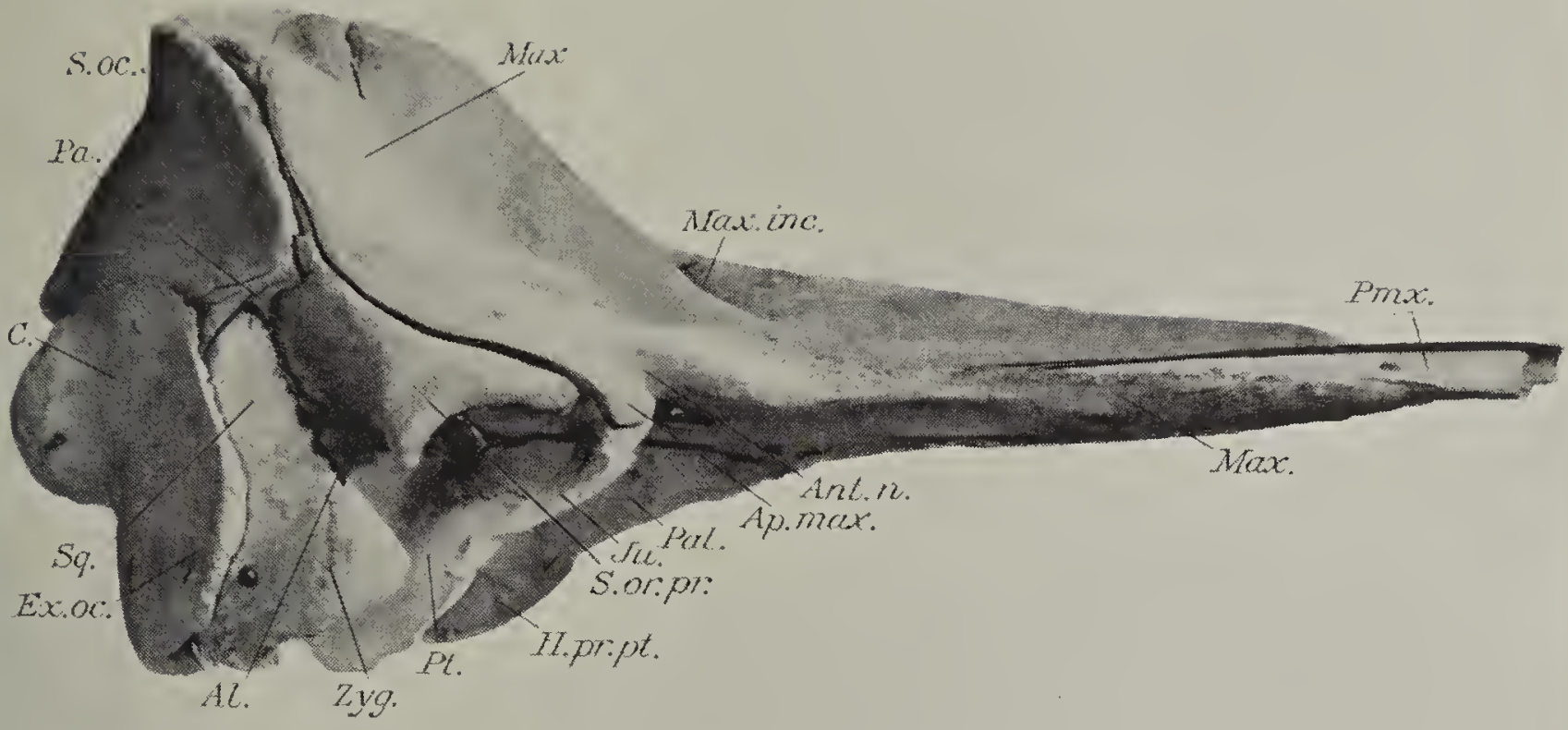

Fig. 1.-Lateral view of skull of a young Physeter catodon. Cat. No. 49488, U. S. Nat. Mus.

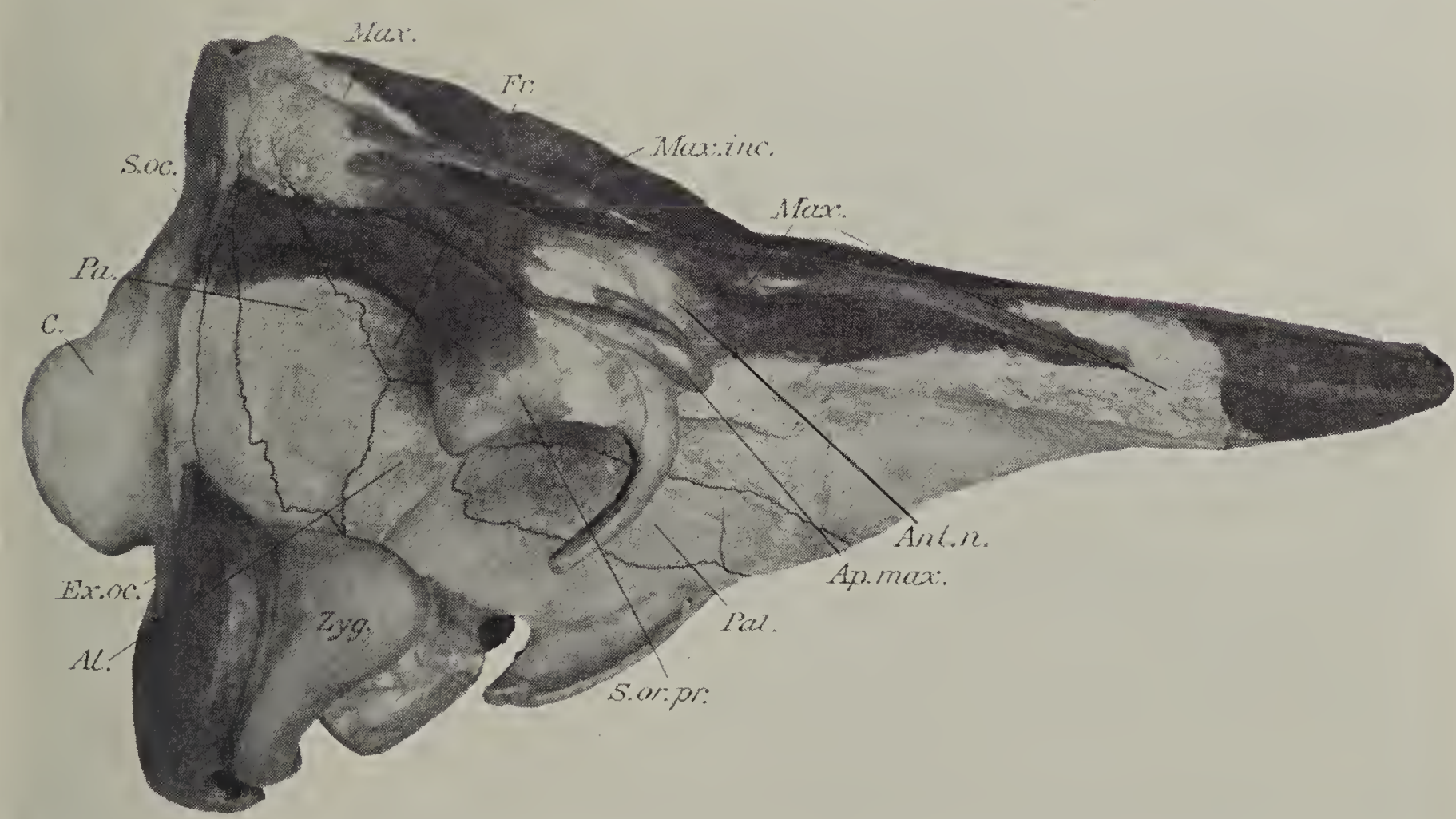

FIG. 2.-Lateral view of skull of Idic physeter merriami.

Restored areas appear darker than original surface. 


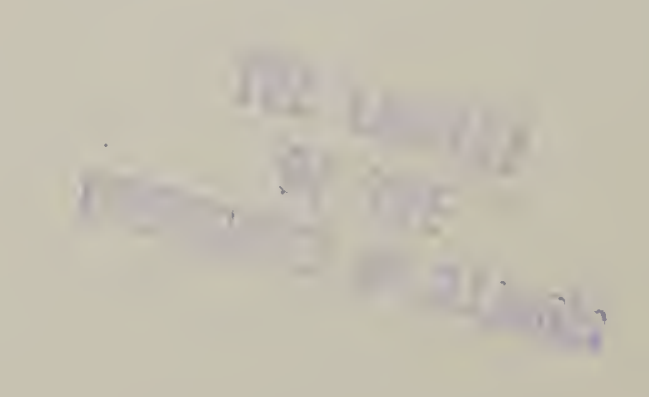




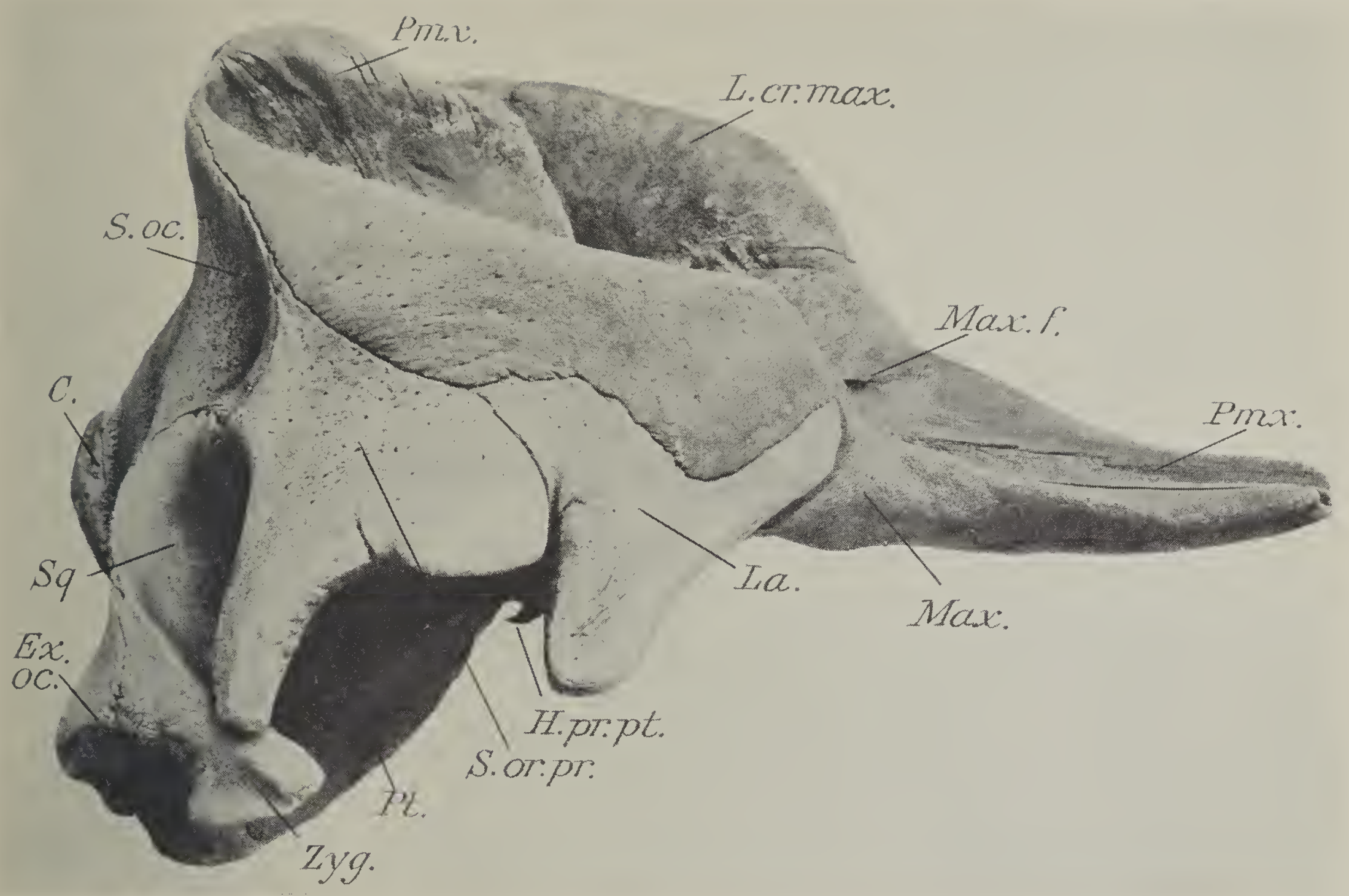

Fig. 1.-Lateral riew of a skull of Kogia breviceps. ('at. No, 22015, U. S. Nat. Mus.

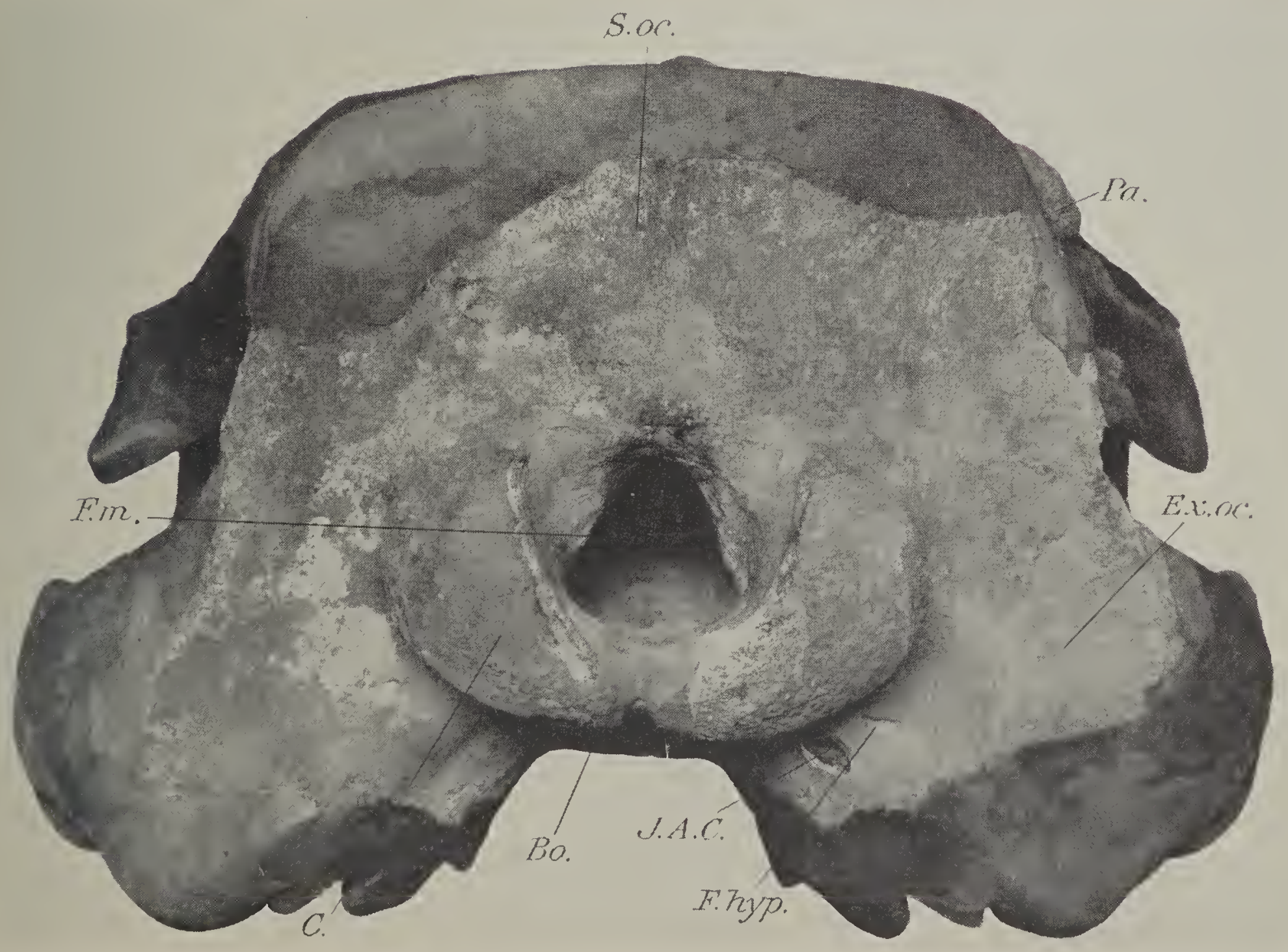

Fig. 2.-Posterior view of type skull of Idiophyseter merriami. Restored areas appear darker than original surface. 

KELLOGG

PLATE 4

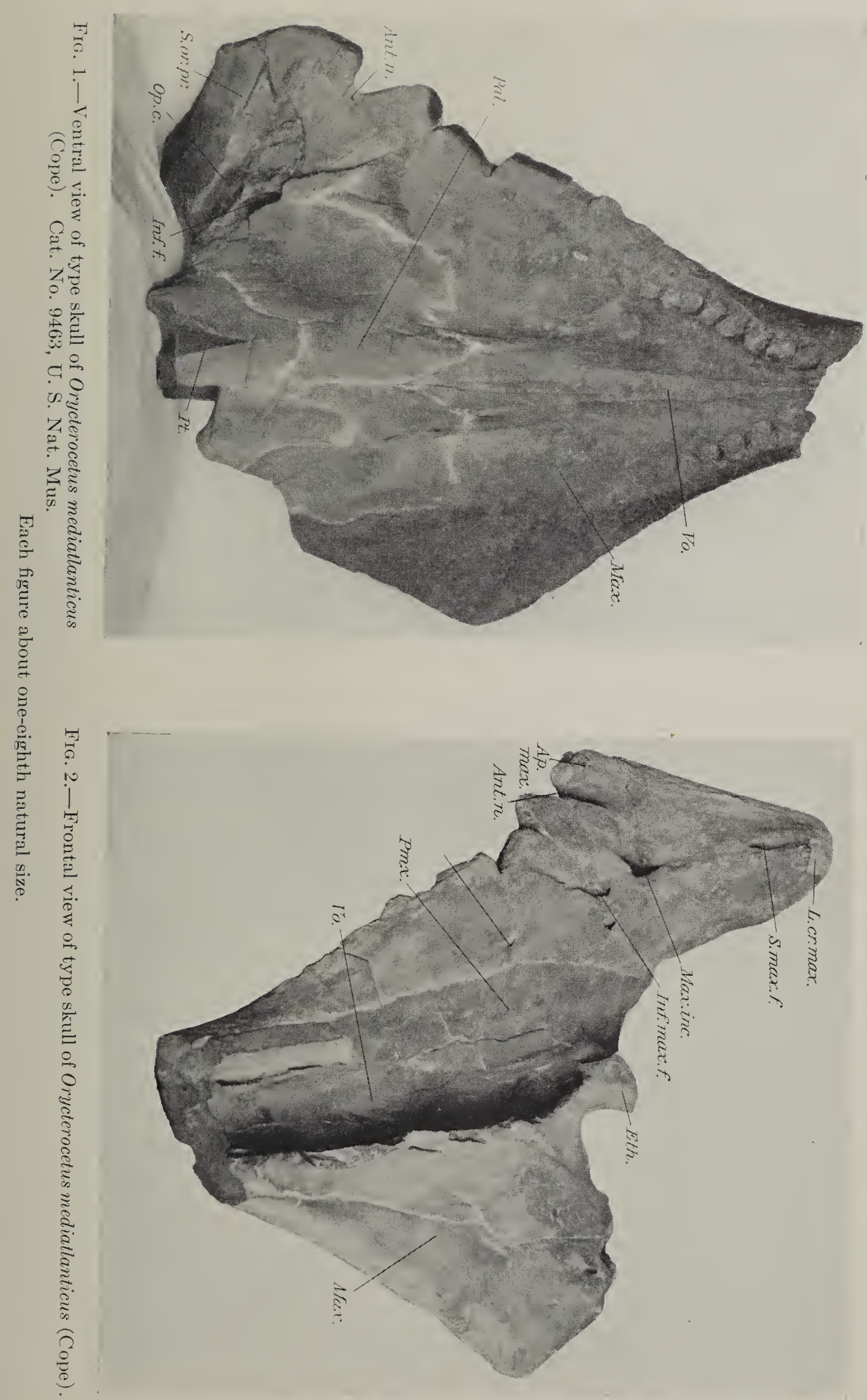




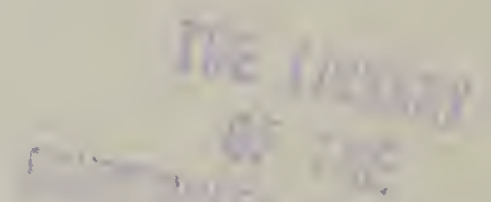

$$
\begin{aligned}
& \text { inf wist: }
\end{aligned}
$$




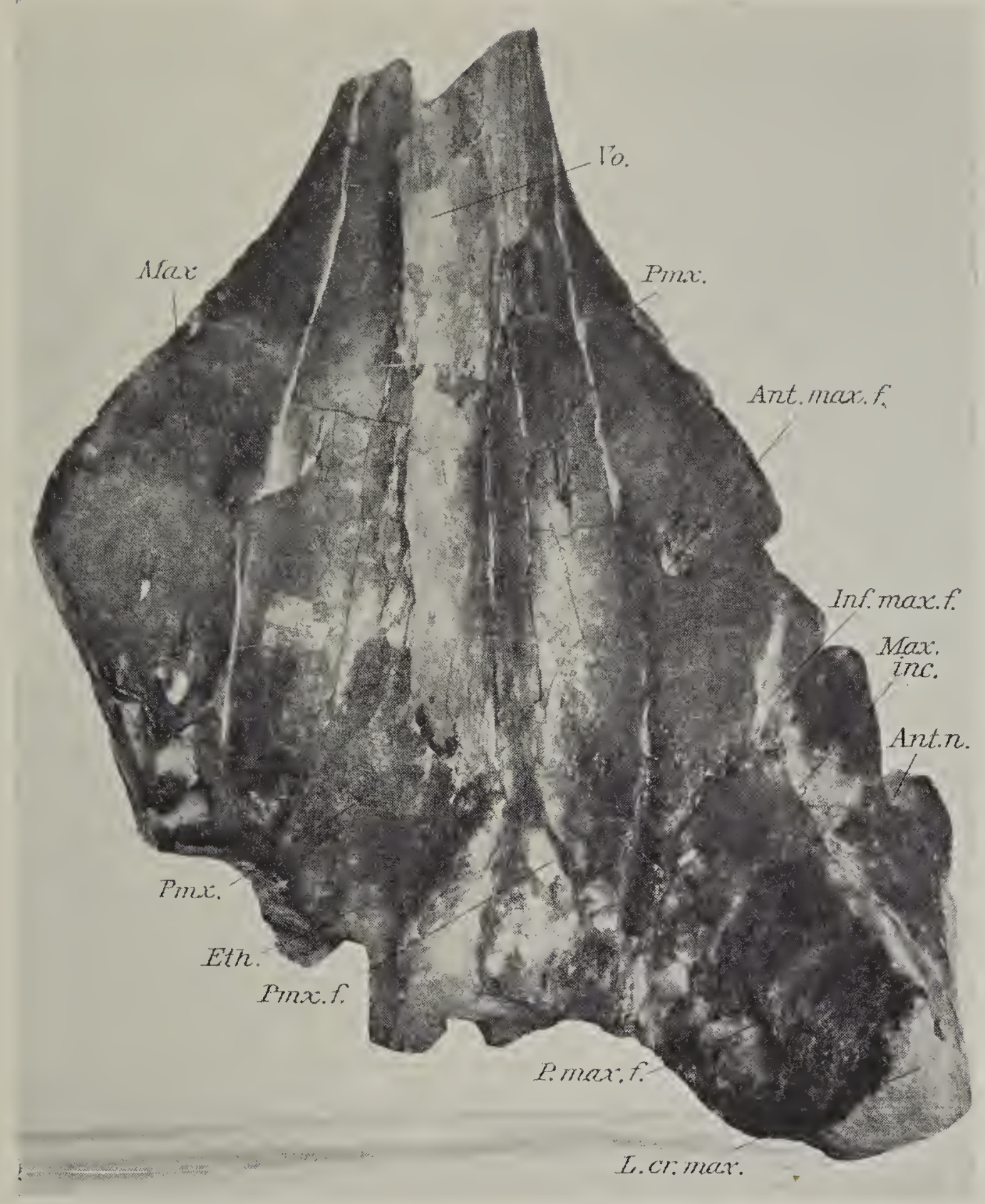

FIG. 1.-Dorsal view of type skull of Orycterocetus mediatlanticus (Cope). Cat. No.9463, U. S. Nat. Mus.

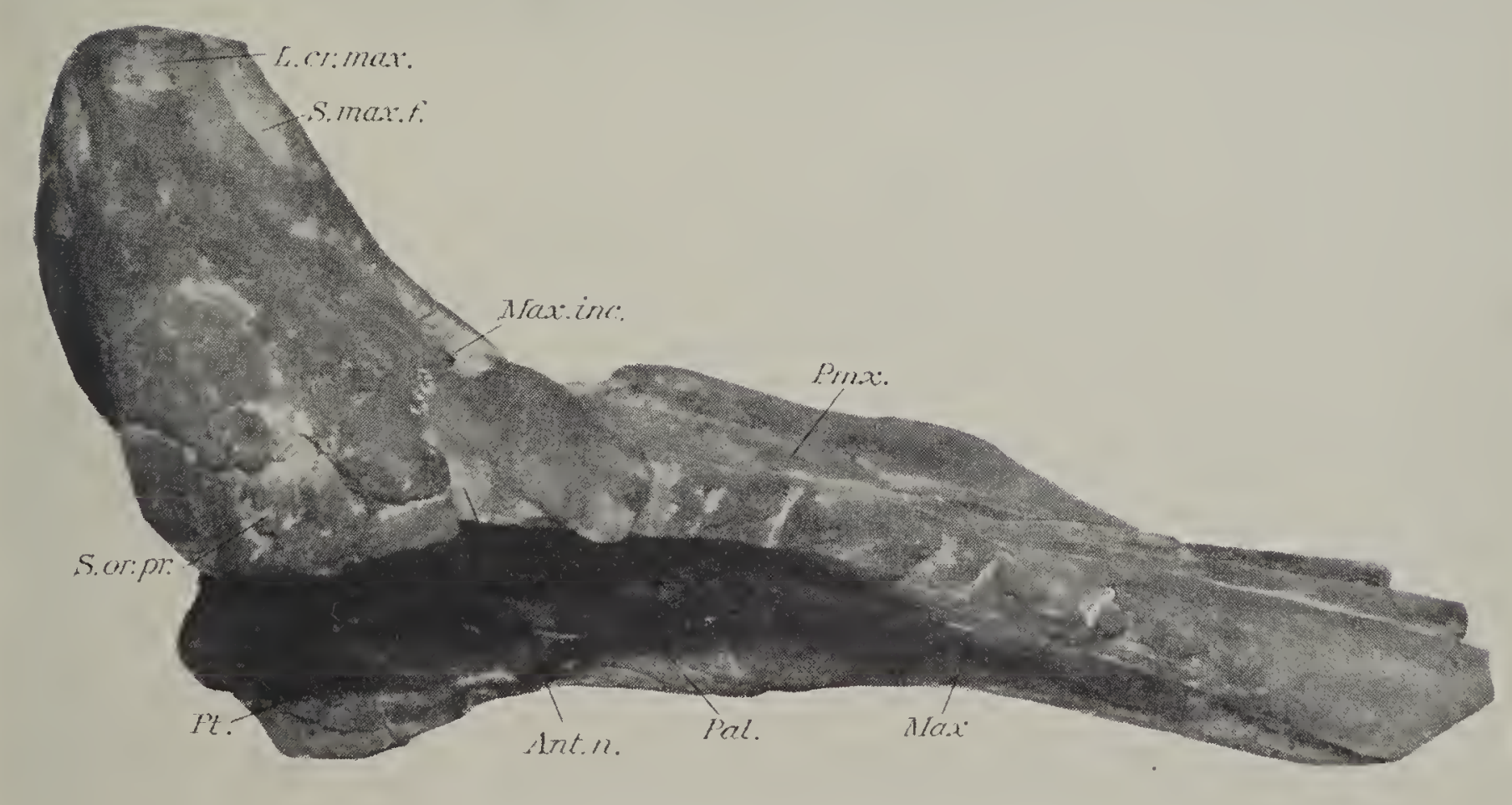

Fig. 2.-Lateral view of type skull of Orycterocetus mediatlanticus (Cope). Each figure about,one-eighth natural size. 
Re lesiny

(B) 102

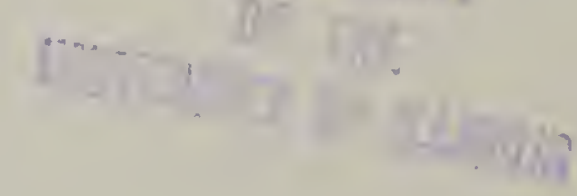




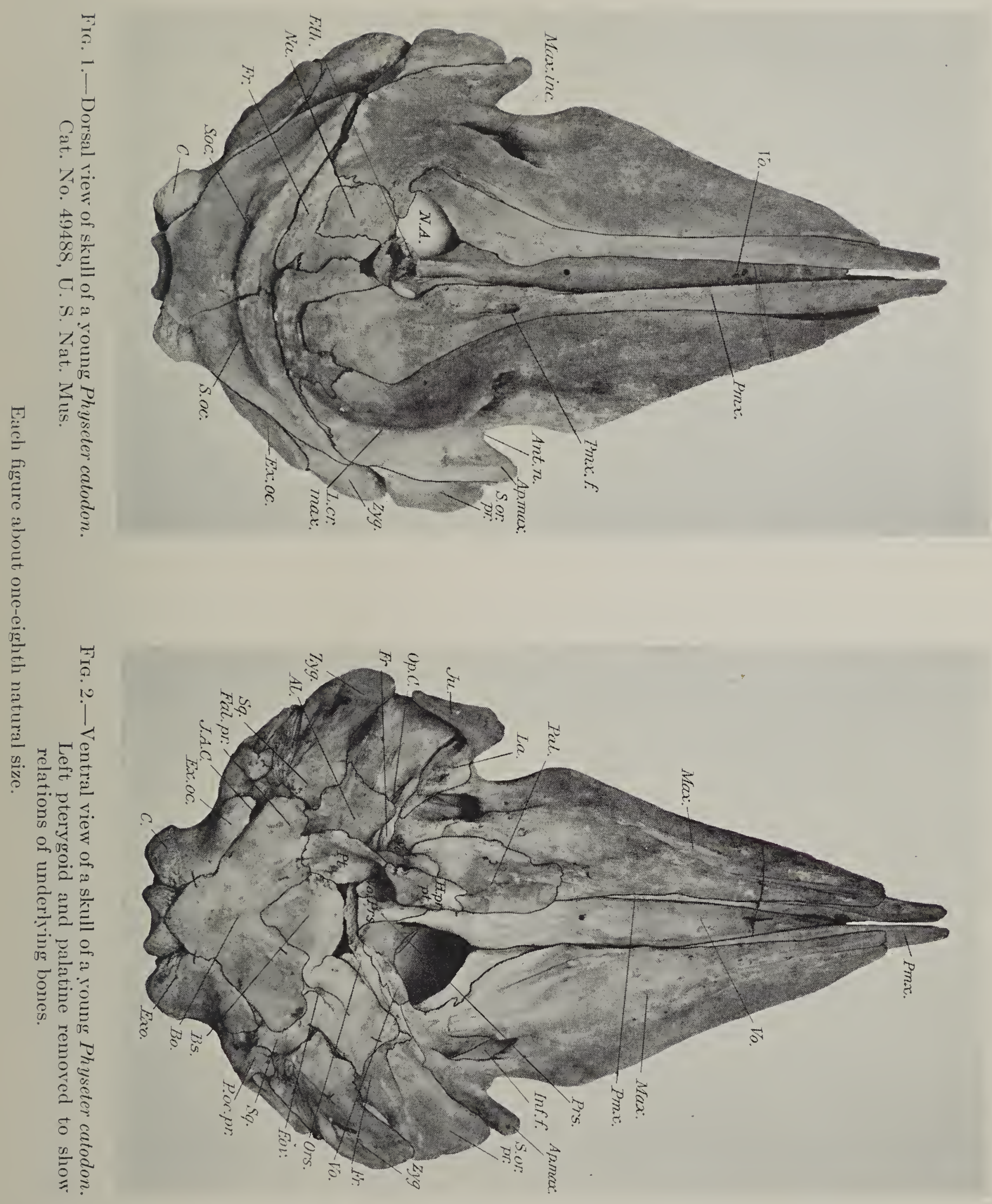




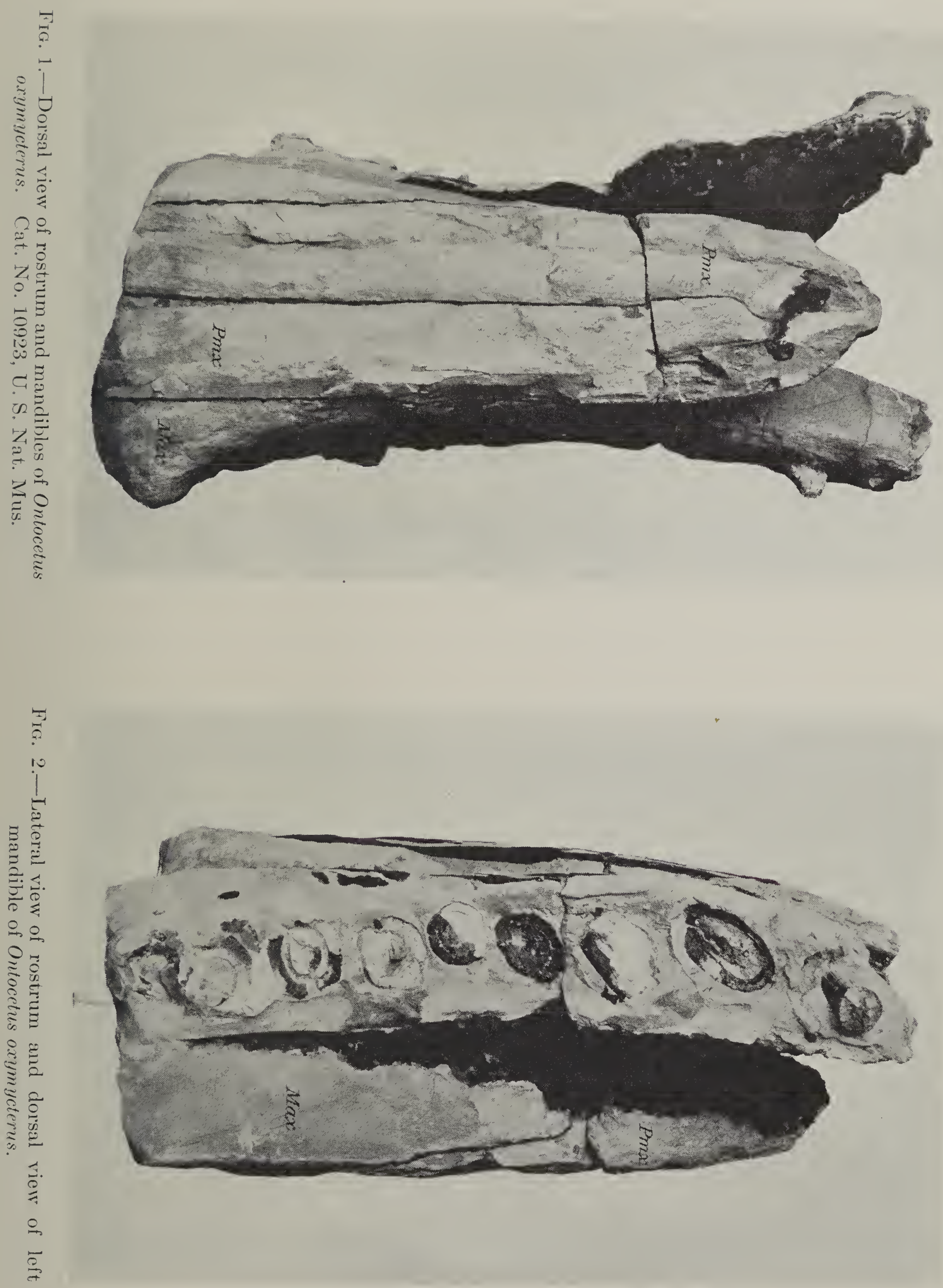


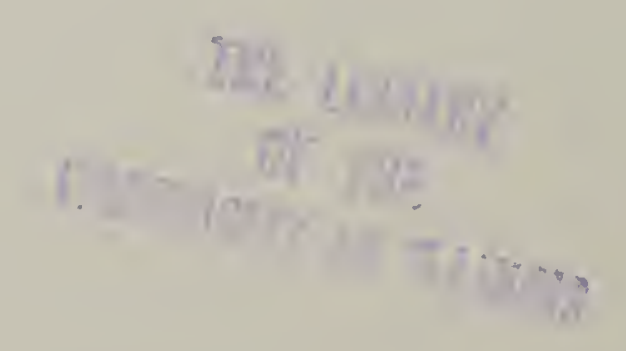




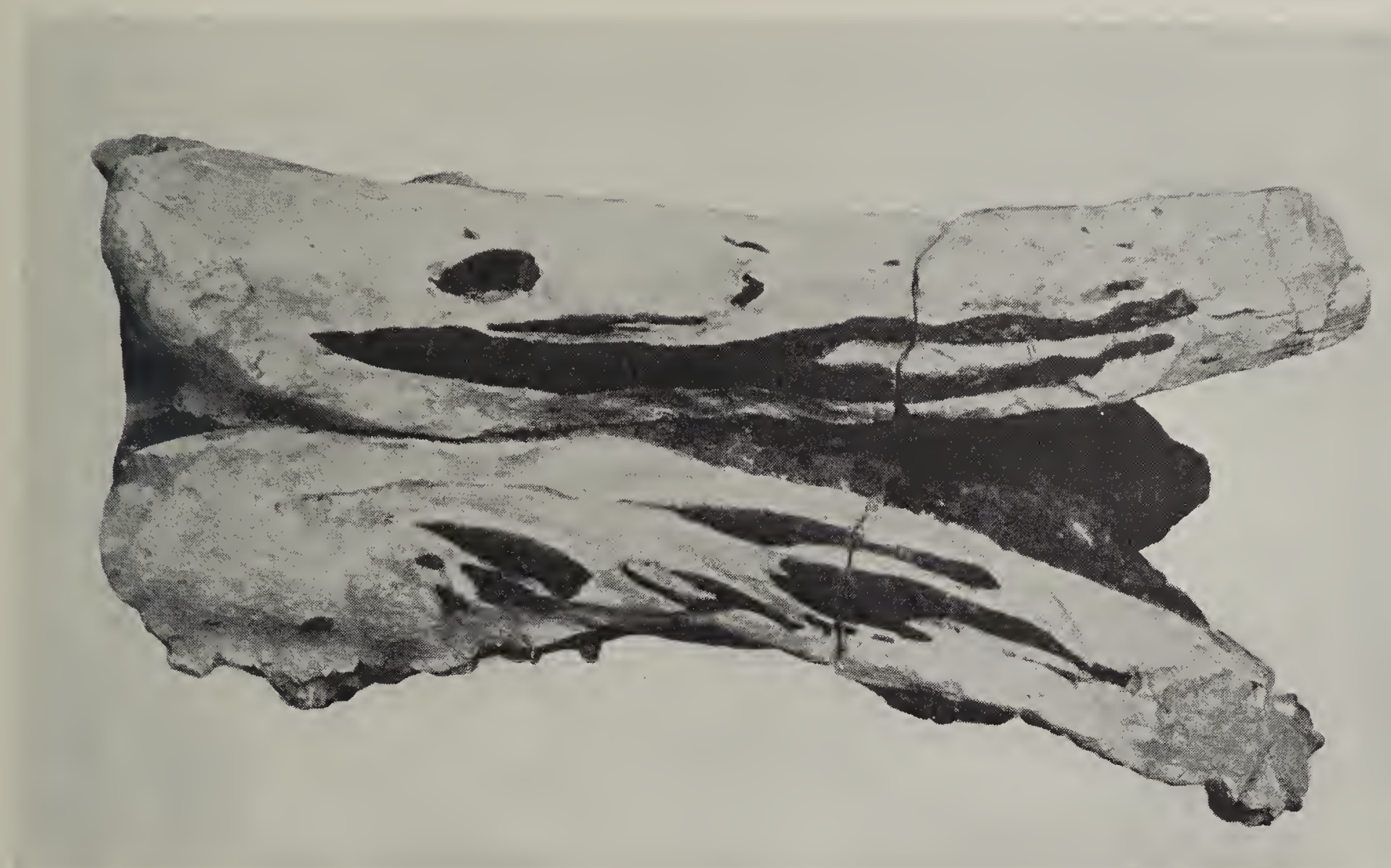

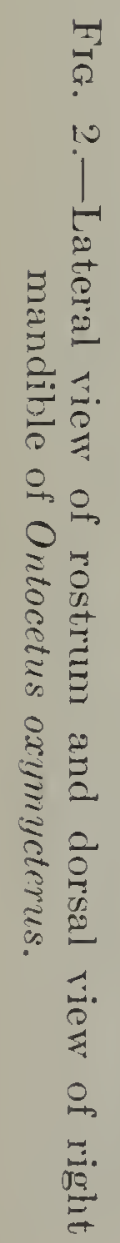

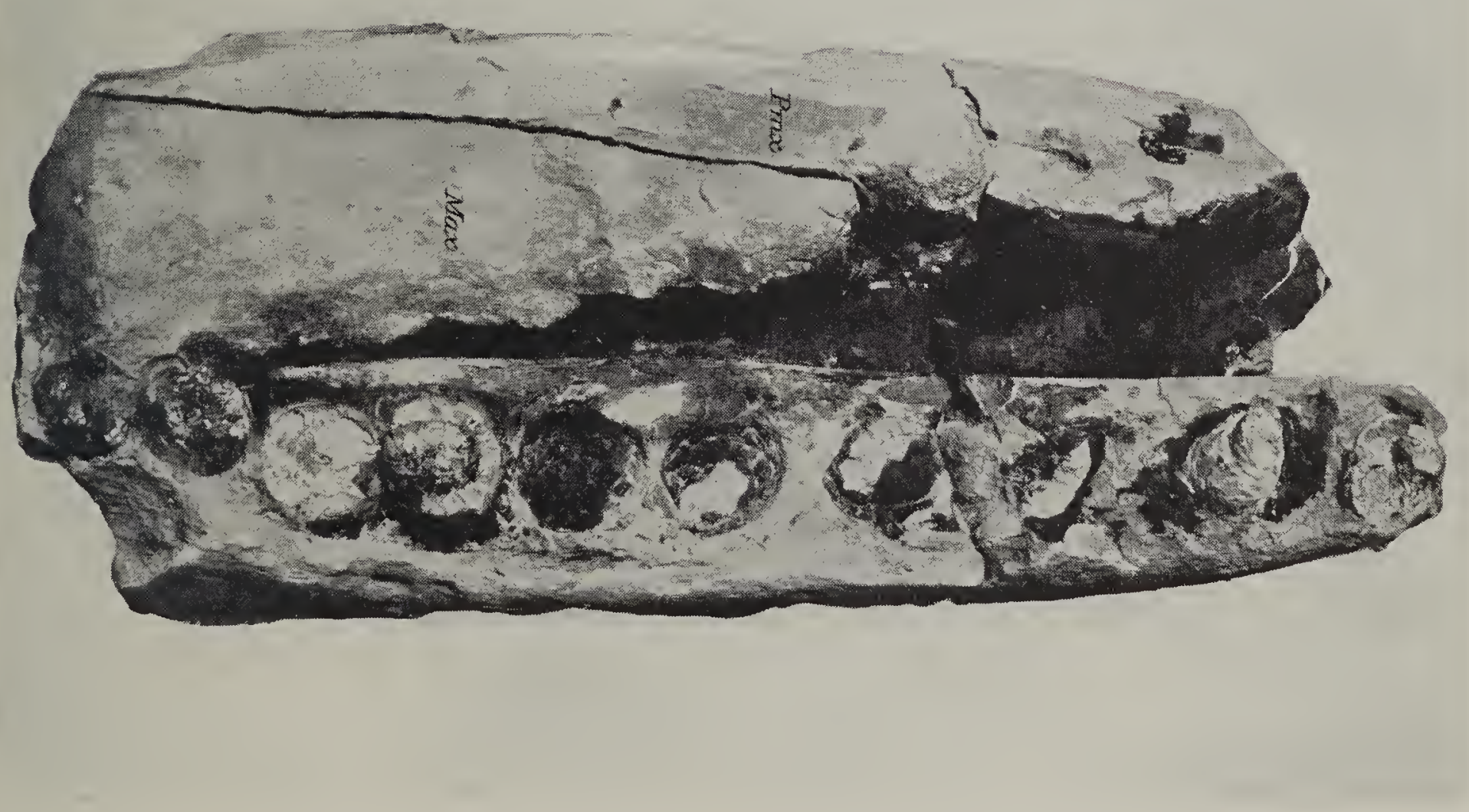




$$
\begin{aligned}
& \text { 16L II I }
\end{aligned}
$$

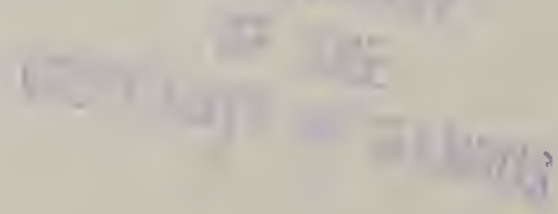



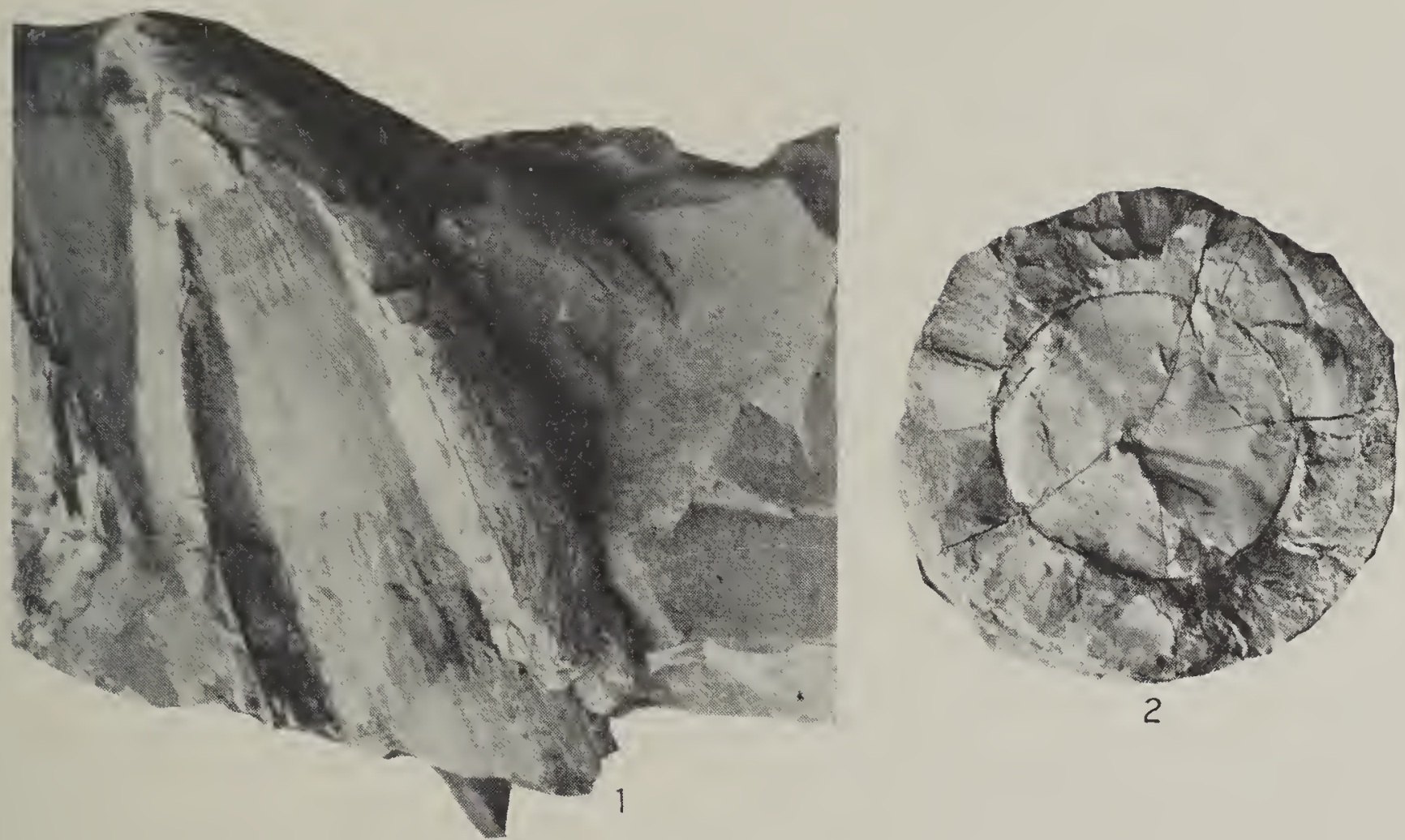

FIc. 1.-Lateral view of crown of a mandibular tooth of Ontocetus oxymycterus with outer laver of cementum removed to show the longitudinal fluting on the dentinal axis.

FIG. 2.-Cross-section of a mandibular tooth showing internal cone of ossified pulp and dentine, and thick external band of cementum.

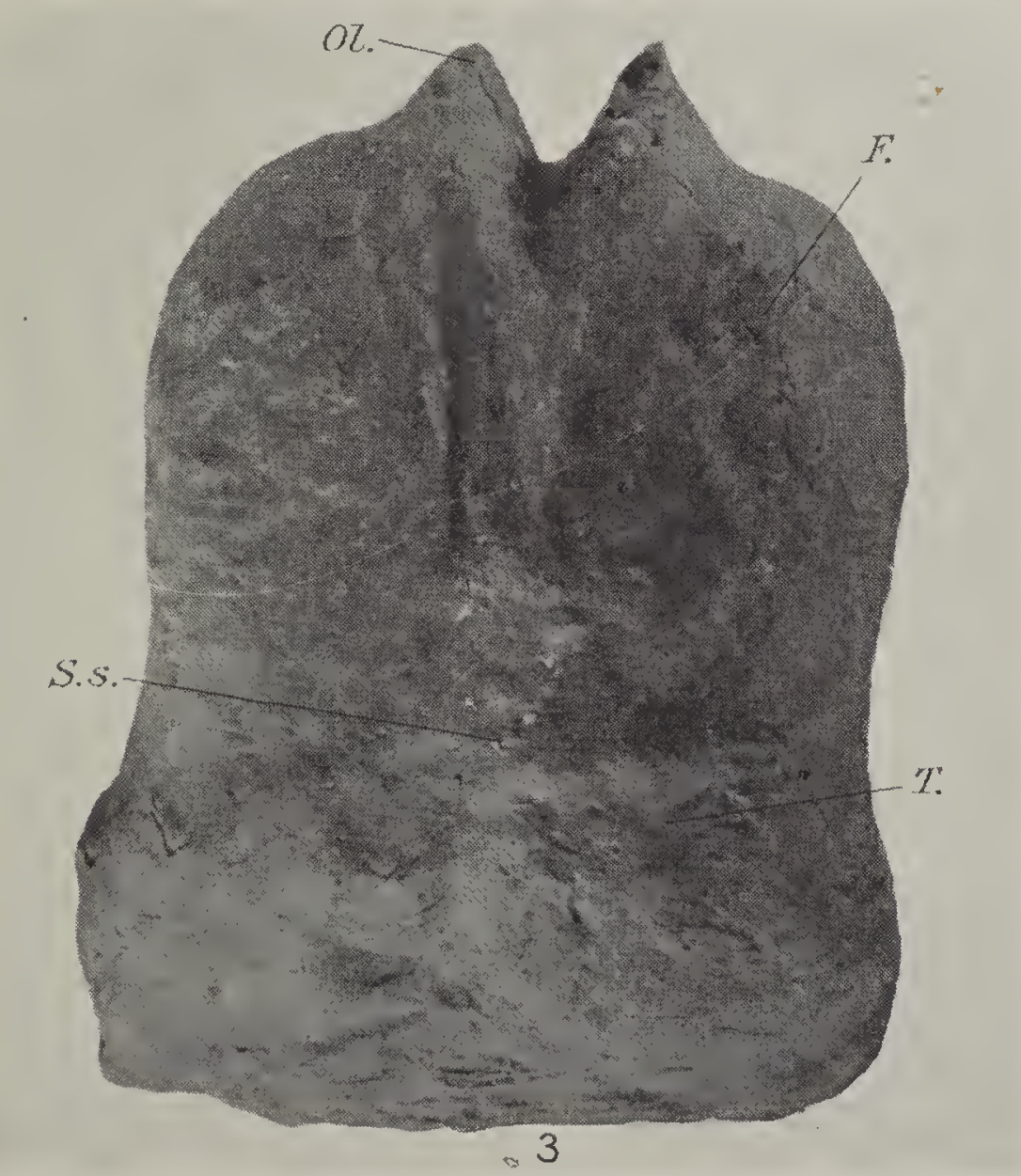

FIG. 3.-Endocranial cast of type skull of Metaxylherium jordani.

Abbreviations: $F$., frontal lobe of cerebrum; $O l$, ol factory lobe; S.s., sagittal sinus; T., temporal lobe of cerebrum. 


$$
\begin{aligned}
& \begin{array}{l}
77 \\
\text { (1) nes }
\end{array}
\end{aligned}
$$

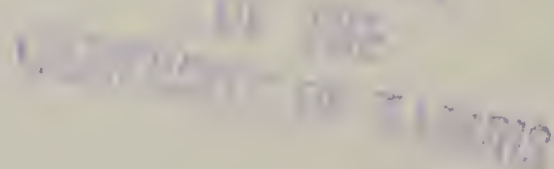




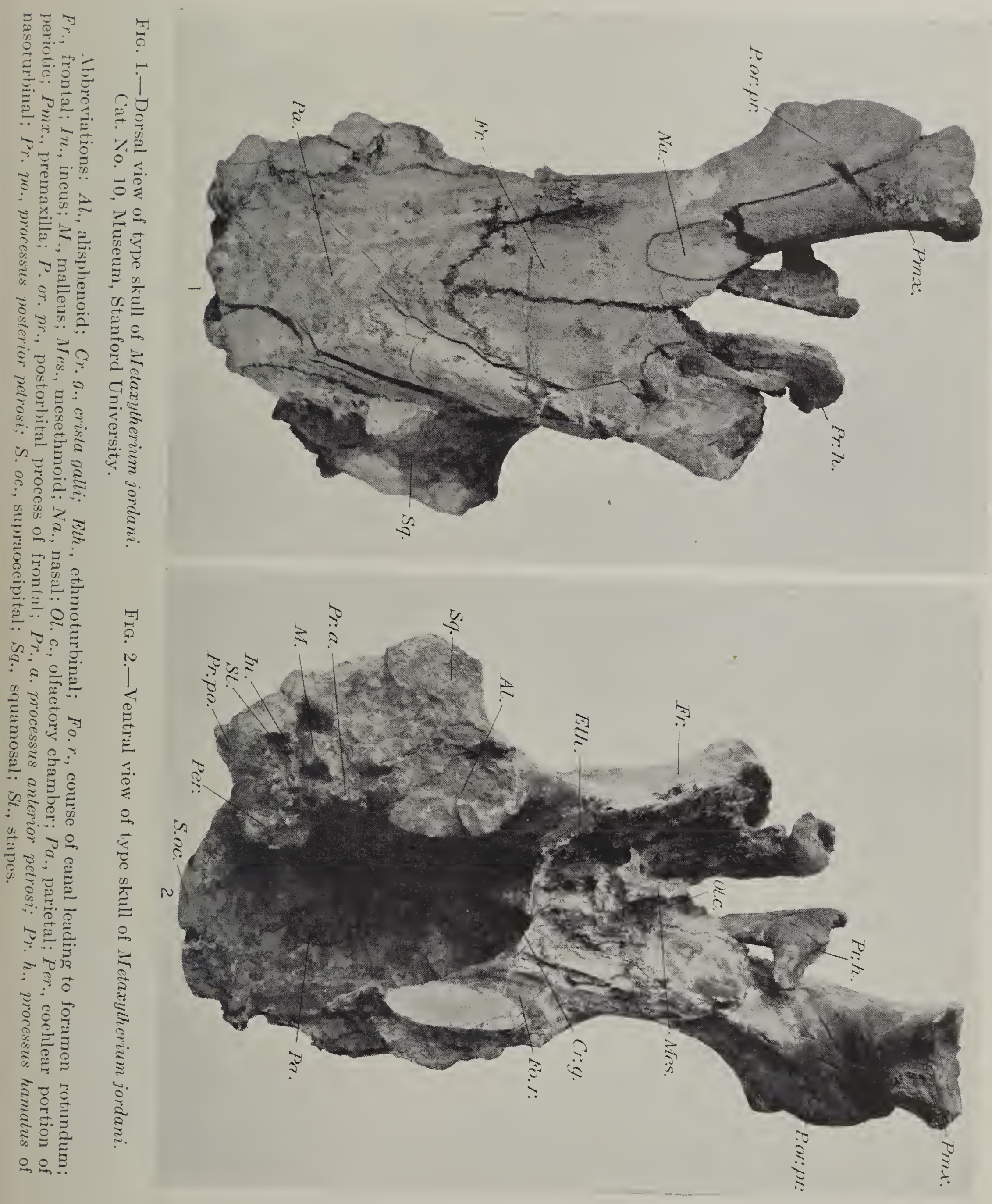




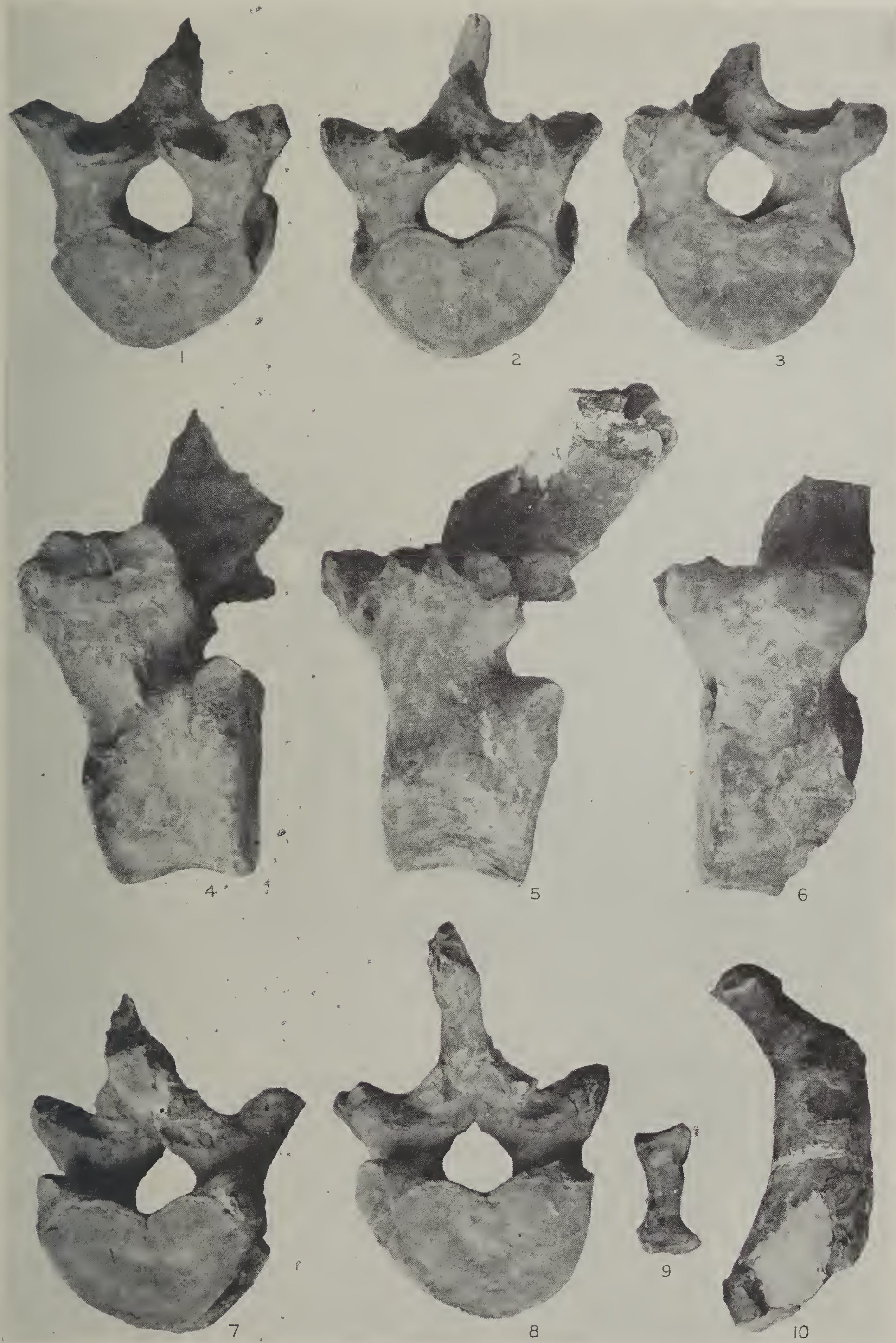

Figs. 1-3. Anterior views of dorsal vertebrae of Metaxytherium jordani. Fig. 1, sixth dorsal; Fig. 2, seventh dorsal; Fig. 3, eighth dorsal.

Figs. 4-6. Lateral views of dorsal vertebrae of Metaxytherium jordani. Fig. 4, sixth dorsal; Fig. 5, seventh dorsal; Fig. 6, eighth dorsal.

Fic.s. 7, 8.-Posterior views of dorsal vertebrae of Melaxytherium jordani. Fig. 7, sixtl dorsal; Fig. 8, seventh dorsal.

Fig. 9.-Posterior view of fifth metacarpal.

Fig. 10.-Proximal end of a rib from left side of body. 


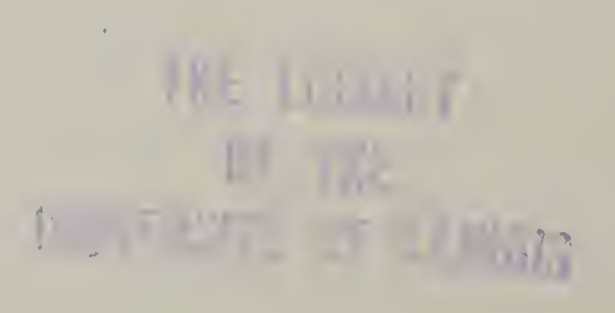




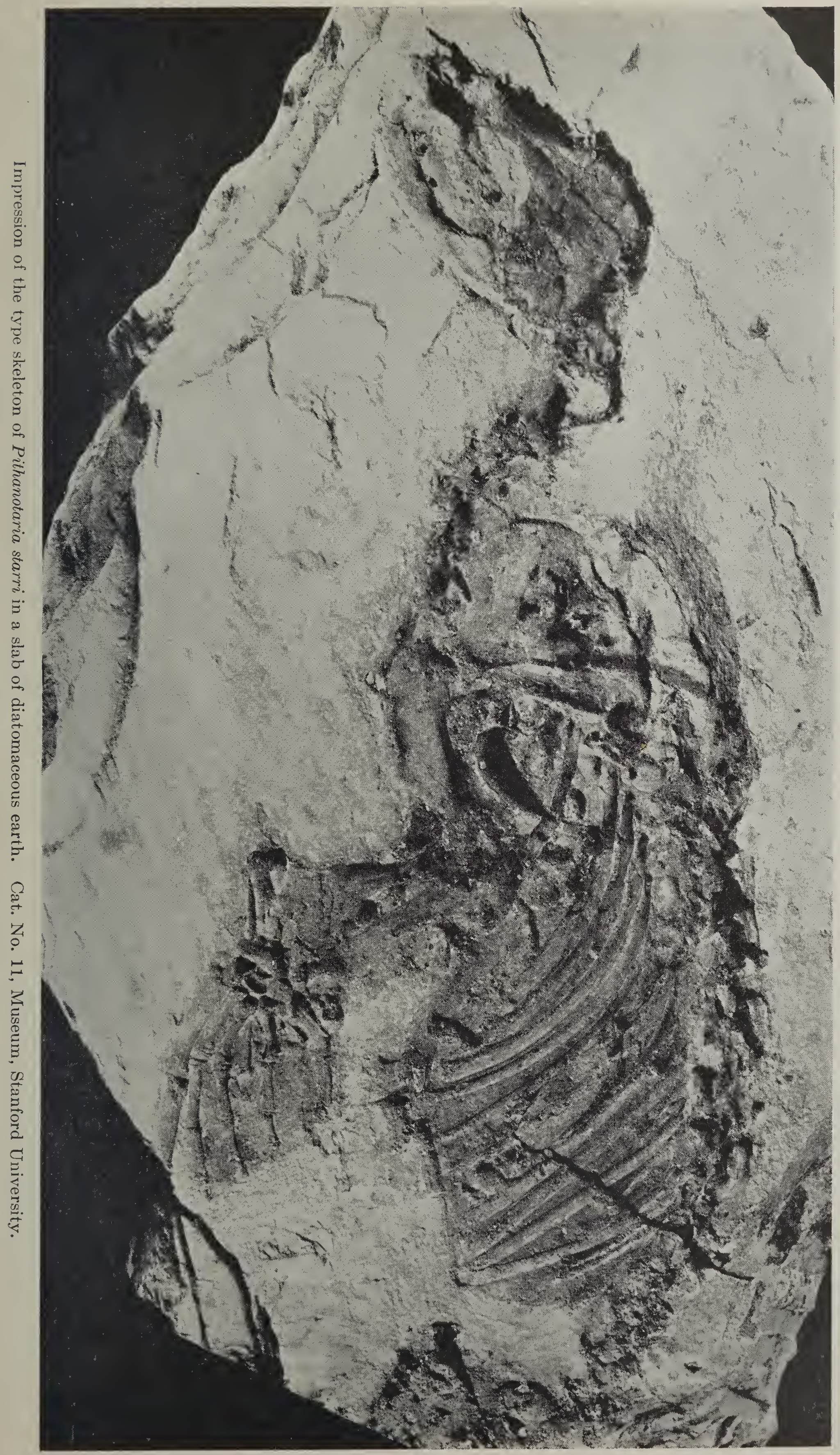




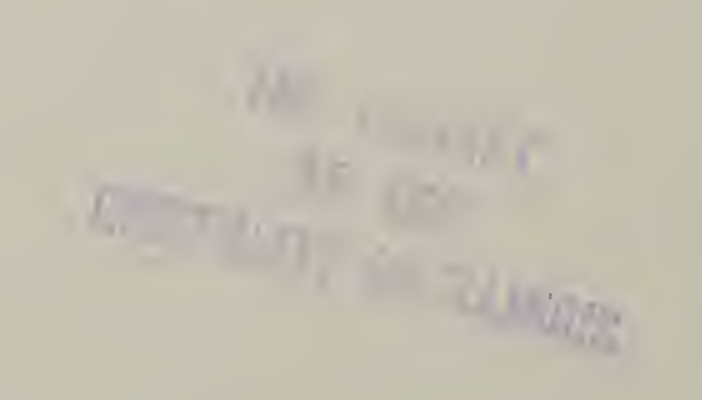



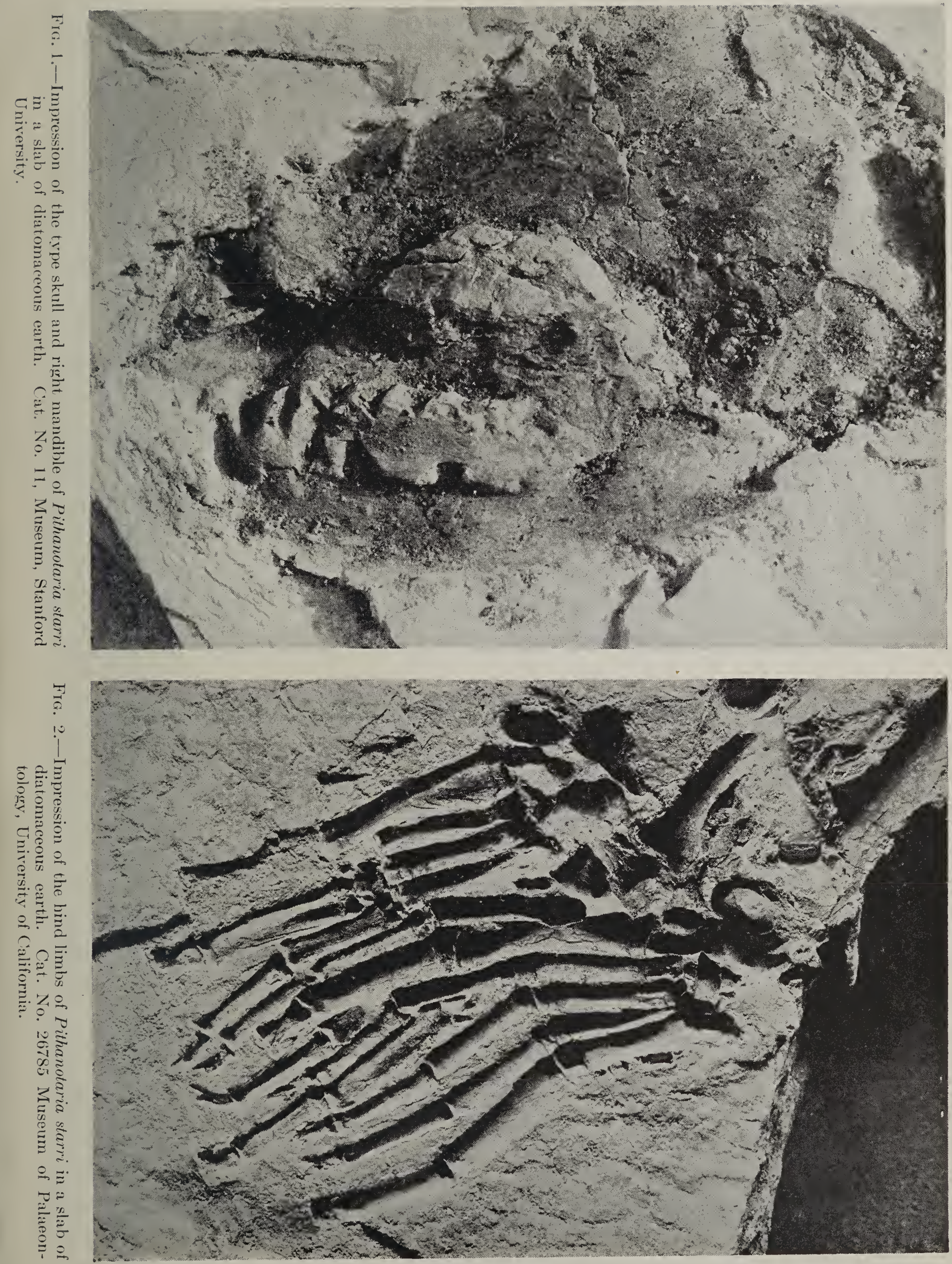


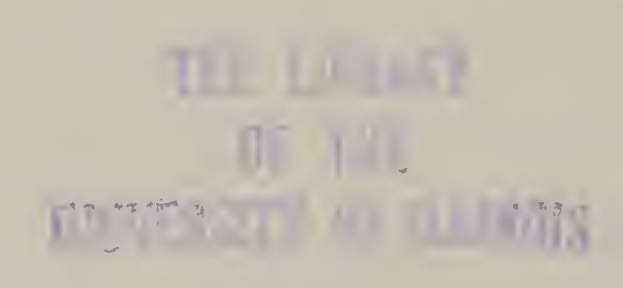





UNIVERSITY OF ILLINOIS-URBANA 569K29A COO1
ADDITIONS TO THE TERTIARY HISTORY OF THE

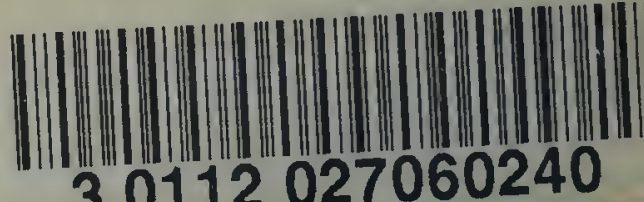

30112027060240

th

都

(i.)

34 